\title{
Effekte der Klasse-3 Semaphorine auf die Entwicklung und Progression maligner Hirntumoren
}

\author{
Dissertation \\ zur Erlangung des Doktorgrades \\ der Mathematisch-Naturwissenschaftlichen Fakultäten \\ der Georg-August-Universität zu Göttingen
}

vorgelegt von
Julia Bode
aus Northeim

Göttingen 2010 
D7

Referent:

Prof. Dr. E. A. Wimmer

Korreferent:

Prof. Dr. M. Kessel

Tag der mündlichen Prüfung:

04.11.2010 



\section{Inhaltsverzeichnis}

Abkürzungsverzeichnis

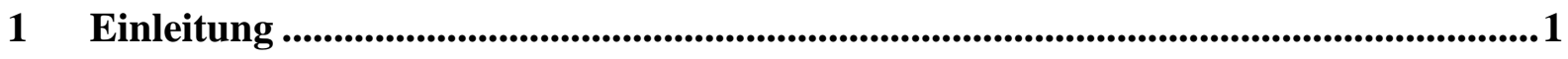

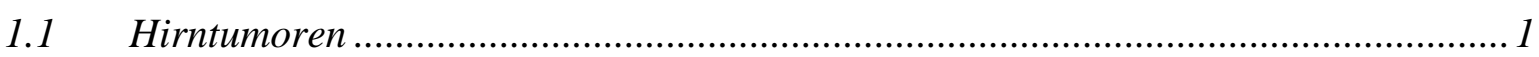

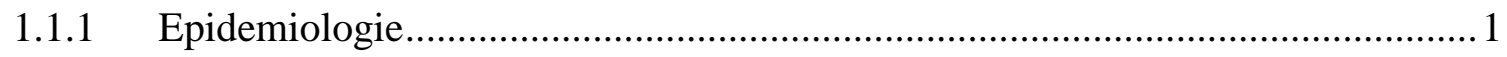

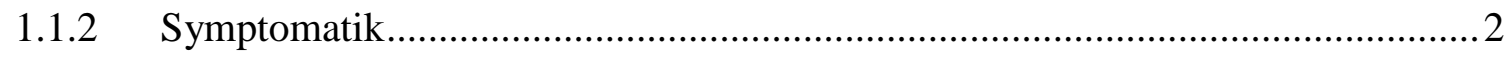

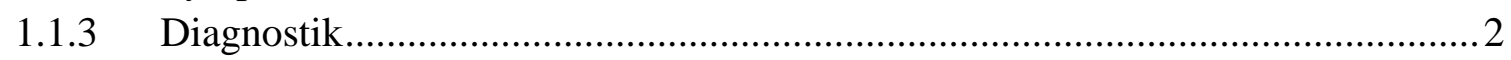

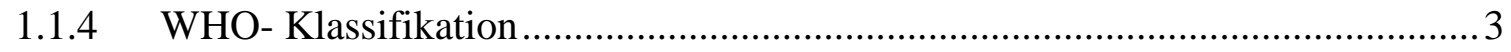

1.1.5 Tumorgenese des Glioblastoms .................................................................... 4

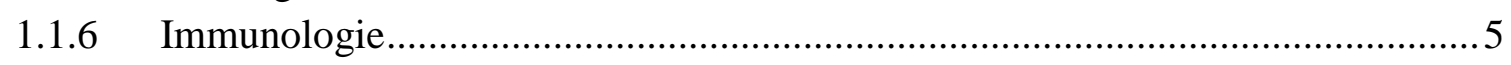

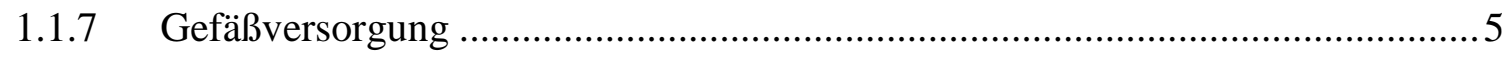

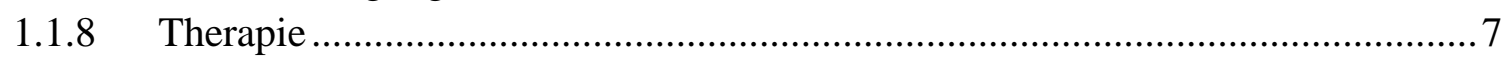

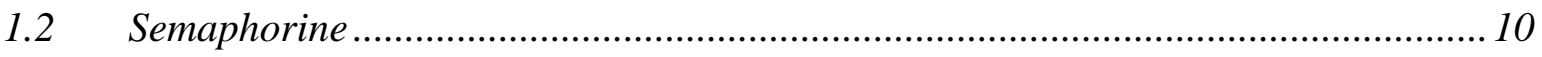

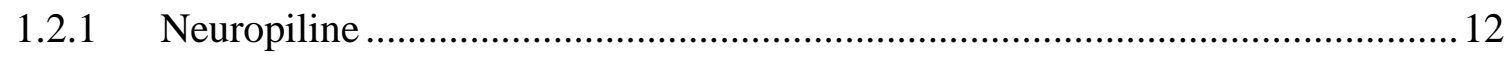

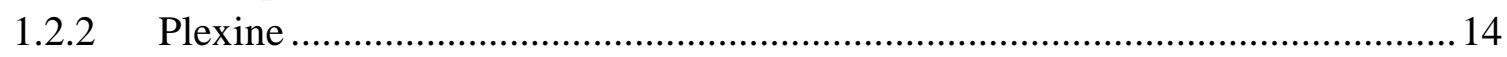

1.2.3 Klasse- 3 Semaphorine und ihr Einfluss auf Tumoren.................................... 15

1.2.4 Die Funktion der Klasse- 3 Semaphorine im vaskulären System ..................... 18

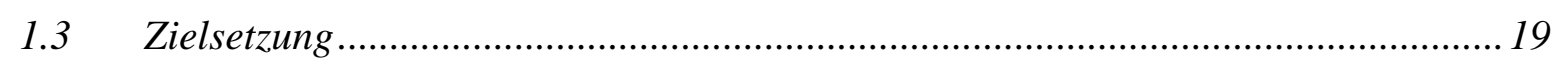

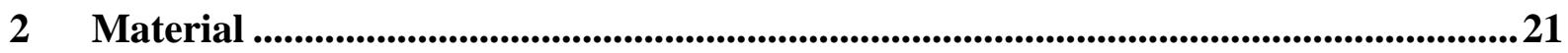

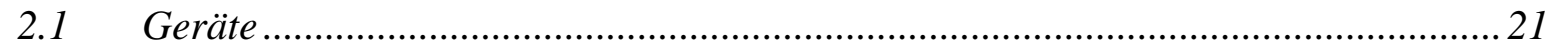

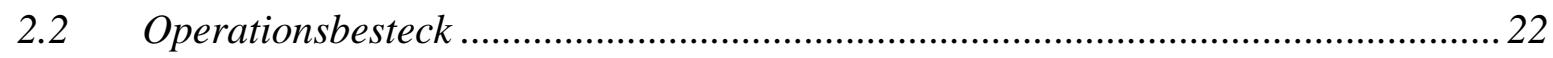

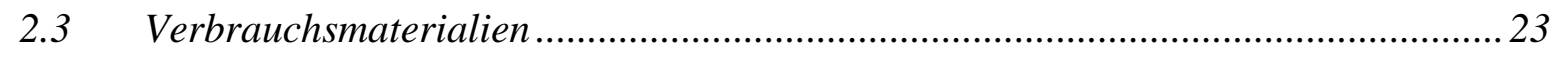

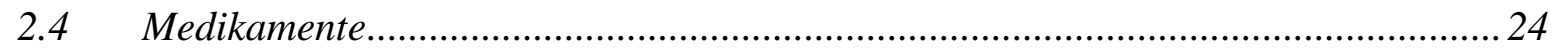

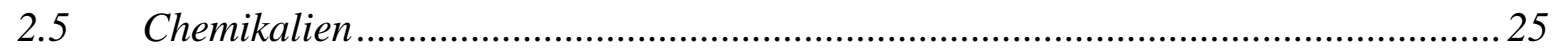

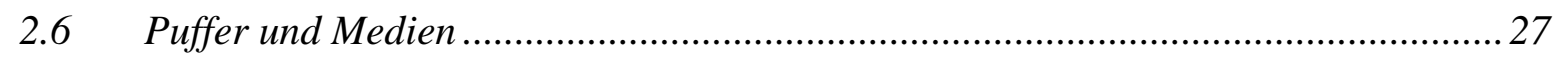

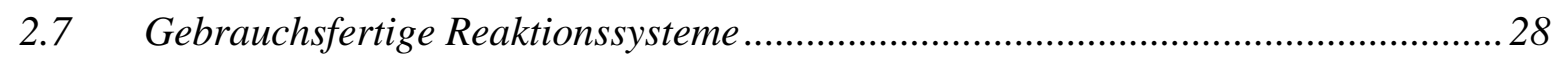

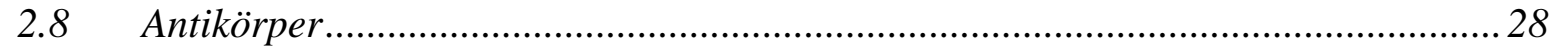

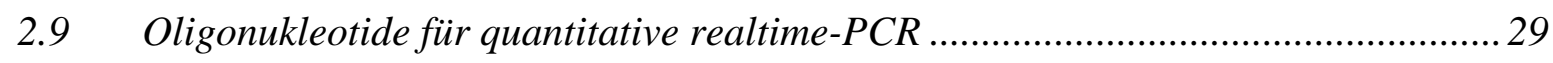

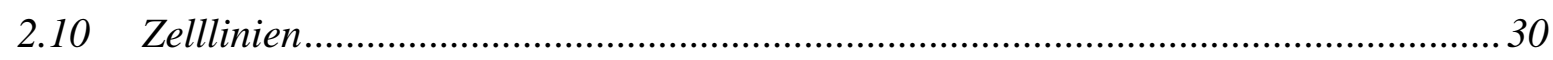

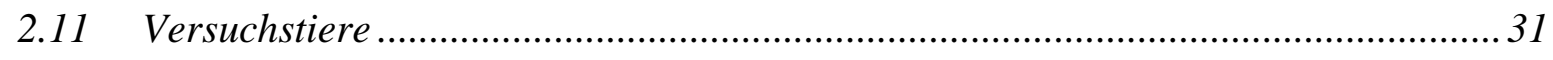

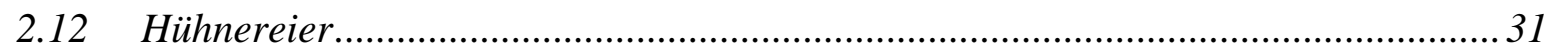

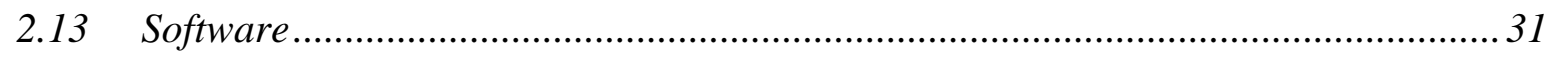




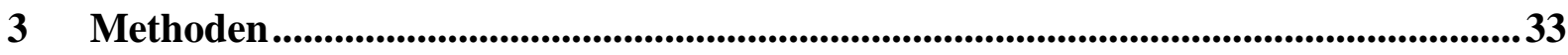

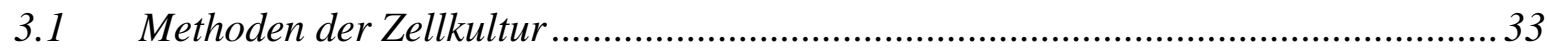

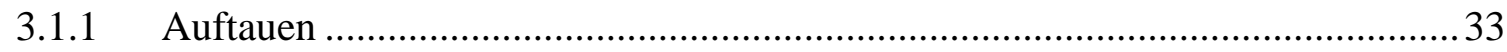

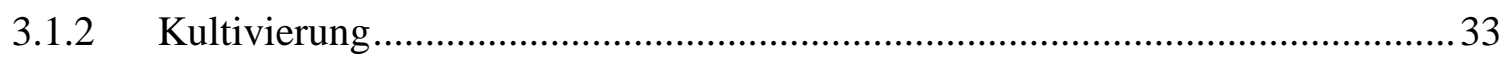

3.1.3 Zellzahlbestimmung und Einfrieren der Zellen .................................................. 33

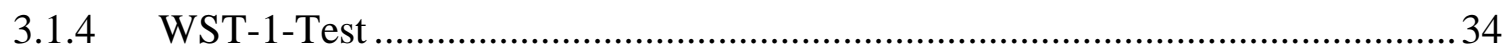

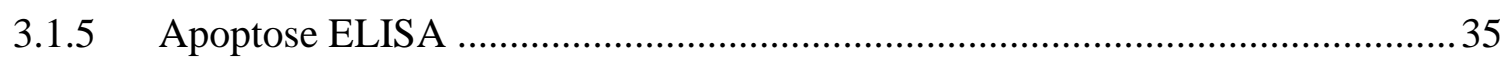

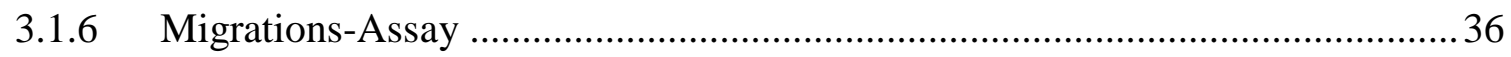

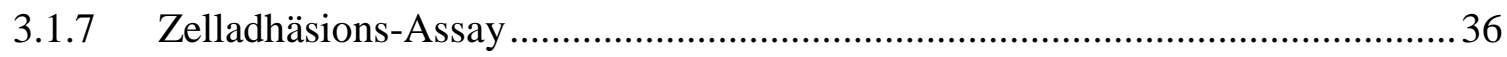

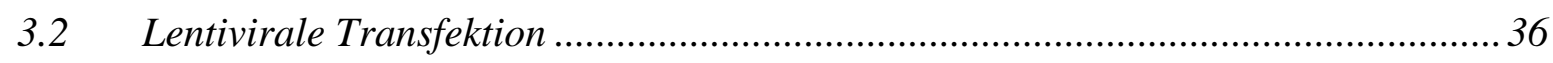

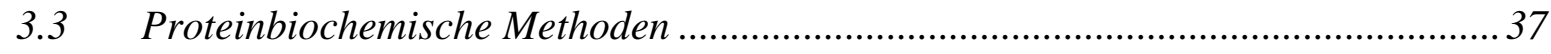

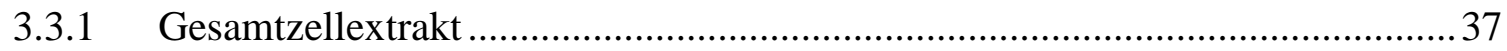

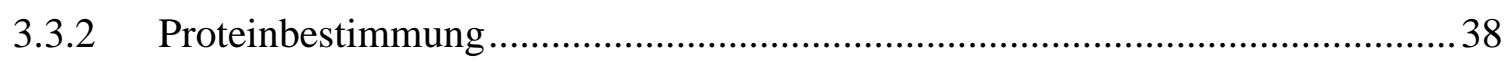

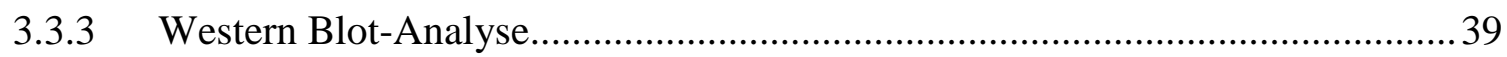

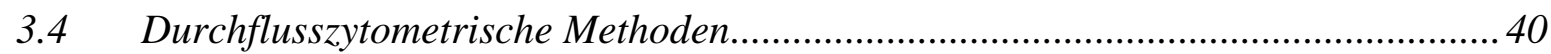

3.4.1 Analyse von Zellen durch Fluoreszenzanregung............................................. 40

3.4.2 Zellzyklus-Analyse nach Nicoletti ............................................................... 41

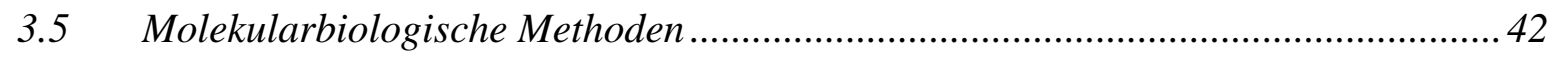

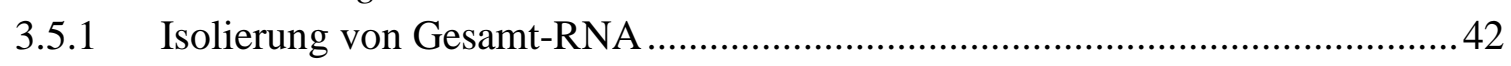

3.5.2 Konzentrationsbestimmung von Nukleinsäuren.............................................. 42

3.5.3 Auftrennung von RNA durch LabChip Micro Gelelektrophorese ..................... 43

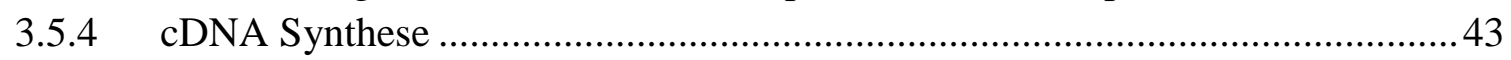

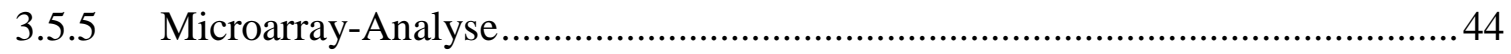

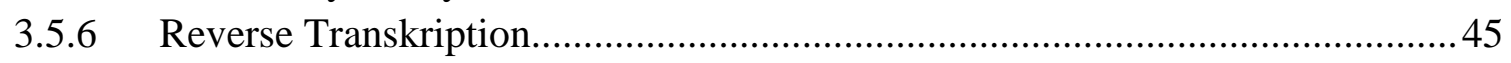

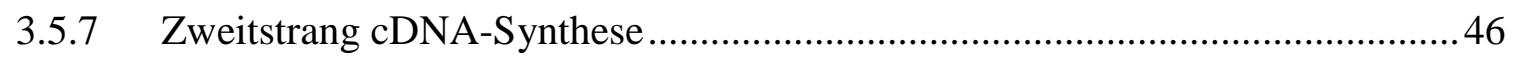

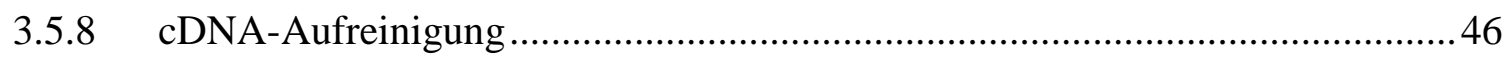

3.5.9 In vitro Transkription zur Synthese Biotin-markierter aRNA ............................ 46

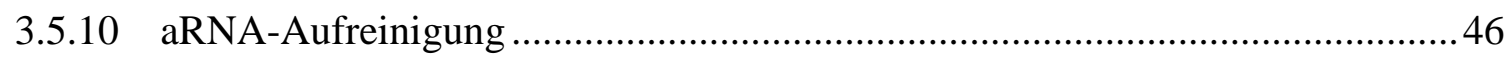

3.5.11 Hybridisierung, waschen und scannen der Microarrays.................................. 47

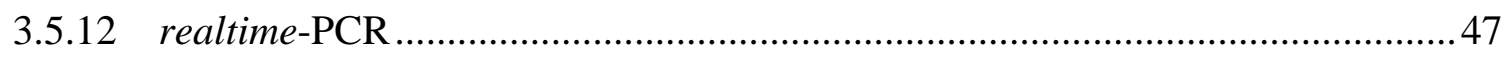

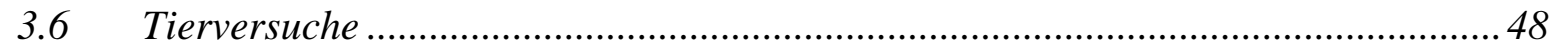

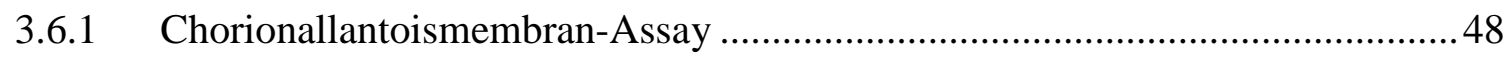

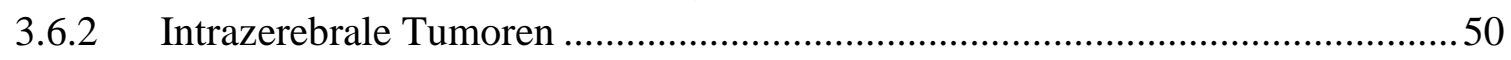

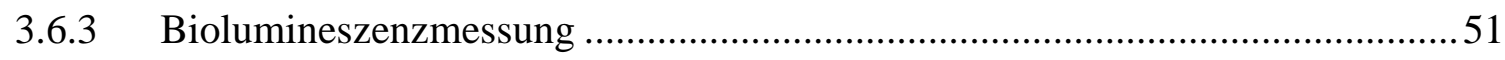

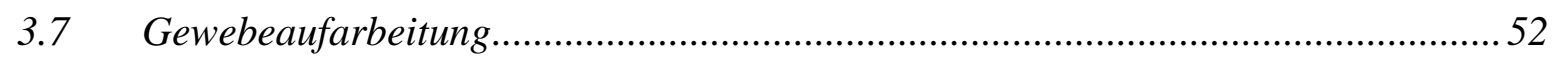

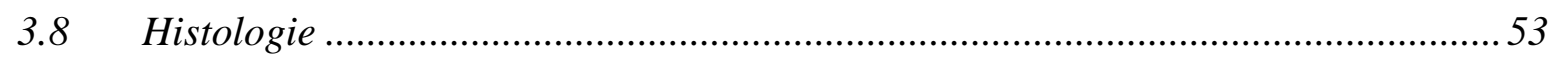

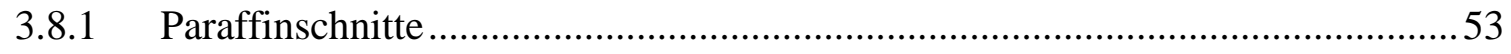

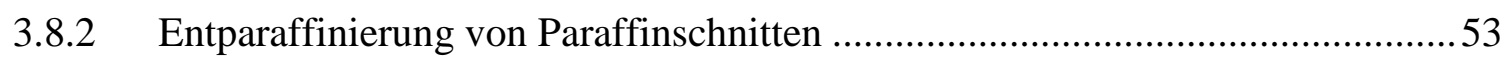

3.8.3 Immunfluoreszenzfärbung von Paraffinschnitten ........................................... 54 


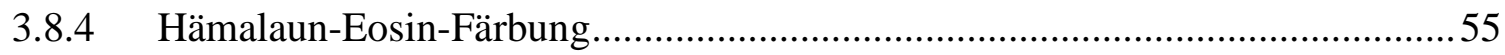

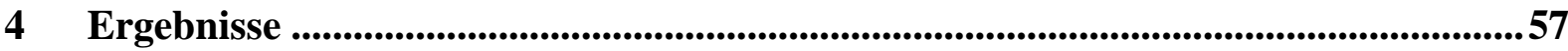

4.1 Effekte der Klasse-3 Semaphorine auf Tumorzellen in vitro..................................57

4.1.1 Auswirkungen einer Behandlung mit rekombinantem Semaphorin....................57

4.1.2 Auswirkungen der stabilen Überexpression verschiedener Klasse-3

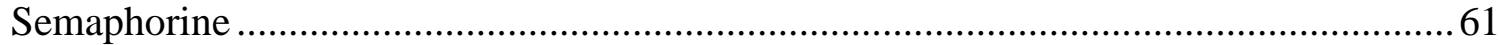

4.1.2.1 Auswirkungen auf die Proliferation der Gliomzellen .................................61

4.1.2.2 Auswirkungen auf den Zellzyklus der Gliomzellen....................................63

4.1.2.3 Auswirkungen auf die Migration der Gliomzellen .....................................65

4.1.2.4 Auswirkungen auf die Adhäsion der Gliomzellen .........................................66

4.1.2.5 Auswirkungen auf die Apoptose der Gliomzellen ......................................6 68

4.1.2.5.1 Effekte der Semaphorine auf die Zellintegrität....................................68

4.1.2.5.2 Auswirkung auf die Aktivierung der Caspase-3 ................................. 70

4.2 Effekte der Klasse-3 Semaphorine auf Tumorzellen in vivo.................................. 72

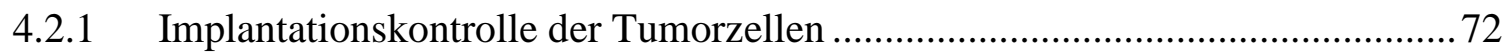

4.2.2 Effekte der Semaphorin-Expression auf intrazerebrale U87MG-Tumoren ....... 73

4.2.3 Effekte der Semaphorin-Expression auf intrazerebrale U373MG-Tumoren ..... 76

4.2.4 Einfluss der Semaphorin-Expression auf die Morphologie der Tumoren und die

Anzahl der gebildeten Blutgefäße ..................................................................... 78

4.2.5 Effekt der Semaphorin-Expression auf die Lebenserwartung der Mäuse nach

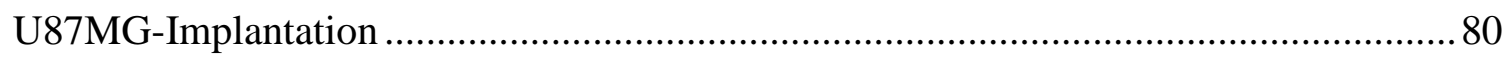

4.2.6 Lebenserwartung der Mäuse nach U373MG-Implantation ................................ 82

4.2.7 Chorionallantoismembran-Assay als alternatives Modell ............................... 83

4.3 Effekte der Klasse-3 Semaphorine auf die Genexpression ....................................... 85

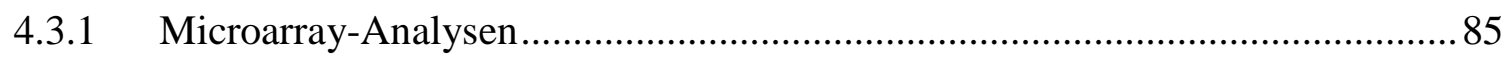

4.3.2 Validierung veränderter Gene mittels realtime-PCR .................................... 91

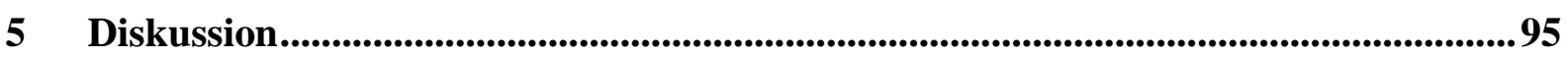

5.1 Effekte der Klasse-3 Semaphorine auf Tumorzellen in vitro................................... 96

5.1.1 Einfluss auf die Proliferation und den Zellzyklus ...............................................96

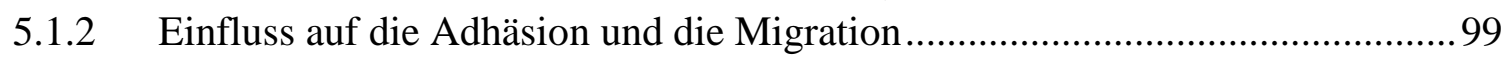

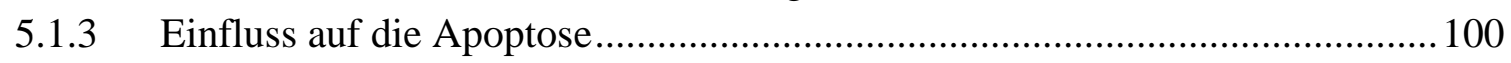

5.2 Effekte der Klasse-3 Semaphorine auf Tumorzellen in vivo................................. 101

5.2.1 Einfluss auf intrazerebrale Tumoren ............................................................. 101

5.2.2 Einfluss auf das Tumorwachstum auf einer CAM .......................................... 105

5.3 Effekte der Klasse-3 Semaphorine auf die Genexpression ................................... 106

5.4 Modell zur Inhibierung des Tumorwachstums durch Semaphorine ....................... 110

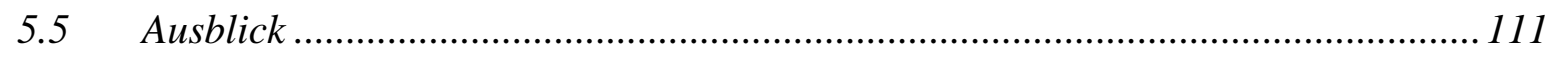




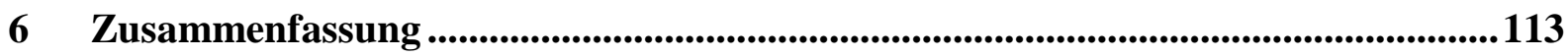

8 Literaturverzeichnis ............................................................................................... 115

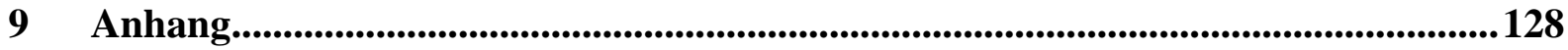

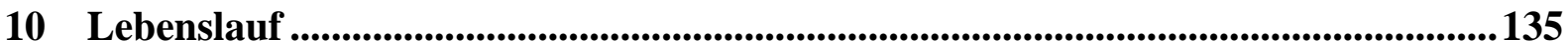

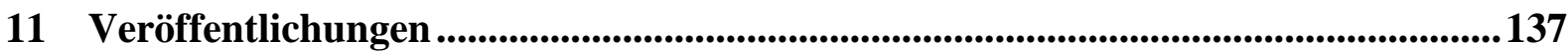

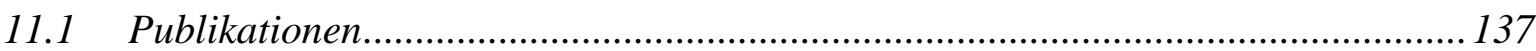

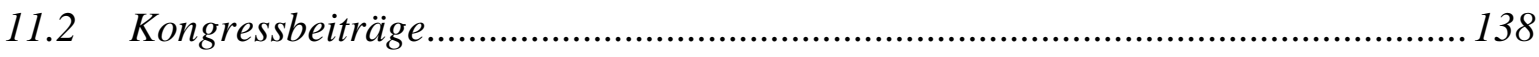

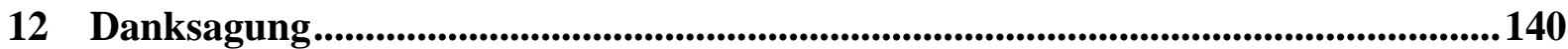




\section{Abkürzungsverzeichnis}

APS

BL

BLI

BSA

bzw.

CAM

CCD

$\mathrm{C}_{\mathrm{T}}$

$\mathrm{Da}$

DKKR

DMSO

DPBS

DTT

EDTA

ELISA

et al.

FCS

$\mathrm{H}_{2} \mathrm{O}$

$\mathrm{H}_{2} \mathrm{O}_{\text {dest }}$

HRP

HUVECs

i.c.

i.p.

i.v.

$\mathrm{kb}$
Ammoniumpersulfat

Biolumineszenz

Biolumineszenz-Messung (engl. Bioluminescence imaging)

Bovines Serumalbumin

beziehungsweise

Chorionallantoismembran

charge-coupled device

Schwellenwert-Zyklus (engl.: Threshold Cycle)

Dalton

Deutsches Kinderkrebsregister

Dimethylsulfoxid

Dulbecco’s Phosphate Buffered Saline

Dithiothreitol

Ethylendiamintetraessigsäure

Enzymgekoppelter Immunadsorbtionstest (enzyme linked immuno sorbent assay)

und andere (lat.: et alii)

Fetales Kälberserum

Wasser

Destilliertes Wasser

Meerrettichperoxidase (engl.: horseradish peroxidase)

engl.: Human Umbilical Vein Endothelial Cells;

Endothelzellen

Intrazerebral

Intraperitoneal

Intravenös

Kilobasenpaar 


\begin{tabular}{|c|c|}
\hline $\mathrm{KG}$ & Körpergewicht \\
\hline Luc & Luziferase (engl.: Luciferase) \\
\hline M & Molar \\
\hline $\min$ & Minute \\
\hline monokl. & Monoklonal \\
\hline $\mathrm{n}$ & Anzahl \\
\hline $\mathrm{NaCl}$ & Natriumchlorid \\
\hline NaDoc & Natriumdeoxycholat \\
\hline Nrp1 & Neuropilin 1 \\
\hline Nrp2 & Neuropilin 2 \\
\hline P.C. & Positivkontrolle \\
\hline PAGE & Polyacrylamidgelelektrophorese \\
\hline PFA & Paraformaldehyd \\
\hline \multirow[t]{3}{*}{$\mathrm{pH}$} & potentia hydrogenii (Negativer dekadischer Logarithmus \\
\hline & der Hydroniumionenkonzentration) Wasserstoffionen- \\
\hline & Aktivität \\
\hline polykl. & Polyklonal \\
\hline PVDF & Polyvinyldifluorid-Membran \\
\hline $\mathrm{rpm}$ & Umdrehungen pro Minute (engl.: rounds per minute) \\
\hline SDS & Natriumdodecylsulfat (engl.: sodium dodecylsulfate) \\
\hline Sema & Semaphorin \\
\hline TBS & Tris gepufferte Kochsalzlösung (Tris buffered saline) \\
\hline \multirow[t]{2}{*}{ TBST } & Tris gepufferte Kochsalzlösung (Tris buffered saline) mit \\
\hline & Tween 20 \\
\hline TEMED & N,N,N',N'-Tetramethylendiamin \\
\hline Tris & Tris-hydroxymethyl-aminomethan \\
\hline Triton $\mathrm{X}-100$ & Octylphenoxypolyethoxyethan \\
\hline Tween & Polyoxyethylensorbitanmonolaurat \\
\hline VEGF & engl.: vascular endothelial growth factor \\
\hline VEGFR-2 & engl.: vascular endothelial growth factor receptor- 2 \\
\hline Vol. & Volumen \\
\hline $\mathrm{w} / \mathrm{v}$ & Gewicht/Volumen (weight/volume) \\
\hline
\end{tabular}




\section{$1 \quad$ Einleitung}

Im Jahr 2007 gehörte Krebs mit 29 \% zu der zweithäufigsten Todesursache in Deutschland (Husmann 2010). Laut Robert-Koch-Institut belief sich die Zahl der Neuerkrankungen im Jahr 2006 auf 426.000 Menschen in Deutschland, was eine leichte Erniedrigung im Vergleich zu 2004 mit 436.500 Neuerkrankungen darstellt. Die häufigste Todesursache aufgrund von Krebserkrankungen, wie auch schon in den vorhergegangenen Jahren, ist Lungenkrebs mit $26 \%$. Bei den Frauen hingegen ist die häufigste Krebsneuerkrankung Brustkrebs mit $29 \%$, die in $18 \%$ zum Tode führt. Für das Jahr 2010 sind aufgrund des demografischen Wandels 450.000 Krebsneuerkrankungen zu erwarten (Robert-Koch-Institut 2004). Beim Erwachsenen sind die Tumoren des zentralen Nervensystems für ca. 3,3\% der krebsbedingten Todesfälle verantwortlich. Im Kindesalter bis 15 Jahre allerdings ist die Zahl der Tumoren des zentralen Nervensystems mit $22 \%$ stark erhöht.

\subsection{Hirntumoren}

\subsubsection{Epidemiologie}

$\mathrm{Zu}$ den Hirntumoren gehören alle benignen und malignen Neoplasien des zentralen Nervensystems. Die Häufigkeit primärer Hirntumoren in Europa und den USA wird mit etwa fünf bis acht Neuerkrankungen pro 100.000 Einwohner und Jahr angegeben, was ungefähr $2 \%$ aller Krebsneuerkrankungen entspricht. Die Glioblastome bilden hier mit $65 \%$ die größte Gruppe unter den hirneigenen Tumoren im Erwachsenenalter (Ohgaki und Kleihues 2005) und die 5-Jahres-Überlebensrate bei Patienten mit einem diagnostizierten Glioblastom beträgt weniger als $3 \%$ (Kleihues et al., 2005).

Im Kindesalter stellen die Tumoren des zentralen Nervensystems mit $22 \%$ neben den Leukämien mit $34 \%$ die zweitgrößte Gruppe der Krebserkrankungen dar, wobei die Gliome bei Kindern und Jugendlichen einen Anteil von $7 \%$ ausmachen und das Glioblastom die höchste Mortalität bei Kindern zeigt (Kaatsch et al. 2001). In verschiedenen Studien konnte gezeigt werden, dass die Krankheitsursache sich nicht auf exogene Faktoren wie Rauchen oder Alkoholmissbrauch während der Schwangerschaft, Kontakt zu Pestiziden, Röntgenstrahlung oder ähnliches zurückführen lässt (Schuz et al. 2001). Im Gegensatz dazu kann jedoch ein Zusammenhang in der Entwicklung von Tumoren im zentralen Nervensystem 
und endogenen Faktoren wie das Li-Fraumeni Syndrom, Neurofibromatose 1, Neurofibromatose 2, das Turcot Syndrom und anderen familiären heriditären Syndromen beobachtet werden, wobei die erwähnten Erkrankungen jedoch sehr selten vorkommen (Louis et al. 2007; Ohgaki und Kleihues 2007).

\subsubsection{Symptomatik}

In mehreren Studien konnte gezeigt werden, dass $48 \%$ der Patienten mit einem primären Gehirntumor oder Metastasen im Gehirn an Kopfschmerzen leiden. Davon fühlten $77 \%$ Spannungskopfschmerzen, $9 \%$ migräneartige Kopfschmerzen und $14 \%$ andere Kopfschmerzen. Weitere Symptome waren Übelkeit (32\%) und Erbrechen (40\%) (Forsyth und Posner 1993). Das Auftreten von epileptischen Anfällen aufgrund eines Hirntumors konnte in mehr als $30 \%$ der Patienten beobachtet werden (van Breemen et al. 2007), wobei eher niedriggradige Tumoren mit einem langsameren Wachstum zu vermehrten Anfällen führten. Desweiteren konnten Schwindel-, Sprach- und Sehstörungen, Lähmungserscheinungen, Vergesslichkeit oder selten eine Stauungspapille beobachtet werden.

\subsubsection{Diagnostik}

Die Diagnostik von Hirntumoren stützt sich hauptsächlich auf bildgebende Untersuchungsverfahren, wobei die wichtigsten die Computertomographie (CT) und Magnetresonanztomographie (MRT) sind.

Die CT-Untersuchungen haben eine hohe Strahlenbelastung und es können vornehmlich Befunde bezüglich der Knochen gemacht oder Blutungen nachgewiesen werden. Aussagen über das Hirnparenchym sind mit dieser Methode nicht möglich. Hier müssen bei bestätigten Verdachtsfällen weitere Untersuchungen mit der MRT durchgeführt werden. Diese Methode besitzt die Vorteile einer sehr geringen Strahlenbelastung und die Möglichkeit der Erkennung kleinerer Strukturen, wie Metastasen (Urbach und Solymosi 2003). Im Vergleich zur CT ist eine MRT-Untersuchung jedoch deutlich zeit- und kostenaufwendiger. Andere Untersuchungsverfahren, wie z.B. das Elektroenzephalogramm (EEG), spielen eine untergeordnete Rolle, da ein Normalbefund im EEG das Vorliegen eines Tumors nicht ausschließen kann. In einigen Fällen wird eine Lumbalpunktion durchgeführt, um eine Aussaat von Tumorzellen im Nervenwasser (Liquor) nachzuweisen. Weitere bildgebende Verfahren wie die Positronen-Emissions-Tomographie (PET) und die Single-Photon- 
Emissions-Computertomographie (SPECT) lassen Rückschlüsse auf Stoffwechselvorgänge und die Durchblutung des Gehirns zu.

\subsubsection{WHO- Klassifikation}

Tumoren des Zentralnervensystems (ZNS) werden aufgrund der Herkunft der TumorUrsprungszelle benannt und anhand ihres histologischen Erscheinungsbildes kategorisiert (Wiestler und Schmidt 1998). Die Gliome, die aus Gliazellen entstehen, werden in astrozytäre und nicht-astrozytäre Tumoren eingeteilt. Astrozyten haben unterschiedliche Funktionen im Gehirn, so besitzen sie eine Stützfunktion, können in den Stoffwechsel eingreifen und sind an der Ausbildung der Blut-Hirn-Schranke beteiligt. Gliome gehören zu den neuroepithelialen Tumoren und werden aufgrund der Tumorzelldichte, der mitotischen Aktivität und Tumorgewebsnekrosen in Gruppen von I bis IV eingeteilt (Schlegel 1998), wobei der Tumorgrad IV die höchste Malignität bedeutet. Tumoren, die benigne oder niedrigmaligne sind, können sich im Laufe der Zeit zu höher malignen Tumoren weiterentwickeln. Im Kindesalter kommen am häufigsten die anaplastischen Astrozytome (Grad III), das Glioblastom (Grad IV) und das Gliosarkom (Grad IV) vor. Die Zuordnung der astrozytären Tumoren, zu denen auch das Glioblastom zählt, ist in der folgenden Tabelle 1 dargestellt.

Tabelle 1: WHO- Klassifikation ausgewählter Gliome (Louis et al. 2007).

\begin{tabular}{|c|c|c|}
\hline WHO-Bezeichnung & WHO-Grad & Histopathologie \\
\hline Pilozytisches Astrozytom & I & $\begin{array}{c}\text { Geringe Zelldichte, } \\
\text { bipolare“pilozytische“Zellen, } \\
\text { Rosenthal-Fasern }\end{array}$ \\
\hline $\begin{array}{c}\text { Niedrig-malignes } \\
\text { Astrozytom }\end{array}$ & II & $\begin{array}{c}\text { Geringe bis mäßige Zelldichte, } \\
\text { fibrilläre oder gemistozytische } \\
\text { Astrozyten, einige Mitosen, } \\
\text { geringe nukleäre Atypien }\end{array}$ \\
\hline $\begin{array}{c}\text { Anaplastisches Astrozytom } \\
\text { III } \\
\text { multiforme, GBM) }\end{array}$ & $\begin{array}{c}\text { Große Zelldichte, mäßige bis } \\
\text { starke Zell-und } \\
\text { Kernpolymorphie, zahlreiche } \\
\text { Mitosen }\end{array}$ \\
\hline $\begin{array}{c}\text { Glioblastom (Glioblastoma } \\
\text { IV }\end{array}$ & $\begin{array}{c}\text { Hohe Zelldichte, Pleomorphie, } \\
\text { zahlreiche atypische Mitosen, } \\
\text { ausgedehnte Nekrosen, } \\
\text { erhebliche Gefäßproliferation }\end{array}$ \\
\hline
\end{tabular}




\subsubsection{Tumorgenese des Glioblastoms}

Maligne Gliome gehören zu den aggressivsten, hoch invasiven und neurologisch destruktivsten Tumoren innerhalb der bei Menschen auftretenden Krebserkrankungen (Maher et al. 2001). Der häufigste und bösartigste Tumortyp innerhalb der Gliome ist das Glioblastoma multiforme (GBM) (Ohgaki et al. 2004). Glioblastome sind gekennzeichnet durch eine weitreichende Invasion in das Gehirngewebe, Resistenz gegenüber traditioneller und neuer therapeutischer Behandlung, Zerstörung des normalen Gehirngewebes und eines sicheren Todes innerhalb von neun bis zwölf Monaten (Furnari et al. 2007). Glioblastome werden in zwei verschiedene Entitäten unterteilt, die jeweils unabhängige genetische Entstehungswege aufweisen (Kleihues und Sobin 2000). Das primäre oder de novo Glioblastom, welches in $90 \%$ der Fälle vorliegt, kommt typischerweise eher in älteren Patienten mit einem mittleren Diagnosealter von 55 Jahren vor. Meist liegen bei diesen Patienten keinerlei Vorerkrankungen vor. Das sekundäre Glioblastom (10 \% der GlioblastomPatienten) kommt bei Patienten unter 45 Jahren vor und entsteht zu ca. $70 \%$ aus Grad-II Tumoren. Die Progression von einem Grad-II-Tumor zu einem Grad-III oder -IV-Tumor geschieht meist innerhalb von fünf bis zehn Jahren nach der Erstdiagnose (Kleihues et al. 2002).

Trotz eines ähnlichen Phänotyps weisen beide Entitäten unterschiedliche Muster an Mutationen auf. Typisch für das primäre Glioblastom sind Mutationen im Gen des „Epidermal growth factor receptor" (EGFR-Gen). In 40-60\% der Fälle kann eine Überexpression dieses Gens und eine daraus resultierende Abweichung von Transkripten und Proteinen beobachtet werden, die hauptsächlich durch sieben vorkommende Mutationen herbei geführt werden (Kanu et al. 2009). Das sekundäre Glioblastom weist häufig Mutationen im p53-Gen auf, wobei $60 \%$ der Mutationen in den ,hot spot“ Kodons 248 und 273 liegen (Ohgaki und Kleihues 2005). Die Inzidenz für eine p53-Mutation liegt bei über $65 \%$ (Kanu et al. 2009). Der p53-Signalweg hat Einfluss auf die Regulation des Zellzyklus, die Zellreparaturmechanismen und das Wachstum. p53-Mutationen können auch im LiFraumeni-Syndrom beobachtet werden, bei dem, wie vorher erwähnt, eine erhöhte Inzidenz für Gliome vorliegt (Malkin et al. 1990).

In einem Gliom können auch andere Zellarten gefunden werden. So befinden sich zusätzlich zu den Tumorzellen auch gefäßbildende Zellen und Mikrogliazellen, welche ZNS-spezifische differenzierte Makrophagen sind, in einem Gliom. In einer Studie mit elf Glioblastom- 
Patienten konnte gezeigt werden, dass Tumoren im Mittel zu $45 \%$ aus Mikrogliazellen bestehen (Badie und Schartner 2001).

\subsubsection{Immunologie}

Das Immunsystem soll den Körper und seine Funktionen vor äußeren aber auch inneren Einflüssen schützen. Das ZNS hat dabei eine Sonderrolle, denn es ist durch den Schädelknochen und die Blut-Hirn-Schranke vom Blutkreislauf isoliert (Walker et al. 2003). Ein wesentlicher Bestandteil der Blut-Hirn-Schranke wird von Endothelzellen, die die kapillaren Blutgefäße zum Blut hin auskleiden, gebildet. Diese Zellen grenzen den Blutkreislauf und das ZNS voneinander ab (Hawkins und Davis 2005). Die Endothelzellen erschweren den Übertritt von z.B. Plasmaproteinen, naiven Lymphozyten, natürlichen Killerzellen und Makrophagen in das Gehirn (Friese et al. 2004). Zusätzlich beschränken immunsuppressive Moleküle wie „Transforming growth factor beta 3“ (TGFß3) aufgrund ihrer inhibierenden Wirkung auf T-Zellen die Immunantwort (Weller und Fontana 1995).

\subsubsection{Gefäßversorgung}

Die physiologische Angiogenese findet hauptsächlich während der Embryonalentwicklung und der frühen postnatalen Entwicklung statt, wobei eine Endothelzellproliferation im Erwachsenen kaum noch zu beobachten ist. Hier findet sie nur noch in einem Bereich von Monaten bis Jahren statt (Hobson und Denekamp 1984). Prozesse, bei denen auch im Erwachsenen eine Angiogenese beobachtet werden kann, sind der weibliche Menstruationszyklus, im Laufe einer Schwangerschaft oder bei Wundheilungsprozessen. Bei der pathologischen Angiogenese allerdings findet ständig Endothelzellproliferation statt. Diese unkontrollierte Proliferation von Endothelzellen kann bei der Vaskularisation von soliden Tumoren beobachtet werden. Somit gehört die Angiogenese zu den sechs wichtigsten Faktoren der Tumorproliferation und fördert das maligne Wachstum (Hanahan und Weinberg 2000).

Ein heranwachsender Tumor, der über 1 bis 2 Millimeter groß ist, benötigt ein eigenes Blutgefäßsystem, um dem Nährstoffbedarf der wachsenden Tumorzellen gerecht zu werden (Folkman 1990; Weidner et al. 1993; Naumov et al. 2006). Zusätzlich wird es kleinen Molekülen erleichtert, längere Entfernungen $\mathrm{zu}$ überbrücken, da die maximale Diffusionsentfernung, die sie überwinden können, nur $100 \mathrm{~mm}$ beträgt. Das tumoreigene Blutgefäßsystem dient nicht nur der Versorgung, sondern kann auch dazu genutzt werden, 
Metastasen in anderen Organen $\mathrm{zu}$ bilden. Das Tumorwachstum induziert in der prävaskulären Phase keine Angiogenese. Durch Hypoxie und erhöhte Gefäßpermeabilität werden in der vaskulären Phase die Angiogenese induziert und zusätzlich verschiedene Wachstumsfaktoren und Cytokine beeinflusst. Es kommt zu einer Veränderung des Verhältnisses von Promotoren und Inhibitoren der Angiogenese, durch die die Zellen schneller proliferieren und metastasieren können (,angiogenic switch“) (Folkman 1992). Die Signalmoleküle für diesen Prozess werden entweder von den Tumorzellen selbst oder von den umliegenden Zellen gebildet. Die veränderte Expression von Angiogenesefaktoren führt zu Tumorgefäßen, die im Gegensatz zu gesunden Gefäßen ungleichmäßige Durchmesser und viele Verzweigungen aufweisen (Carmeliet und Jain 2000). Es gibt verschiedenste Faktoren, die in vitro und in vivo das Gefäßwachstum beeinflussen. Die wichtigsten Faktoren scheinen die Mitglieder der „Vascular endothelial growth factor” (VEGF)-Familie, vier Mitglieder der Angiopoietin-Familie und die Mitglieder der Ephrin-Familie zu sein, da sie spezifisch auf die vaskulären Endothelzellen wirken (Yancopoulos et al. 2000).

Anfangs wurde VEGF als ein Molekül beschrieben, welches die Durchlässigkeit von Blutgefäßen beeinflusst und zusätzlich die Proliferation von Endothelzellen begünstigt (Ferrara 1999). Die Rezeptoren, die für die Signalweitergabe eine Rolle spielen, gehören zu der Familie der Rezeptor-Tyrosin-Kinasen und beinhalten drei Mitglieder: „Vascular endothelial growth factor receptor" (VEGFR)-1, -2 und -3, wobei der wichtigste Rezeptor VEGFR-2 zu sein scheint, da er die Mehrheit der VEGF-Signale vermittelt (Hicklin und Ellis 2005).

Die Funktionen des VEGFR-2 sind vielseitig. Die Signaltransduktion beginnt mit der Aktivierung der Phospholipase C- $\gamma$ (PLC- $\gamma$ ). Diese bindet über eine SH-2-Domäne (Src Homology region 2) an einen einzigen Phosphotyrosinrest (Y1175) des VEGFR-2. Dabei wird es selbst phosphoryliert und hydrolysiert in der Zellmembran vorliegendes Phosphatidylinositol-2-Phosphat $\left(\mathrm{PIP}_{2}\right)$ zu Diacylglycerol (DAG) und Inositol-Trisphosphat $\left(\mathrm{IP}_{3}\right)$ (Olsson et al. 2006). DAG und $\mathrm{IP}_{3}$ wirken als sekundäre Botenstoffe und können Raf aktivieren, welches die Proliferation der Endothelzellen über den „Mitogen activated protein“ (MAP)-Kinase-Signalweg induzieren kann. Auch bei einer Auswirkung auf die Migration der Zellen wird von einer Beteiligung des PLC- $\gamma$-Proteinkinase C (PKC)- $\beta$-Raf-MAPK-Weges ausgegangen. Es soll eine Vinculin-Ballung, die unentbehrlich für die Migration ist, durch die Bildung von „Focal adhesion plaques“ über die PKC abhängige Phosphorylierung von 
Paxillin und der p125-,,Focal adhesion Kinase“ (FAK) erfolgen (Abdollahi und Folkman 2010). Zusätzlich kann VEGF über VEGFR-2 auch als „survival factor“ für Endothelzellen durch Hemmung der Apoptose wirken. Wahrscheinlich geschieht dieses über die Aktivierung der Serin/Threonin Proteinkinase B ( $\mathrm{PKB} \alpha, \mathrm{Akt})$, die durch die Phosphoinositid-3-Kinase (PI3K) aktiviert wird. Weiter werden Einflüsse auf die Gefäßpermeabilität und Strukturveränderung des Aktins beschrieben (Folkman 1992).

Im Vergleich zu anderen Tumoren wurden höhere VEGF-Mengen in Tumoren des GBM gemessen und erhöhte VEGF-Mengen scheinen mit einer höheren Blutgefäßdichte im Tumor zu korrelieren (Takano et al. 1996). Zusätzlich gibt es noch Rezeptoren, wie die Neuropiline, die in Zusammenhang mit der Blutgefäßentwicklung gebracht werden können (Soker et al. 1998). Diese werden in Abschnitt 1.2.1 weiter erläutert.

Die Angiopoietine wurden als Liganden der Tie-Rezeptoren entdeckt, die ebenfalls zur Familie der Rezeptor-Tyrosin-Kinasen gehören und genau wie die VEGF-Rezeptoren in den vaskulären Endothelzellen exprimiert werden (Korhonen et al. 1992). Die größte Bedeutung scheint Angiopoietin-2 zu besitzen, welches in wachsenden Blutgefäßen exprimiert wird und die Angiogenese sowie das Tumorwachstum begünstigt. Eine Inhibierung des Angiopoietin-2 führt zu instabilen Blutgefäßen, somit zu einer minimierten Angiogenese und daraus resultierend zu verlangsamtem Tumorwachstum (Hashizume et al. 2010).

Die Ephrine modulieren die Differenzierung der Blutgefäße in Arterien und Venen, interagieren mit den Eph-Rezeptor-Tyrosin-Kinasen und gehören zu den ersten Mitgliedern einer Proteinfamilie, für die eine Beteiligung an Blutgefäßentwicklung und axonaler Wegfindung beschrieben wurden.

\subsubsection{Therapie}

Vor Beginn einer Therapie müssen mehrere Faktoren berücksichtigt werden. So müssen die Lage und die Größe des Tumors durch bildgebende Verfahren festgestellt werden. Zusätzlich geben das Alter eines Patienten und die molekularbiologischen Auswertungen des Tumorgewebes nach einer Biopsie Aufschluss über weitere Behandlungsmethoden. Die Entnahme einer Tumorprobe aus dem Gehirn des Patienten erfolgt meist gleichzeitig mit der vollständigen Entnahme des Tumorgewebes. In einer Studie konnte gezeigt werden, dass eine nahezu vollständige Resektion des Tumorgewebes, welches zuvor durch einen Fluoreszenzfarbstoff angefärbt wurde, zu einer erhöhten Überlebenschance des Patienten 
führte (Stummer et al. 2006). Zu weiteren klassischen Therapien gehören die Bestrahlung und die Chemotherapie. Für die Bestrahlung eines Glioblastoms ist eine Strahlendosis von 60 Gy notwendig (Shapiro und Shapiro 1998). Das Wachstum des Tumors kann durch die Bestrahlung für eine gewisse Zeit zum Stillstand kommen. In den häufigsten Fällen wird eine Bestrahlung in der Kombination mit einer Chemotherapie verabreicht. Stewart et al. konnten zeigen, dass die 1-Jahres-Überlebensrate der Patienten durch zusätzliche Chemotherapie um $6 \%$ erhöht werden konnte (von 40 auf $46 \%$ ) (Stewart 2002).

Bei Kindern unter drei Jahren wird in der Regel keine Radiotherapie angewandt, da sie zu schwersten neurologischen Defiziten führen kann, da das kindliche Gehirn sehr strahlenempfindlich ist. Nebenwirkungen, die auftreten können, beinhalten Kopfschmerzen, Haarausfall, Strahlenödeme, Müdigkeit in Verbindung mit einem erhöhten Schlafbedürfnis und ein Nachlassen der Merkfähigkeit. Zusätzlich können noch Spätfolgen auftreten, die unter anderem Störungen der geistigen Entwicklung oder des Wachstums umfassen. Außerdem kann durch die Bestrahlung das Risiko für ein Zweitgliom erhöht werden (Meadows et al. 1985; Neglia et al. 2006).

Für die Behandlung mittels Chemotherapie müssen mehrere Barrieren überwunden werden, wie z.B. die Blut-Hirn-Schranke und die Blut-Liquor-Schranke. Ein zusätzliches Problem stellt die Zytostatika-Resistenz der Tumorzellen dar, die durch genomische Abweichungen, abweichende Regulation der Membrantransportproteine und zelluläre Enzyme hervorgerufen wird. Der am besten beschriebene Mechanismus ist der des „Multiple-drug-resistance 1genes“ (mdrl)/ P-Glykoprotein (Pgp), welches auf der luminalen Membran der Endothelzellen exprimiert wird und dort die Versorgung des Gehirns mit Medikamenten verhindert (Bredel 2001). Eine Studie mit 206 Glioblastom Patienten zeigte zudem, dass $45 \%$ des Tumorprobenmaterials eine fehlende Methylierung der Promotorregion des O6Methylguanin-Methyltransferase-Enzyms (MGMT) aufwiesen, welches in der Zelle an der Reparatur alkylierter DNA beteiligt ist. Eine Inhibition des MGMT-Genes durch PromotorMethylierung beeinträchtigt die Reparatur der DNA und wird mit einem längeren Überleben der Glioblastom-Patienten assoziiert. Durch eine Kombination von Radiotherapie und dem Medikament Temozolomid konnte die Überlebenserwartung von Glioblastom-Patienten, im Vergleich zu Patienten, die nur eine Radiotherapie erhielten, von 15,3 Monaten auf 21,7 Monaten verlängert werden (Hegi et al. 2005). 
In den letzten Jahren wurden viele verschiedene neue Medikamente eingeführt, wobei eine Kombination zwischen Target-spezifischen Medikamenten und einer Chemotherapie am effektivsten zu sein scheint (Stern und Raizer 2006). Zusätzlich sind in den letzten Jahren immer mehr alternative Behandlungsmöglichkeiten aufgekommen, wie z.B eine intraarterielle Gabe von hypertonem Mannitol, welches die Blut-Hirn-Schranke teilweise öffnen oder für eine Medikamentengabe durchlässiger machen soll (Kemper et al. 2004). Für den gleichen Zweck können auch Bradykinin-Analoga (Lobradimil) (Warren et al. 2006) oder kurzkettige Alkylglycerine (Erdlenbruch et al. 2003) verwendet werden.

Obwohl viele Behandlungsstrategien im Labor vielversprechend $\mathrm{zu}$ sein scheinen, liegen die Umsetzungen im klinischen Bereich am Patienten weiterhin hinter den Erwartungen (Bidros und Vogelbaum 2009).

Da EGFR in GBM sehr häufig überexprimiert vorliegt, kann es als Ziel einer AntikörperTherapie dienen. TP-38, ein rekombinant hergestelltes Pseudomonas-Exotoxin, bei dem die native Bindedomäne durch TGF- $\alpha$ ausgetauscht wurde, blockiert EGFR und ermöglicht somit ein längeres Überleben der Patienten (Sampson et al. 2008), welches in einer Studie gezeigt werden konnte, in der eine Patientin sogar mehr als fünf Jahre nach der GBM-Diagnose überlebte (Okada et al. 2009).

Eine weitere Möglichkeit für die Behandlung ist die Gabe von Anti-Angiogenese Wirkstoffen. Dieses sind Medikamente, die auf die Blutgefäße des Tumors abzielen, die Permeabilität der Gefäße reduzieren und einen normalisierenden Effekt auf die Morphologie der veränderten Blutgefäße ausüben sollen (Jain 2001). In einem präklinischen Tumormodell konnte gezeigt werden, dass eine Gabe von anti-VEGF die Versorgung der Tumoren durch therapeutische Mittel verbesserte und eine Tumorhypoxie verringerte (Gerstner et al. 2009). Mithilfe eines Mausmodells und Nierenkarzinomzellen konnte eine Verminderung der Gefäßdurchblutung und des Blutvolumens nach Behandlung mit Vatalanib, einem VEGFRInhibitor, nachgewiesen werden. Diese Beobachtungen konnten in einer Phase-I/-II-Studie mit Patienten, die an einem GBM litten, durch Gabe des Medikamentes Vatalanib mittels MRTUntersuchungen bestätigt werden (Conrad 2004). Vatalanib, ein Aminophthalazin, blockiert nach oraler Gabe alle bekannten VEGFR mit einer besonderen Affinität zu VEGFR-1 und -2 (Jost et al. 2006). 


\subsection{Semaphorine}

In den letzten Jahren konnten vier Proteinfamilien identifiziert werden, die eine wesentliche Rolle bei der axonalen Wegfindung spielen: Die Netrine, die Ephrine, die Slit-Proteine und die Semaphorine. Sie sind evolutionär konserviert und üben häufig ähnliche Funktionen während der Wegfindung von Axonen aus.

Die Semaphorine wurden zum ersten Mal 1993 als Proteine beschrieben, die wichtig für die Wegfindung der Axone sind. Aufgrund ihrer Wirkung auf neuronale Zellen in Hühnern wurden sie als Collapsine bezeichnet (Luo et al. 1993). Sie wurden als $100 \mathrm{kDa}$ große Proteine, die den Zusammenbruch und die Lähmung von Wachstumskegeln in neuronalen Zellen induzieren können, beschrieben. Heute umfasst die Familie der Semaphorine mehr als 21 Gene in Vertebraten und acht Gene in Invertebraten. Sie sind in acht Gruppen auf der Basis der Ähnlichkeit ihrer strukturellen Einheiten eingeteilt. In den Klassen 1 und 2 befinden sich die Semaphorine der Invertebraten, die Klassen 3 bis 7 beinhalten die Semaphorine der Vertebraten (Neufeld und Kessler 2008) und die viralen Semaphorine sind in Klasse V eingruppiert (Yazdani und Terman 2006).

Bei der Nomenklatur der Semaphorine deutet die Abkürzung SEMA auf die Familie hin, die Zahl dahinter zeigt die Zugehörigkeit zur jeweiligen Gruppe an (von 1 bis 8 und die viralen Semaphorine) und ein weiterer Buchstabe das spezielle Mitglied in der Gruppe. SEMA3A bedeutet also ein Semaphorin aus der Gruppe 3A (Commitee 1999). Alle Semaphorine haben an ihrem amino-terminalen Ende eine etwa 500 Aminosäuren lange Sema-Domäne, welche für die Signalweiterleitung essentiell ist. Diese Domäne wird in eine Hauptgruppe und eine kleine Cystein-reiche-Region am C-terminalen Ende (CRD) eingeteilt. Zusätzlich findet man die Sema-Domäne auch in MET- und RON-Rezeptor-Tyrosinkinasen in Vertebraten. Eine 70 Aminosäuren lange Sequenz innerhalb dieser Domäne ist wichtig für die Spezifität einiger Semaphorine (Gherardi et al. 2004). Am C-Terminus der Sema-Domäne befindet sich eine 54 Aminosäuren lange Sequenz, die Homologie zu der N-terminalen Region der $\beta$-Integrine aufweist.

Zusätzlich haben alle Semaphorine eine PSI-(Plexin, Semaphorin und Integrin) Domäne, eine Immunglobulin-ähnliche Domäne und eine Thrombospondin-Domäne (Zhou et al. 2008). Für die Klasse-5 Semaphorine sind sieben Typ-1 Thrombospondin-Kassetten typisch, welche auch Bestandteil der extrazellulären Matrix-Proteine Thrombospondin-1 und -2 sind (Adams et al. 1996). Die Familie der Semaphorine beinhaltet sezernierte (Semaphorine der Klasse-2 
und -3) aber auch membranständige Mitglieder, die durch eine Transmembrandomäne (Klasse-1, -4, -5 und -6) oder mit einem Glykosylphosphatidylinositol (GPI)-Anker (Klasse7) in der Plasmamembran verankert sind.

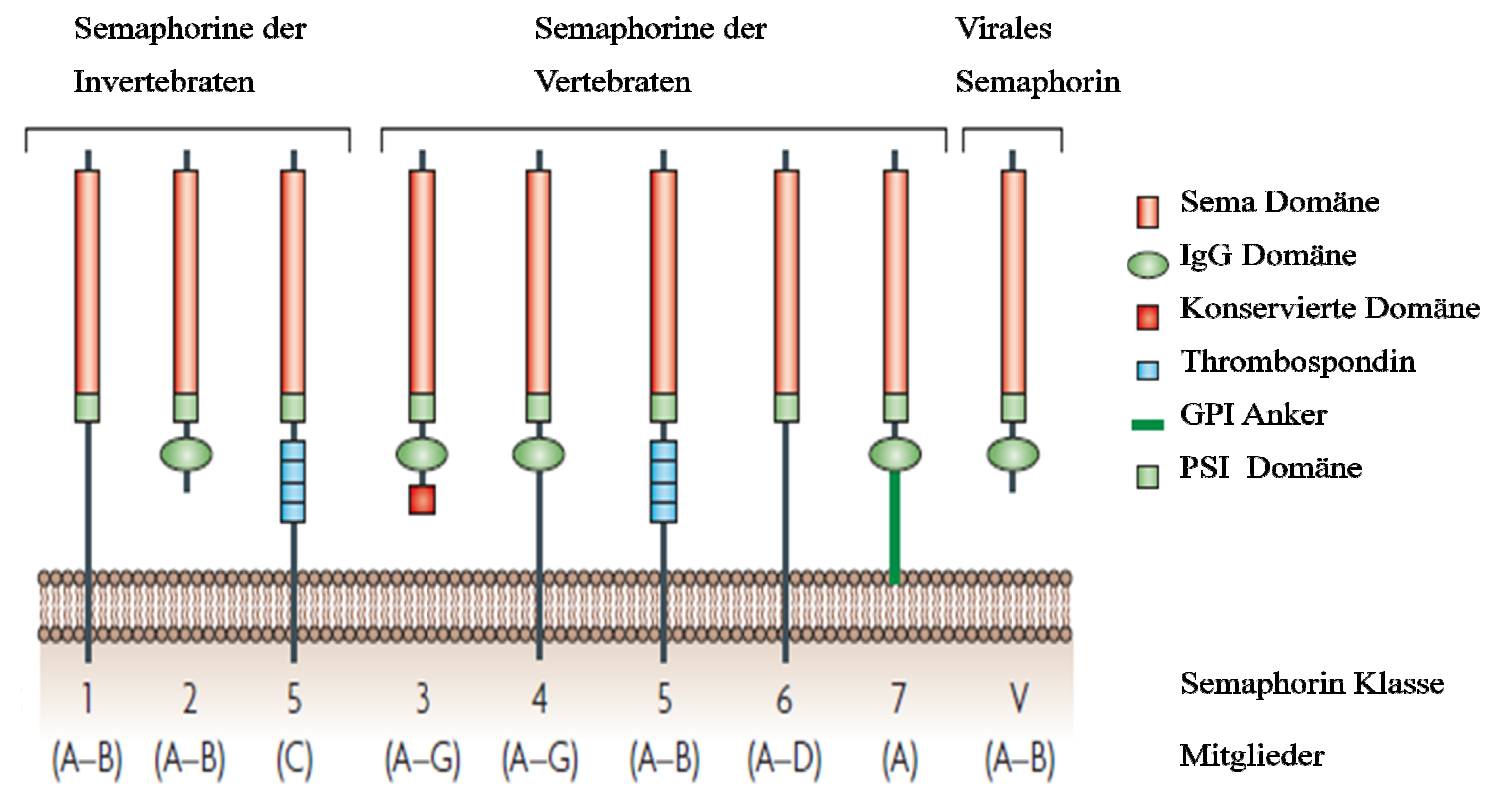

\section{Abbildung 1: Einteilung und Aufbau der Semaphorine}

Die Semaphorine besitzen an ihrem Amino-terminalen Ende eine Sema-Domäne, die für die Signalweitergabe wichtig ist. Am Carboxy-terminalen Ende befindet sich die PSI-Domäne, die eine Homologie zu einem Teilstück der Integrine besitzt. Die Klasse-3 Semaphorine besitzen eine konservierte Domäne an ihrem C-Terminus. Die Klasse-4 bis 7 Semaphorine sind durch eine transmembrane Domäne mit der Membran verbunden. Das Sema7A stellt eine Ausnahme dar, da es mit einem Glykosylphosphatidylinositol (GPI)-Anker mit der Membran verbunden ist. Die Klasse-5 Semaphorine haben Thrombospondin-Wiederholungen. Bis auf Klasse-5 und -6 besitzen die Semaphorine der Vertebraten eine Immunglobulin-ähnliche-Domäne (nach (Neufeld und Kessler 2008)).

Die Semaphorine werden in den verschiedensten Zellen exprimiert, so können sie z.B. in Endothelzellen und vielen Tumorzellen gefunden werden (Yazdani und Terman 2006). Für das ZNS konnte gezeigt werden, dass veränderte Semaphorin-Mengen für einige Krankheiten, wie Epilepsie, Alzheimer, Schizophrenie oder Parkinson typisch sind. Mäusen, denen Sema4A fehlte, zeigten z.B. starke Netzhautablösungen (Rice et al. 2004). Außerdem spielen Semaphorine eine Rolle in der Entwicklung von Krebserkrankungen. Sie beeinflussen die Chemotaxis, das Überleben, Tumorwachstum, Metastasenbildung und die Angiogenese (Neufeld und Kessler 2008). Semaphorinen kommt zusätzlich eine Bedeutung in der Immunabwehr zu. So konnte für Sema4D gezeigt werden, dass es auf der Zelloberfläche von 
aktivierten T-Helferzellen exprimiert wird und eine Rolle bei der Aggregation und Aktivierung von B-Lymphozyten spielt (Kumanogoh et al. 2002).

Die Rezeptoren der Semaphorine sind die Neuropiline und Plexine. Dabei binden sich die Semaphorine zuerst an Neuropiline, die dann wiederum als Komplex an die Plexine binden (Kigel et al. 2008).

\subsubsection{Neuropiline}

Es sind zwei unterschiedliche Neuropiline (Nrp) bekannt (Nrp1 und Nrp2), bei denen es sich jeweils um transmembrane Glykoproteine mit einer kurzen zytoplasmatischen Domäne (42-44 Aminosäuren) handelt. Nrp1 wurde 1995 als Antikörper gegen ein monoklonales neuronales Zelloberflächen-Protein, A5, entdeckt (Fujisawa et al. 1995) und ist essentiell für die neuronale und kardiovaskuläre Entwicklung. Nrp2 besitzt einen eher eingeschränkten Einfluss auf neuronale Abläufe und das Lymphgefäßsystem. Neuropiline werden in verschiedensten Tumorzellen stark exprimiert und spielen eine Rolle im Tumorwachstum und der Gefäßausbildung (Pellet-Many et al. 2008).

Nrp1 und Nrp2 haben eine Länge von 923 bzw. 926 Aminosäuren und besitzen eine ähnliche Struktur, allerdings weisen sie auf Aminosäure-Basis nur eine Homologie von $44 \%$ auf (Giger et al. 1998). Nrp1 und 2 besitzen jeweils eine große extrazelluläre Region, dazu gehört z.B. eine „Complement binding“ (CUB) und EGF (EGF-like Domäne; entdeckt in einem Seeigel)) Domäne, zwei Koagulationsfaktor V/ VIII-ähnliche Domänen (b1 and b2) und eine MAM-Domäne (Meprin A5, Rezeptor-Tyrosin-Phosphatase). Die MAM-Domäne spielt eine Rolle in der Bindung von Neuropilinen an andere Membranrezeptoren (Chen et al. 1997). Die Neuropiline besitzen die Fähigkeit, zwei strukturell unterschiedliche Klassen von Liganden zu binden, denn sie können mit den Klasse-3 Semaphorinen sowie einigen Mitgliedern der VEGF-Familie interagieren. Die meisten der Klasse-3 Semaphorine benötigen Nrp1 oder Nrp2 als Co-Rezeptor. Der Hauptligand für Nrp1 ist Sema3A (Bagnard et al. 2001). Mit geringerer Affinität bindet der Rezeptor auch an Sema3B, C, E und F. Die Liganden, die am besten für die Bindung an Nrp2 charakterisiert sind, sind Sema3B, C, F und G. Die Semaphorine3B, C und F fungieren als Antagonisten von Sema3A, wenn es um die Bindung an den Rezeptor geht (Chen et al. 1997).

Zusätzlich zu den Semaphorinen können sich auch verschiedene Angiogenese-Faktoren wie VEGF und „Hepatocyte growth factor/ scatter factor“ (HGF/ SF) an die Neuropiline binden und auf diese Weise Einfluss auf die Angiogenese nehmen. (Sulpice et al. 2008; Gaur et al. 
2009). In Säugetieren gibt es fünf Mitglieder der VEGF-Familie: VEGF-A bis -D und „Placental growth factor“ (PIGF). Zusätzlich konnten VEGF-E aus einem Virus und VEGF-F aus einem Schlangengift identifiziert werden (Ferrara et al. 2003). VEGF-A spielt eine große Rolle in der Blutgefäßneubildung während der frühen embryonalen Entwicklung der Gefäße und der Angiogenese, bei der neue Blutgefäße aus schon bestehenden wachsen (Risau 1997). Von VEGF-A kennt man sechs verschiedene Varianten $\left(\mathrm{VEGF}_{121}, \mathrm{VEGF}_{145}, \mathrm{VEGF}_{165}\right.$, $\mathrm{VEGF}_{165 \mathrm{~b}}, \mathrm{VEGF}_{189}$ und $\left.\mathrm{VEGF}_{206}\right)$ (Neufeld et al. 1996), die jeweils andere Bindungseigenschaften besitzen. Von den weiteren vier VEGF-Familienmitgliedern gibt es ebenfalls unterschiedliche Spleiß-Varianten, die sich in Affinität und Spezifität unterscheiden. Die Rolle der Neuropiline in Bezug auf Entwicklung und Krankheiten wurde schon in mehreren Arbeiten untersucht. So führte ein Nrp1 „knockout“ bei Mausembryonen zwischen den Tagen 12 und 13,5 zu schweren kardiovaskulären und neuronalen Defekten, die zum Tode führten. Zum Vergleich führte eine Überexpression von Nrp1 ebenfalls zum Tode der Embryonen (Kawasaki et al. 1999). Eine Überexpression von Nrp1 in RattenProstatakarzinomzellen (AT2.1) hingegen steigerte das Wachstum der Zellen in vivo während ein siRNA „knockdown“ die Migration von Brustkrebszellen inhibierte. Erhöhte Nrp1 Expressionen wurden auch in Melanom-, Astrozytom- und Neuroblastomzellen gefunden (Miao et al. 2000). Die Möglichkeit die Wirkung von Neuropilinen als Antitumormittel einzusetzen, wurde bereits getestet. So sind Antikörper gegen Nrp1 und Nrp2 in der Lage, die Progression von Tumoren zu inhibieren. Caunt et. al. konnten zeigen, dass eine Behandlung mit einem Nrp2-Antikörper die durch VEGF-C vermittelte Signalantwort unterdrückt und zu geringerer Metastasenausbildung bei Lymphangiomen in vitro und in vivo führt (Caunt et al. 2008). 


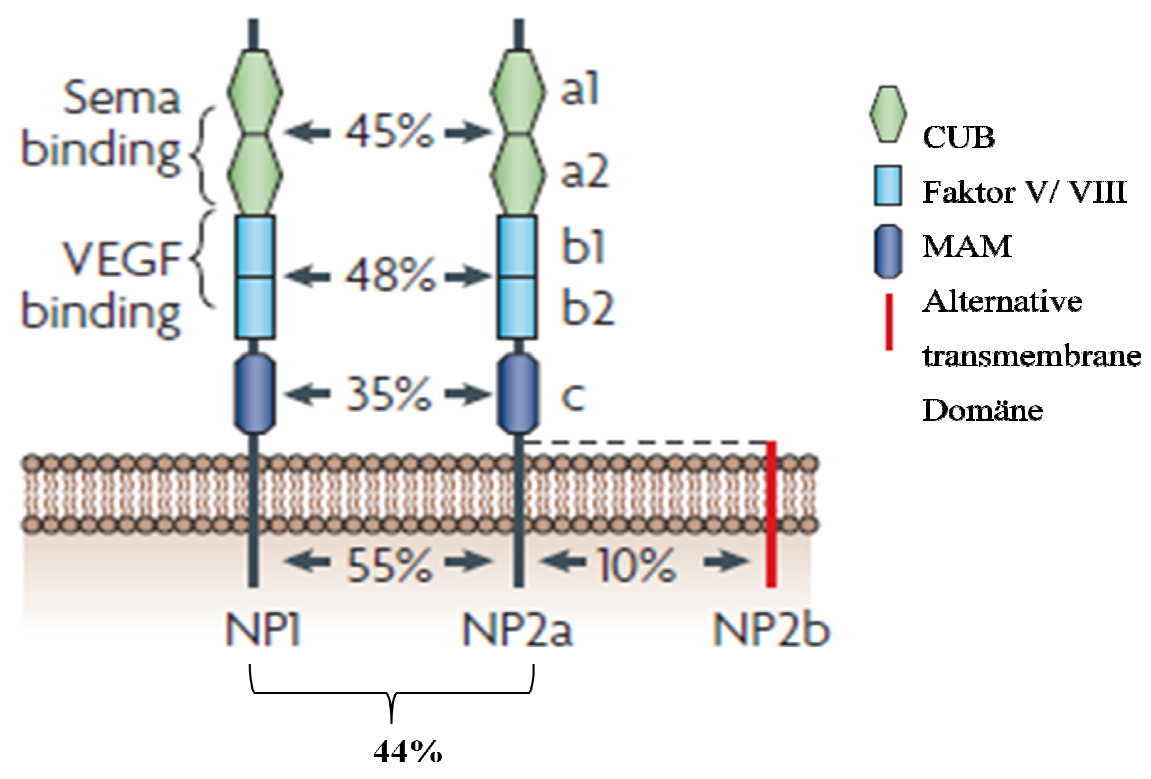

\section{Abbildung 2: Übersicht über die Neuropiline}

Die zwei Neuropiline haben eine CUB-Domäne (a1 oder a2), zwei Faktor V/ VIII Domänen und eine MAMDomäne (C-Domäne). Die Bindungsdomäne für Semaphorine ist in der a1/ a2-Domäne lokalisiert, während die VEGF-Bindung über b1/ b2 vermittelt wird (nach (Neufeld und Kessler 2008)).

\subsubsection{Plexine}

Bis heute konnten in Vertebraten neun verschiedene Plexine gefunden werden, die in vier Klassen, A-D, eingeteilt werden (Tamagnone et al., 1999). Es gibt vier Typ A Plexine (A1-4), drei Typ B Plexine (B1-3) und die Plexine C1 und D1 (Gaur et al. 2009). Plexine sind die Rezeptoren vieler Semaphorine und leiten Signale entweder alleine oder in Kombination mit Neuropilinen weiter. Sie sind ungefähr $200 \mathrm{kDa}$ groß und durchspannen die Membran. Ihre extrazelluläre Domäne enthält auch eine ca. 500 Aminosäuren lange Sema-Domäne und Cystein-reiche-Sequenzen, die auch im „Scatter factor/hepatocyte Growth Factor“ (SF/HGF) vorkommen (Tamagnone et al. 1999; Oinuma et al. 2004). Die humanen Plexine B und C binden nur die Semaphorine der Klassen vier und sieben, welche Membran-assoziiert sind. Die sieben verschiedenen Klasse-3 Semaphorine besitzen unterschiedliche Affinitäten für die Neuropiline. Die Komplexe aus Neuropilin und Klasse-3 Semaphorin binden an verschiedene Plexine, um Signale weiter zu geben (Gaur et al. 2009). Hierfür werden jedoch ausschließlich Plexine des Typs A oder D1 verwendet. Obwohl in diesem Bereich intensiv geforscht wird, gibt es noch keine genauen Vorstellungen, wie die intrazelluläre Signalkaskade abläuft. Serini et al. konnten allerdings zusätzlich zeigen, dass Klasse-3 Semaphorine fähig sind, die Integrin 
Aktivierung in Endothelzellen zu inhibieren. Dieser Vorgang ist essentiell für die Migration und unabhängig von der Signalweitergabe über die Plexine (Serini et al. 2003).
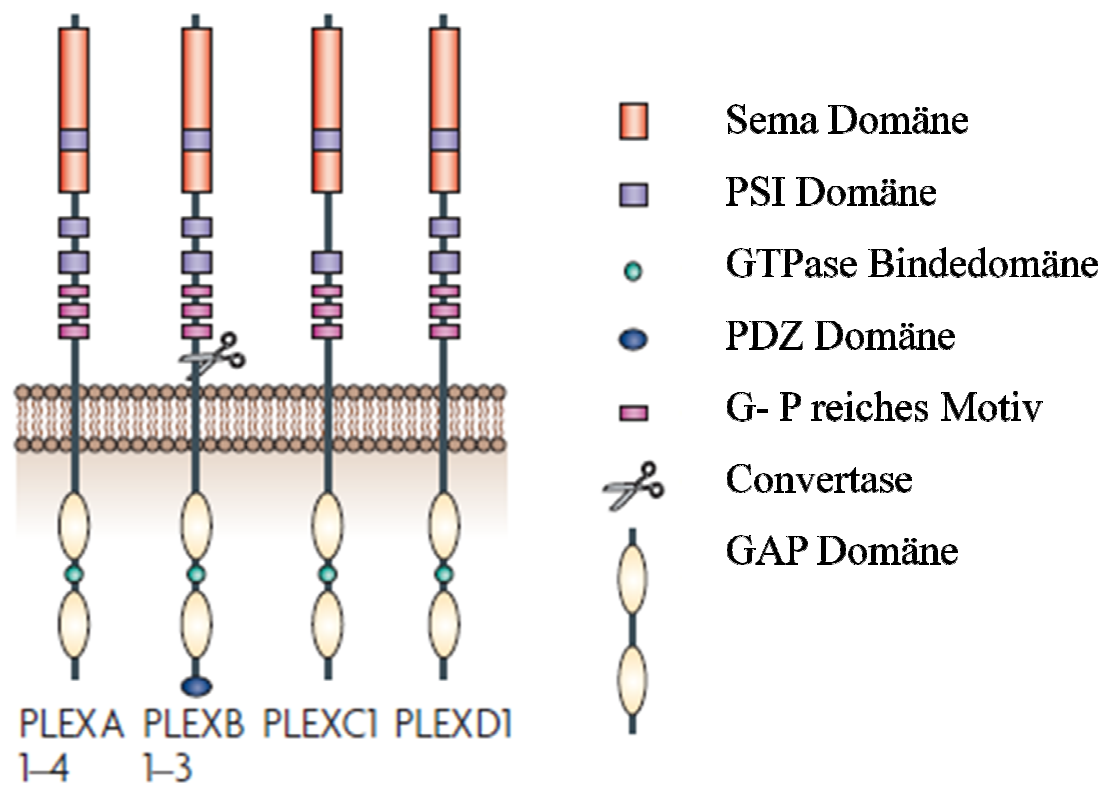

Abbildung 3: Übersicht über die Plexine nach Neufeld et al., 2008

Die neun verschiedenen Plexine der Vertebraten werden in vier Gruppen eingeteilt. Es gibt vier Typ A, drei Typ B, C1 und D1 Plexine. Die Plexine sind membrangebunden und besitzen extrazellulär eine Sema-Domäne, eine PSI-Domäne und ein Glycin-Prolin reiches Motiv (G-P), welches sie mit den Tyrosin-Kinase-Rezeptoren der Met-Familie teilen (nach Neufeld und Kessler 2008).

\subsubsection{Klasse- 3 Semaphorine und ihr Einfluss auf Tumoren}

Die Semaphorine der Klasse-3 sind besonders innerhalb der Semaphorine der Vertebraten, da sie die einzigen sezernierten Semaphorine sind (Bielenberg et al. 2004; Guttmann-Raviv et al. 2007). Außerdem besitzen sie eine konservierte Domäne an ihrem C-Terminus.

Es gibt sieben verschiedene Klasse-3 Semaphorine, A bis G, die ungefähr 100 kDa groß sind. Sie werden von verschiedensten Zelllinien, wie Epithelzellen, neuronalen Zellen oder Tumorzellen sezerniert.

Sechs der Klasse-3 Semaphorine binden sich an die Rezeptoren Nrp1, Nrp2 oder an beide, während Sema3E nur an PlexinD1 bindet. Die Klasse-3 Semaphorine spielen eine wichtige Rolle in der Biologie der Tumoren und sind fähig Tumorwachstum und Angiogenese zu hemmen (Gaur et al. 2009). Besonders gut untersucht sind dabei die Auswirkungen der Semaphorine 3B und 3F. Weiterhin ist bekannt, dass Sema3A in der Lage ist, die Apoptose von Zellen induzieren zu können (Kessler et al. 2004). Es ist in der Lage die Adhäsion der Endothelzellen an Komponenten der extrazellulären Matrix, wie Fibronektin, und die Entwicklung der Angiogenese in Hühnerembryonen zu inhibieren. Auf neuronaler Ebene 
konnte in in vitro-Versuchen gezeigt werden, dass Plexine Semaphorin-induzierten Zelltod übermitteln (Ben-Zvi et al. 2008). Durch das Vorhandensein von Neuropilinen und Plexinen in vielen Krebszelllinien, liegt es nahe, dass eine Verbindung zum Tumorwachstum besteht. Xiang et al. untersuchten den Einfluss der Semaphorine 3F und 3B auf Lungenkrebszellen und fanden eine Inhibierung der Adhäsion, Migration und Proliferation (Xiang et al. 2002). Sema3A führt zu einer Inhibierung der Zellmigration und Chemotaxis in Brustkrebszellen (Bachelder et al. 2003) und inhibiert die Adhäsion und Invasion von Prostatakrebszellen (Herman und Meadows 2007), während Sema3B Apoptose in Lungen- und Brustkrebszellen induziert (Castro-Rivera et al. 2004).

Über den Einfluss der Semaphorine auf Glioblastome ist nur wenig bekannt. In einer Arbeit von Bagci et al. wurde gezeigt, dass Nrp1 für die Zellmigration von GBM-Zellen notwendig ist. Außerdem konnte beobachtet werden, dass die Tumorzellen Sema3A sezernieren. Eine verminderte Expression von Sema3A inhibiert die Migration und verändert die Zellmorphologie, die von Rac1 abhängig ist. Zusätzlich schränkt die Verminderung von Sema3A die Verteilung der Zellen ein. Ein Effekt, der jedoch durch exogene Gabe wieder aufgehoben werden kann. Somit vermittelt Sema3A über Nrp1 Signale, welche das Infiltrationsverhalten von GBM Zellen limitiert (Bagci et al. 2009). Die Bindung von Sema3A an Nrp1, PlexinA1 und die daraus resultierende Signalkaskade ist für die Entwicklung des ZNS gut charakterisiert. Durch die Aktivierung der GTPase Rac1 nimmt diese Kaskade Einfluss auf die Bildung des F-Aktins (Kolodkin et al. 1997). In einer Studie mit 38 erwachsenen Gliom-Patienten wurde die Expression der verschiedenen Klasse-3 Semaphorine, VEGF, Nrp1 und Nrp2 untersucht. Dabei wiesen höher-gradige Tumoren eine reduzierte Expression von Sema3D im Vergleich zu niedrig-gradigen Gliomen auf. Genau der gegensätzliche Effekt wurde für VEGF beobachtet, dort führte eine höhere VEGF-Expression in höher-gradigen Gliomen zu einem verkürzten Überleben der Patienten (Karayan-Tapon et al. 2008). 
Tabelle 2: Klasse-3 Semaphorine und ausgewählte Funktionen (verändert nach Gaur et. al. 2009)

\begin{tabular}{|c|c|c|c|}
\hline Semaphorin & Zelllinie & Funktion & Referenz \\
\hline $3 \mathrm{~A}$ & $\begin{array}{l}\text { Endothel } \\
\text { Brustkrebs }\end{array}$ & $\begin{array}{l}\text { Beeinflussung der Adhäsion } \\
\text { und Migration } \\
\text { Inhibierung der Zellmigration } \\
\text { in vitro und des } \\
\text { Tumorwachstums in vivo }\end{array}$ & $\begin{array}{l}\text { (Serini et al. 2003) } \\
\text { (Bachelder et al. } \\
\text { 2003) }\end{array}$ \\
\hline 3B & $\begin{array}{l}\text { Lungen- und } \\
\text { Brustkrebs }\end{array}$ & $\begin{array}{l}\text { induziert Apoptose und anti- } \\
\text { proliferativer Effekt }\end{array}$ & (Kondo et al. 2001) \\
\hline $3 \mathrm{C}$ & Prostatakrebs & $\begin{array}{l}\text { Überexpression führt zu } \\
\text { verringerter Adhäsion und } \\
\text { Invasion }\end{array}$ & $\begin{array}{l}\text { (Herman und } \\
\text { Meadows 2007) }\end{array}$ \\
\hline $3 \mathrm{D}$ & Brustkrebs & $\begin{array}{l}\text { Überexpression inhibiert } \\
\text { Tumorentwicklung und } \\
\text { Angiogenese in vivo }\end{array}$ & (Kigel et al. 2008) \\
\hline $3 \mathrm{E}$ & Prostatakrebs & $\begin{array}{l}\text { Überexpression führt zu } \\
\text { verstärkter Adhäsion und } \\
\text { Invasion in vitro }\end{array}$ & $\begin{array}{l}\text { (Herman und } \\
\text { Meadows 2007) }\end{array}$ \\
\hline $3 \mathrm{~F}$ & $\begin{array}{l}\text { HUVEC } \\
\text { Brustkrebs } \\
\text { Fibrosarkom }\end{array}$ & $\begin{array}{l}\text { inhibiert durch VEGF- } \\
\text { übermittelte Proliferation } \\
\text { inhibiert Proliferation und } \\
\text { Zellkontakte } \\
\text { Überexpression führt zu } \\
\text { verringertem Tumorwachstum } \\
\text { in vivo }\end{array}$ & $\begin{array}{l}\text { (Kessler et al. 2004) } \\
\text { (Nasarre et al. 2003) } \\
\text { (Xiang et al. 2002) }\end{array}$ \\
\hline $3 \mathrm{G}$ & Brustkrebs & $\begin{array}{l}\text { Überexpression inhibiert die } \\
\text { Angiogenese in vivo }\end{array}$ & (Kigel et al. 2008) \\
\hline
\end{tabular}




\subsubsection{Die Funktion der Klasse- 3 Semaphorine im vaskulären System}

Wie bereits zuvor erwähnt, können Semaphorine ihre Wirkung über verschiedene Rezeptoren vermitteln und somit Einfluss auf das Verhalten von Endothelzellen ausüben (Miao et al. 1999). Für die am besten untersuchten Klasse-3 Semaphorine A und F konnte gezeigt werden, dass sie anti-angiogen wirken können. So wurde Sema3A als Gegenspieler von VEGF beschrieben (Acevedo et al. 2008). Im Gegensatz dazu beobachteten Banu et al. für Sema3C, dass es in Endothelzellen des Glomerulus die Zellproliferation, Adhäsion, direktionale Migration und Röhrenbildung (,tube formation") in vitro stimuliert. Diese Funktionen des Sema3C wurden durch Integrin-Phosphorylierung und $\mathrm{VEGF}_{120}$-Sekretion vermittelt (Banu et al. 2006).

Eine Inhibierung von $\mathrm{VEGF}_{165}$ und „basic fibroblast growth factor" (bFGF) in „Human Umbilical Vein Endothelial Cells" (HUVECs) kann durch Sema3F erzielt werden, welches durch Nrp2-Bindung seine Signale weiter gibt.

Wird Sema3F in „Human embryonic kidney“ (HEK293)-Zellen überexprimiert, wachsen die resultierenden Tumoren im Vergleich zu Kontrolltumoren in vivo langsamer an. Außerdem war die Anzahl an Blutgefäßen, die den Tumor versorgten, signifikant geringer als in den Kontrolltumoren (Kessler et al. 2004). Maione et al. zeigten, dass Sema3A in Endothelzellen exprimiert wird und als endogener Inhibitor der Angiogenese auftritt. Wird Sema3A vor dem „, angiogenic switch“ inhibiert, führt dies zu einer verminderten Entwicklung von Blutgefäßen und einer Inhibierung der Tumorentwicklung (Maione et al. 2009).

Nrp1, ein Rezeptor der Klasse-3 Semaphorine, übt zusätzlich eine Funktion im vaskulären System aus. Eine Nrp1-Überexpression in transgenen Mäusen führte zu einer Überproduktion an Blutgefäßen im Nervensystem (Kitsukawa et al. 1997). Im Vergleich dazu zeigten Nrp1 defiziente Mausembryonen eine verminderte Blutgefäßanzahl im ZNS, eine Transposition der großen Gefäße und andersartig angeordnete vaskuläre Gefäße im Dottersack (Kawasaki et al. 1999). Nrp2-Mausmutanten wiesen keine Defekte in der Vaskularisation auf (Chen et al. 2000). Takashima et al. erzeugten eine Nrp1 und Nrp2 Doppelmutante. Die Mäuse starben an Tag 8,5 in der Gebärmutter (Takashima et al. 2002). Die Dottersäcke wiesen keinerlei Gefäße auf. 


\subsection{Zielsetzung}

Übergeordnetes Ziel dieser Arbeit ist die Entwicklung effektiverer Therapiestrategien bei der Behandlung maligner Hirntumoren. Glioblastome sind die häufigsten und zugleich aggressivsten Tumoren des ZNS bei Erwachsenen. In Deutschland erkranken jährlich etwa 300 Kinder neu an einem Hirntumor. Die mediane Überlebenszeit beträgt trotz aggressiver, multimodaler Antitumortherapie nur neun bis zwölf Monate. Vor diesem Hintergrund ist es verständlich, dass die Suche nach alternativen Konzepten zur Behandlung von ZNS-Tumoren einen besonders hohen Stellenwert einnimmt.

In verschiedenen Arbeiten konnte gezeigt werden, dass Proteine der Semaphorin-Familie die Zelladhäsion und Beweglichkeit von Zellen beeinflussen können. Aus der Literatur ist ferner bekannt, dass die Transfektion von Brustkrebszellen mit verschiedenen Klasse-3 Semaphorinen zu einer Reduktion der Anzahl Tumor-assoziierter Blutgefäße und einer Verminderung des Tumorwachstums führt (Kigel et al. 2008).

In dieser Arbeit soll daher die Hypothese überprüft werden, ob es sich bei den Beobachtungen von Kigel et al. nicht nur um ein zelltypspezifisches Charakteristikum der Semaphorine handelt, sondern um eine generelle Eigenschaft, die folglich auch für Hirntumorzellen gilt. Voraussetzung für die Analyse der Effekte verschiedener Klasse-3 Semaphorine auf das Wachstum von Gehirntumoren ist die stabile, lentivirale Transfektion humaner Hirntumorzellinien (U87MG, U373MG) mit entsprechenden Semaphorin-Expressionsvektoren. Der mögliche Effekt, den die Semaphorine auf die Tumorzellen (Angiogenese, Proliferation, Migration und Apoptose) ausüben, soll mit Hilfe zweier unterschiedlicher Modellsysteme untersucht werden:

1. Im Chorionallantoismembran (CAM)-Modell werden Semaphorin-überexprimierende Gliomzellen auf die CAM von 10 Tage alten Hühnerembryonen gebracht, um das Wachstum der Tumorzellen und die damit einhergehende Entwicklung von Blutgefäßen im Vergleich zu Kontrollzellen makroskopisch zu bestimmen.

2. Im Nacktmaus-Modell werden die transfizierten Zellen in immundefiziente Nacktmäuse intrazerebral implantiert, um das Wachstum der Tumoren in vivo zu bestimmen. Die Größe der Tumoren und deren Versorgung mit Blutgefäßen werden durch Biolumineszenzmessung und Fluoreszenzmikroskopie bestimmt, ergänzt durch eine detaillierte immunhistologische Charakterisierung. 
Durch die Transfektion der Semaphorine kann es zu möglichen Veränderungen auf der Ebene der Genexpression kommen. Diese sollen durch ergänzende Untersuchungen mittels Microarray-Analysen und realtime-PCR bestimmt werden. Ein besonderes Augenmerk wird dabei auf die Gene gelegt, die mit Zelladhäsion, Apoptose, Zellzyklus oder Angiogenese in Zusammenhang gebracht werden.

Die Erkenntnisse dieser Arbeit sollen dazu dienen, ausgewählte Semaphorine in ein therapeutisches Konzept zur Behandlung maligner Hirntumoren zu integrieren. 


\section{$2 \quad$ Material}

\subsection{Geräte}

Eine Übersicht der in dieser Arbeit verwendeten Geräte ist in der folgenden Tabelle zu finden.

Tabelle 3: Verwendete Geräte und deren Hersteller

\begin{tabular}{|c|c|}
\hline Gerät & Hersteller \\
\hline ABI GeneAmp PCR System 9700 & Applied Biosystems, Foster City, USA \\
\hline ABI Prism 7900HT & Applied Biosystems, Foster City, USA \\
\hline Analysewaage Sartorius excellence & Sartorius, GöttingenFC \\
\hline Auflichtmikroskop DMIRB & Leica Microsystems, Wetzlar \\
\hline Automatischer Pipettierer Microlab m & Hamilton, Bonaduz, Schweiz \\
\hline Bioanalyzer 2100 & Agilent, Santa Clara, USA \\
\hline Biolumineszenz Imager (VisiLuxx) & Visitron Systems, Puchheim \\
\hline Brutschrank BBD6220 & $\begin{array}{l}\text { Haereus Instruments, Schütt Labortechnik } \\
\text { Göttingen }\end{array}$ \\
\hline $\begin{array}{l}\text { Durchlicht- und Fluoreszenzmikroskop } \\
\text { Leica 5000B }\end{array}$ & Leica Microsystems, Wetzlar \\
\hline Einbettstation EG1160 & Leica Microsystems, Wetzlar \\
\hline Entwässerungsautomat TP1020 & Leica Microsystems, Wetzlar \\
\hline FACScan & Becton Dickinson, Heidelberg \\
\hline Fujifilm LAS-3000 & Fujifilm, Düsseldorf \\
\hline Gelkammer, Vertikale Minigelanlage & Biometra, Göttingen \\
\hline $\begin{array}{l}\text { GeneChip AutoLoader with External } \\
\text { Barcode Reader }\end{array}$ & Affymetrix, Santa Clara, USA \\
\hline GeneChip Fluidics Station 450 & Affymetrix, Santa Clara, USA \\
\hline GeneChip Hybridization Oven & Affymetrix, Santa Clara, USA \\
\hline GeneChip Scanner 3000 7G & Affymetrix, Santa Clara, USA \\
\hline Hamilton Microliter Syringes, $10 \mu 1$ & Hamilton, Bonaduz, Schweiz \\
\hline Heizblock & VWR, Darmstadt \\
\hline $\begin{array}{l}\text { Mikrotiterplatten } \\
\text { Lesegerät (SUNRISE) }\end{array}$ & Tecan, Crailsheim \\
\hline
\end{tabular}




\begin{tabular}{|c|c|}
\hline Mikrotom Leica RM 2165 & Leica Microsystems, Wetzlar \\
\hline NanoDrop ND-1000 & NanoDrop Technologies, Wilmington, USA \\
\hline Operationsleuchte Hanaulux 2208 & Medap, Feldkirch \\
\hline Operationsmikroskop OpMi- 1 & Zeiss, Göttingen \\
\hline PicoFuge & Stratagene, La Jolla, USA \\
\hline Pipettus Easypet & Eppendorf, Wesseling- Berzdorf \\
\hline Schüttler Polymax 1040 & Heidolph Elektro, Kelheim \\
\hline $\begin{array}{l}\text { Semi-Dry-Blot-Apparatur } \\
\text { Fastblot B44 }\end{array}$ & Biometra, Göttingen \\
\hline $\begin{array}{l}\text { Spannungsgeber für Gelkammer EPS } \\
3500\end{array}$ & Pharmacia Biotech, Uppsala, Schweden \\
\hline Spannungsqueller Blotting CP 200/400 & Pharmacia Biotech, Uppsala, Schweden \\
\hline Stereomikroskop Leica MZFL III & Leica Microsystems, Wetzlar \\
\hline Stereotaxiegerät Modell 900 & $\begin{array}{l}\text { Kopf Instruments, Tujunga, } \\
\text { California }\end{array}$ \\
\hline Sterilbank BioGuard Hood & Baker, Sanford, Maine, USA \\
\hline Thermocycler T Gradient & Biometra, Göttingen \\
\hline Trockenschrank Memmert & Schütt Labortechnik, Göttingen \\
\hline Vortex Heidolph Relax top & Oehmen Labortechnik, Essen \\
\hline $\begin{array}{llll}\text { Wallac } & 1420 & \text { Victor2 } & \text { Multilabel } \\
\text { Counter } & & & \\
\end{array}$ & PerkinElmer, Rodgau - Jügesheim \\
\hline Wasserbad GFC & Krannich, Göttingen \\
\hline Zellkulturinkubator & Heraeus Instruments, Hanau \\
\hline Zentrifuge Biofuge 13 & $\begin{array}{l}\text { Haereus Instruments, Schütt } \\
\text { Labortechnik, Göttingen }\end{array}$ \\
\hline
\end{tabular}

Alle weiteren verwendeten Geräte sind im entsprechenden Methodenteil zu finden.

\subsection{Operationsbesteck}

Für die Operationen an den Mausmodellen wurden anatomische Pinzetten, Fremdkörperpinzetten, Mikrochirurgiepinzetten, Iridektomiescheren der Carl Teufel GmbH \& Co (Liptingen) und Gefäßklemmen von Fine Science Tools (Heidelberg) verwendet. 


\subsection{Verbrauchsmaterialien}

Eine Zusammenstellung der häufig verwendeten Materialien in dieser Arbeit ist in der folgenden Tabelle zu finden.

Tabelle 4: Verwendete Verbrauchsmaterialien und deren Hersteller

\begin{tabular}{|c|c|}
\hline Material & Hersteller \\
\hline 6-Well Flachbodenkulturplatten & NUNC, Wiesbaden \\
\hline 96-Well Flachbodenkulturplatten & NUNC, Wiesbaden \\
\hline $\begin{array}{l}\text { 96-Well Flachbodenkulturplatten } \\
\text { (optical bottom) }\end{array}$ & NUNC, Wiesbaden \\
\hline Deckgläschen & $\begin{array}{l}\text { Menzel-GmbH\&Co } \\
\text { KG, Braunschweig }\end{array}$ \\
\hline Einmalhandschuhe & Hartmann, Heidenheim \\
\hline Filterpapier & Schleicher und Schüll, Dassel \\
\hline Fluoromount-G & Southern Biotech, Birmingham, USA \\
\hline Gewebekassetten & Klinipath b.v., Duiven, Niederlande \\
\hline Haut-Antiseptik, Kodan ${ }^{\circledR}$ & Schülke \& Mayr, Norderstedt \\
\hline Immobilion-P (PVDF; 0,45 $\mu \mathrm{M}$ ) & Millipore, Schwalbach \\
\hline Kanülen 27G und 20G & B. Braun, Melsungen \\
\hline Kryoröhrchen $(2 \mathrm{ml})$ & Greiner, Solingen \\
\hline Mikrotom-Klingen N35 & Feather, Köln \\
\hline Nahtmaterial für Mäuse, Seralon 7/0 & DCV-INstrumente, Seitingen- Oberflacht \\
\hline $\begin{array}{l}\text { Objektträger für } \quad \text { Paraffinschnitte, } \\
\text { Superfrost Plus }\end{array}$ & $\begin{array}{l}\text { Menzel-GmbH\&Co } \\
\text { KG, Braunschweig }\end{array}$ \\
\hline Paraffin, Paraplast Plus & tyco Healthcare, Kendall, USA \\
\hline Perfusor-Einheit, $120 \mathrm{ml}$ & B. Braun, Melsungen \\
\hline Petrischalen, Falcon 3003 & $\begin{array}{l}\text { Becton Dickinson, Le Pont De Claix, } \\
\text { Frankreich }\end{array}$ \\
\hline Pipetten $1 \mathrm{ml}, 5 \mathrm{ml}, 10 \mathrm{ml}, 20 \mathrm{ml}$ & Sarstedt, Nümbrecht \\
\hline Pipettenspitzen $10 \mu \mathrm{l}, 100 \mu \mathrm{l}, 1000 \mu \mathrm{l}$ & Sarstedt, Nümbrecht \\
\hline $\begin{array}{l}\text { Polyethylen-Röhrchen mit Schraubver- } \\
\text { schluß } 10 \mathrm{ml}, 50 \mathrm{ml}\end{array}$ & Greiner bio-one, Frickenhausen \\
\hline
\end{tabular}




\begin{tabular}{|l|l|}
\hline Reagiergefäße 1,5 ml, $2 \mathrm{ml}$ & Sarstedt, Nümbrecht \\
\hline Sephadex G25 Medium & $\begin{array}{l}\text { Pharmacia Fine Chemicals, Uppsala, } \\
\text { Schweden }\end{array}$ \\
\hline Skalpelle & HMD Healthcare Ltd. Norsham, England \\
\hline Spritzen, 1 ml, $5 \mathrm{ml}$ & $\begin{array}{l}\text { Beckton Dickinson, Le Pont De Claix, } \\
\text { Frankreich }\end{array}$ \\
\hline Sterile Wundkompressen & Hartmann, Heidenheim \\
\hline $\begin{array}{l}\text { Sterilfilter, Minisart, } 0,2 \\
\text { Porengröße }\end{array}$ & Sartorius, Göttingen \\
\hline $\begin{array}{l}\text { U-100 Insulin-Spritzen } 0,5 \mathrm{ml}, \mathrm{Micro}^{-} \\
\text {Fine+ }\end{array}$ & $\begin{array}{l}\text { Beckton Dickinson, Le Pont De Claix, } \\
\text { Frankreich }\end{array}$ \\
\hline $\begin{array}{l}\text { Zellkulturflaschen } 25 \mathrm{~cm}^{2}, 75 \mathrm{~cm}^{2} \text { und } \\
175 \mathrm{~cm}^{2}\end{array}$ & Greiner bio-one, Frickenhausen \\
\hline Zellschaber & Sarstedt, Nümbrecht \\
\hline Zellstoff, Pehazell & Hartmann, Heidenheim \\
\hline Zentrifugenröhrchen $\left(15 \mathrm{ml}^{\prime} 50 \mathrm{ml}^{2}\right.$ & Greiner Bio-one, Frickenhausen \\
\hline
\end{tabular}

\subsection{Medikamente}

In der folgenden Tabelle sind die in Tierversuchen verwendeten Medikamente aufgeführt.

Tabelle 5: Verwendete Medikamente

\begin{tabular}{|c|c|c|}
\hline Medikament & Hersteller & Dosierung \\
\hline $\begin{array}{l}\text { Antisedan }{ }^{\circledR} \\
\text { (Atipamezolhydrochlorid) }\end{array}$ & Pfizer & $0,2 \mathrm{mg} \mathrm{kg}^{-1}$ Körpergewicht \\
\hline $\begin{array}{l}\text { Hostaket }^{\circledR} \\
\text { (Ketaminhydrochlorid) }\end{array}$ & Intervent & $85 \mathrm{mg} \mathrm{kg}^{-1}$ Körpergewicht \\
\hline Isofluran & Baxter GmbH & Sauerstoff-Isofluran Gasmix \\
\hline Rimadyl $^{\circledR}$ & Pfizer & $5 \mathrm{mg} \mathrm{kg}^{-1}$ Körpergewicht \\
\hline $\begin{array}{l}\text { Rompun }^{\circledR} \\
\text { (Xylazinhydrochlorid) }\end{array}$ & Bayer & 7,5 $\mathrm{mg} \mathrm{kg}^{-1}$ Körpergewicht \\
\hline
\end{tabular}




\subsection{Chemikalien}

In der folgenden Tabelle sind die verwendeten Chemikalien und deren Hersteller aufgelistet.

\section{Tabelle 6:Verwendete Chemikalien}

\begin{tabular}{|c|c|}
\hline Chemikalie & Hersteller \\
\hline 2-Methylbutan & Riedel-de-Haën, Seelze \\
\hline $\begin{array}{l}\text { 3,3-Diaminobenzidin- } \\
\text { Tetrahydrochlorid (DAB) }\end{array}$ & Roth, Karlsruhe \\
\hline Aceton & Sigma, Deisenhofen \\
\hline Acrylamid-Mix Rotiphorese Gel 30 & Roth, Karlsruhe \\
\hline Ammoniumpersulfat (APS) & Merck, Darmstadt \\
\hline Aqua ad iniectabilia & B. Braun, Melsungen \\
\hline Betain & Sigma-Aldrich, Steinheim am Albuch \\
\hline Bromphenolblau & Sigma, Deisenhofen \\
\hline Dimethylsulfoxid (DMSO) & Sigma, Deisenhofen \\
\hline Dithiothreitol (DTT) & Merck, Darmstadt \\
\hline D-Luziferin (firefly) & Biosynth, Staad, Schweiz \\
\hline Eisessig (Essigsäure 100\%) & Roth, Karlsruhe \\
\hline $\begin{array}{l}\text { Entellan-Neu (nicht-wässriges } \\
\text { Eindeckmedium) }\end{array}$ & Merck, Darmstadt \\
\hline Eosin C.I. 45380 & Roth, Karlsruhe \\
\hline Essigsäure & Roth, Karlsruhe \\
\hline Ethanol $99 \%$ vergällt & Chemie-Vertrieb, Hannover \\
\hline FACS Flow & Becton Dickinson, Heidelberg \\
\hline Fetal calf serum (FCS) & Biochrom, Berlin \\
\hline $\begin{array}{l}\text { Fluoromount G } \\
\text { (wässriges Eindeckmedium) }\end{array}$ & Biozol, Eching \\
\hline Glycin & Sigma, Deisenhofen \\
\hline Hämalaun nach Mayer & Roth, Karlsruhe \\
\hline $\begin{array}{l}\text { HEPES (2-(4-(2-Hydroxyethyl)-1- } \\
\text { piperazinyl)-ethansulfonsäure) }\end{array}$ & Invitrogen, Karlsruhe \\
\hline Hoechst Farbstoff 33342 & Invitrogen, Karlsruhe \\
\hline
\end{tabular}




\begin{tabular}{|c|c|}
\hline Isopropanol & Fluka, Chemie GmbH, Buchs, Schweiz \\
\hline Isotone Natriumchloridlösung( $0,9 \%)$ & B. Braun, Melsungen \\
\hline Kernechtrot & Appli Chem, Darmstadt \\
\hline Methanol 99,9\% & Roth, Karlsruhe \\
\hline Milchpulver (non-fat) & Bio-Rad, München \\
\hline $\begin{array}{l}\text { N, N, N', N'-Tetramethylethylendiamin } \\
\text { (TEMED) }\end{array}$ & Roth, Karlsruhe \\
\hline Natriumchlorid & Merck, Darmstadt \\
\hline Natriumcitrat & Sigma, Deisenhofen \\
\hline Natriumdodecylsulfat (SDS) & Serva, Heidelberg \\
\hline Natriumhypochloritlösung $12 \% \mathrm{Cl}$ & Roth, Karlsruhe \\
\hline Natronlauge & Merck, Darmstadt \\
\hline Paraformaldehyd & Roth, Karlsruhe \\
\hline Penicillin/Streptamycin (je 5000 U/ml) & Cambrex, Oberhaching \\
\hline $\begin{array}{l}\text { Phospate buffered saline (PBS } \\
\text { Dulbecco) (Pulver) }\end{array}$ & Biochrom, Berlin \\
\hline Polyethylenglycol MG 20000 & Serva, Heidelberg \\
\hline Ponceau S & Sigma, Deisenhofen \\
\hline Recombinant human Sema3E & R\&D systems Minneapolis, USA \\
\hline Recombinant human $\mathrm{VEGF}_{165}$ & R\&D systems Minneapolis, USA \\
\hline Recombinant mouse Sema3F & R\&D systems Minneapolis, USA \\
\hline Rinderserumalbumin (BSA) & Fermentas, St. Leon- Rot \\
\hline Roti-Histol & Roth, Karlsruhe \\
\hline Salzsäure & Merck, Darmstadt \\
\hline Tris X (Base) & Merck, Darmstadt \\
\hline Trypan blue solution $(0,4 \%)$ & Sigma, Deisenhofen \\
\hline Tween 20 & $\begin{array}{l}\text { Calbiochem (Merck4Biosciences), } \\
\text { Darmstadt }\end{array}$ \\
\hline Wasserstoffperoxid $30 \%$ & Roth, Karlsruhe \\
\hline Xylol & Roth, Karlsruhe \\
\hline Zitronensäure & Merck, Darmstadt \\
\hline$\beta$-Mercaptoethanol & Serva, Heidelberg \\
\hline
\end{tabular}

Alle weiteren verwendeten Chemikalien sind in dem entsprechenden Methodenteil zu finden. 


\subsection{Puffer und Medien}

Alle fertigen Puffer/ Medien, deren Verwendung und Hersteller sind in der folgenden Tabelle aufgelistet.

Tabelle 7: Verwendete Puffer und Medien

\begin{tabular}{|l|l|l|}
\hline Fertige Puffer/Medien & Verwendung & Hersteller \\
\hline $\begin{array}{l}\text { DMEM 1 g/l Glukose und L- } \\
\text { Glutamin }\end{array}$ & Zellkultur & Biochrom, Berlin \\
\hline EGM-2 MV Single Quots & Zellkultur & Lonza, Basel, Schweiz \\
\hline MEM-Earle & Zellkultur & Biochrom, Berlin \\
\hline PBS (fertiger Puffer) & $\begin{array}{l}\text { Zellkultur, Perfusion, } \\
\text { Immunfluoreszenz }\end{array}$ & Lonza, Basel, Schweiz \\
\hline RPMI 1640 & Zellkultur & Lonza, Basel, Schweiz \\
\hline $\begin{array}{l}\text { Trypsin 200 mg/l Versene } \\
\text { EDTA) }\end{array}$ & Zellkultur & Lonza, Basel, Schweiz \\
\hline
\end{tabular}

Tabelle 8: Puffer für Western Blot-Analyse

\begin{tabular}{|l|l|}
\hline Puffer & Zusammensetzung \\
\hline 1. Antikörper-Puffer & TBS mit \\
& $5 \%$ BSA \\
& $0,1 \%$ Tween 20 \\
\hline Block-Puffer (entspricht auch & TBS mit \\
dem 2. Antikörper-Puffer) & $0,1 \%$ Tween 20 \\
& $5 \%$ non-fat-dry milk \\
\hline Laufpuffer & $0,5 \%$ SDS \\
& $0,125 \mathrm{M}$ Tris X \\
& $1,25 \mathrm{M}$ Glycin \\
\hline TBS-Puffer & $150 \mathrm{mM}$ NaCl \\
& $20 \mathrm{mM}$ Tris-Cl pH 7,5 \\
\hline Wasch-Puffer & TBS mit \\
& $0,1 \%$ Tween 20 \\
\hline Blot-Puffer pH $(\sim 9,2)$ & $48 \mathrm{mM}$ Tris \\
& $39 \mathrm{mM}$ Glycin \\
& $20 \%$ Methanol \\
\hline
\end{tabular}




\subsection{Gebrauchsfertige Reaktionssysteme}

In der folgenden Tabelle sind die häufig verwendeten gebrauchsfertigen Reaktionssysteme aufgeführt.

Tabelle 9: Gebrauchsfertige Reaktionssysteme

\begin{tabular}{|l|l|}
\hline Bezeichnung & Hersteller \\
\hline $\begin{array}{l}\text { „Cell Proliferation Reagent“ } \\
\text { WST-1 }\end{array}$ & Roche Applied Science, Mannheim \\
\hline $\begin{array}{l}\text { ATP-Bioluminescence Assay Kit } \\
\text { CLS II }\end{array}$ & Roche Applied Science, Mannheim \\
\hline BCA Protein Assay Kit & Pierce (über Perbio Science), Bonn \\
\hline $\begin{array}{l}\text { GeneChip hybridization, wash, } \\
\text { stain and control kit }\end{array}$ & Affymetrix, Santa Clara, USA \\
\hline GeneChip IVT cRNA cleanup kit & Affymetrix, Santa Clara, USA \\
\hline GeneChip sample cleanup module & Affymetrix, Santa Clara, USA \\
\hline $\begin{array}{l}\text { GeneChip whole transcript cDNA } \\
\text { synthesis and amplification kit }\end{array}$ & Affymetrix, Santa Clara, USA \\
\hline $\begin{array}{l}\text { GeneChip whole transcript } \\
\text { terminal labeling kit }\end{array}$ & Affymetrix, Santa Clara, USA \\
\hline iSript cDNA Synthesis Kit & BioRad,Hercules, CA, USA \\
\hline Luciferase Assay System & Promega, Mannheim \\
\hline $\begin{array}{l}\text { MessageAmp } \\
\text { Kit II-Biotin } \text { enhanced }\end{array}$ & Ambion, Austin, USA \\
\hline $\begin{array}{l}\text { RiboMinus Transcriptome } \\
\text { Isolation Kit (human/mouse) }\end{array}$ & Invitrogen, Karlsruhe \\
\hline SYBR Green Mastermix & Applied Biosystems, Foster City, USA \\
\hline $\begin{array}{l}\text { Western blotting detection reagents } \\
\text { ECL Kit }\end{array}$ & Amersham, Braunschweig \\
\hline $\begin{array}{l}\text { Cyto Select } \\
\text { adhesion assay (ECM Array) }\end{array}$ & Cell Biolabs, San Diego, USA \\
\hline
\end{tabular}

\subsection{Antikörper}

In Tabelle 10 sind die verwendeten Antikörper für FACS-Analyse, Western Blot-Analyse und Immunhistochemie aufgelistet. 
Tabelle 10: Primäre Antikörper und deren eingesetzte Verdünnung

\begin{tabular}{|l|l|l|}
\hline Primäre Antikörper & Verdünnung & Hersteller/Vertreiber \\
\hline $\begin{array}{l}\text { Anti- Actin clone C4 } \\
\text { mouse } \\
\text { antibody }\end{array}$ & $1: 10000$ & Millipore, Billerica, USA \\
\hline $\begin{array}{l}\text { Anti- VEGFR-2 } \\
\text { biotinyliert }\end{array}$ & $1: 200$ & $\begin{array}{l}\text { R\&D, Wiesbaden- } \\
\text { Nordenstadt }\end{array}$ \\
\hline $\begin{array}{l}\text { caspase-3 rabbit } \\
\text { monoclonal antibody }\end{array}$ & $1: 7000$ & $\begin{array}{l}\text { cell signaling, Boston, } \\
\text { USA }\end{array}$ \\
\hline $\begin{array}{l}\text { Goat anti-firefly luciferase } \\
\text { polyclonal antibody }\end{array}$ & $1: 50$ & Abcam, Cambridge, UK \\
\hline $\begin{array}{l}\text { Rabbit anti-human } \\
\text { polyclonal F8 (von- } \\
\begin{array}{l}\text { Willebrand-Faktor) Alexa } \\
\text { Fluor 594 }\end{array}\end{array}$ & $1: 200$ & $\begin{array}{l}\text { Invitrogen Molecular } \\
\text { Probes, Darmstadt }\end{array}$ \\
\hline$\alpha v \beta 3$ & $1: 200$ & $\begin{array}{l}\text { Chemicon International; } \\
\text { Millipore; Schwalbach }\end{array}$ \\
\hline$\alpha v \beta 5$ & $1: 200$ & $\begin{array}{l}\text { Chemicon International; } \\
\text { Millipore; Schwalbach }\end{array}$ \\
\hline$\beta 5$ & $1: 200$ & $\begin{array}{l}\text { Chemicon International; } \\
\text { Millipore; Schwalbach }\end{array}$ \\
\hline
\end{tabular}

Tabelle 11: Sekundäre Antikörper und deren eingesetzte Verdünnung

\begin{tabular}{|l|l|l|}
\hline Sekundäre Antikörper & Verdünnung & Hersteller/Vertreiber \\
\hline $\begin{array}{l}\text { Anti-rabbit antibody HRP- } \\
\text { linked igG (H+L) }\end{array}$ & $1: 10000$ & $\begin{array}{l}\text { cell signaling, Boston, } \\
\text { USA }\end{array}$ \\
\hline $\begin{array}{l}\text { Goat anti-rabbit polyclonal } \\
\text { Alexa Fluor 594 }\end{array}$ & $1: 200$ & Invitrogen, Karlsruhe \\
\hline Streptavidin APC & $1: 100$ & $\begin{array}{l}\text { BD Biosciences } \\
\text { Pharmingen, Heidelberg }\end{array}$ \\
\hline $\begin{array}{l}\text { Biotin SP conjugated } \\
\text { donkey anti mouse }\end{array}$ & $1: 200$ & $\begin{array}{l}\text { Jackson Immuno Research, } \\
\text { West Grove, USA }\end{array}$ \\
\hline $\begin{array}{l}\text { DAPI } \\
\text { (4',6-Diamidin-2- } \\
\text { phenylindol) }\end{array}$ & $1: 10000$ & Sigma-Aldrich, München \\
\hline $\begin{array}{l}\text { Donkey anti-goat Alexa } \\
\text { Fluor 488 }\end{array}$ & $1: 200$ & Invitrogen, Karlsruhe \\
\hline
\end{tabular}

\subsection{Oligonukleotide für quantitative realtime-PCR}

Alle verwendeten Primer werden in der folgenden Tabelle aufgeführt. Primer wurden von der Firma IBA (Göttingen) synthetisiert und geliefert. 
Tabelle 12: Oligonukleotide und deren Verwendung

\begin{tabular}{|l|l|l|}
\hline Name & Sequenz & Verwendung \\
\hline 18 s fwd & $5^{\prime}$-AACTTTCGATGGTAGTCGCCG-3' & $\begin{array}{l}\text { SYBR Green realtime- } \\
\text { PCR }\end{array}$ \\
\hline 18 s rev & $5^{\prime}$-GGATGTGGTAGCCGTTTCTCAG-3' & $\begin{array}{l}\text { SYBR Green realtime- } \\
\text { PCR }\end{array}$ \\
\hline CADM2 fwd & $5^{\prime}$-ACCATCGACTCCTTTTCCACAA-3' & $\begin{array}{l}\text { SYBR Green realtime- } \\
\text { PCR }\end{array}$ \\
\hline CADM2 rev & $5^{\prime}$-ACCATTCGGTCAGGATCTGGTA-3' & $\begin{array}{l}\text { SYBR Green realtime- } \\
\text { PCR }\end{array}$ \\
\hline $\begin{array}{l}\text { Integrin alpha } 7 \\
\text { fwd }\end{array}$ & $5^{\prime}$-AATGCCTCCCATGTTGAGTGTG -3' & $\begin{array}{l}\text { SYBR Green realtime- } \\
\text { PCR }\end{array}$ \\
\hline $\begin{array}{l}\text { Integrin alpha } 7 \\
\text { rev }\end{array}$ & $5^{\prime}$-CAGTTCCGTGGTCTCAATGCT-3' & $\begin{array}{l}\text { SYBR Green realtime- } \\
\text { PCR }\end{array}$ \\
\hline $\begin{array}{l}\text { Angiopoietin } 1 \\
\text { fwd }\end{array}$ & $5^{\prime}$-GAGCAGCCTGATCTTACACGGT-3' & $\begin{array}{l}\text { SYBR Green realtime- } \\
\text { PCR }\end{array}$ \\
\hline $\begin{array}{l}\text { Angiopoietin 1 } \\
\text { rev }\end{array}$ & $5^{\prime}$-CCACAAGCATCAAACCACCAT-3' & $\begin{array}{l}\text { SYBR Green realtime- } \\
\text { PCR }\end{array}$ \\
\hline $\begin{array}{l}\text { Vasohibin 2 fwd } \\
\text { Pa'-GTGCTGTTCCACGTCAACAAG A-3' }\end{array}$ & $\begin{array}{l}\text { SYBR Green realtime- } \\
\text { PCR }\end{array}$ \\
\hline $\begin{array}{l}\text { Vasohibin 2 rev } \\
\text { PY'-TCGTCATCGACAGCCTGTAGT T-3' }\end{array}$ & $\begin{array}{l}\text { SYBR Green realtime- } \\
\text { PCR }\end{array}$ \\
\hline
\end{tabular}

\subsection{Zelllinien}

Tabelle 13: Verwendete Zelllinien und ihre Herkunft

\begin{tabular}{|l|l|l|}
\hline Zelllinie & Zelluläre Herkunft & Medium \\
\hline humane Gliomzelllinie & Prof. G. Bernhardt, Universität & MEM, \\
U87MG & Regensburg* & $10 \%$ FCS, \\
& Diese Zelllinie wurde ursprünglich & $1 \%$ Pen/Strep, \\
aus dem Tumormaterial (Grad IV) & $1 \%$ NEAA, \\
& einer 44-jährigen Frau in Kultur & 1 mM Pyruvat \\
& genommen. & \\
& Mit Erlaubnis von Prof. G. & \\
& Bernhardt, Universität Regensburg, & \\
& verwendet & \\
\hline humane Gliomzelllinie & Die Zelllinie stammt ursprünglich & RPMI-1640, \\
U373MG & aus dem Tumormaterial (Grad III) & $10 \%$ FCS, \\
& eines 61-jährigen Mannes. Mit & $1 \%$ Pen/Strep \\
& Erlaubnis von Prof. G. Bernhardt, & \\
& Universität Regensburg, verwendet & \\
\hline
\end{tabular}




\begin{tabular}{|l|l|l|}
\hline $\begin{array}{l}\text { Human umbilical vein } \\
\text { endothelial cells (HUVECs) }\end{array}$ & $\begin{array}{l}\text { Die Lymphendothelzellen wurden } \\
\text { aus Patienten isoliert und der } \\
\text { Abteilung zur Verfügung gestellt. }\end{array}$ & $\begin{array}{l}\text { EGM-2 MV Single } \\
\text { Quots }\end{array}$ \\
\hline
\end{tabular}

* Ursprünglich von ATCC

\subsection{Versuchstiere}

Die Tierhaltung erfolgte in der zentralen Tierstalleinrichtung (ZTE) des Universitätsklinikums Göttingen unter standardisierten Bedingungen. Die Raumtemperatur wurde konstant bei $21{ }^{\circ} \mathrm{C}\left( \pm 5{ }^{\circ} \mathrm{C}\right)$, die Luftfeuchtigkeit bei $70 \%( \pm 10 \%)$ gehalten. Hell-/ Dunkel-Phasen wurden in zwölf-stündigem Rhythmus gewechselt. Die Versuchstiere wurden, soweit möglich, in Gruppen (4-5 Tiere) gehalten und hatten Zugang zu Futter und Wasser. Für die Tierversuche wurde das Nacktmausmodell $\mathrm{CD}^{\circledR}-1$ Nude Maus (Crl:CD1-Foxn $1^{\text {nu }}$ ) der Firma Charles River verwendet. Die Mutation Foxn $1^{\text {nu }}$ trat erstmals 1962 in einer Kolonie von albino Auszuchtmäusen auf. Diese Mutation wurde in Glasgow auf verschiedene In- und Auszuchtmäuse durch Rückkreuzung übertragen. Das mutante Allel des nude-Locus (Symbol: nu) wird autosomal und rezessiv vererbt. Homozygote Tiere sind haarlos und besitzen keinen Thymus. Daher fehlen die thymusabhängigen T-Lymphozyten und die dadurch vermittelten Immunreaktionen. Bei konventioneller Haltung dominieren chronische Infektionskrankheiten. Die Zucht dieser Tiere erfolgt bei Charles River Deutschland in einem Isolator.

\subsection{Hühnereier}

Für das Chorionallantoismembran (CAM)-Modell wurden befruchtete pathogenfreie Hühnereier (specific pathogen free chicken egg) der Firma Charles River verwendet.

\subsection{Software}

In der folgenden Tabelle sind die Programme aufgelistet, die für Messungen und Auswertungen verwendet wurden. 
Tabelle 14: Verwendete Software und deren Anwendung

\begin{tabular}{|l|l|}
\hline Programm & Verwendung \\
\hline Adobe Photoshop CS2 & Bildbearbeitung \\
\hline Cell Quest Pro & FACS Messung und Auswertung \\
\hline $\begin{array}{l}\text { DAVID bioinformatics resources 2008 } \\
\text { http://david.abcc.ncifcrf.gov:8080/home.jsp }\end{array}$ & Bearbeitungssoftware für Microarray Daten \\
\hline Endnote X1 & Literaturverwaltung \\
\hline Excel & Grafiken erstellen \\
\hline LAS Core & $\begin{array}{l}\text { Aufnahmeprogramm für Stereomikroskop- und } \\
\text { Mikroskopbilder }\end{array}$ \\
\hline Meta Vue 6.1 & $\begin{array}{l}\text { Bildbearbeitungsprogramm für } \\
\text { Biolumineszenzmessungen }\end{array}$ \\
\hline $\begin{array}{l}\text { PAST 1.74 (Palaentological Statistics } \\
\text { software package for education and data } \\
\text { analysis) }\end{array}$ & T- Test (Statistik) \\
\hline Patek & Microarray chips Auswertung \\
\hline Primer Express 2.0 & Primer Design für realtime-PCR \\
\hline Word & Textverarbeitung \\
\hline Magellan & ELISA Messung \\
\hline $\begin{array}{l}\text { LAS-4000 FujiFilm (LifeScience), } \\
\text { Düsseldorf }\end{array}$ & Western Blot Detektion \\
\hline
\end{tabular}




\section{Methoden}

\subsection{Methoden der Zellkultur}

\subsubsection{Auftauen}

Die in dieser Arbeit verwendeten Gliomzelllinien und HUVECs wurden in Einfriermedium (RPMI mit $10 \%$ DMSO) in flüssigem Stickstoff bzw. bei $-80{ }^{\circ} \mathrm{C}$ gelagert. Die Gliomzellen U87MG und U373MG wuchsen adhärent in einer Einzelschicht. Die HUVECs wuchsen ebenfalls adhärent und wurden immer nur bis $\mathrm{zu}$ ihrer 12. Passage verwendet. Für die Versuche wurden die Zellen im $37{ }^{\circ} \mathrm{C}$ Wasserbad aufgetaut und mit $10 \mathrm{ml}$ des jeweiligen Mediums in ein Zentrifugenröhrchen überführt. Die Zellsuspension wurde anschließend 1 min bei 1000 x g zentrifugiert, der Überstand abgenommen und $1 \mathrm{ml}$ des jeweiligen Mediums hinzugegeben. Das Zellpellet wurde resuspendiert und $500 \mu 1$ in eine $75 \mathrm{~cm}^{2}$ Zellkulturflasche mit $15 \mathrm{ml}$ Medium gegeben. Die Zellen wurden in gesättigter Wasserdampfatmosphäre (5\% $\mathrm{CO}_{2}, 95 \%$ Luftfeuchtigkeit) bei $37^{\circ} \mathrm{C}$ in einem Wärmeschrank kultiviert.

\subsubsection{Kultivierung}

Die Zellen wurden zweimal die Woche passagiert. Dafür wurde das Medium aus den Zellkulturflaschen abgesaugt, die Zellen 2 x mit $5 \mathrm{ml}$ PBS gespült und anschließend mit $3 \mathrm{ml}$ Trypsin-EDTA $\left(0,5 \%\right.$ Trypsin, $0,02 \%$ Natrium-EDTA) unter Wärmeeinwirkung $\left(37^{\circ} \mathrm{C}\right.$, 3 min) inkubiert. Dabei lösten sich die adhärenten Zellen von dem Flaschenboden. Die Reaktion wurde durch die Zugabe von $7 \mathrm{ml}$ Medium gestoppt. Die Zellsuspension wurde in ein Zentrifugenröhrchen überführt, $5 \mathrm{~min}$ bei $1000 \mathrm{x} \mathrm{g}$ zentrifugiert, der Überstand abgenommen und das Pellet in $1 \mathrm{ml}$ Medium resuspendiert. Je $150 \mu \mathrm{l}$ wurden in eine neue Zellkulturflasche mit $15 \mathrm{ml}$ Medium gegeben. Die Zellen wurden für 3-4 Tage bis zu einer Konfluenz von 90 \% im Wärmeschrank inkubiert und anschließend für Versuche verwendet.

\subsubsection{Zellzahlbestimmung und Einfrieren der Zellen}

Für die jeweiligen Versuche musste eine feststehende Zellzahl gezählt werden. Um die Zellzahl zu ermitteln, wurden die Zellen immer in 1ml Medium aufgenommen und die Zellsupension mit einer Trypanblau-Lösung im Verhältnis 1:10 gemischt. Anschließend 
wurden $10 \mu \mathrm{l}$ des Gemisches in eine Neubauer- Zählkammer pipettiert. Unter einem Lichtmikroskop wurden die Zellen gezählt, die sich in vier Großquadraten befanden. Jedes dieser Quadrate war noch in vier weitere Kleinquadrate unterteilt. Die Gesamtzellzahl in einem ml wurde mit folgender Formel errechnet:

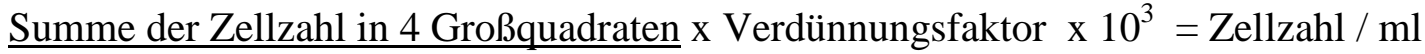

$$
0,4
$$

Die in dieser Arbeit verwendeten humanen Gliomzellen und die Endothelzellen, wurden in flüssigem Stickstoff gelagert. Die Zellen wurden für die Lagerung vorbereitet, indem aus dem $75 \mathrm{~cm}^{2}$ Kulturgefäß zuerst das Medium abgesaugt und die Zellen mit 2x $7 \mathrm{ml}$ PBS gewaschen wurden. Anschließend wurden die Zellen mit $6 \mathrm{ml}$ Trypsin behandelt und für $3 \mathrm{~min}$ bei $37^{\circ} \mathrm{C}$ im Wärmeschrank inkubiert. Anschließend wurde Medium hinzu gegeben, um die Reaktion zu stoppen. Die Suspension wurde in ein Zentrifugenröhren überführt und für $10 \mathrm{~min}$ bei $20{ }^{\circ} \mathrm{C}$ und $1000 \mathrm{~g}$ zentrifugiert. Anschließend wurde der Überstand abgesaugt und das Pellet in $4 \mathrm{ml}$ Einfriermedium (RPMI mit $10 \%$ DMSO) aufgenommen, resuspendiert und je $400 \mu 1$ in Kryoröhrchen pipettiert. Die Zellen wurden zunächst für $1 \mathrm{~h}$ bei $-18{ }^{\circ} \mathrm{C}$, dann über Nacht bei $-80{ }^{\circ} \mathrm{C}$ gelagert, um dann langfristig in flüssigem Stickstoff aufbewahrt zu werden.

\subsubsection{WST-1-Test}

Der WST-1-Test ist ein kolorimetrisches Verfahren, mit dem die relative Proliferationsrate von Zellen, die sich in Kultur befinden, bestimmt werden kann. Ferner können Vitalitätsanalysen und Zytotoxizitätsanalysen durchgeführt werden. Das Prinzip der Reaktion ist die Umsetzung des Tetrazoliumsalzes WST-1 durch ein mitochondriales Enzym der Atmungskette (Succinat-Tetrazolium-Reduktase) zu dem Farbstoff Formazan. Der zu messende Farbumschlag der Probe von hellrot zu dunkelrot ist proportional zu der Menge des Enzyms in der Kultur, die verwendet wird. Die photometrische Messung der Proben wurde in einem Mikrotiterplatten-Lesegerät (SUNRISE) durchgeführt. Die Absorption wurde bei $450 \mathrm{~nm}$ gegen die Referenzwellenlänge $690 \mathrm{~nm}$ gemessen. Um das Wachstum der Zellen unter Normalbedingungen zu bestimmen, wurden Zellen in einer Dichte von $5 \times 10^{3}$ in $100 \mu 1$ Medium pro well in einer 96-well Flachbodenkulturplatte ausgesät. Die Zellen wurden bei $37{ }^{\circ} \mathrm{C}$ für $24 \mathrm{~h}$ in einem Brutschrank inkubiert. Anschließend wurden die Zellen mit $10 \mu \mathrm{l}$ des WST-1-Reagenzes behandelt und für weitere $2 \mathrm{~h}$ im Brutschrank inkubiert. Nach der 
Inkubationszeit wurde die 96-well Platte für $20 \mathrm{sec}$ ausserhalb des MikrotiterplattenLesegerätes geschüttelt und anschließend die Absorption photometrisch bestimmt. Als Leerwert für diesen Versuch diente $100 \mu$ l Medium, welches ebenfalls mit dem WST-1Reagenz behandelt und photometrisch gemessen wurde. Die Absorption des Leerwertes wurde in der Auswertung des Versuches von den Absorptionswerten der eigentlichen Proben abgezogen. Für Zeitkinetiken wurden Zellen in 96-well Flachbodenkulturplatten ausgesät und nach 24 h, 48 h, 72 h und 96 h mit dem WST-1 Reagenz behandelt und weitere $2 \mathrm{~h}$ später die Absorption gemessen.

\subsubsection{Apoptose ELISA}

Zur quantitativen Bestimmung der Basisapoptose der Zellen wurde ein Sandwich-ELISA durchgeführt. Der dabei eingesetzte „Cell Death Detection ELISA“ ist ein Assay, mit dessen Hilfe Mono- und Oligonukleosomen nachgewiesen werden können, die nach dem Zusammenbruch der Plasmamembran im Zytoplasma der apoptotischen Zellen entstehen.

Durch einen Biotin-gekoppelten Anti-Histon-Antikörper werden die Nukleosomen an die Streptavidin-beschichtete Oberfläche einer Mikrotiterplatte gebunden. Ein weiterer Peroxidase-gekoppelter Antikörper reagiert mit dem DNA-Anteil der Nukleosomen (Sandwich). Die Antigenmenge und somit die Apoptoseneigung der Zellen kann anschließend anhand der Peroxidase-katalysierten Umsetzung des Substrats „ABTS“ (Salz der 2,2'-Azinodi-(3-ethylbenzthiazolin)-6-sulfonsäure) relativ quantifiziert werden. Die zu untersuchenden Gliomzellen wurden durch Trypsinierung geerntet und $5 \times 10^{3}$ Zellen in $100 \mu 1$ Medium in einer 96-well Platte ausgesät. Nach 24 h wurden die Zellen mit Trypsin-EDTA lysiert und das Lysat in eine Antikörper-beschichtete Mikrotiterplatte überführt. Ein Anti-Histon-Biotingekoppelter monoklonaler Antikörper und ein Anti-DNA-Peroxidase konjugierter monoklonaler Antikörper wurden dazu gegeben und für $2 \mathrm{~h}$ inkubiert. Nach zweifachem Waschen mit Inkubationspuffer wurde „ABTS“, das Substrat der Peroxidase, hinzugegeben. Nach weiteren 10 min konnte eine Farbentwicklung (grün) bei den Proben beobachtet werden, die apoptotisch sind. Die Messung der Absorption erfolgte bei $405 \mathrm{~nm}$ (Referenz-Wellenlänge $490 \mathrm{~nm})$. 


\subsubsection{Migrations-Assay}

Die Migrationseigenschaften der Semaphorin exprimierenden U87MG Zellen wurden als Invasion der Zellen durch eine Membran mit definierter Porengröße in einer „Boyden chamber" bestimmt. Die Membran mit einer Porengröße von $8 \mu \mathrm{m}$ (Nucleopore, Pleasanton, CA) wurde mit Matrigel (ECM Gel) 1:3 in Serum-freien RPMI-Medium dünn beschichtet (Hagemann et al. 2004). U87-N, U87-D and U87-G wurden aus einer konfluenten $75 \mathrm{~cm}^{2}$ Zellkulturflasche durch Trypsinierung geerntet und gezählt. Der untere Teil der „Boyden chamber“" wurde mit 2,6 ml Medium befüllt und je 1 x $10^{5}$ Zellen in 0,5 ml Zellmedium in den oberen Teil der Boyden chamber pipettiert. 96 Stunden später wurden die Zellen, die durch die Membran in den unteren Teil der Boyden chamber migriert waren, abgesaugt, zentrifugiert (1000 x g, $6 \mathrm{~min})$, in Trypan Blau aufgenommen und mithilfe einer Neubauer Zählkammer gezählt. Pro Zelllinie wurde pro Versuch eine Vierfach-Bestimmung durchgeführt und in zwei unabhängigen Messungen bestimmt.

\subsubsection{Zelladhäsions-Assay}

Für den Zelladhäsions-Assay (Cyto Select ${ }^{\mathrm{TM}}$ 48-well Cell adhesion assay (ECM Array); Cell Biolabs, San Diego, USA) wurden U87-N, U87-D und U87-G Zellen aus einer $90 \%$ konfluenten $75 \mathrm{~cm}^{2}$ Zellkulturflasche mittels Trypsinierung geerntet und gezählt. $1 \times 10^{5}$ Zellen wurden je Zelllinie für diesen Assay verwendet. Die Anweisungen des Herstellers wurden befolgt und die Absorption der Proben bei $560 \mathrm{~nm}$ gemessen. Es wurde jeweils eine Doppelbestimmung durchgeführt und die Ergebnisse als absolute Messwerte dargestellt. Dafür wurden die Absorptionswerte der Kontrollzelllinie auf 1 gesetzt.

\subsection{Lentivirale Transfektion}

Die in dieser Arbeit verwendeten Gliomzelllinien U87MG und U373MG wurden lentiviral mit Klasse-3 Semaphorinen (A, B, C, D, E, F und G) und der firefly Luziferase transfiziert. Als Kontrollzelllinien dienten Zellen, die mit einem Leervektor (NSPI) und der firefly Luziferase transfiziert wurden.

Diese Arbeiten wurden in der Arbeitsgruppe von Prof. Gera Neufeld, Abteilung Anatomie und Zellbiologie, am Technion in Haifa, Israel durchgeführt. Die Zellen wurden wie in Kigel et al. beschrieben transfiziert und mir für diese Arbeit zur Verfügung gestellt (Kigel et al. 
2008). Mithilfe von Western Blot-Analysen wurde die Expression des jeweiligen Semaphorins bestimmt (Daten nicht gezeigt).

Die Aktivität der Luziferase wurde mithilfe des Wallac Victor 21420 Multilabel Reader (Perkin Elmer, Waltham, USA) bestimmt. Die Reaktion beruht auf der Umsetzung von Luziferin zu Oxyluziferin. Bei dieser Reaktion entsteht Licht, welches in dem Wellenlängenbereich von $550 \mathrm{~nm}$ bis $570 \mathrm{~nm}$ detektiert werden kann. Für die Messungen wurden 1 x $10^{4}$ Zellen in einer schwarzen 6-well Platte ausgesät und bei einer Konfluenz von $90 \%$ geerntet. Die Zellen wurden mit $60 \mu 1$ des „1x cell culture lysis reagent“ behandelt und mithilfe eines Zellschabers vom Untergrund der Platte gelöst. Die Suspension wurde gevortext, zentrifugiert und der Überstand in ein neues Eppendorf Gefäß überführt.

Die Proteinkonzentration wurde mit Hilfe einer Bradford Eichgerade bestimmt. Für die Biolumineszenz Messung wurden 2,5 $\mu 1$ der Probe verwendet und die Biolumineszenz in counts per seconds (CPS) pro $\mu$ g Protein ermittelt.

\subsection{Proteinbiochemische Methoden}

\subsubsection{Gesamtzellextrakt}

Für die Bestimmung der Caspase-3-Expression in Gliomzelllinien mittels Western BlotAnalyse wurden Zellextrakte hergestellt. Die Ernte der Zellen wurde während des gesamten Versuches auf Eis durchgeführt. Das Zellmedium wurde hierfür aus den Zellkulturflaschen in Zentrifugenröhrchen überführt und die adhärenten Zellen mit PBS bedeckt. Mithilfe eines Zellschabers wurden die Zellen nun vorsichtig von dem Flaschenboden abgeschabt und die Zellsuspension ebenfalls in das Zentrifugenröhrchen gegeben. Dieser Vorgang wurde zweimal wiederholt, um möglichst alle Zellen zu lösen. Die Zellsuspension wurde bei $4{ }^{\circ} \mathrm{C}$ 10 min bei 650 x g zentrifugiert und anschließend der Überstand abgegossen. Das entstandene Zellpellet wurde in PBS resuspendiert und in ein Eppendorfgefäß überführt. Das Zentrifugenröhrchen wurde erneut mit PBS gespült und die Suspension in das Eppendorfgefäß überführt. Es folgte ein erneuter Zentrifugationsschritt für 10 min bei $4{ }^{\circ} \mathrm{C}$ und $650 \mathrm{x}$ g. Der Überstand wurde verworfen und das Zellpellet in Lysispuffer resuspendiert. Nach einer Inkubation bei $4{ }^{\circ} \mathrm{C}$ für 30 min erfolgte eine Zentrifugation bei $13100 \mathrm{x} \mathrm{g}$ bei $4{ }^{\circ} \mathrm{C}$ für $30 \mathrm{~min}$. Der Überstand wurde abgenommen, in ein Eppendorfgefäß aliquotiert und bei $70{ }^{\circ} \mathrm{C}$ gelagert. 
Lysispuffer: 30 mM Tris- HCL pH 7,5

$150 \mathrm{mM} \mathrm{NaCl}$

1 mM EDTA

$0,5 \%$ Triton $\mathrm{X}-100$

$0,5 \% \mathrm{NaDoc}$

$1 \mathrm{mM}$ Dithiothreitol (DTT)

$\mathrm{H}_{2} \mathrm{O}_{\text {dest }}$

\subsubsection{Proteinbestimmung}

Für die Western Blot-Analyse sollten immer gleiche Mengen Protein eingesetzt werden. Daher musste eine Proteinbestimmung des gewonnenen Lysates durchgeführt werden. Mithilfe des BCA Protein Assay Kit (siehe Tabelle 9) wurde die Proteinkonzentration durch einen Farbumschlag und eine Messung der Absorption bestimmt. Das Testprinzip dieser Proteinbestimmung beruht auf zwei Reaktionen. In der ersten Reaktion wird $\mathrm{Cu}^{2+} \mathrm{zu} \mathrm{Cu}^{+}$ durch Proteine im alkalischen Medium reduziert (Biuret-Reaktion). In der zweiten Reaktion bildet das $\mathrm{Cu}^{+}$mit zwei Molekülen Bicinchoninsäure (BCA) einen Chelatkomplex. Dieser entstandene Komplex hat eine lila Farbe. Je mehr Protein sich in der Probe befindet, desto intensiver ist der Farbumschlag und desto höher ist die gemessene Absorption, die bei einer Wellenlänge von $562 \mathrm{~nm}$ gemessen werden kann. Somit sind die Proteinkonzentration und die Absorption proportional. Für die Messungen der Proteinkonzentration wurde zunächst mithilfe eines Proteinstandards (BSA) eine Verdünnungsreihe mit sechs Verdünnungen im Bereich von $125 \mu \mathrm{g}$ Protein $/ \mathrm{ml}$ bis $1500 \mu \mathrm{g} / \mathrm{ml}$ angefertigt. $25 \mu \mathrm{l}$ der jeweiligen Standardkonzentrationen wurden in einem Dreifachansatz in eine 96-well Flachbodenkulturplatte pipettiert. Zusätzlich wurden als Leerkontrolle $25 \mu$ l Lysispuffer ohne Zusätze in einem Dreifachansatz in die Platte pipettiert. Die Proteinproben wurden 1:20 mit Lysispuffer verdünnt und ebenfalls in die 96-well Platte pipettiert. $\mathrm{Zu}$ jeder Probe wurde $200 \mu \mathrm{l}$ BCA-Reagenz zugegegeben und es erfolgte ein Inkubationsschritt bei $37^{\circ} \mathrm{C}$ für 30 min. Anschließend wurde die Absorption der Proteinproben, der Leerkontrolle und der Proben der Standardreihe im Mikrotiterplatten-Lesegerät (SUNRISE) gemessen. In der Auswertung wurde die gemittelte Absorption des Leerwertes von den Absorptionswerten der übrigen Proben abgezogen. Da die Konzentration der Standardreihe bekannt war (125$1500 \mu \mathrm{l} / \mathrm{ml}$ ), konnte die Konzentration der unbekannten Proben anhand einer Standardkurve rechnerisch bestimmt werden. 


\subsubsection{Western Blot-Analyse}

Vor der eigentlichen Western Blot-Analyse wurde ein Proteingemisch in einer SDS-PAGE nach der Größe und der Ladung der Proteine in Banden aufgetrennt. Bei der Western BlotAnalyse werden die Proteinbanden durch Anlegen eines elektrischen Feldes auf eine PVDFMembran übertragen. Die gewünschten Proteine können nun über weitere Methoden (z.B. Antikörper-Bindung) nachgewiesen werden. Dafür werden spezifische primäre Antikörper verwendet, die sich an das passende Protein auf der Membran binden. Unspezifisch gebundene Antikörper werden durch Puffer von der Membran gewaschen. An den sekundären Antikörper ist eine Merrettichperoxidase gekoppelt. Wird Luminol hinzu gegeben, wird dieses oxidiert und die freiwerdende Lumineszenz kann mit einem Autoradiographie-Detektor gemessen werden. Die Antikörper-gebundenen Proteine können auf diese Weise sichtbar gemacht werden.

$\mathrm{Zu}$ Beginn des Versuches wurden für die SDS-PAGE ein Trenn- und ein Sammelgel gegossen. Nach deren Polymerisation wurde das fertige Gel in eine Gelkammer gespannt und diese mit 1x Laufpuffer gefüllt. Die Gesamtzellextrakte wurden entsprechend der eingesetzten Proteinkonzentration (20 $\mu \mathrm{g}$ Protein) mit DPBS verdünnt und mit 1/4 Volumen Roti-Load Proteinladepuffer (Carl Roth, Karlsruhe) versetzt. Die Proben wurden bei $100{ }^{\circ} \mathrm{C}$ für $5 \mathrm{~min}$ in einem Wasserbad gekocht, wodurch die Proteine denaturierten. Anschließend wurden die Proben für $2 \mathrm{~min}$ auf Eis gelagert, zentrifugiert und mit einer Hamilton-Spritze in die Probentaschen des Gels aufgetragen. Die Gelelektrophorese erfolgte bei $60 \mathrm{~V}$ durch das Kammgel und bei $130 \mathrm{~V}$ im Trenngel. Anschließend wurden die Proteine aus dem Gel mittels „Semi-Dry-Blot“ in „Sandwichform“ auf eine Membran übertragen. Für den Transfer auf die Membran (eigentlicher Blot) wurden drei Lagen Filterpapier, PVDF-Membran, SDS-Gel und drei weitere Lagen Filterpapier, die zuvor in Blotpuffer äquilibriert worden waren, auf der Anode luftblasenfrei gestapelt. Anschließend wurde die Deckplatte (Kathode) aufgesetzt und der Transfer der Proteine erfolgte für $1 \mathrm{~h}$ mit $0,8 \mathrm{~mA} / \mathrm{cm}^{2}$ Gelfläche. Die Membran wurde nach dem Transfer $1 \mathrm{~h}$ in Blockpuffer und danach über Nacht mit dem ersten Antikörper bei $4{ }^{\circ} \mathrm{C}$ auf einem Schüttler inkubiert. Am nächsten Tag wurde die Membran 3x mit Waschpuffer für je 7 min gewaschen und dann für $1 \mathrm{~h}$ bei RT mit dem zweiten Antikörper inkubiert. Anschließend wurde die Membran 3x für 15 min mit Waschpuffer gewaschen und mit ECL-Reagenz (Luminol-enthaltendes Chemilumineszenz-System) $\left(0,125 \mathrm{ml} / \mathrm{cm}^{2}\right.$ ) für 5 min inkubiert. Da die in dieser Arbeit verwendeten sekundären Antikörper alle mit einer 
Meerettich-Peroxidase (engl. horseradish peroxidase, HRP) gekoppelt waren, die in der Lage ist, Luminol zu oxidieren, wurde bei der Oxidation von Luminol Licht emittiert, das durch Autoradiographie detektiert werden konnte.

Trenngel 15\%:

$\begin{array}{llll}\mathrm{H}_{2} \mathrm{O} & 3,4 \mathrm{ml} & \mathrm{H}_{2} \mathrm{O} & 1,4 \mathrm{ml} \\ 30 \% \text { Acyrylamid Mix } & 7,5 \mathrm{ml} & 30 \% \text { Acyrylamid Mix } & 0,33 \mathrm{ml} \\ 1,5 \mathrm{M} \text { Tris }(\mathrm{pH} 8,8) & 3,8 \mathrm{ml} & 1 \mathrm{M} \text { Tris }(\mathrm{pH} 6,8) & 0,25 \mathrm{ml} \\ 10 \% \text { SDS } & 0,15 \mathrm{ml} & 10 \% \text { SDS } & 0,02 \mathrm{ml} \\ 10 \% \text { Ammoniumpersulfat } & 0,15 \mathrm{ml} & 10 \% \text { Ammoniumpersulfat } & 0,02 \mathrm{ml} \\ \text { TEMED } & 0,006 \mathrm{ml} & \text { TEMED } & 0,002 \mathrm{ml}\end{array}$

\subsection{Durchflusszytometrische Methoden}

Die Durchflusszytometrie dient zur Analyse der Eigenschaften von großen Mengen einzelner Zellen. Dazu werden diese aus dem Probenröhrchen in einen laminaren Trägerflüssigkeitsstrom hydrodynamisch fokussiert und einzeln an einem scharf gebündelten Laser (Argonlaser, $\lambda=488 \mathrm{~nm}$ ) vorbeigeführt. Jede Zelle streut dabei den Laser. Die Vorwärts-Streuung (forward scatter, FSC) entspricht dabei der Größe der Zelle, während die Seitwärts-Streuung (sideward scatter, SSC) ein Maß für die Granularität der Zelle ist. Besitzt die Zelle auf ihrer Oberfläche Fluorochrome z. B. durch markierte Antikörper, die durch die Wellenlänge des Lasers angeregt werden können, so detektiert das Gerät diese Signale ebenfalls. Die durchflusszytometrischen Analysen erfolgten an einem FACScan-Gerät (Fa. Becton Dickinson, Heidelberg). Das Gerät kann bis zu vier unterschiedliche Fluoreszenzen gleichzeitig detektieren. Mit dem Softwareprogramm CellQuest ${ }^{\mathrm{TM}}$ (Fa. Becton Dickinson, Heidelberg) werden diese Vorgänge grafisch dargestellt, sodass Zellpopulationen und auch einzelne Zellen sichtbar werden. Die spätere Auswertung der Analyse erfolgte mit dem Programm CellQuest ${ }^{\mathrm{TM}}$.

\subsubsection{Analyse von Zellen durch Fluoreszenzanregung}

In dieser Arbeit wurden HUVECs und U87-N-Zellen analysiert, die durch fluorochrome Antikörper markiert waren. Zu Beginn des Versuches wurden 3 x $10^{5}$ HUVECS oder U87-NZellen ausgesät. Am Tag der Aussaat, einen und zwei Tage später wurden die Zellen mit aufgereinigtem Semaphorin3F (3 nM) in $4 \mathrm{ml}$ Medium behandelt. Die Zellen wurden zunächst trypsiniert, die Suspension in PBS aufgenommen und sedimentiert $\left(1700 \mathrm{rpm}, 4{ }^{\circ} \mathrm{C}\right.$, 
3 min). Anschließend wurde das Pellet in $650 \mu$ FACS- Puffer aufgenommen und je $200 \mu 1$ der Zellsuspension erneut sedimentiert.

Für die Färbung der Zellen durch Fluorochrom-markierte Antikörper wurden die zu färbenden Zellen in $100 \mu \mathrm{l}$ FACS-Puffer und dem primären Antikörper (VEGFR-2) überführt. Die Verdünnungen der Antikörper können der Tabelle 10 entnommen werden. Nach einer Inkubation von $1 \mathrm{~h}$ bei $4{ }^{\circ} \mathrm{C}$ im Dunkeln wurden die Zellen mit PBS gewaschen und sedimentiert. Anschließend wurde der biotinmarkierte zweite Antikörper in FACS-Puffer aufgenommen und erneut für $1 \mathrm{~h}$ bei $4{ }^{\circ} \mathrm{C}$ im Dunkeln inkubiert. Die Zellen wurden mit PBS gewaschen, nochmals sedimentiert und in $100 \mu \mathrm{l}$ FACS-Puffer aufgenommen, der Streptavidin enthielt. Streptavidin kann an den biotinylierten sekundären Antikörper binden und das entstehende Signal verstärken. Nach $1 \mathrm{~h}$ Inkubation bei $4{ }^{\circ} \mathrm{C}$ im Dunkeln wurden die Zellen mit PBS gewaschen, sedimentiert und das Zellpellet in einem Volumen von $250 \mu 1$ FACS-Puffer aufgenommen und am FACScan analysiert.

\author{
FACS Puffer \\ $1 \% \mathrm{BSA}$ \\ $0,03 \% \mathrm{NaN}_{3}$ \\ $25 \mathrm{mM}$ HEPES $\mathrm{pH}$ 7,4 in PBS \\ steril filtrieren, Lagerung $4{ }^{\circ} \mathrm{C}$
}

\title{
3.4.2 Zellzyklus-Analyse nach Nicoletti
}

Die Grundlage der Zellzyklus-Analyse ist die Messung des DNA Gehaltes in den Kernen der Zelle, der mithilfe von Propidiumiodid angefärbt und mittels FACS-Analyse bestimmt werden kann. Propidiumiodid hat ein Absorptionsmaximum bei $488 \mathrm{~nm}$ und ein Emissionsmaximum bei $590 \mathrm{~nm}$. Durch die Bindung an die DNA verschieben sich diese Maxima (Nicoletti et al. 1991).

Für den Versuch wurden $3 \times 10^{5}$ Zellen aus einer konfluenten $75 \mathrm{~cm}^{2}$ Zellkulturflasche geerntet und 7 min bei 1000 x g sedimentiert. Das Pellet wurde in $500 \mu 1$ hypotonen Nicoletti Puffer (Nicoletti et al., 1991) resuspendiert. In Folge des hypotonen Stresses wird die Zellmembran zerstört, wodurch das Propidiumiodid mit dem Zellkern interkalieren kann.

Die Messung des DNA Gehaltes erfolgte mit FACScan. In der G1-Phase haben die Kerne einen einfachen Chromosomensatz $(n=1)$ und somit das geringste PI-Signal, darunter liegen 
nur apoptotische Zellen, die einen geringeren DNA-Gehalt aufweisen und hier einen präapoptotischen Peak bilden. Mit der S-Phase steigt der DNA Gehalt an und in der G2- und MPhase ist er verdoppelt $(n=2)$. Aufgrund der DNA-Gehalte in den einzelnen Zellzyklusphasen kommt es zu einem charakteristischen Kurvenverlauf mit zwei Hauptpeaks. Die Flächen der Peaks wurden mit dem Programm „Cell Quest Pro“ bestimmt.

\subsection{Molekularbiologische Methoden}

\subsubsection{Isolierung von Gesamt-RNA}

Beim Arbeiten mit RNA wurde auf äußerste Sauberkeit geachtet. Dafür wurden alle Geräte und Materialien mit $1 \mathrm{M} \mathrm{NaOH}$ gründlich gewaschen und mit Diethylpyrocarbonatbehandeltem $\mathrm{H}_{2} \mathrm{O}$ gespült, um RNasen zu entfernen. Die Gesamt-RNA wurde aus den transfizierten Gliomzellen U87-N (Kontrollzelllinie), U87-D und U87-G mit dem RNeasy Midi Kit (Qiagen, Hilden) isoliert. Es wurde standardmäßig das Zellpellet einer konfluenten $75 \mathrm{~cm}^{2}$ Gewebekulturflasche für die Isolierung verwendet. Die Isolierung erfolgte gemäß dem Herstellerprotokoll (RNeasy Handbook, 2001). Zusätzlich wurde der Standardprozedur ein DNase I-Verdau hinzugefügt (RNase-free DNase Set, Qiagen), wobei ein enzymatischer Verdau möglicher genomischer DNA-Kontaminationen stattfand, während die RNA an der Silika-Gel-Säule gebunden war für 30 min bei RT. Anschließend wurde die Säule gewaschen und die RNA eluiert.

\subsubsection{Konzentrationsbestimmung von Nukleinsäuren}

Die Konzentration von Nukleinsäuren in wässrigen Lösungen wurde durch Messung der Absorption bei Anregung durch UV-Licht mit einer Wellenlänge von $260 \mathrm{~nm}$ bestimmt. Eine optische Dichte (OD) von 1,0 entspricht dabei einer Nukleinsäurekonzentration von $50 \mu \mathrm{g} / \mathrm{ml}$ bei doppelsträngiger DNA und $40 \mu \mathrm{g} / \mathrm{ml}$ bei RNA. Die Messung erfolgte im Biophotometer (Eppendorf, Hamburg). RNA für die Transkriptomanalyse wurde zusätzlich im sensitiveren NanoDrop-Photometer (PeqLab, Erlangen) vermessen. Dazu wurde $1 \mu \mathrm{l}$ RNA-Lösung verwendet. Ein Absorptionsspektrum von 220 - 350 nm erlaubt zudem eine Beurteilung der Verunreinigung der RNA-Präparation durch Proteine. 


\subsubsection{Auftrennung von RNA durch LabChip Micro Gelelektrophorese}

RNA für Microarray- und realtime-PCR-Analysen wurde einer Qualitätskontrolle durch eine LabChip-Micro-Gelelektrophorese in einem Bioanalyzer 2100 (Agilent, Palo Alto, USA) unterzogen. In diesem System sind mikrofeine Kanäle in einer Chip-Struktur integriert. Eine Gel-Matrix wird in diese Kanäle gegossen und Proben (RNA, DNA oder Proteine) können im elektrischen Feld aufgetrennt werden. In dem Chip ist ein Detektor-System integriert, das (bei RNA und DNA Proben) die Fluoreszenz eines im Analyten interkalierenden Farbstoffes ausliest. Die Ergebnisse werden als Elektropherogramm dargestellt. Anhand der Verhältnisse von $18 \mathrm{~S}$ zu $28 \mathrm{~S}$ ribosomaler RNA sowie der Anwesenheit von Degradationsprodukten, lässt sich ein definierter Qualitätsindex der Probe mit Werten von 1 (schlechte Qualität) bis 10 (gute Qualität) erstellen (RNA integrity number, RIN) (Schroeder et al. 2006). Beide Elektroden wurden mit RNaseZap (Applied Biosystems, Darmstadt) dekontaminiert und mit RNase-freiem $\mathrm{dH}_{2} \mathrm{O}$ gespült. $550 \mu \mathrm{l}$ Gel-Matrix wurden in einer mitgelieferten Filter-Säule 10 min bei RT bei 1500 x g zentrifugiert. $65 \mu$ der Gel-Matrix wurden dann mit $1 \mu \mathrm{l}$ Fluoreszenz-Farbstoff-Konzentrat vermischt und $5 \mathrm{~min}$ bei 13000 x g zentrifugiert. Anschließend wurden mithilfe einer Spritze je $9 \mu \mathrm{l}$ Gel-Matrix in jede verwendete Kapillare eingespritzt. Pro Kapillare wurden dann $5 \mu$ eines internen Standards und anschließend je $1 \mu \mathrm{l}$ der zuvor für 2 min bei $70^{\circ} \mathrm{C}$ denaturierten RNA-Probe bzw. des RNA-Standards aufgetragen. Schließlich wurde die Elektrophorese laut Herstellerprotokoll (,eukaryote total $R N A^{\text {") }}$ durchgeführt.

\subsection{4 cDNA Synthese}

Um Transkripte in Gesamt-RNA nachzuweisen, wurde die RNA mithilfe der Reversen Transkriptase (RT) in komplementäre DNA (complementary DNA, cDNA) umgeschrieben.

Für einen Standardreaktionsansatz wurde $1 \mu \mathrm{g}$ Gesamt-RNA für die RT-Reaktion eingesetzt. Für die Reaktion wurde das iScrip Kit (Bio Rad) verwendet:

Reaktionsansatz: $1 \mu \mathrm{g}$ Gesamt-RNA

$1 \mu 1$ Reverse Transkriptase (Bio Rad)

$4 \mu 1$ iScript Reaction Mix

Add $20 \mu \mathrm{ld} \mathrm{d}_{2} \mathrm{O}$ 
Tabelle 15: Reverse Transkriptase-Reaktion

\begin{tabular}{|c|c|}
\hline Zeit in $\mathbf{m i n}$ & Temperatur in ${ }^{\circ} \mathbf{C}$ \\
\hline 5 & 25 \\
\hline 30 & 42 \\
\hline 5 & 85 \\
\hline hold & 4 \\
\hline
\end{tabular}

\subsubsection{Microarray-Analyse}

Für die Markierung der RNA für die Microarray-Analyse wurde das "MessageAmp" ${ }^{\mathrm{TM}}$ IIBiotin enhanced Kit" der Firma Ambion (Austin, USA) verwendet. RNA wird dabei durch reverse Transkription in cDNA umgeschrieben, durch DNA-Polymerase und RNaseH zu doppelsträngiger cDNA (dsDNA) synthetisiert. Schließlich wird durch in vitro-Transkription unter Verwendung Biotin-konjugierter Nukleotide mit der dsDNA als Matrize zu Biotinmarkierter aRNA (amino allyl-RNA) amplifiziert. 
1. Reverse Transkription

2. Zweitstrangsynthese

3. cDNA Aufreinigung

4. In vitro Transkription

\section{5. aRNA Aufreinigung}

5

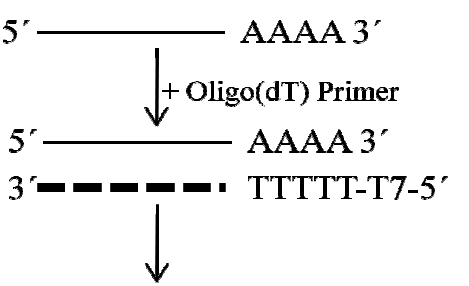

Gesamt- RNA

cDNA

5'-ோ- ' AAAAA-T7-3'

- TTTTT-T7-5' dsDNA Transkript
Salze, Enzym, Primer
- AAAAA-T7-3'

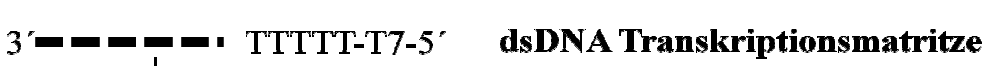

$\int_{0}^{9}$

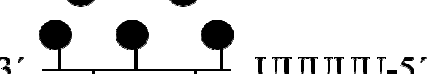

Biotin- markierte aRNA
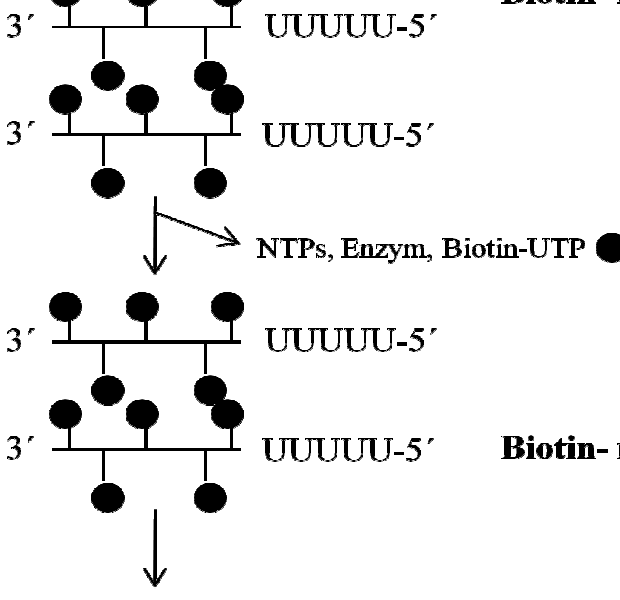

Biotin- markierte aRNA

Oligo Microarrays

Abbildung 4: Übersicht über die RNA-Markierung für Microarray-Analyse

Die Gesamt-RNA wird in cDNA umgeschrieben (1). Anschließend ein komplementärer Zweitstrang synthetisiert (doppelsträngige DNA) (2) und aufgereinigt (3). Dieser wird durch den Einbau Biotin-konjugierter Nukleotide durch in vitro Transkription mit Hilfe von T7 RNA-Polymerase markiert (4). Die markierte aRNA (amino allylRNA) wird aufgereinigt (5) und auf den Microarray-Chip für die Analyse gebracht.

\subsubsection{Reverse Transkription}

$1 \mu \mathrm{g}$ Gesamt-RNA und $1 \mu \mathrm{l}$ T7 Oligo(dT) wurden in einem Gesamtvolumen von $12 \mu \mathrm{l}$ bei $70{ }^{\circ} \mathrm{C}$ für 10 min denaturiert.

Ansatz pro RT-Reaktion: $\quad 2 \mu 110 \times$ First Strand Buffer

$4 \mu \mathrm{lNTP}$ Mix

$1 \mu \mathrm{l}$ RNase Inhibitor

$1 \mu 1$ ArrayScript Reverse Transkriptase 
$8 \mu \mathrm{l}$ des Mastermix wurden zu den denaturierten RNA-Proben gegeben und für 2 Std. bei $42{ }^{\circ} \mathrm{C}$ inkubiert.

\subsubsection{Zweitstrang cDNA-Synthese}

Zweitstrangsynthese-Mastermix: $63 \mu 1$ Nuclease-freies Wasser

$10 \mu 110 \times$ Second Strand Buffer

$4 \mu \mathrm{l}$ dNTP Mix

$2 \mu 1$ DNA Polymerase

$1 \mu \mathrm{l}$ RNase $\mathrm{H}$

Je $80 \mu \mathrm{l}$ des Zweitstrangsynthese-Mastermix wurden zu $12 \mu \mathrm{l}$ cDNA gegeben und bei $16{ }^{\circ} \mathrm{C}$ für $2 \mathrm{~h}$ inkubiert.

\subsection{8 cDNA-Aufreinigung}

$250 \mu \mathrm{l}$ cDNA-Bindepuffer wurden zu den $92 \mu \mathrm{l}$ Zweitstrang-cDNA gegeben und der Ansatz auf cDNA-Filter-Säulen gegeben und anschließend 1 min bei 10000 Upm zentrifugiert. Nach dem Waschen mit $500 \mu \mathrm{l}$ Waschpuffer wurde die cDNA mit zweimal $12 \mu 150{ }^{\circ} \mathrm{C}$ warmem $\mathrm{dH}_{2} \mathrm{O}$ eluiert.

\subsubsection{In vitro Transkription zur Synthese Biotin-markierter aRNA}

Markierungs-Mastermix: $\quad 12 \mu 1$ Biotin-NTP Mix

$4 \mu \mathrm{T} 710$ x Reaction Buffer

$4 \mu \mathrm{T}$ T7 Enzyme Mix

$20 \mu \mathrm{l}$ der aufgereinigten cDNA wurden mit $20 \mu \mathrm{l}$ des Biotin-Markierungs-Mastermix gemischt und bei $37{ }^{\circ} \mathrm{C}$ für $14 \mathrm{~h}$ inkubiert, um Biotin-markierte Nukleotide in den neusynthetisierten aRNA-Strang einzubauen. Die Reaktion wurde mit $60 \mu 1$ nuklease-freiem $\mathrm{dH}_{2} \mathrm{O}$ gestoppt.

\subsubsection{0 aRNA-Aufreinigung}

$100 \mu \mathrm{l}$ Biotin-markierter aRNA wurden mit $350 \mu \mathrm{l}$ aRNA Binding Puffer gemischt, anschließend $100 \mu 1100 \% \mathrm{EtOH}$ hinzugefügt und der Ansatz sofort danach auf aRNA-FilterSäulen gegeben und bei 10000 Upm zentrifugiert. Die Säulen wurden mit $650 \mu 1$ Wasch- 
Puffer gewaschen und die aRNA schließlich durch Zentrifugation für 1 min bei 10000 Upm mit $100 \mu 150{ }^{\circ} \mathrm{C}$ warmen $\mathrm{dH}_{2} \mathrm{O}$ eluiert.

\subsubsection{Hybridisierung, waschen und scannen der Microarrays}

Hybridisierung und waschen der Microarrays wurde nach Angaben des „GeneChip® Expression Analysis“"-Handbuchs durchgeführt.

\subsubsection{2 realtime-PCR}

Bei der klassischen RT-PCR wird cDNA als Matrize eingesetzt und ein bestimmtes Transkript mit spezifischen Primern amplifiziert. Dabei wird eine Endpunktbestimmung durch Gelelektrophorese und Fluoreszenz des interkalierenden EtBr nach Abschluss der PCR durchgeführt. Da in der Endphase der PCR keine exponentielle Amplifikation mehr stattfindet, ist eine solche Quantifizierung nur semi-quantitativ. Um die Menge von Transkripten innerhalb mehrerer Proben quantitativ zu vergleichen, wurde das Verfahren der realtime-PCR angewendet. Im Unterschied zur RT-PCR wird ein anderes interkalierendes Fluorophor (SYBR-Green) verwendet und die relative Fluoreszenz wird während der PCR nach jedem Amplifikationszyklus durch einen Laser in Echtzeit bestimmt. Aus der Anzahl von Zyklen, die für das Erreichen eines bestimmten Fluoreszenz-Schwellenwertes benötigt werden, lässt sich so quantitativ auf die relative Menge eingesetzten Transkripts schließen. In dieser Arbeit sollen nur relative Mengen von Transkripten in verschiedenen Proben bestimmt werden, daher wurde eine relative Quantifizierung nach Pfaffl durchgeführt (Pfaffl 2001). Hierbei wird die Anzahl von Zyklen, die für das Erreichen einer relativen FluoreszenzSchwelle (threshold cycle, CT) bei dem zu untersuchenden Transkript (gene of interest, GOI) nötig sind, auf die Anzahl von Zyklen normalisiert, die notwendig sind, um die relative Fluoreszenz-Schwelle eines internen Referenz-Standard-Transkripts (housekeeping-Gen) zu erreichen. Als Referenz-Transkript wurde 18S rRNA verwendet. Das Referenz-Gen sollte in allen Proben gleich exprimiert vorliegen.

Die Berechnung der differentiellen Expression wurde wie folgt berechnet:

$$
\mathrm{CT}_{\mathrm{GOI}}-\mathrm{CT}_{18 \mathrm{~S}}=\Delta \mathrm{CT}
$$

Anschließend wird die Differenz aus beiden $\Delta \mathrm{CT}$-Werten der zu vergleichenden Proben gebildet: 


$$
\Delta \mathrm{CT}_{\text {Probe1 }}-\Delta \mathrm{CT}_{\text {Probe2 }}=\Delta \Delta \mathrm{CT}
$$

$\Delta \Delta \mathrm{CT}$ gibt die differentielle Expression zwischen Probe 1 und Probe 2 an. Die Expression von Transkripten in der ersten Kontrolle werden auf 1 normalisiert und der Expressionsunterschied $\mathrm{zu}$ den anderen Proben in $\mathrm{x}$-fach angegeben. realtime-PCRs wurden im ABI Prism 7900HT der Firma Applied Biosystems in 384-well Platten durchgeführt. Alle Messungen erfolgten in technischen Triplikaten. Es wurden $2 \mu \mathrm{l}$ des zuvor 1:5 verdünnten $20 \mu \mathrm{l}$ cDNA-Synthese Ansatzes pro Amplifikation eingesetzt (entsprechend $20 \mathrm{ng}$ revers transkribierter RNA).

Reaktionsansatz: $2 \mu \mathrm{l}$ cDNA

$1 \mu \mathrm{l}$ Primer for $(10 \mathrm{pmol} / \mu \mathrm{l})$

$1 \mu \mathrm{l}$ Primer rev $(10 \mathrm{pmol} / \mu \mathrm{l})$

5,0 $\mu 1$ SYBR-green Mix (2x)

$1 \mu \mathrm{dH}_{2} \mathrm{O}$

Tabelle 16: realtime- PCR Programm

\begin{tabular}{|l|l|l|}
\hline & Dauer & Temperatur \\
\hline & $12 \mathrm{~min}$ & $95^{\circ} \mathrm{C}$ \\
\hline & $15 \mathrm{sec}$ & $95^{\circ} \mathrm{C}$ \\
\hline & $1 \mathrm{~min}$ & $60^{\circ} \mathrm{C}$ \\
\hline 40 Zyklen & $15 \mathrm{sec}$ & $95^{\circ} \mathrm{C}$ \\
\hline & $15 \mathrm{sec}$ & $60^{\circ} \mathrm{C}$ \\
\hline & $15 \mathrm{sec}$ & $95^{\circ} \mathrm{C}$ \\
\hline
\end{tabular}

\subsection{Tierversuche}

\subsubsection{Chorionallantoismembran-Assay}

Bei den Hühnern (Gallus gallus domesticus) dauert die Entwicklung von der Eizelle zur Dotterkugel und zum fertigen Ei mit Eiweiß und Schale ca. 24 h. Nach einer erfolgreichen Paarung dauert es ca. 21 Tage, bis ein Küken schlüpfen kann. Ab dem 10. Tag kann die Chorioallantoismembran (CAM) der Hühnerembryonen dazu verwendet werden, Tumoren anzuziehen oder Medikamente zu testen. Der Versuch kann in drei Phasen unterteilt werden. In der ersten Phase werden die Eier gefenstert, um vor der Entwicklung der CAM einen Zugang zu diesem Bereich zu schaffen. In der zweiten Phase werden die Zellen, die einen 
Tumor ausbilden sollen und Substanzen zur Behandlung der Tumoren aufgetragen. In der letzten Phase wird die CAM mit Tumoren oder behandeltem Tumorgewebe geerntet.

In diesen Versuchen wurde die Kontroll-Gliomzelllinie U373-N und die U373-D Zelllinie auf die CAM aufgetragen. Als Negativkontrolle wurde nur PBS auf die CAM gegeben.

Alle Geräte wurden vor Gebrauch sterilisiert und während der Verwendung mehrfach mit $70 \%$ igem Ethanol gereinigt. Die befruchteten Eier wurden bei $37^{\circ} \mathrm{C}$ und $80 \%$ relativer Luftfeuchtigkeit inkubiert. An Tag 3 der Inkubation wurde ein etwa $1 \mathrm{~cm}^{2}$ großes Fenster oberhalb des Embryos in die Eierschale gesägt und die darunterliegende Eihaut vorsichtig entfernt. Vor dem Entfernen der Schale wurde diese mit Locke-Lösung befeuchtet, um sie leichter abheben zu können. Im seitlichen Bereich des Eies, im Bereich der Luftkammer, wurde die Schale ebenfalls angesägt, was zum Entweichen von Luft und damit zum Absenken des Embryos führte. Das Fenster wurde mit Leukosilk S (BSNmedicalGmbH, Hamburg) verschlossen und die Eier weiter in dem Brutschrank inkubiert. An Tag 10 wurden die Tumorzellen auf die CAM aufgetragen. Dafür wurden die Zellen durch Trypsinieren geerntet und in einer Dichte von $10^{7}$ Zellen in $40 \mu$ Medium resuspendiert. Eine Thermanox-Scheibe (Thermanox Plastic Coverslips, Nunc, Rochester NY) wurde in der Mitte mit einer ringförmigen Aussparung versehen und auf die CAM gelegt. Die Membran wurde im Bereich der Aussparung mit einer angerauhten Glassonde leicht angekratzt und $40 \mu \mathrm{l}$ Zellsuspension $\left(10^{7}\right.$ Zellen $)$ in die rundliche Aussparung pipettiert. Die Eier wurden wieder verschlossen und weiter inkubiert. An Tag 17 wurden die entstandenen Tumoren geerntet. Die Fixierung erfolgte in Karnowsky-Lösung. Zur Dokumentation wurden die Tumoren am Stereomikroskop (Leica Microsystems) untersucht und fotografiert. Die Lagerung erfolgt in Fixans bei $4^{\circ} \mathrm{C}$.

Sörensen-Puffer (0,3 M; pH 7,4) : $\quad \mathrm{KH}_{2} \mathrm{PO}_{4}(0,3 \mathrm{M}) \quad 18,2 \mathrm{ml}, \mathrm{Na}_{2} \mathrm{HPO}_{4} \quad(0,3 \mathrm{M}) \quad 81,8 \mathrm{ml}$

Locke-Lösung:

Karnowsky- Lösung:
$\mathrm{NaCl}(1,61 \mathrm{M}) 100 \mathrm{ml}, \mathrm{KCl}(0,16 \mathrm{M}) 37 \mathrm{ml}, \mathrm{CaCl} 2$ $(0,14 \mathrm{M}) 21 \mathrm{ml}, \mathrm{H}_{2} \mathrm{O}$ dest ad $1000 \mathrm{ml}$

Glutaraldehyd $3 \%$, Formaldehyd $3 \%$, Sörensen-Puffer (pH 7,4; 0,15 M)

Nach dem Autoklavieren wurde der Locke-Lösung 1 \%ig Pen/Strep-Lösung (Lonza,Basel, Schweiz) zugesetzt. 


\subsubsection{Intrazerebrale Tumoren}

Aus einer Kultur von Semaphorin-überexprimierenden U87MG- oder U373MG- Zellen wurde eine Suspension mit einer Zelldichte von 75000 Zellen in $5 \mu$ PBS hergestellt. Die Suspension wurde während des Experimentes auf Eis gelagert. Zu Beginn des Versuches wurden die Mäuse durch eine i.p. Injektion (Ketamin 10\% (90 $\mu \mathrm{g} / \mathrm{g}$ KG) und Xylazinhydrochlorid $2 \%(6,7 \mu \mathrm{g} / \mathrm{g} \mathrm{KG}))$ narkotisiert. Nach einer Mittellinieninzision mithilfe eines Skalpells wurde das Periost der rechten Schädelkalotte vorsichtig entfernt. $1 \mathrm{~mm}$ rostral und $2 \mathrm{~mm}$ lateral rechts des Bregmas wurde mit einem zahntechnischen Bohrer ein Bohrloch von ca. $1 \mathrm{~mm}$ Durchmesser gebohrt. Dabei wurde die Dura nicht geöffnet. Die Maus wurde in einen stereotaktischen Rahmen gelagert, sodass sich der Schädel der Maus waagerecht zur Unterlage befand. Die Zellsuspension wurde vor jedem Gebrauch vorsichtig gemischt und anschließend wurden $5 \mu \mathrm{l}$ der Zellsuspension in eine $10 \mu \mathrm{l}$ Spritze mit angeschrägter Kanüle aufgezogen. Die Spritze wurde in eine Halterung am Mikromanipulator des stereotaktischen Rahmens gespannt, dabei befand sich die Nadel senkrecht zur Nadelfläche. Die Öffnung der Kanüle zeigte nach rechts. Die Nadel wurde 3,5 mm tief ins Gehirn gestochen und anschließend 0,5 mm zurück gezogen, damit sich ein kleiner Hohlraum unter der Nadel bildete, der die Zellsuspension nach der Injektion der Zellen aufnehmen konnte. Die Injektionsnadel wurde in dieser Position für 3 min belassen. Anschließend wurde die Nadel unter gleichzeitiger Spülung mit physiologischer Kochsalzlösung aus dem Gehirn entfernt. Die Kopfhaut wurde durch sechs Stiche mit Seralon 7/0 genäht. Anschließend wurde s.c. zur Schmerzbehandlung $5 \mu \mathrm{g} / \mathrm{g}$ KG Rimadyl und für ein schnelleres Erwachen nach der Narkose $5 \mathrm{mg} / \mathrm{kg} \mathrm{KG}$ Antisedan injiziert. Die Tiere wurden die nächsten Stunden bis zum vollständigen Erwachen unter einer Wärmelampe belassen und beobachtet. Die Tiere wurden täglich kontrolliert und deren Gewicht im Abstand von zwei Tagen gemessen. Bei einem Gewichtsverlust von $20 \%$ zum Ausgangsgewicht, Entzündungen der Augen oder Apathie wurden die Tiere aus dem Versuch genommen. Zusätzlich wurden die Tiere von einem Tierarzt täglich überprüft. Um den Nachweis zu erbringen, dass sich die Gliomzellen auch wirklich im Gehirn der Mäuse befanden, wurden U373-N-, -D- und -E-Zellen, wie oben beschrieben, in die Gehirne von Mäusen implantiert. Nach zwei und vier Tagen wurden die Gehirne entnommen, in Paraffin eingebettet, geschnitten und mithilfe eines anti-Luziferase Antikörpers untersucht (siehe Tabelle 10). 


\subsubsection{Biolumineszenzmessung}

Die Biolumineszenzmessung (BLI, bioluminescence imaging) ist eine optische Technik für die funktionelle Bildgebung. Biolumineszenz bedeutet die Produktion und Emission von Licht durch eine enzymatische Oxidation in einem lebenden Organismus. Biolumineszenz ist eine Form der Lumineszenz und kommt in marinen Vertebraten, Invertebraten, Mikroorgansimen und terrestrischen Tieren vor. Der am häufigsten benutzte biolumineszente Reporter ist die Luziferase des Nordamerikanischen Glühwürmchens (Photinus pyralis). In Anwesenheit von ATP und Sauerstoff katalysiert die Glühwürmchen-Luziferase die Umsetzung des Substrates D-Luziferin zu Oxyluziferin. Ein Nebenprodukt dieser chemischen Reaktion ist Energie, die in Form von Licht mit einer Wellenlänge von 530-640 nm emittiert wird. BLI kann verwendet werden, um in vivo die Migration und die Bestimmung von transplantierten Tumorzellen zu verfolgen. Ein großer Vorteil dieser Messmethode ist eine hohe Sensitivität, da es in Zellen von Säugetieren keine Hintergrundsignale gibt (Henriquez et al. 2007).

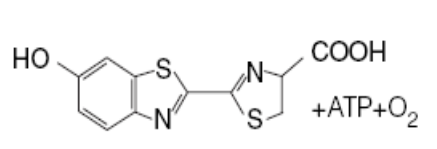

Beetle Luciferin

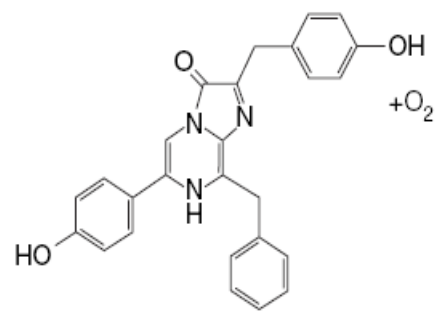

Coelenterazine

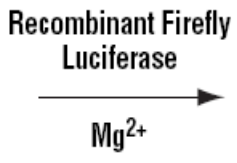

$\mathrm{Mg}^{2+}$

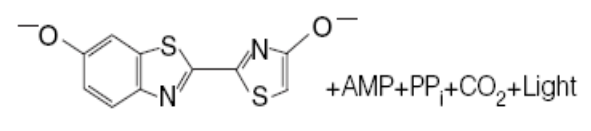

Oxyluciferin

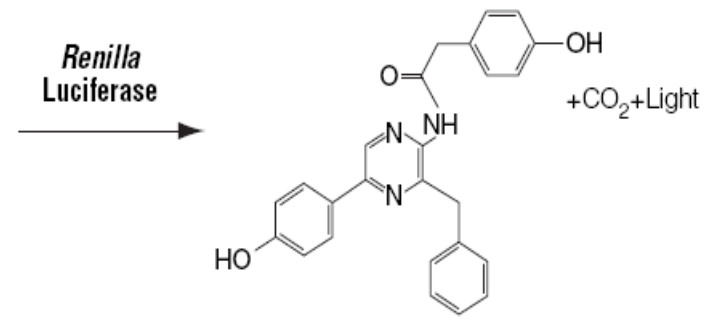

Coelenteramide

\section{Abbildung 5: Übersicht über die Biolumineszenzreaktion}

Gezeigt wird die Reaktion des Luziferins zum Oxyluziferin durch die Luziferase

Für die Versuche wurden CD1 nu/nu Mäusen intrazerebral Gliomzellen (U87MG oder U373MG) implantiert, die die Glühwürmchen-Luziferase exprimierten. Das Substrat dieses Enzymes wurde den Tieren in einer Konzentration von $150 \mathrm{mg} / \mathrm{kg}$ Körpergewicht i.p. gespritzt. Diese Methode wurde dazu verwendet, um das Tumorwachstum in vivo über einen bestimmten Zeitraum zu messen. Für die Messungen wurden die Mäuse mithilfe des VisiLuxx Imagers (Visitron Systems) gescannt. Nach der Gabe des Substrates konnte das emittierte 
Licht, welches in den Tumorzellen entstand, von dem Biolumineszenz-Imager detektiert werden. Die Messungen begannen an Tag 12 nach der Implantation der Zellen. Zuvor waren die Signale der kleinen Tumore zu schwach, um durch den Schädelknochen detektiert zu werden. Die Tiere wurden für die Messungen in eine schwarze Box gelegt, die zum Imager gehörte. Das emittierte Licht hatte eine Wellenlänge von 530-640 nm. Die Photonen wurden von einer sensitiven CCD-Kamera detektiert, die diese in Elektronen umwandelte. Aus diesen Energiepunkten kann ein Bild erzeugt werden. Das Hintergrundrauschen des Systems wurde durch ein starkes Abkühlen der CCD-Kamera auf $-120^{\circ} \mathrm{C}$ erreicht. Die Pixel des CCD-Chips in der Kamera wurden auf ein Binning von 4 eingestellt, um das Rauschen zu minimieren, welches mit der Bildentstehung einhergeht. Ein hohes Binning führt zu einer guten Signal- zu Rausch-Rate. Die Mäuse wurden mit einer Konzentration von $2 \%$ Isofluran in Sauerstoff während einer Messung narkotisiert, um sie zu fixieren. Zehn Minuten nach der D-LuziferinGabe i.p. wurde das Tier in den VisiLuxx Imager gelegt und mit einer Belichtungszeit von 0,5 sec ein Graustufenbild erstellt. Das Biolumineszenz-Bild wurde in einer schwarzen Kiste mit einer Belichtungszeit von 10 min erstellt. Diese Prozedur wurde zweimal wiederholt. Für alle Messungen wurden diese Einstellungen beibehalten.

Für die Auswertung der erhaltenen Biolumineszenzwerte und Bilder wurde das Programm Meta Vue 6.1 (Universal Imaging Corporation) verwendet. Über das Signal des Tumors wurde eine Region eingegrenzt, die berechnet werden sollte. Die relative Biolumineszensintensität wurde bestimmt. Die Einheit für diese Messung war Sekunden pro Zeit und Fläche des Tumors. Zum Schluss wurde eine Unecht-Farben-Überlagerung der Biolumineszenz-Signalintensität und den Mausbildern mithilfe der Software VCTEO2D Image Analyze (entwickelt von Dipl. Phys. Christian Dullin, Göttingen) generiert.

\subsection{Gewebeaufarbeitung}

Die Tiere, die aus einem Versuch genommen wurden, wurden mit einer Narkoseüberdosis (Ketamin $10 \%(90 \mu \mathrm{g} / \mathrm{g} \mathrm{KG})$ und Xylazinhydrochlorid $2 \%(6,7 \mu \mathrm{g} / \mathrm{g} \mathrm{KG})$; dreifache Menge) narkotisiert. Zuerst wurde die Haut in einem Schnitt längs des Bauches und anschließend der Bauchraum geöffnet. Das Perikard wurde vorsichtig geöffnet und mit einer Schere ein kleines Loch in den rechten Herz-Vorhof geschnitten. Durch diese Öffnung konnte das Blut aus dem Körper des Tieres gelassen werden. In die linke Hauptkammer wurde PBS geleitet, um das Blut aus dem Körper zu pumpen. Anschließend wurde dem Tier das Gehirn 
entnommen und in Paraformaldehyd (PFA) $4 \%$ in PBS für zwei bis drei Tage fixiert. Das Gehirn wurde in koronare Scheiben geschnitten. Die Schnittstellen befanden sich in Höhe der Implantationsstelle, auf Höhe der Sehnervenkreuzung und die letzte kurz vor dem Beginn des Kleinhirns. Die Scheiben wurden photografiert bevor sie in einer Gewebekassette $30 \mathrm{~min}$ gewässert wurden. Anschließend wurde das Gewebe in einem Entwässerungsautomaten (TP 1020) über Nacht entwässert.

Tabelle 17: Entwässerungsschema

\begin{tabular}{|l|l|}
\hline Zeit in min & Substanz \\
\hline $3 \times 60$ & $75 \%$ Ethanol \\
\hline $2 \times 90$ & $96 \%$ Ethanol \\
\hline $3 \times 75$ & $100 \%$ Ethanol \\
\hline $2 \times 120$ & Xylol \\
\hline
\end{tabular}

Danach wurde das Gehirn in einer Ausgießstation in Paraffin eingebettet. Die jeweils schmalere Schnittseite wurde auf die Unterseite des Einbettförmchens liegend eingebettet, sodass in dem späteren Paraffinblock alle Schnittstellen eines Gehirnschnittes für Färbungen zugänglich waren.

\subsection{Histologie}

\subsubsection{Paraffinschnitte}

Von den Gehirnen, die in Paraffin eingebettet worden waren, wurden mithilfe eines Mikrotoms (Leica) $4 \mu \mathrm{m}$ dicke Schnitte angefertigt. Die Schnitte wurden in $37^{\circ} \mathrm{C}$ warmes Wasser gelegt, damit sie sich strecken konnten. Anschließend wurden diese auf einen Objektträger gezogen und über Nacht in einem $37^{\circ} \mathrm{C}$ Wärmeschrank getrocknet. Am folgenden Tag waren die Gewebeschnitte besser auf dem Objektträger fixiert und konnten entweder sofort für Färbungen verwendet oder bis zur Verarbeitung bei RT in Kassetten gelagert werden.

\subsubsection{Entparaffinierung von Paraffinschnitten}

Vor der Färbung mussten die Schnitte entparaffiniert werden um die unspezifische Hintergrundfärbung zu minimieren. 
Tabelle 18: Entparaffinierung

\begin{tabular}{|l|l|}
\hline Zeit in min & Substanz \\
\hline $3 \times 5$ min & Xylol \\
\hline $2 \times 5$ min & $100 \%$ Ethanol \\
\hline 3 min & $96 \%$ Ethanol \\
\hline 3 min & $80 \%$ Ethanol \\
\hline 3 min & $70 \%$ Ethanol \\
\hline 3 min & $\mathrm{H}_{2} \mathrm{O}$ \\
\hline
\end{tabular}

Anschließend wurden die Schnitte bei $100{ }^{\circ} \mathrm{C}$ in Natriumcitratpuffer für 20 min gekocht und nach einer Abkühlzeit von 10 min weitere 10 min unter fließendem Wasser gespült.

Natriumcitratpuffer (pH6):

1,8 mM Zitronensäure

$11 \mathrm{mM}$ Natriumacetat

\subsubsection{Immunfluoreszenzfärbung von Paraffinschnitten}

Nach der Entparaffinierung wurden die Schnitte je zweimal für 3 min mit PBS unter leichtem Schütteln inkubiert. Für 20 min wurden die Bindestellen mit $2 \%$ BSA in PBS blockiert und anschließend wurde mit dem ersten Antikörper (anti-firefly luciferase oder anti-von Willebrand Faktor (F8)) in $2 \%$ BSA in PBS über Nacht bei $4{ }^{\circ} \mathrm{C}$ unkubiert. Am folgenden Tag wurden wurden die Schnitte zweimal je 3 min mit PBS gespült und anschließend der zweite Antikörper (donkey anti-goat Alexa Fluor 488 bzw. goat anti-rabbit polyclonal Alexa Fluor 594) für eine Inkubationszeit von $1 \mathrm{~h}$ ebenfalls in $2 \%$ BSA in PBS im Dunkeln auf die Schnitte gegeben. Anschließend wurden die Schnitte zweimal je 3 min mit PBS gewaschen. Zusätzlich zu der Endothelzellanfärbung mit von-Willebrand-Faktor (F8) wurden die Zellkerne zusätzlich nach dem zweiten Antikörper noch mit DAPI (1:10000 in PBS) für 10 min angefärbt. Die Schnitte wurden mit Fluoromount $G$ eingedeckelt und trockneten anschließend im Dunkeln über Nacht. Am folgenden Tag konnten die Schnitte mithilfe des Fluoreszemzmikroskops (Durchlicht- und Fluoreszenzmikroskop Leica 5000B) begutachtet werden. 


\subsubsection{Hämalaun-Eosin-Färbung}

Die Hämalaun-Eosin (HE)-Färbung von Paraffinschnitten färbt das Gewebe direkt an.

Hämalaun färbt Zellkerne blau an, Eosin färbt das Zytoplasma der Zellen rosarot.

Tabelle 19: Hämalaun- Eosin Färbungsschema

\begin{tabular}{|l|l|}
\hline Zeit in min & Substanz \\
\hline 3 & Roti- Histol \\
\hline 3 & Roti- Histol \\
\hline 3 & Roti- Histol \\
\hline 2 & $100 \%$ Ethanol \\
\hline 2 & $100 \%$ Ethanol \\
\hline 2 & $96 \%$ Ethanol \\
\hline 2 & $70 \%$ Ethanol \\
\hline 2 & $50 \%$ Ethanol \\
\hline 2 & $30 \%$ Ethanol \\
\hline 3 & Aqua dest. \\
\hline 5 & Hämalaun (nach Mayer) \\
\hline 10 & Fließendes Leitungswasser \\
\hline 2 & Aqua dest. \\
\hline 3 & $1 \%$ Eosin \\
\hline wenige sec & Aqua dest. \\
\hline 1 & $70 \%$ Ethanol \\
\hline 1 & $80 \%$ Ethanol \\
\hline 1 & $90 \%$ Ethanol \\
\hline 1 & $96 \%$ Ethanol \\
\hline 2 & $100 \%$ Ethanol \\
\hline 2 & $100 \%$ Ethanol \\
\hline 2 & Roti- Histol \\
\hline 2 & Roti- Histol \\
\hline 2 & Roti- Histol \\
\hline & \\
\hline
\end{tabular}


Danach wird die Eindeckelflüssigkeit Entellan vorsichtig auf den gefärbten Schnitten verteilt. Am Besten oberhalb einer Linie über dem Gewebe. Dann vorsichtig von einer Seite das Deckgläschen auf die Eindeckelflüssigkeit gleiten lassen. Dabei sollten möglichst keine Luftblasen eingeschlossen werden. Anschließend die Präparate unter dem Abzug trocknen lassen. 


\section{Ergebnisse}

Es wurde bereits beschrieben, dass Semaphorine funktionelle Einflüsse auf verschiedene Tumorzellen haben (Capparuccia und Tamagnone 2009), darunter wurde auch die Inhibierung von VEGF $_{165}$ und der Proliferation von HUVECs durch eine Behandlung mit Sema3F nachgewiesen (Kessler et al. 2004). Bislang liegen jedoch keine Studien über den Einfluss von Semaphorinen auf Glioblastomzellen vor. Aus diesem Grund sollte der publizierte Effekt einer Semaphorin-Behandlung auf HUVECs bestätigt und mit möglichen Effekten auf Gliomzellen verglichen werden. Zu diesem Zweck wurden das Wachtumsverhalten, die Apoptoseeigenschaften, die Migration und die Adhäsion unterschiedlicher humaner Gliomzelllinien in Gegenwart von Semaphorinen untersucht. Für die Nomenklatur werden im gesamten Ergebnis- und Diskussionsteil der Arbeit Kurzformen der Zellnamen verwendet. So wird beispielsweise statt U87MG transfiziert mit Sema3A das Kürzel U87-A und statt der U87MG Kontrollzellline transfiziert mit dem NSPI-Leervektor das Kürzel U87-N benutzt.

\subsection{Effekte der Klasse-3 Semaphorine auf Tumorzellen in vitro}

\subsubsection{Auswirkungen einer Behandlung mit rekombinantem Semaphorin}

Endothelzellen kleiden die innerste Wand zum Gefäßlumen der Blutgefäße aus und spielen somit z.B. eine Rolle bei der Versorgung von Tumoren mit Nährstoffen. Ihr Wachstum wird von verschiedensten Wachstumsfaktoren, wie z.B. VEGF, bestimmt. Eine Behandlung mit Sema3F zeigte eine Inhibierung des $\mathrm{VEGF}_{165}$ und der Proliferation der Endothelzellen (Kessler et al. 2004).

Um einen möglichen Effekt einer Sema3E-Behandlung auf die Proliferation der Endothelzellen zu untersuchen, wurden in einem Dreifachansatz Endothelzellen aus der humanen Nabelschnurvene (HUVECs) ausgesät und an Tag 1, 2 und 4 nach der Aussaat im Dreifachansatz mit VEGF, Sema3F oder Sema3E behandelt. Fünf Tage nach Aussaat wurden die Zellen gezählt (Abbildung 6). Die mit VEGF behandelten Zellen verdreifachten ihre Zellzahl von 40.000 Zellen auf 117.000 Zellen, während die unbehandelten Kulturen etwa 90.000 Zellen bildeten. Das Wachstum der mit Sema3E behandelten Kulturen wurde, verglichen mit den unbehandelten Zellen, auf $46 \%$ reduziert, während das Wachstum der mit Sema3F behandelten Zellen komplett stagnierte und den Befund aus der Literatur bestätigte. 
Eine Inhibierung der Proliferation der HUVECs konnte nach einer Behandlung somit auch für Sema3E nachgewiesen werden. Die Behandlung mit VEGF zeigte den erwarteten Effekt einer Proliferationssteigerung.

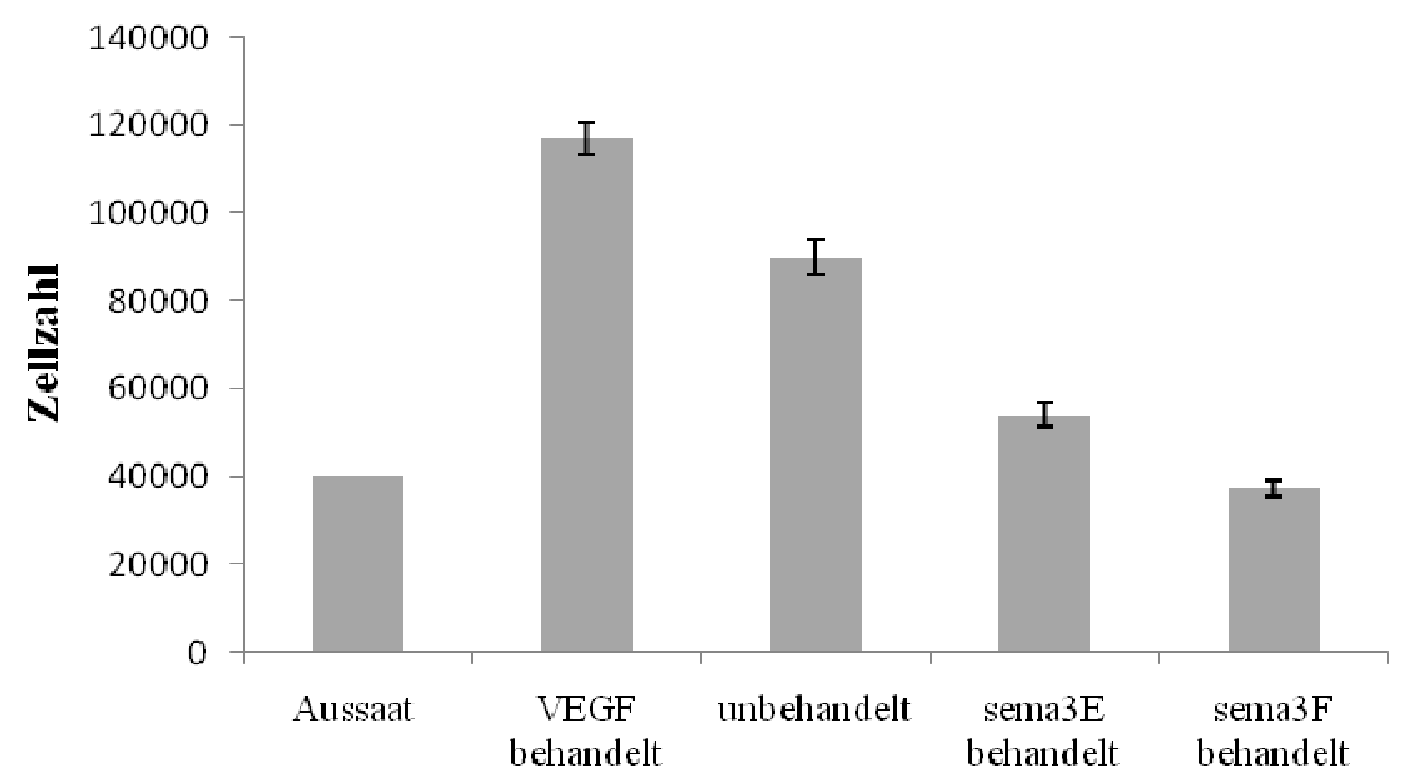

\section{Abbildung 6: Inhibierung der Proliferation von HUVECs durch Sema-Behandlung}

$4 \times 10^{4}$ Zellen wurden im Dreifachansatz ausgesät und an Tag 1, 2 und 4 mit Sema3E, Sema3F oder VEGF (je $3 \mathrm{nM}$ ) behandelt. An Tag 5 wurde die Zellzahl in einer Dreifachbestimmung ermittelt. Die Messung wurde in zwei unabhängigen Versuchen wiederholt. Gezeigt sind die arithmetischen Mittelwerte $\pm S D(n=6)$.

Die HUVECs zeigten nach einer Behandlung mit Sema3F und Sema3E eine deutliche Inhibierung der Proliferation. Um einen möglichen Wirkmechanismus für den beobachteten Effekt zu untersuchen, wurde der Einfluss der Behandlung auf die Präsenz von Oberflächenproteinen und Rezeptoren getestet, die das Wachstum von HUVECs beeinflussen können.

HUVECs wurden mit Sema3F behandelt, da hier der deutlichste Effekt beobachtet werden konnte (siehe Abbildung 6). An Tag 5 nach Aussaat wurden die Zellen geerntet, mit einem VEGFR-2-Antikörper markiert und mittels Durchflusszytometrie detektiert. Abbildung 7 zeigt die Ergebnisse der FACS-Analyse. Die Summe der Zellen, die mit dem Antikörper gegen VEGFR-2 markiert sind, ist auf der x-Achse aufgetragen. Für eine Messung wurden je 10.000 Zellen verwendet. Die schwarze Linie zeigt die unbehandelten Kontrollzellen, während die rote Linie die mit Sema3F behandelten Zellen zeigt. Es ist deutlich zu sehen, 
dass die Präsenz von VEGFR-2 auf der Oberfläche der mit Sema3F behandelten Zellen reduziert ist.

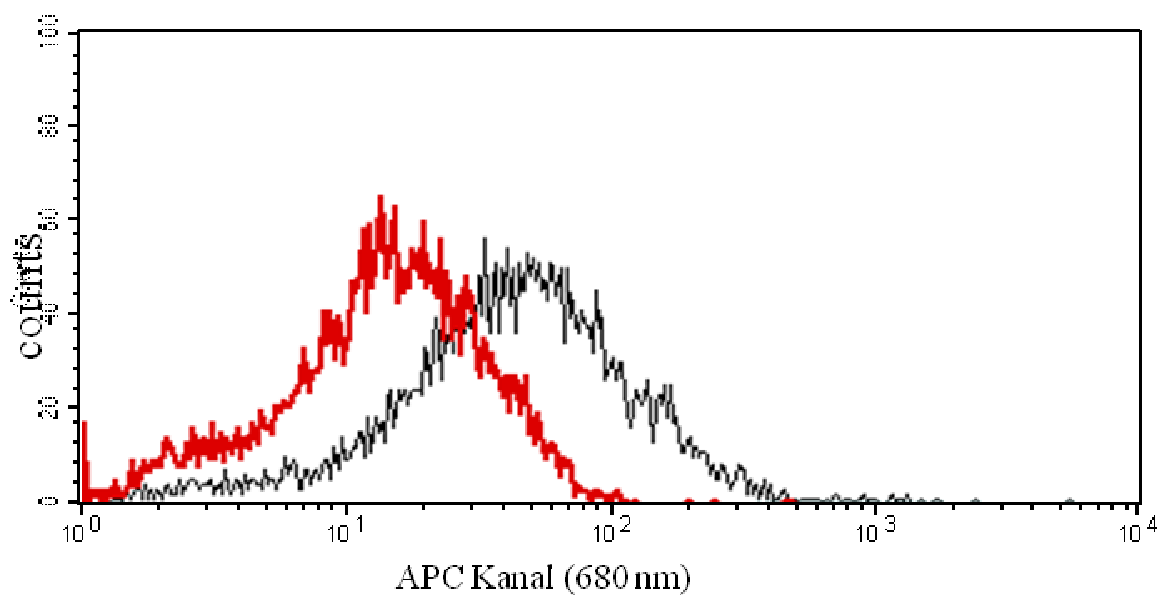

Abbildung 7: Einfluss der Semaphorine auf die VEGFR-2-Präsentation auf HUVECs

HUVECs wurden dreimal mit je $3 \mathrm{nM}$ Sema3F behandelt und mit einem VEGFR-2-Antikörper angefärbt. Die schwarze Linie zeigt unbehandelte HUVECs als Kontrolle und die rote Linie die Sema3F behandelten HUVECs. Gezeigt wird eine repräsentative Abbildung von insgesamt drei Messungen.

Zusätzlich wurde auch der Effekt von Sema3F auf verschiedene Integrine ( $\alpha$ v $\beta 3$, $\alpha$ v $\beta 5$ und B5) analysiert. Dabei zeigten sich allerdings keine Veränderungen im Oberflächenexpressionsmuster der behandelten Zellen (nicht abgebildet).

Zusammengefasst führt die Behandlung von HUVECs mit Sema3F zu einer spezifischen Verminderung der VEGFR-2-Präsentation auf der Zelloberfläche.

Durch die Behandlung von HUVECs mit rekombinantem Sema3E und Sema3F konnte gezeigt werden, dass die Proliferation der Zellen und die Präsentation des VEGFR-2 auf der Oberfläche der Zellen inhibiert wurden. Um zu prüfen, ob der Zusatz von Semaphorinprotein ins Medium einen Effekt auf die Proliferation zeigt, wurden die transfizierten Gliomzellen (U87-N und U373-N) zusätzlich mit rekombinantem Sema3F-Protein behandelt. Die Zellen wurden ausgesät und an Tag 1, 2 und 4 nach der Aussaat im Dreifachansatz mit Sema3F behandelt. Fünf Tage nach der Aussaat wurden die Zellen gezählt; das Ergebnis ist in Abbildung 8 dargestellt. Gezeigt ist die Anzahl der Zellen in der Startkultur im Vergleich zu den Zellzahlen der unbehandelten und behandelten Zellen am Versuchsende. Die unbehandelten U373MG-Kulturen wuchsen innerhalb der Versuchstage bis auf 118.000 
Zellen heran, während die behandelten Kulturen etwas unter dieser Zellzahl (114.000) blieben. Von den U87MG-Zellen wurden ebenfalls 4 x $10^{4}$ Zellen ausgesät und wie die U373MG-Zellen behandelt. An Tag fünf nach der Aussaat wurden die Zellen gezählt; die Ergebnisse sind ebenfalls in Abbildung 8 dargestellt. Die U87-N-Zellen wuchsen im Vergleich zu den U373-N-Zellen viel stärker an. Am Tag der Zellzählung konnten 195.000 unbehandelte U87MG-Zellen gezählt werden, während nach der Behandlung mit Sema3F eine minimale Erhöhung der Zellanzahl beobachtet werden konnte (198.000 Zellen). Somit zeigt auch die Behandlung mit rekombinantem Sema3F keinen Effekt auf die Proliferation der transfizierten Gliomzellen (U87-N und U373-N).

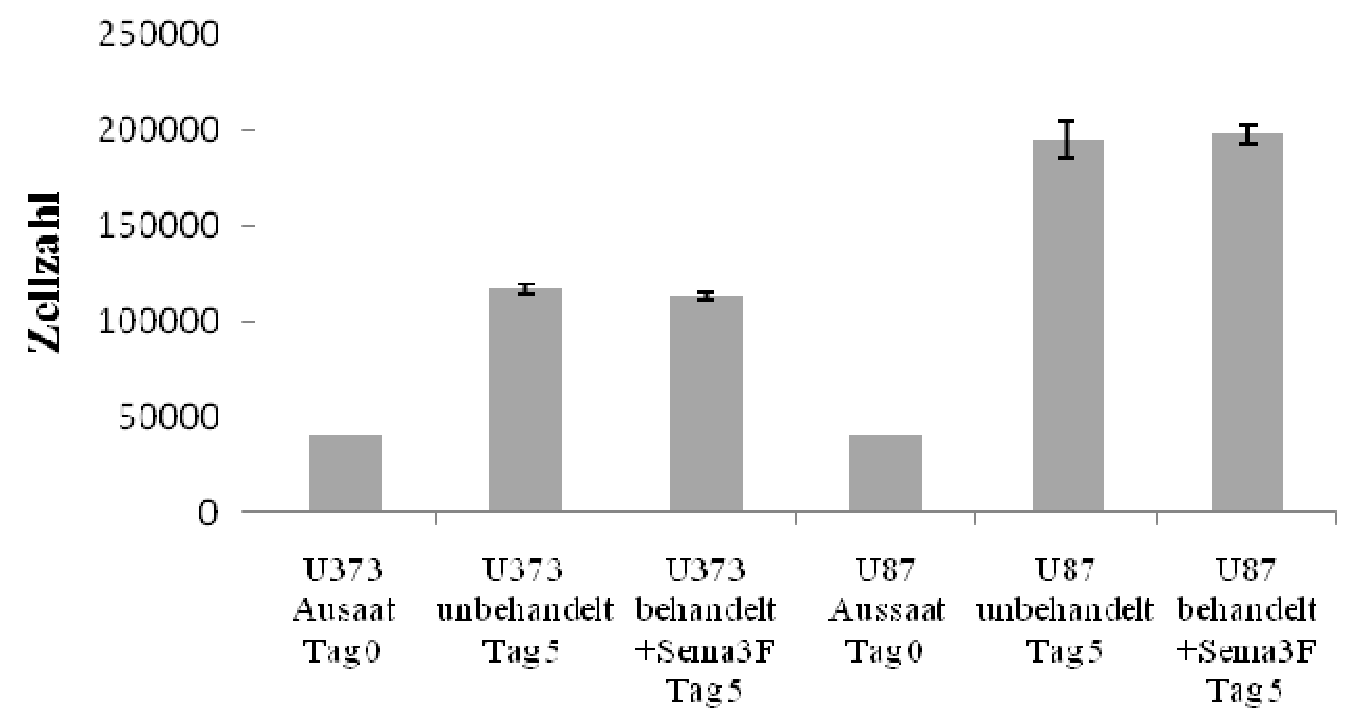

\section{Abbildung 8: Effekt der Sema3F-Behandlung auf die Gliomzellen}

Es wurden $4 \times 10^{4}$ U373MG- und U87MG-Kontrollzellen ausgesät und an Tag 1, 2 und 4 mit $3 \mathrm{nM} \mathrm{Sema3F}$ behandelt. Die Messung wurde in Triplikaten durchgeführt und in zwei unabhängigen Versuchen bestimmt. An Tag 5 wurden die Zellen gezählt und deren Anzahl im Vergleich zu den unbehandelten Zellen aufgetragen. Gezeigt sind die arithmetischen Mittelwerte und $\pm \mathrm{SD}(\mathrm{n}=6)$.

Bei HUVECs führte eine Sema3F-Behandlung zu einer Verringerung des VEGFR-2 auf der Zelloberfläche. Um zu prüfen, ob nach Ausbleiben des Effektes von Semaphorinen auf die Proliferation von Gliomzellen auch die Präsenz von VEGFR-2 unverändert ist, wurden die Zellen an drei Tagen mit rekombinantem Sema3F behandelt und an Tag fünf nach Aussaat geerntet. Die Zellen wurden mit einem VEGFR-2-Antikörper markiert und mittels Durchflusszytometrie detektiert. Es wurden wiederholt je 10.000 Zellen für eine Messung verwendet. Die Summe der Zellen, die mit dem Antikörper gegen VEGFR-2 markiert ist, ist 
auf der x-Achse aufgetragen. Die schwarze Linie zeigt die unbehandelten Kontrollzellen, während die rote Linie die Zellen zeigt, die mit Sema3F behandelt wurden. Die rote und die schwarze Linie liegen direkt übereinander und es zeigt sich kein Unterschied in der Präsenz des Rezeptors.

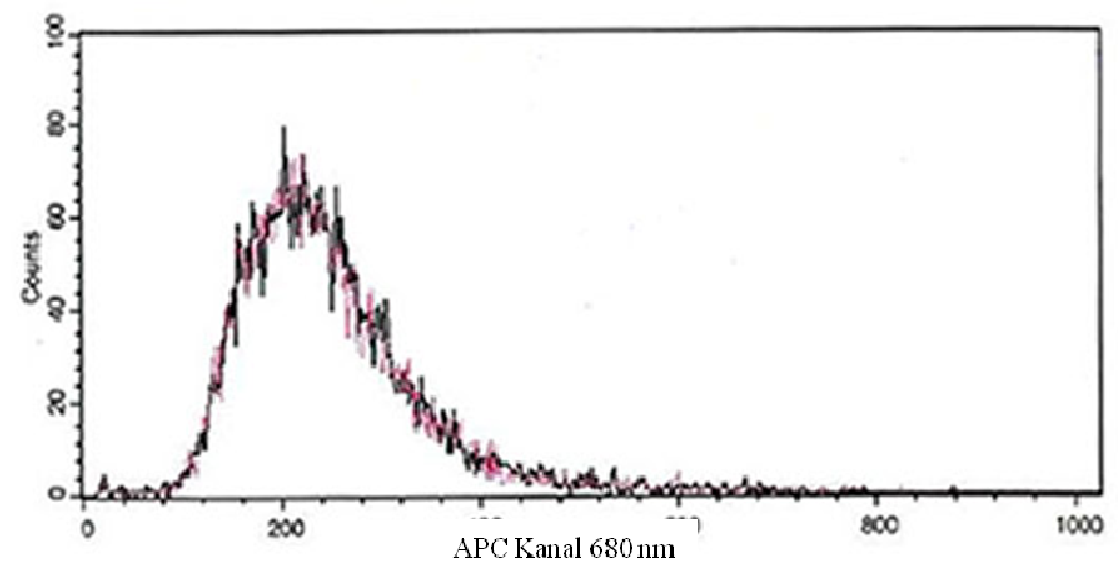

Abbildung 9: Präsentation des VEGFR-2 auf der Oberfläche von U87MG-Zellen

Es wurden $3 \times 10^{5}$ U87MG-Zellen an Tag 1,2 und 4 nach Aussaat mit $3 \mathrm{nM} \mathrm{Sema3F}$ behandelt und an Tag 5 mit einem VEGFR-2-Antikörper inkubiert. Die schwarze Linie zeigt die Anzahl unbehandelter Zellen, die rote Linie mit Sema3F behandelte Zellen. Gezeigt wird eine beispielhafte Abbildung von insgesamt drei Messungen $(n=3)$, die jeweils gleiche Ergebnisse zeigten. Die rote und die schwarze Linie liegen direkt übereinander.

\subsubsection{Auswirkungen der stabilen Überexpression verschiedener Klasse-3}

\section{Semaphorine}

\subsubsection{Auswirkungen auf die Proliferation der Gliomzellen}

In Arbeiten von Kessler et al. konnte eine Proliferationshemmung der HUVECs durch Sema3F und in dieser Arbeit zusätzlich durch Sema3E beschrieben werden. Außerdem zeigten auch „Human Embryonic Kidney“ (HEK)-293-Zellen eine Inhibierung der Proliferation durch Sema3F (Kessler et al. 2004). Proliferationsmessungen an humanen U87MG- und U373MG-Glioblastomzellen, die lentiviral mit verschiedenen Klasse-3 Semaphorinen transfiziert worden waren, sollten zeigen, ob dieser Effekt auch auf Gliomzellen zutrifft. Zur Analyse des Wachstumsverhaltens wurde eine definierte Zellzahl ausgesät und über $96 \mathrm{~h}$ beobachtet. Alle $24 \mathrm{~h}$ wurde ein WST-1-Test durchgeführt und die Absorption des Farbstoffes Formazan bestimmt. Die Reaktion beruht auf der Umsetzung des Tetrazoliumsalzes WST-1 durch ein mitochondriales Enzym der Atmungskette (Succinat- 
Tetrazolium-Reduktase) zu dem Farbstoff Formazan. Der gemessene Farbumschlag ist proportional zu der Menge des Enzyms (siehe 3.1.4).

Abbildung 10 zeigt die Proliferationskurven der transfizierten U87MG-Zelllinien. Die Zelllinien U87-A,-B,-E,-F und -G proliferieren im Vergleich zur Kontrollzelllinie (U87-N) und U87-D etwas schwächer, zeigen aber untereinander keine signifikanten Wachstumsunterschiede. Die U87-B- und U87-F-Zellen proliferieren weniger stark, wobei sich mit zunehmender Inkubationszeit die Zellzahlen wieder annähern. Während der Versuchszeit konnte kein Abschwimmen der Zellen bzw. eine Minimierung der Absorption beobachtet werden, was darauf hindeutet, dass sich die Zellen während der Versuchstage in der exponentiellen Wachstumsphase und nicht in der stationären oder Absterbephase befanden.

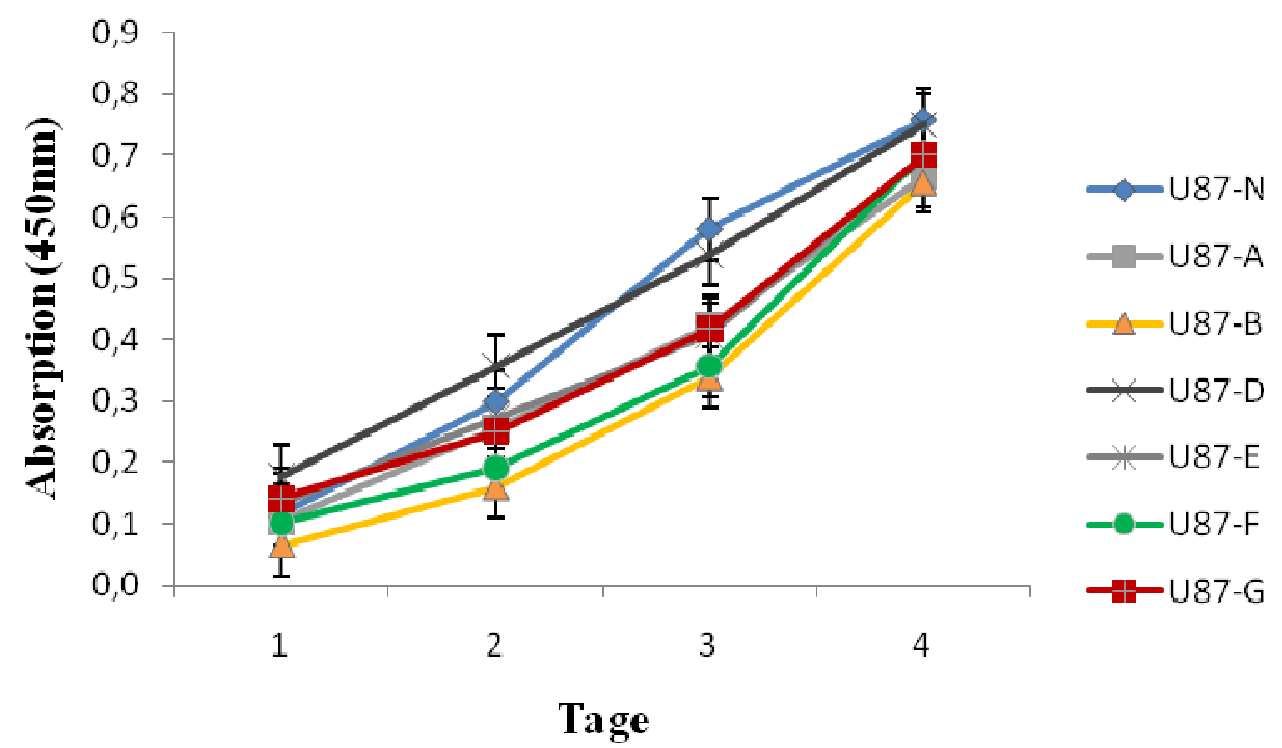

Abbildung 10: Effekt der Semaphorin-Expression auf U87MG-Zellen

Die Proliferation der mit Klasse-3 Semaphorinen transfizierten U87MG-Gliomzellinie wurde mittels WST-1Test über einen Zeitraum von vier Tagen bestimmt. Gezeigt sind die arithmetischen Mittelwerte \pm SD. Die Messung wurde in einer Achtfachmessung in zwei unabhängigen Versuchen durchgeführt $(n=16)$.

Abbildung 11 zeigt das Wachstum verschiedener Semaphorin-überexprimierender U373MGZelllinien. Die Proliferation der U373-N-, -D- oder -E-Zellen wurde über vier Messtage beobachtet. Die Versuchsbedingungen für die WST-1-Messungen der zweiten Gliomzelllinie wurden, wie bei den U87MG-Zellen, beibehalten. Die U373-D- und U373-E-Zellen weisen im Vergleich zu der Kontrollzelllinie minimal höhere Absorptionswerte auf. Die Proliferation der Zellen stieg bis zum vierten Messtag an und die Zellen befanden sich in der 
exponentiellen Wachstumsphase. Am letzten Tag der Messung zeichnete sich ein Übergang in die stationäre Phase ab. Die lentivirale Expression verschiedener Klasse 3-Semaphorine scheint, verglichen mit der Leervektor-Kontrolle, insgesamt keinen signifikanten Einfluss auf die Proliferation der Gliomzellen U87MG und U373MG auszuüben.

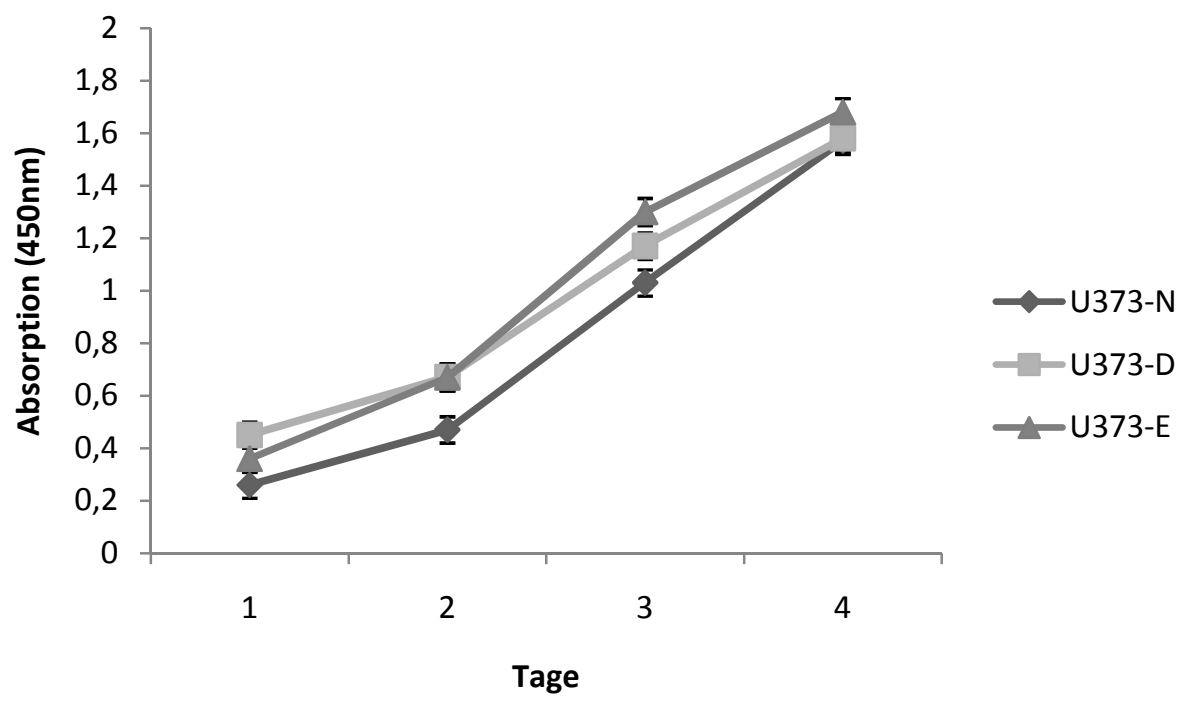

Abbildung 11: Effekt der Semaphorin-Expression auf U373MG-Zellen

Die Proliferation unbehandelter, mit Klasse-3 Semaphorinen transfizierter U373MG-Gliomzellen wurde mittels WST-1-Test über einen Zeitraum von vier Tagen bestimmt. Gezeigt sind die arithmetischen Mittelwerte \pm SD. Die Messung wurde in einer Achtfachmessung in zwei unabhängigen Versuchen durchgeführt. Gezeigt sind die Mittelwerte einer Achtfachbestimmung ( $\mathrm{n}=16)$.

\subsubsection{Auswirkungen auf den Zellzyklus der Gliomzellen}

Da die untersuchten Klasse-3 Semaphorine keinen Einfluss auf die Proliferation der Zellen zeigten, sollte überprüft werden, ob durch die Expression der Klasse-3 Semaphorine Veränderungen im Zellzyklus auftreten. Dafür wurde die DNA der U87-N-, U87-D- und U87G-Zellen mittels Propidiumiodid angefärbt. Mithilfe eines Durchflusszytometers wurde die Fluoreszenzintensität der DNA gemessen und auf diese Weise die Zellen einer bestimmten Zellzyklusphase zugeordnet (siehe 3.4.2). Abbildung 12 zeigt pro Zelllinie ein repräsentatives Messergebnis. Mit M1 sind die präapoptotischen Kerne gekennzeichnet, M2, M3 und M4 entsprechen den Zellzyklusphasen G1, S und G2. Abbildung 13 zeigt die Einteilung der Zellen in die jeweilige Zyklusphase. In den U87-N- und U87-G-Zellen befanden sich 63,5 \% bzw. 65,3\% der Zellkerne in der G1-Phase, wobei von den Sema3D transfizierten Zellen nur $56 \%$ der Zellkerne in dieser Zellzyklusphase waren. 10,9\% der Zellkerne der U87-D- 
Zelllinie befanden sich in der Synthesephase, während im Vergleich dazu die Anzahl in den U87-N- und U87-G-Zellen mit 8,5\% und 7,6 \% niedriger war. Die Zahl der sich in der G2Phase befindlichen Zellkerne lag bei den U87-N-Zellen bei 20,4 \%, bei den U87-D-Zellen bei $24,3 \%$ und bei den U87-G-Zellen bei 19,6\%. Im Vergleich zu U87-N- und U87-G-Zellen ist der Anteil der U87-D-Zellen in der G1-Phase um 7-8 \% niedriger, in der G2- und S-Phase um $4 \%$ bzw. $2 \%$ höher.

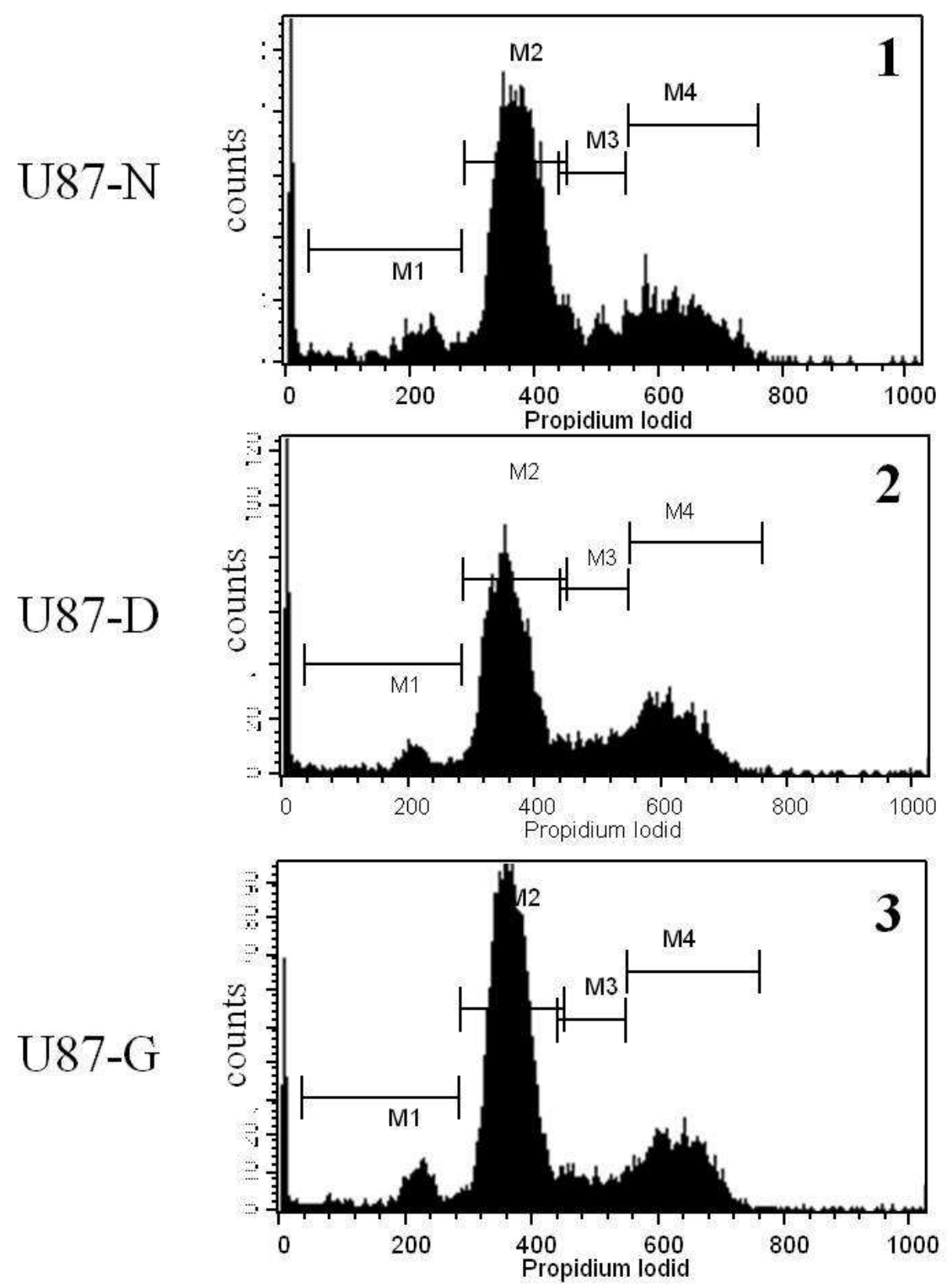

Abbildung 12: Zellzyklusanalysen der transfizierten U87MG-Zellen

Gezeigt ist pro gemessene Zelllinie ein repräsentatives Beispielbild einer FACS-Zellzyklusanalyse. Die Zellkerne wurden zuvor mittels Propidiumiodid angefärbt. Die eingezeichneten Balken markieren die Zellkerne, die sich in den verschiedenen Zellzyklusphasen befinden. Bild 1 zeigt die Verteilung der Zellkerne der Kontrollzelllinie U87-N, Bild 2 der U87-D- und Bild 3 der U87-G-Zelllinie. 


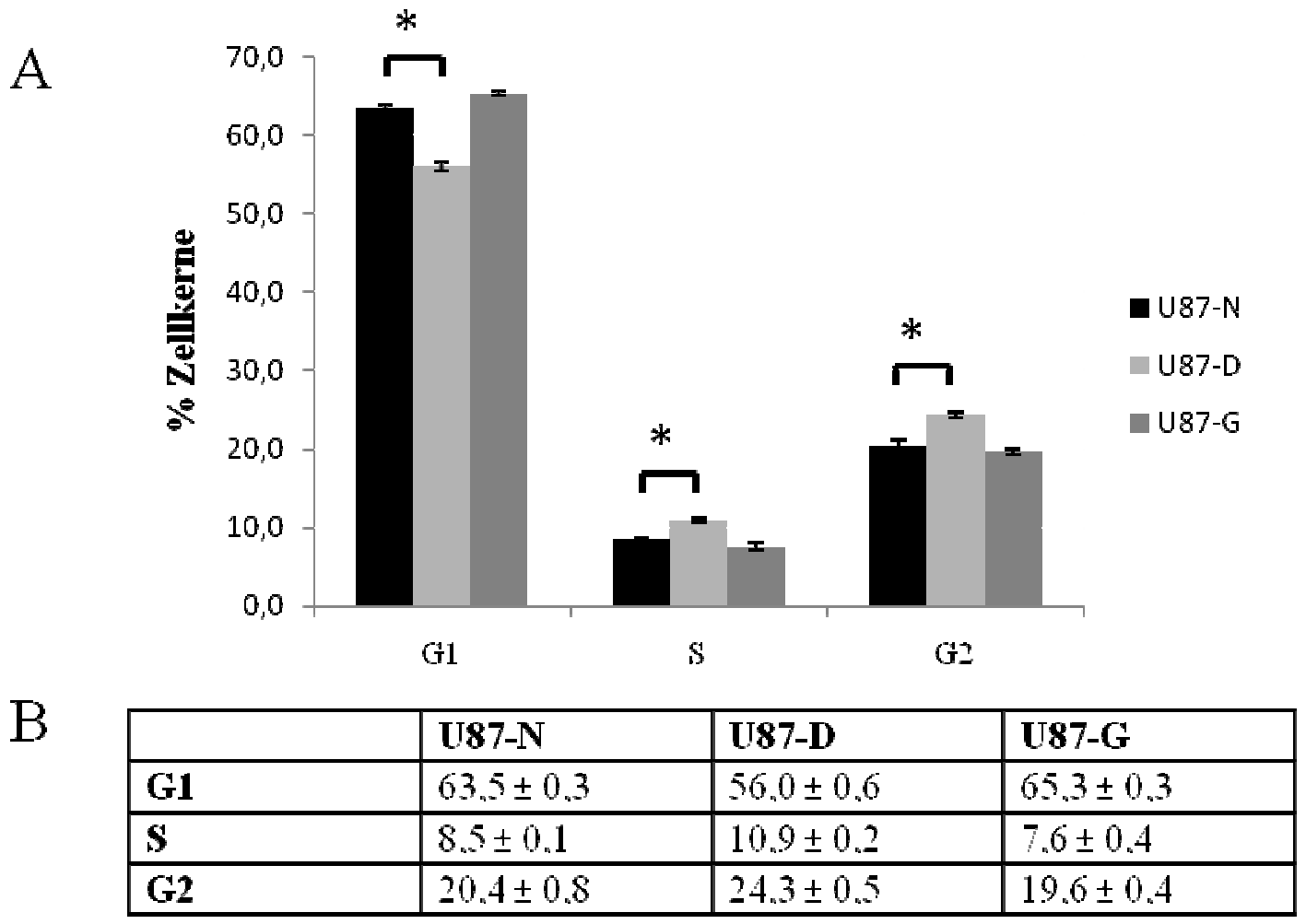

Abbildung 13: Verteilung der Zellzyklusphasen in transfizierten U87MG-Zellen.

Die prozentuale Verteilung der Zellkerne der U87-N-, U87-D- und U87-G-Zellen (y- Achse) auf die verschiedenen Zellzyklusstadien (x-Achse) wird in der oberen Grafik dargestellt (A). Die Tabelle gibt die Prozentzahlen der Kerne pro Zellzyklusphase an (B). Die lysierten Zellen wurden mit Propidiumiodid behandelt, welches in die DNA im Kern interkaliert. Anschließend wurde im Durchflusszytometer die Fluoreszenzintensität bestimmt. Die Intensität ändert sich, je nachdem wie viel DNA sich im Kern befindet. In der G1-Phase befindet sich ein einfacher Chromosomensatz im Kern und in der G2-Phase der doppelte Satz. In der S-Phase findet die Replikation der DNA statt. Gezeigt sind die Mittelwerte einer repräsentativen Dreifachbestimmung. Gezeigt sind die arithmetischen Mittelwerte einer Dreifachbestimmung und \pm SD. Eine Student's t-test Berechnung ergab * $\mathrm{p} \leq 0,01$ für die Zellzyklusphasen der U87-D im Vergleich zu U87-N.

\subsubsection{Auswirkungen auf die Migration der Gliomzellen}

Für Brustkrebszellen wurde eine Inhibierung der Migrationseigenschaften durch Sema3F beschrieben (Nasarre et al. 2003). Um eine mögliche Beeinflussung der Migrationseigenschaften der Gliomzellen durch die Überexpression von Semaphorinen zu untersuchen, wurden U87-N-, U87-D- und U87-G-Zellen in Zellmedium auf einem Filtereinsatz mit $8 \mu \mathrm{m}$ Porengröße und einer Matrigel-Beschichtung ausgesät. Vier Tage später wurden die Zellen, die durch die Membran hindurch in die Vertiefung einer 24-well Platte gewandert waren, gezählt (siehe 3.1.6). Abbildung 14 zeigt die durch die Membran migrierten Zellen. Auf der x-Achse sind die Zelllinien aufgetragen, die y-Achse zeigt die 
migrierten Zellen nach vier Tagen. Im Mittel wurden 64.000 Zellen von den U87-N gezählt. Im Vergleich zu der Kontrolle migrierten $75 \%$ weniger U87-D-Zellen, während von den U87-G-Zellen etwa $50 \%$ durch die Membran wanderten. Dieser Versuch zeigt eine deutliche Inhibierung der Migration der Gliomzellen durch die Expression der Klasse-3 Semaphorine D und G.

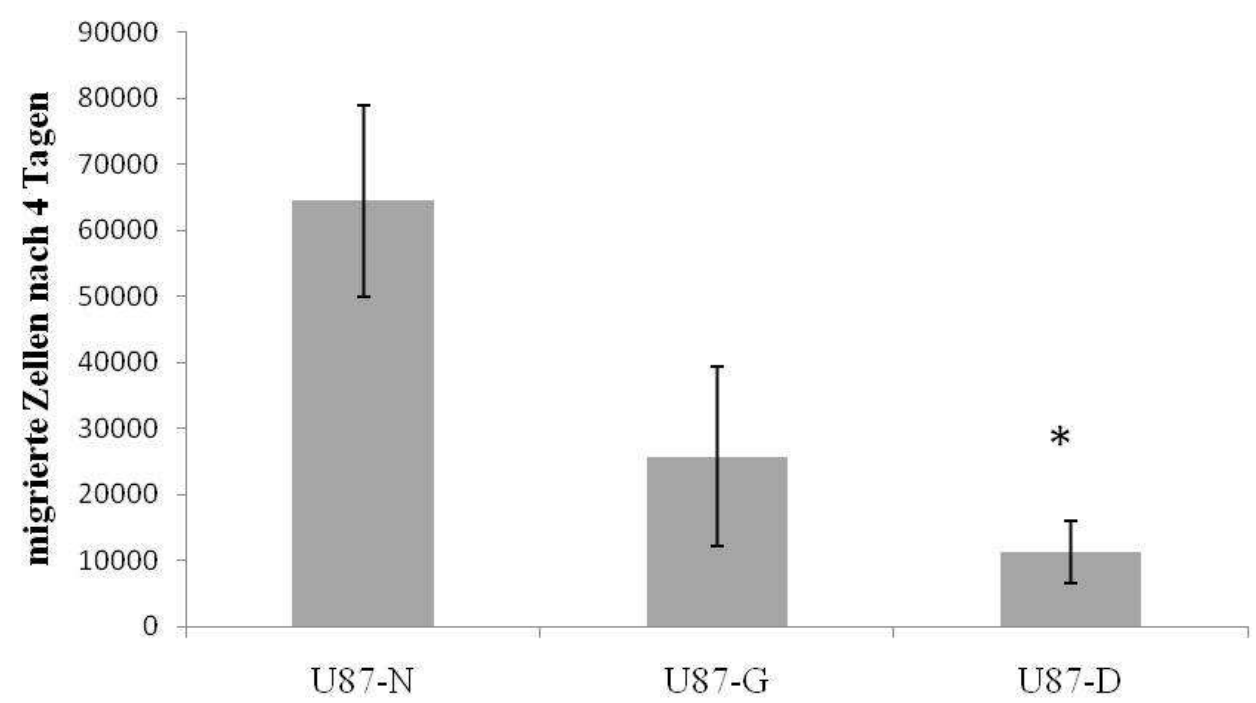

Abbildung 14: Effekte der Semaphorin-Expression auf die Migration der Zellen

Die durch eine Membran migrierten transfizierten Gliomzellen in einer „Boyden chamber“ wurden an Tag 4 nach Aussaat gezählt und die Ergebnisse aufgetragen. Ausgesät wurden 1 x $10^{4}$ Zellen in 0,5 ml Medium. Die angezeigten Zellzahlen stellen arithmetische Mittelwerte $\pm \mathrm{SD}$ dar $(\mathrm{n}=4)$. Die Migration jeder Zelllinie wurde in zwei unabhängigen Versuchen bestimmt. * $\mathrm{p} \leq 0,01$

\subsubsection{Auswirkungen auf die Adhäsion der Gliomzellen}

Aufgrund der beobachteten Effekte der Semaphorin-Expression auf das Migrationsverhalten der Zellen, wurde im Folgenden der Einfluss der Semaphorin-Expression auf das Adhäsionsverhalten der Zellen mithilfe des "Cell adhesion assay (ECM Array)" untersucht. Zelladhäsion spielt eine wichtige Rolle bei der Migration und Invasion, Wundheilung und Gewebeumstrukturierung. Proteine der extrazellulären Matrix formen Komplexe mit Komponenten des Zytoskeletts, welches Einfluss auf die Bewegung, Proliferation und das Überleben der Zelle nehmen kann. Für diesen Versuch waren die Vertiefungen einer 24-well Platte mit unterschiedlichen extrazellulären Matrix (ECM)-Proteinen wie Fibronectin, Collagen I, Collagen IV, Laminin I und Fibrinogen beschichtet. 
In Abbildung 15 sind die Bindungseigenschaften der transfizierten U87MG-Zellen an die jeweiligen ECM-Proteine vergleichend dargestellt. Die Bindung der Zellen an die Proteine wird durch einen Farbstoff (keine Angaben des Herstellers) markiert. Je höher der gemessene Absorptionswert des Farbstoffes, desto stärker ist die Bindung der Zellen an die Proteine. Die stärksten Bindungseigenschaften an die einzelnen ECM-Proteine besitzt die Zelllinie U87-D. Für jedes der getesteten ECM-Proteine konnte im Vergleich zu den Kontrollzellen eine starke Adhäsion beobachtet werden.

Die U87-G-Zellen binden weniger stark an Fibronectin, Collagen I, und Laminin und gar nicht an Fibrinogen. Nur an das Collagen IV heften sich die Zellen etwas stärker an als die Kontrollzellen. Durch die Expression des Sema3D wird das Adhäsionsverhalten der Zellen verstärkt, während die Anwesenheit von Sema3G bei allen getesteten ECM-Proteinen bis auf Collagen IV eine Abschwächung des Adhäsionsverhaltens bewirkt.

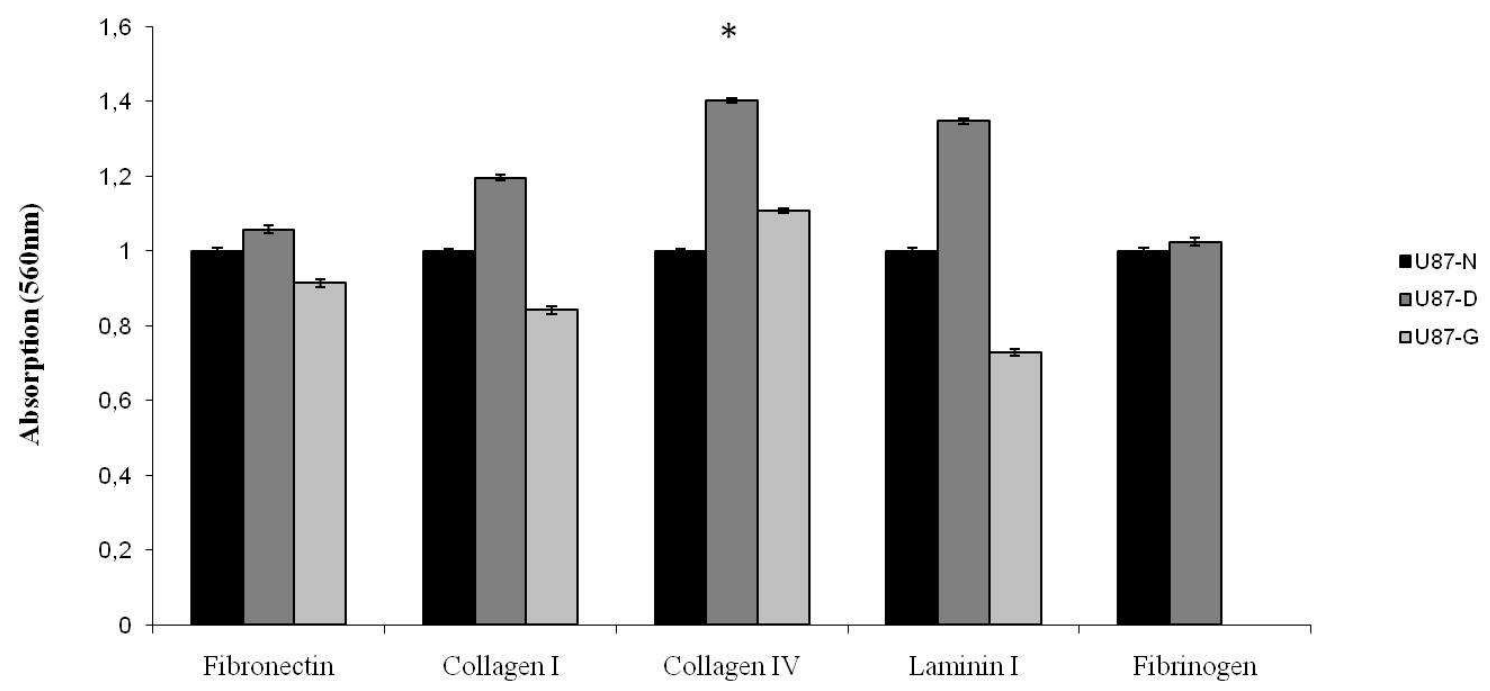

Abbildung 15: Unterschiede in der Zelladhäsion durch Expression der Semaphorine in U87MG-Zellen

Die Abbildung zeigt die Unterschiede der transfizierten U87MG-Zellen in ihrer Eigenschaft, sich an extrazelluläre Matrixproteine anzuheften. Die relativen Werte der U87-D- und U87-G-Zellen sind in Bezug zu der Kontrollzelllinie, dessen Absorption auf 1 gesetzt wurde, aufgetragen. Dargestellt sind die arithmetischen Mittelwerte einer Doppelbestimmung \pm SD $(n=2)$. Die Berechnung mit Student's t-test ergab ein * $p \leq 0,01$ für den Vergleich von U87-D mit U87-N. 


\subsubsection{Auswirkungen auf die Apoptose der Gliomzellen}

In den Tierversuchen (siehe 4.2) führte die intrazerebrale Implantation der U87-N-, U87-Gund U373-N-Zellen zu Tumorwachstum, während die U87-A-, -B-, -D-, -E- und -F, sowie U373-D und -E-Zellen nicht zu einem Tumor anwuchsen.

Für Sem3B und Sema3F konnte in Lungen- bzw. Eierstockkrebszellen gezeigt werden, dass sie eine pro-apoptotische Wirkung besitzen (Xiang et al. 2002; Castro-Rivera et al. 2004; Castro-Rivera et al. 2008). Um zu prüfen, ob die Zelllinien, die in den hier gezeigten Versuchen keine Tumoren bildeten, durch einen möglichen pro-apoptotischen Effekt der Semaphorine beeinflusst wurden, wurde die Zellmorphologie und die Aktivierung der Caspase-3 bestimmt.

\subsection{Effekte der Semaphorine auf die Zellintegrität}

Um die Auswirkungen der Expression der Klasse-3 Semaphorine auf das endogene Apoptoseverhalten von Gliomzellen zu untersuchen, wurde deren Basisapoptose bestimmt. Als Basisapoptose wird das natürliche Absterben von Zellen beispielsweise nach Kontaktinhibition bezeichnet. Für diesen Versuch wurden 5 x $10^{3}$ Zellen ausgesät und mithilfe des „Cell Death Detection ELISA“ untersucht. Mit dieser Methode können Mono- und Oligonukleosomen nachgewiesen werden, die nach dem Zusammenbruch der Plasmamembran im Zytoplasma der apoptotischen Zellen zu finden sind. Als Positivkontrolle dienten Zellen, bei denen die Apoptose durch Behandlung mit Staurosporin induziert wurde. Abbildung 16 zeigt die Basisapoptose der transfizierten U87MG-Gliomzellen und der Positivkontrolle (P.C.). Die mit Staurosporin behandelten Zellen zeigen ein deutliches Apoptosesignal. In keiner der Semaphorin-exprimierenden Zelllinien konnte, im Vergleich zur Leervektorkontrolle (U87-N), ein Effekt auf das Apoptoseverhalten nachgewiesen werden. 


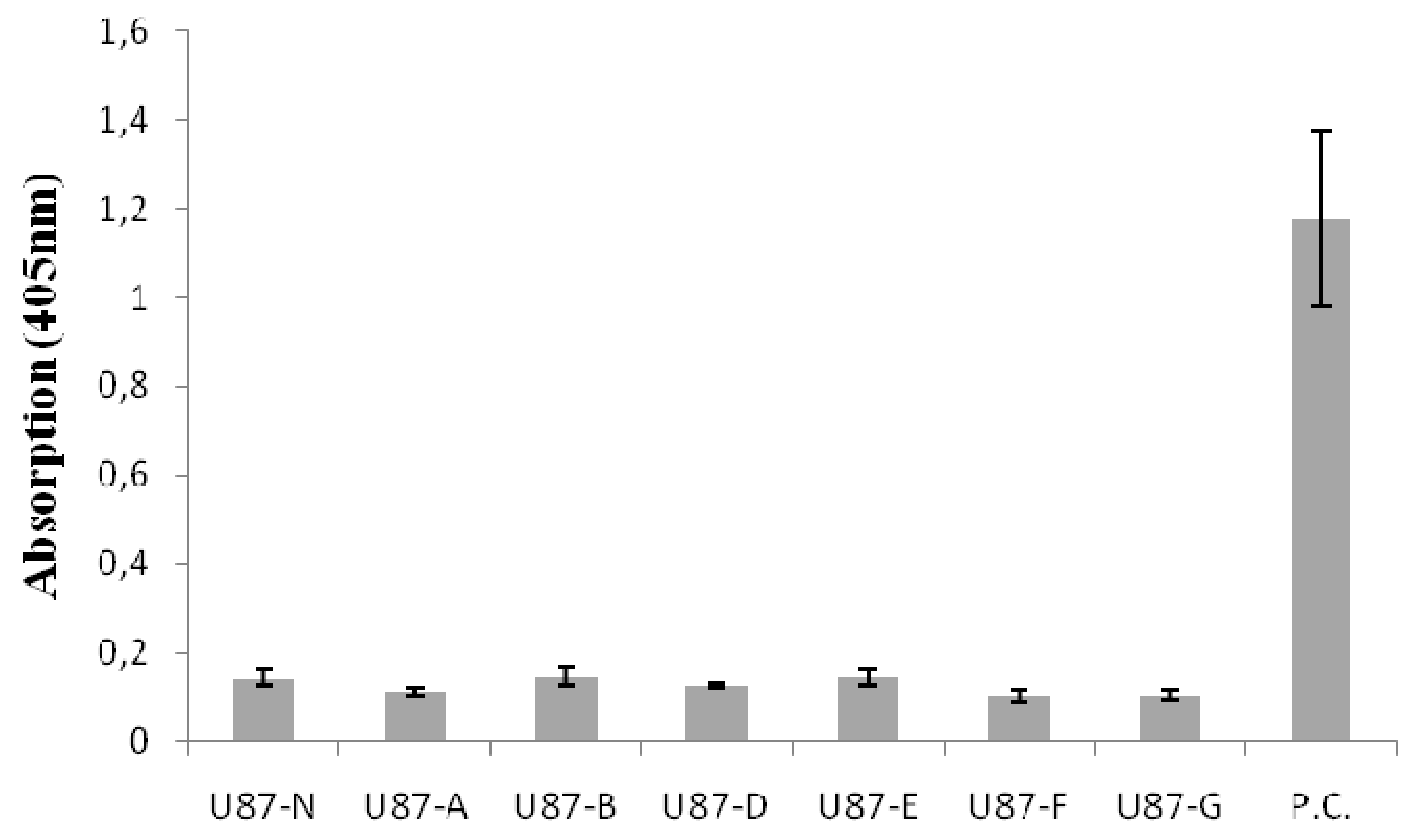

Abbildung 16: Effekte der Semaphorin-Expression auf die Apoptose der U87MG-Zellen

Die Basisapoptose der transfizierten U87MG-Zellen wurde mithilfe des „Cell Death Detection ELISA“ ermittelt. Die Absorption wurde bestimmt und die Werte für die einzelnen Zelllinien im Vergleich zu einer Positivkontrolle (P.C.) aufgetragen. Gezeigt sind die arithmetischen Mittelwerte aus einer Achtfachmessung die in zwei unabhängigen Messungen durchgeführt wurden $(n=8) \pm S$.

Auf die gleiche Weise wurde die Basisapoptose der transfizierten U373MG-Zelllinien untersucht. Auch in diesem Fall konnte kein Effekt der Semaphorin-Expression auf das Apoptoseverhalten der Zellen beobachtet werden (Abbildung 17). Die Abbildung zeigt die U373N, -D und -E Zellen und die P.C. aufgetragen gegen die gemessenen Absorptionswerte. Die P.C. zeigt eine deutliche höhere Absorption als die anderen Proben. Die Basisapoptose der Semaphorin-exprimierenden Zellen liegt sogar etwas unter der Basisapoptose der Kontrollzelllinie. 


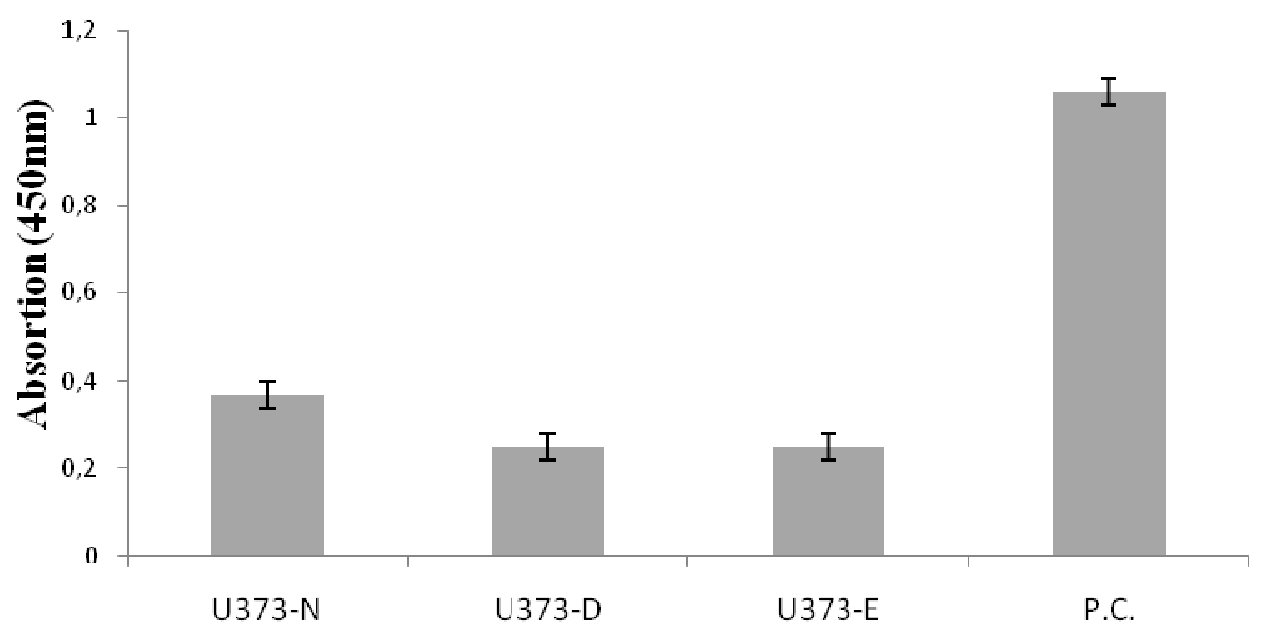

Abbildung 17: Effekte der Semaphorin-Expression auf die Apoptose der U373MG-Zellen Um die Basisapoptose der transfizierten U373MG-Zellen zu messen, wurde die Absorption ermittelt. Zusätzlich wurde eine Positivkontrolle (P.C.) mitgeführt. Die Abbildung zeigt die Absorptionswerte einer Achtfachbestimmung, die in zwei unabhängigen Versuchen bestimmt wurden. Gezeigt sind die arithmetischen Mittelwerte $(\mathrm{n}=8) \pm \mathrm{SD}$.

\subsection{Auswirkung auf die Aktivierung der Caspase-3}

Caspasen gehören zu den wichtigsten Enzymen der Apoptose. Initiator- und EffektorCaspasen, zu denen auch die Caspase-3 gehört, übermitteln Signale, die z.B. die DNA im Rahmen der Apoptose spalten. Die Aktivierung der Caspase-3 durch proteolytische Spaltung führt zu zwei charakteristischen Untereinheiten, die wiederum eine Signalkaskade anschaltet, die unter anderem in der Fragmentierung der DNA oder dem Abbau der Zellwand endet.

In den Semaphorin-überexprimierenden U87MG- und U373MG-Zelllinien konnte jeweils nur die intakte und somit inaktive Proform der Caspase-3 detektiert werden, d.h. die Zellen waren somit nicht apoptotisch. Abbildung 18 zeigt die Proben der Semaphorin-überexprimierenden U87MG- und U373MG-Zelllinien, die zusammen mit der P.C. aufgetragen sind. Um die Beladung des Gels mit Protein zu überprüfen, wurde eine Aktinfärbung angeschlossen. $\mathrm{Zu}$ sehen ist, dass der Auftrag für alle Proben erfolgreich war und dieselben Mengen Protein aufgetragen wurden

Bei den mit Staurosporin-behandelten Zellen (P.C.) ist anhand der detektierten Spaltprodukte zu erkennen, dass die Caspase in ihrer aktivierten Form vorliegt. $\mathrm{Zu}$ sehen sind die $19 \mathrm{kDa}$ und 17 kDa große Untereinheit (Earnshaw et al. 1999; Kugler et al. 2002; Pop und Salvesen 2009). Diese Doppelbande konnte in keiner der transfizierten U87MG- oder U373MGZelllinien nachgewiesen werden. Somit konnte eine Apoptose der Zellen ausgelöst durch die Expression von Semaphorinen ausgeschlossen werden. 


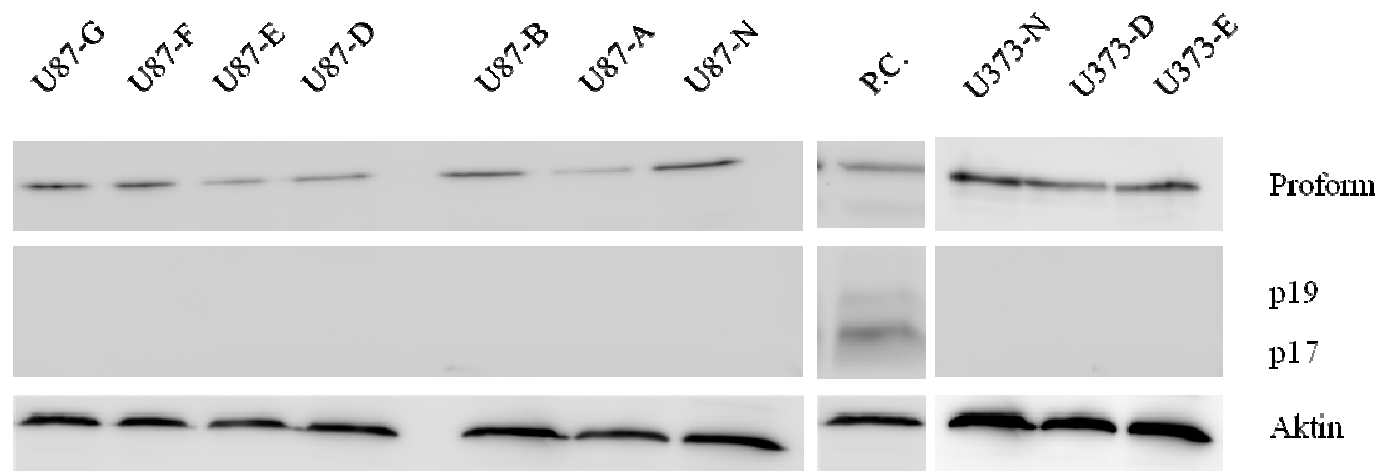

Abbildung 18: Effekte der Semaphorin-Expression auf die Spaltung der Caspase-3

Aus unbehandelten transfizierten U87MG- und U373MG-Gliomzelllinien wurden Gesamtzellextrakte hergestellt. Die Abbildung zeigt die Detektion der Caspase-3 in den Gliomzellen im Vergleich zur P.C.. Jede Zelllinie wurde mindestens dreimal analysiert.

Die in dieser Arbeit durchgeführten in vitro-Studien zum Einfluss der Klasse-3 Semaphorine auf HUVECs und Gliomzellen konnten zeigen, dass

- die Behandlung mit rekombinanten Semaphorinen die Proliferation der HUVECs hemmt und die Präsenz des VEGFR-2 auf der Zelloberfläche herabsetzt.

- weder die Behandlung mit rekombinantem Semaphorin noch die Überexpression dieser zu einer Veränderung der Gliomzell-Proliferation führt.

- das Adhäsions- und Migrationsverhalten, sowie die Zellzyklusphasen der U87-D verändert waren, im Gegensatz aber kein Effekt auf die Apoptose der Zellen vorlag. 


\subsection{Effekte der Klasse-3 Semaphorine auf Tumorzellen in vivo}

\subsubsection{Implantationskontrolle der Tumorzellen}

Um zu überprüfen, ob die lentiviral transfizierten Gliomzellen die Implantation in das Mausgehirn überleben und auch einige Tage nach der Implantation noch wiederzufinden sind, wurden U373-N-, U373-D- und U373-E-Zellen in je 2 immunkompetente CD1 nu/nu Mäuse intrazerebral implantiert, die Gehirne an Tag 2 und 4 entnommen und in Paraffin eingebettet. Da die eingesetzten Zellen zusätzlich mit einem firefly Luziferase-exprimierenden Vektor transfiziert worden waren, wurden Schnitte angefertigt und die Tumorzellen mit einem Antikörper gegen Luziferase (Goat anti-firefly luciferase polyclonal antibody) angefärbt. Abbildung 19 zeigt die angefärbten Tumorzellen in Paraffinschnitten von entnommenen Gehirnen an Tag 2 und 4 nach der Implantation. Schnitt 1 und 2 zeigen implantierte U373-NZellen an Tag 2 bzw. 4. Im Vergleich zu Tag 2 sind an Tag 4 mehr Tumorzellen zu sehen, die strahlenförmig in dem Schnitt verteilt sind.

In den Schnitten 3 und 4, nach der Implantation von U373-D-Zellen, und in den Schnitten 5 und 6, nach U373-E-Implantation, sind ebenfalls Tumorzellen zu sehen. Es kann allerdings keine Aussage darüber getroffen werden, ob sich die Anzahl der Zellen von Tag 2 zu Tag 4 vergrößert hat.

In jedem Fall konnten die Gliomzellen auch zwei und vier Tage nach Implantation in das Gehirn der Mäuse in den Gewebeschnitten wiedergefunden werden. 

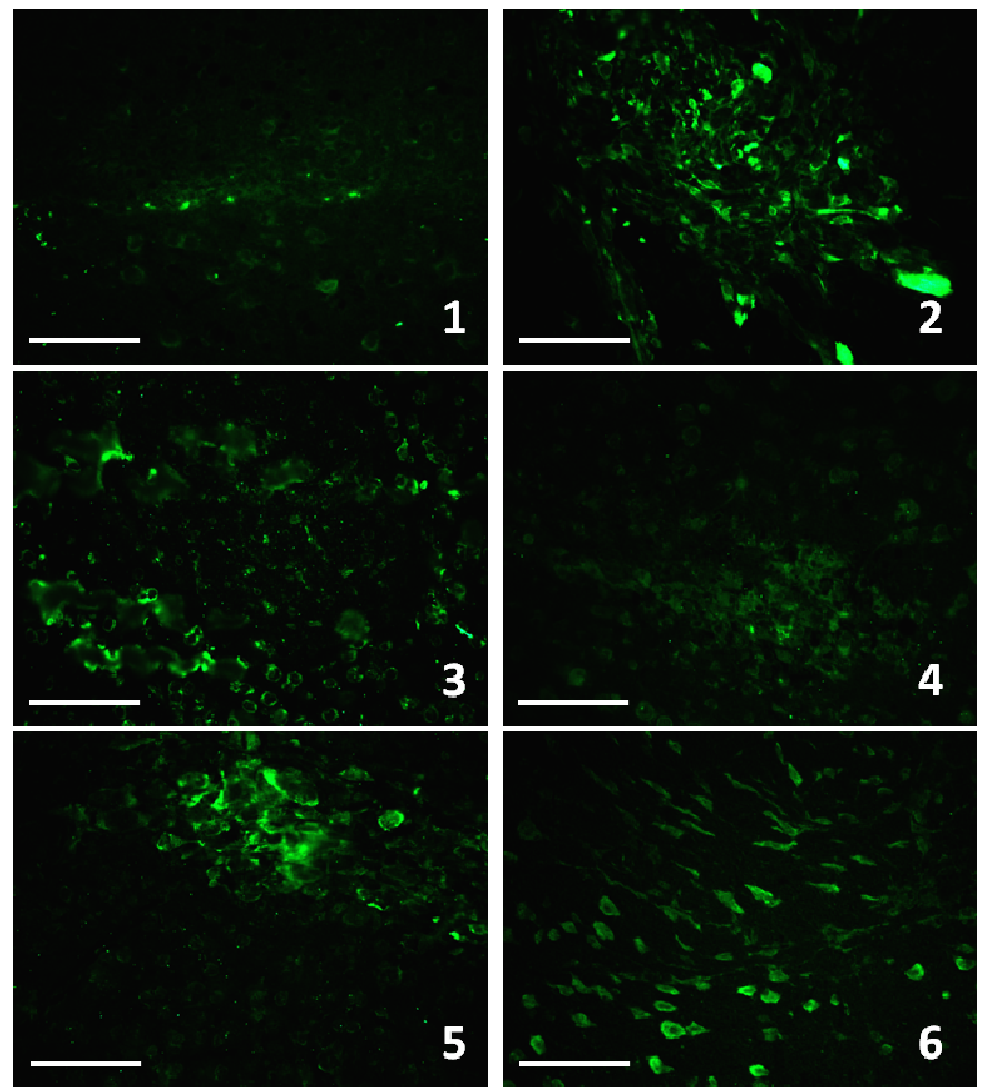

Abbildung 19: Detektion der Tumorzellen an Tag 2 und 4 nach Implantation

75.000 U373-N-, -D- und -E-Zellen wurden intrazerebral in CD1 nu/nu Mäuse implantiert und nach 2 und 4 Tagen mittels Luziferase-Antikörper-Färbung nachgewiesen. Es wurden jeweils zwei Tiere pro Versuchstag eingesetzt. Bild 1 und 2 zeigen U373-N-Zellen nach 2 bzw. 4 Tagen, Bild 3 und 4 U373-D-Zellen nach 2 bzw. 4 Tagen und Bild 5 und 6 U373-E-Zellen nach 2 und 4 Tagen. Der Balken entspricht $100 \mu \mathrm{m}$ in den Schnitten.

\subsubsection{Effekte der Semaphorin-Expression auf intrazerebrale U87MG-Tumoren}

Obwohl in den Zellkulturversuchen kein Effekt der Semaphorine auf die Proliferation der Gliomzellen zu beobachten war (siehe Abbildung 10), zeigten subkutane Implantationen dieser Zellen in die Flanke von Nacktmäusen eine Inhibierung des Tumorwachstums (nicht gezeigt). Außerdem zeigten Brustkrebszellen, die Klasse-3 Semaphorine überexprimieren, eine Hemmung des Tumorwachstums nach subkutaner Implantation in ein Mausmodell (Kigel et al. 2008). Daher sollten im nächsten Schritt die Auswirkungen der SemaphorinÜberexpression in Gliomzellen auf das Wachstum dieser Zellen im Gehirn einer Nacktmaus bestimmt werden. U373MG- und U87MG-Zellen wurden lentiviral mit Expressionsvektoren für Klasse-3 Semaphorine und firefly Luziferase transfiziert und in das Mausgehirn implantiert. Die Größe der Versuchsgruppen lag dabei jeweils zwischen acht und zehn Tieren. Es wurde immer eine Kontrollgruppe im Vergleich zu ein bis zwei Gruppen gemessen, denen 
Semaphorin überexprimierende Zellen implantiert wurden. Jedes Experiment wurde mit mindestens zwei unabhängigen Gruppen an Mäusen durchgeführt. Basierend auf den Ergebnissen von Vorversuchen wurde an Tag 12 begonnen, das Wachstum der Zellen im Mausgehirn zu messen. Die ersten 12 Tage kann aufgrund der geringen Tumorgröße und der Abschirmung des Signals durch den Schädelknochen der Mäuse kein Biolumineszenzsignal aufgenommen werden.

Den Mäusen wurde D-Luziferin, das Substrat der Luziferase, in einer Konzentration von $150 \mathrm{mg} / \mathrm{kg}$ Körpergewicht i.p. gespritzt. Die Luziferase setzt das D-Luziferin zu Oxyluziferin um und es entsteht ein Lichtsignal, welches detektiert werden kann. Vor der eigentlichen Biolumineszenz (BLI)-Aufnahme wurde ein Graustufenbild aufgenommen und anschließend zweimal für je 10 min Messzeit und einem Binning von vier das BLI-Signal gemessen. Unter Binning versteht man die Zusammenfassung der gemessenen Pixel, wodurch das Auflösungsvermögen leicht reduziert, die Sensitivität der Messung aber heraufgesetzt wird. Die Einstellungen der Kamera (Messzeit und Binning) wurden bei allen Messungen beibehalten. Um die durchschnittliche Biolumineszenzintensität in Impuls (counts) pro Sekunde pro Fläche zu ermitteln, wurde das Programm Meta Vue 6.1 (Universal Imaging Corporation) verwendet. Mithilfe des Programmes VCTEO2DImageAnalyze (erstellt von Dipl. Physiker Christian Dullin, Universitätsmedizin Göttingen) wurden farbkodierte Bilder der Signale aus den Biolumineszenzmessungen und den Graustufenbildern der Mäuse generiert. Im Mittel wurde das Wachstum der Tumoren von Tag 12 bis Tag 24 nach der Implantation verfolgt. Übten die Tumoren Einfluss auf die Gesundheit oder das Verhalten der Mäuse aus, wurden sämtliche Tiere der Messreihe zum gleichen Zeitpunkt aus dem Versuch genommen. Einer der Vorteile dieser Messmethode liegt darin, dass sie in vivo an narkotisierten Mäusen durchgeführt werden kann und somit an verschiedenen Tagen wiederholt werden kann.

Abbildung 20 zeigt pro Implantations-Gruppe ein repräsentatives Beispiel einer Maus nach einer Biolumineszenz-Messung. Die Stärke des Signals wird in Farbabstufungen von lila zu rot angegeben, wobei ein rotes Signal einer hohen Luziferase-Aktivität bzw. einem großen Tumor entspricht. Pro Gruppe wurden mindestens zwei Messungen mit jeweils acht Tieren durchgeführt. Die Bilder einer Maus nach Implantation von U87-N- und U87-G-Zellen zeigen Signale in der Kopfregion. Die Bilder der anderen Implantationsgruppen (U87-A-, -B-, -D-, E- und -F-Zellen) zeigen keine BLI-Signale in der Kopfregion der Mäuse. 
Die Ergebnisse der Messung wurden als relative Biolumineszenzwerte ermittelt, normalisiert und zusammen in Abbildung 21 aufgetragen. Balken 1 und Balken 7 zeigen die Biolumineszenzsignale der angewachsenen U87-N- und U87-G-Tumoren, während die Signale nach Implantation von U87-A-, -B-, -D-, -E- und -F-Zellen nur sehr gering bis gar nicht vorhanden ausfallen. Die Biolumineszenzsignale der U87-G-Zellen waren jedoch geringer als die Signale der Kontrollzellen.

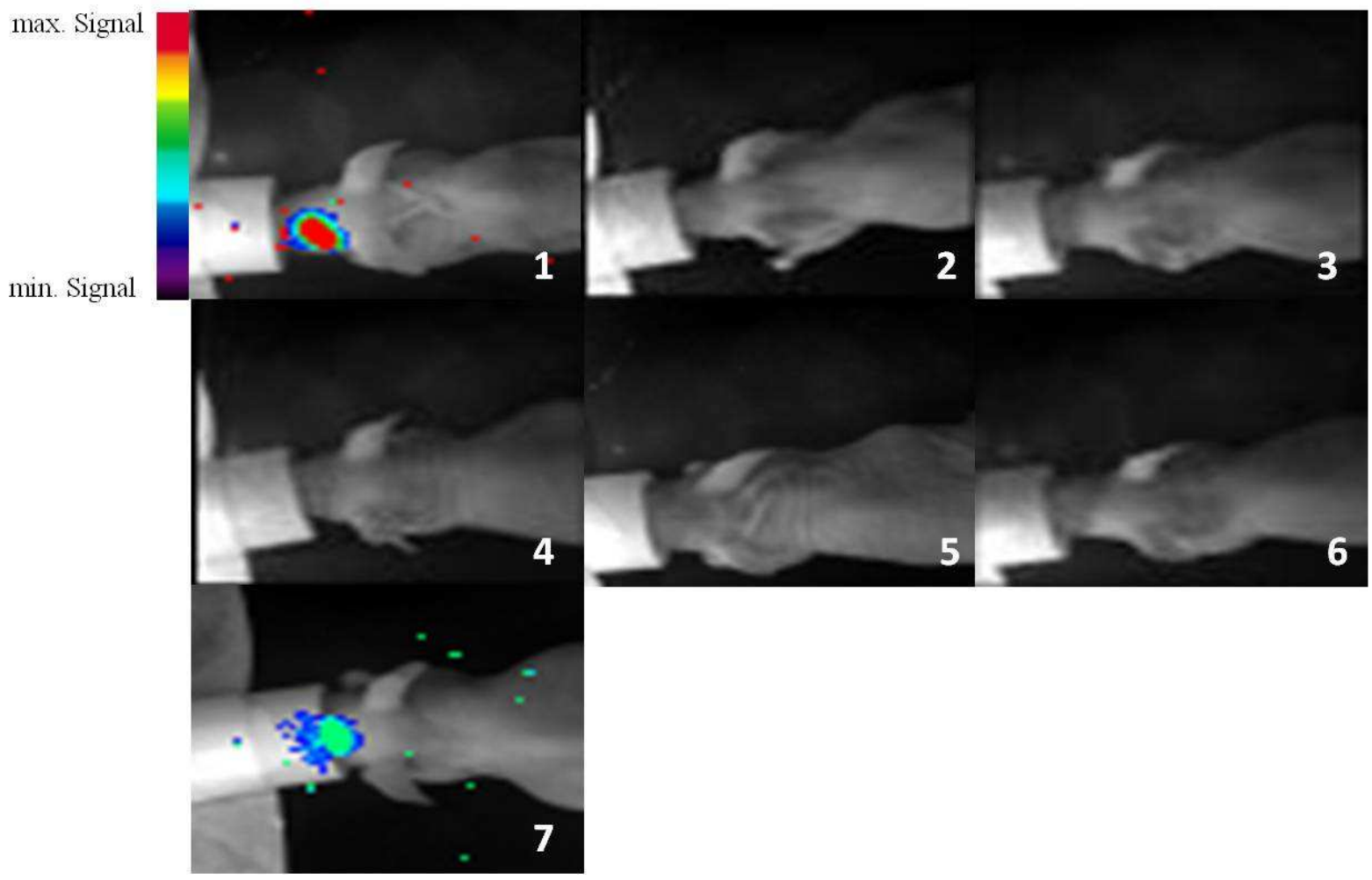

Abbildung 20: Einfluss der Semaphorine auf das Wachstum von U87MG-Zellen im Gehirn Die mit Expressionskonstrukten für Klasse-3 Semaphorine transfizierten U87MG-Zellen wurden in das Mausgehirn implantiert und das Wachstum der Tumoren mittels Biolumineszenz-Messung bestimmt.Pro Implantationsgruppe wird ein repräsentatives Bild gezeigt. Bild 1 zeigt ein Bild einer Kontrollmaus (U87-NZellen), Bild 2-7 die implantierten Zellen U87-A,-B,-D,-E,-F und -G.

Die Expression der Semaphorine in U87MG-Zellen inhibierte das Wachstum nach Implantation in das Mausgehirn. Um die Größe der gebildeten Tumoren mit den BLIMessungen $\mathrm{zu}$ korrelieren und die Tumoren näher $\mathrm{zu}$ charakterisieren, wurden die Gehirne nach Beendigung der Biolumineszenz-Messreihe, im Mittel an Tag 24, dem Mausschädel entnommen und histologisch untersucht (siehe 4.2.4.). 


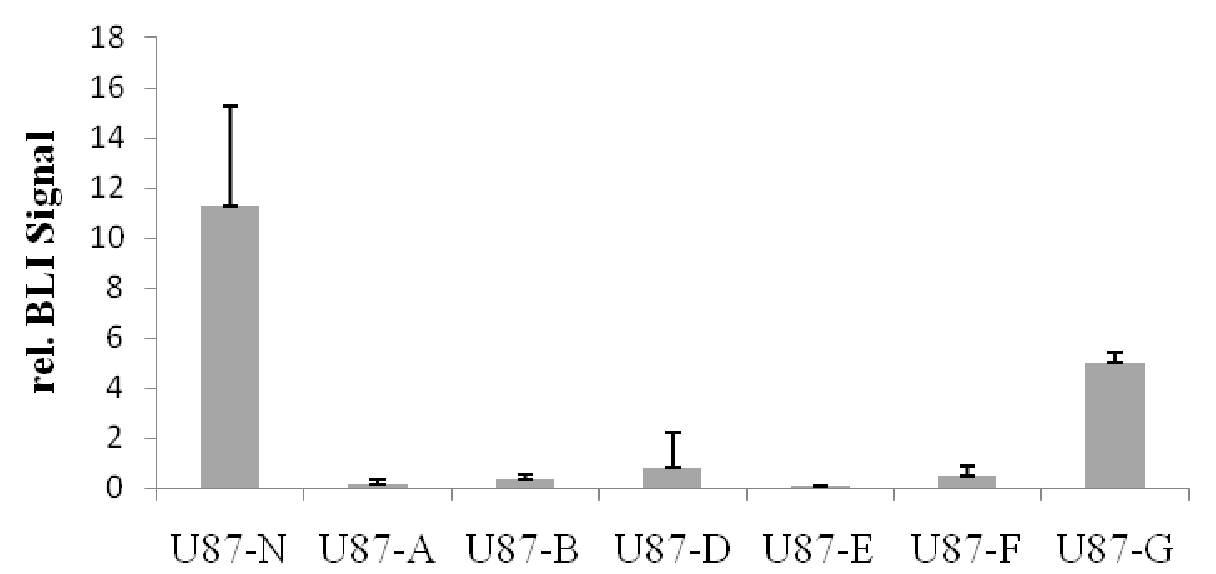

\section{Abbildung 21: Relative Biolumineszenz-Signale der Semaphorin- überexprimierenden U87MG-Zellenan Tag 24 nach der Implantation}

Die Mittelwerte der relativen BLI-Signale am letzten Tag der Messreihe von zwei unabhängigen Versuchen mit je acht Tieren pro Implantationsgruppe $(n=16)$ wurden in dieser Abbildung aufgetragen. Auf der $\mathrm{x}$-Achse sind die Semaphorin-überexprimierenden Zellen angegeben und auf der y-Achse das relative BLI-Signal der eingesetzten Zelllinien. Gezeigt sind die arithmetischen Mittelwerte $\pm \operatorname{SD}(n=16)$.

\subsubsection{Effekte der Semaphorin-Expression auf intrazerebrale U373MG-Tumoren}

In Semaphorin-überexprimierenden U87MG-Zellen zeigte sich eine Inhibierung des Wachstums nach intrazerebraler Implantation. Um zu prüfen, ob es sich um einen generellen Effekt auf das Wachstum der Gliomzellen handelt, wurde auch der Effekt der SemaphorinÜberexpression auf intrazerebrale U373MG-Tumoren untersucht. Dabei wurden die Semaphorine 3D und 3E untersucht, da sie zuvor einen deutlichen Effekt zeigten und bisher kaum charakterisiert sind. 12 Tage nach der Implantation wurde mit den BLI-Messungen begonnen. Die Einstellungen der Instrumente, sowie die Art der Auswertung, wurden beibehalten.

Abbildung 22 zeigt je ein repräsentatives Bild einer Maus, der U373-N- (1), U373-D- (2) oder U373-E-Zellen (3) implantiert wurden. Die Stärke des Signals wird in Farbabstufungen von lila zu rot angegeben, wobei ein rotes Signal einer hohen Luziferase Aktivität bzw. einem großen Tumor entspricht. 


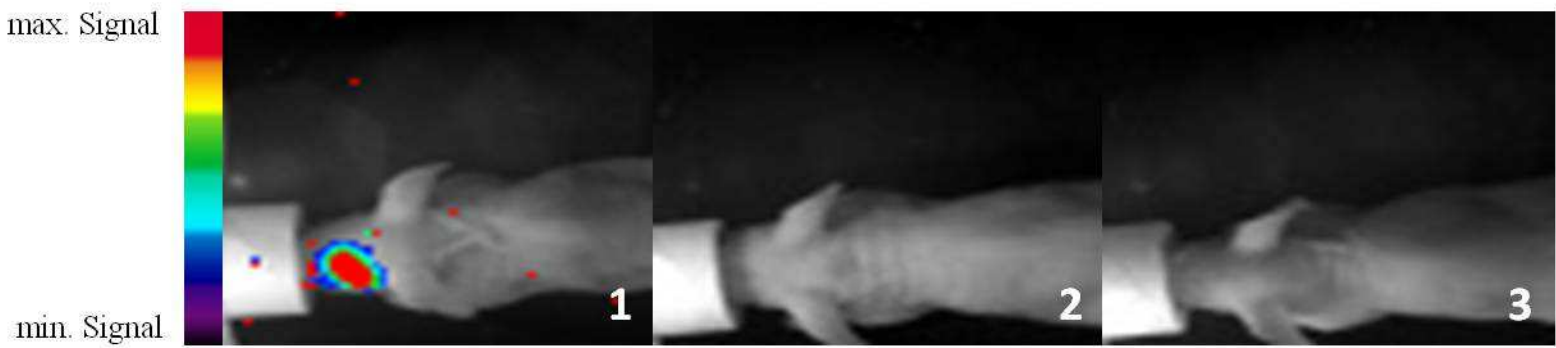

Abbildung 22:Einfluss der Semaphorine auf das Wachstum von U373MG-Zellen im Gehirn Die Abbildungen zeigen je ein repräsentatives Bild einer Biolumineszenzmessung einer Kontrollmaus (U373-N) (1), einer Maus mit Sema3D transfizierten U373MG-Zellen (2) und einer Maus mit Sema3E transfizierten U373Zellen (3), die intrazerebral implantiert wurden. Jede Gruppe bestand aus acht Tieren und wurde mindestens zweimal in unabhängigen Versuchen gemessen.

Abbildung 23 zeigt die normalisierten relativen Biolumineszenz-Werte. Aufgetragen sind die relativen BLI-Signale (y-Achse) gegen die Semaphorin-überexprimierenden U373-Zellen. In den Kontrollmäusen war deutliches Tumorwachstum sichtbar, während im Vergleich keine Signale in den Mäusen gemessen werden konnten, denen Semaphorin exprimierende Zellen implantiert worden waren (U373-D und -E).

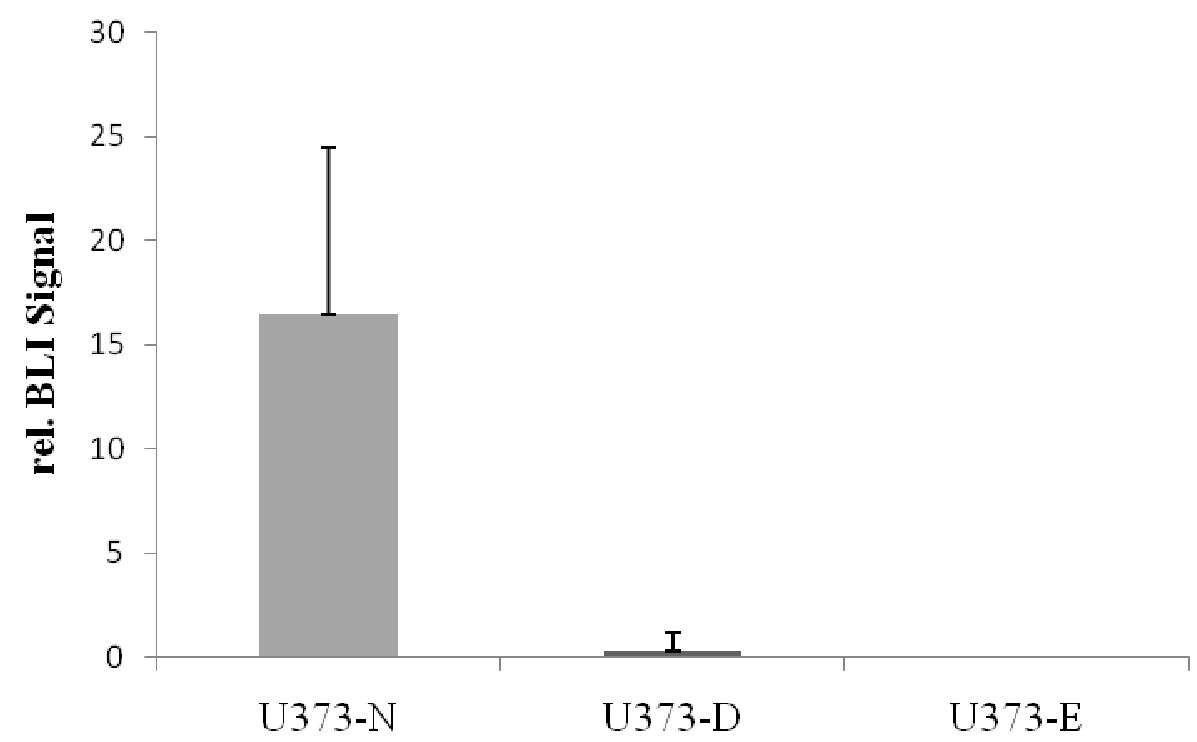

Abbildung 23: Relative Biolumineszenz-Signale der Semaphorin-überexprimierenden U373MG-Zellen nach Implantation an Tag 30 der Messreihe

Die Biolumineszenzwerte der intrazerebralen U373MG-Tumoren wurden gemittelt und vergleichend in der Grafik aufgetragen. Die Signale in den Kontrollmäusen waren im Mittel deutlich höher als die Signale nach U373-D und -E Implantation . Gezeigt sind die arithmetischen Mittelwerte und \pm SD $(n=16)$. 
Im Vergleich zu den U87MG-Zellen konnten die ersten Signale erst ab Tag 16 nach der Implantation gemessen werden. Im Mittel wurde ein Versuch mit U373MG-Zellen 30 Tage nach der Implantation beendet. Auch in den U373MG-Zellen wird eine deutliche Inhibierung des Tumorwachstums durch die Expression der Semaphorine in den intrazerebral implantierten Zellen sichtbar.

\subsubsection{Einfluss der Semaphorin-Expression auf die Morphologie der Tumoren und die Anzahl der gebildeten Blutgefäße}

Nach der Entnahme der Gehirne wurden die Tumorregionen und assoziierten Blutgefäße angefärbt, um deren Größe und Morphologie zu untersuchen. Zudem sollte gezeigt werden, dass deutliche Signale bei den Biolumineszmessungen mit starkem Tumorwachstum korrelieren, was mit einer erhöhten Blutgefäßanzahl einhergeht. Die Gehirne wurden entnommen und in koronare Scheiben geschnitten. Bild 1 der Abbildung 24 zeigt den Schnitt eines Mausgehirns, in das Kontrollzellen (U87-N) implantiert wurden. Der Farbstoff Hämalaun ist in der Lage, Zellkerne zu färben und erscheint in den Schnitten blau/lila, während Eosin das Zellplasma hellrot färbt. In Bild 1 ist in der rechten Hemisphäre (linke Seite des Gehirns) deutlich ein Tumor mit diffusem Wachstum und Bereichen mit höherem Zellkernanteil zu sehen. Glioblastome sind durch ihr diffuses Wachstum und hohe Zelldichten gekennzeichnet. Bild 2 und 3 zeigen Vergrößerungen des Tumorbereiches. Es ist deutlich zu sehen, dass die Tumorzellen dicht gepackt und infiltrierend wachsen. Im Vergleich zeigt Bild 4 die Aufsicht auf ein Gehirn, in das U87-D Zellen implantiert wurden. In der Aufsicht und auch in den Vergrößerungen (100x und 400x) ist eine gleichmäßige Färbung sowohl des Zellplasmas, als auch der Zellkerne zu sehen. Bereiche mit erhöhtem Zellkernanteil und damit verbundene Tumorbildung sind hier nicht zu erkennen. Die Bilder 7 bis 9 zeigen ein Gehirn, in das U87-G Zellen implantiert worden waren. Es ist ein Tumor zu sehen, der in seinen Ausmaßen kleiner ist, als der Kontrolltumor. Diese histologischen Befunde bestätigen eindeutig die Messungen der Tumorentwicklung mittels Biolumineszenz. 

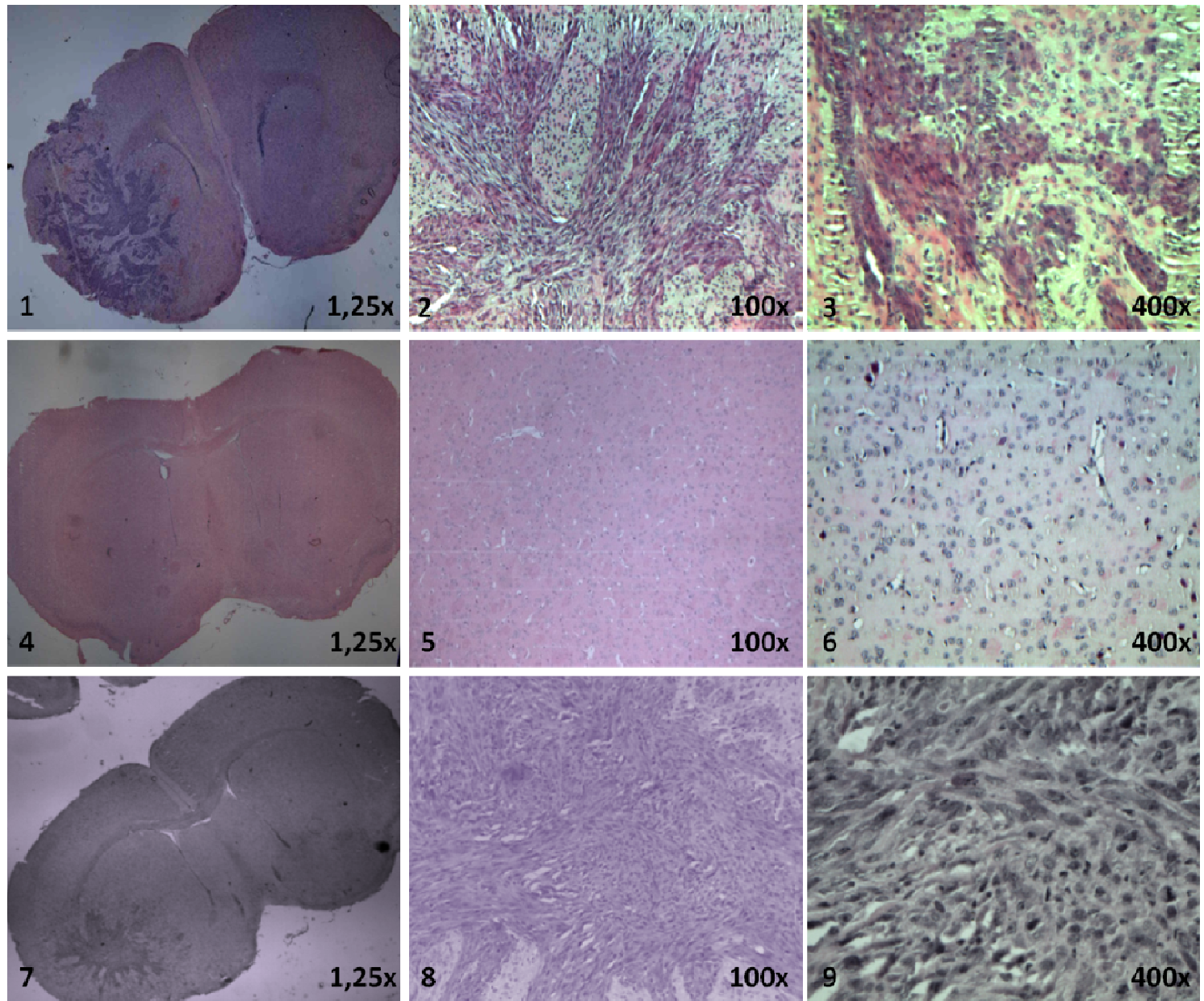

\section{Abbildung 24: HE-Färbung an Gehirnschnitten}

Die entnommenen Mausgehirne wurden in Paraffin eingebettet und in $4 \mu \mathrm{m}$ dicke Scheiben geschnitten. Nach einer anschließenden HE-Färbung wurden die Schnitte in verschiedenen Vergrößerungen (siehe rechte untere Ecke) aufgenommen. Bilder 1-3 zeigen Kontrolltumoren (U87-N) in unterschiedlichen Vergrößerungen, Bilder 4-6 stammen von Gehirnen, in die U87-D Zellen implantiert wurden. Die Bilder 7-9 zeigen Tumoren nach der Implantation von U87-G Zellen.

Um die Versorgung der Gehirntumoren mit Blutgefäßen zu untersuchen, wurden die Endothelzellen, die die Wände der Blutgefäße auskleiden, mit einem Antikörper gegen den von Willebrand-Faktor detektiert (rote Färbung). Zusätzlich wurden die Zellkerne mit DAPI angefärbt (blaue Färbung). Bild 1 in Abbildung 25 zeigt die Blutgefäße in einem Gehirntumor, gewachsen aus U87-N Zellen. Deutlich zu erkennen ist hier ein dichtes Netz von Blutgefäßen. Die Bilder 2 und 3 zeigen die Blutgefäße in den rechten Hemisphären von Mausgehirnen, in die U87-D bzw. U87-E Zellen implantiert worden waren. Hier zeigt sich eine normale Verteilung der Endothelzellen, wie sie üblicherweise in Gehirnen ohne Tumorwachstum zu finden ist. Diese Detektionsmethode gibt jedoch keinen Aufschluss über 
den Aufbau oder die Entwicklung der Blutgefäße. Eine verstärkte Ausbildung von Blutgefäßen korreliert somit deutlich mit einem erhöhten Tumorwachstum.
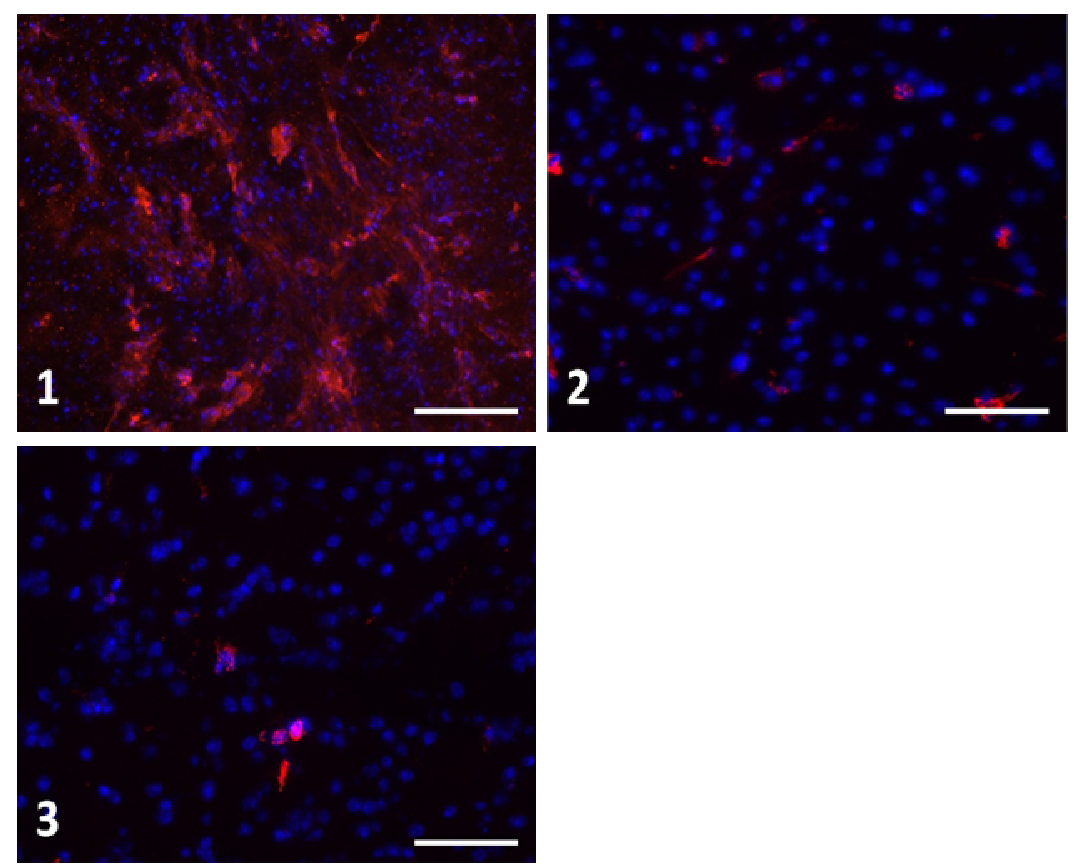

Abbildung 25: Anzahl der Blutgefäße in Tumoren nach Implantation von transfizierten U87M-Zellen

Endothelzellen wurden mithilfe eines van Willebrand-Antikörpers (rot) und die Zellkerne mittels DAPI blau angefärbt. Bild 1 zeigt die Tumorregion eines Kontrolltumors (U87-N), Bild 2 und Bild 3 die Gehirnregionen der Maus, in die U87-D bzw. U87-E Zellen implantiert wurden. Der Balken entspricht $100 \mu \mathrm{m}$.

\subsubsection{Effekt der Semaphorin-Expression auf die Lebenserwartung der Mäuse nach} U87MG-Implantation

Die Expression der Semaphorine in U87MG- und U373MG-Zellen führte zu einer Inhibierung des Tumorwachstums in Mausgehirnen. Um die Lebenserwartung der Mäuse nach intrazerebraler Implantation von Semaphorin-überexprimierenden U87MG-Zellen zu ermitteln, wurden erneut entsprechende Zellen in Mausgehirne implantiert. Die Mäuse wurden alle zwei bis drei Tage gewogen und ihr Allgemeinzustand beobachtet. Änderte sich das Verhalten in Bezug auf Nahrungsaufnahme oder Bewegungsabläufe, wurde jede Maus einzeln aus dem Versuch genommen. Nach einer Narkoseüberdosis wurden die Mäuse perfundiert und die Gehirne entnommen. Abbildung 26 zeigt, dass bei einer Gruppengröße von 9 Tieren die Kontrolltiere innerhalb von 33 Tagen nach der Implantation der Zellen in das Gehirn den Folgen des Tumors erlagen (schwarze Linie). Dabei lagen zwischen den ersten und den zuletzt verstorbenen Kontrolltieren 7 Tage. Die ersten Mäuse, denen U87-D- oder 
U87-E-Zellen implantiert wurden, verstarben erst, nachdem die letzte Kontrollmaus schon verstorben war (graue und rote Linie). An Tag 63 wurde der Versuch beendet. Die Kontrollmäuse wiesen allesamt Gehirntumoren auf, während die Mäuse nach Implantation von U87-D- und U87-E-Zellen zum größten Teil nicht an Gehirntumoren, sondern an Infekten der Augen oder an Bisswunden, die sie sich untereinander zugefügt hatten, verstarben. Am letzten Tag des Versuches (Tag 63) waren noch je zwei Mäuse pro U87-D und U87-E Implantationsgruppe am Leben. Die Gehirne der Mäuse wurden entnommen und die Größe der Tumoren mittels HE-Färbung bestimmt. Abbildung 27 zeigt pro implantierter Zelllinie ein repräsentatives Beispiel eines HE-angefärbten Gehirnschnittes. Bild 1 zeigt die Tumorregion einer Kontrollmaus mit diffusem Zellwachstum und Bereichen mit höherem Zellkernanteil. Die Bilder 2 und 3 zeigen die rechten Hemisphären nach U87-D- bzw. U87-E-Implantation, wobei Bereiche mit erhöhtem Zellkernanteil und damit verbundener Tumorbildung hier nicht zu erkennen sind.

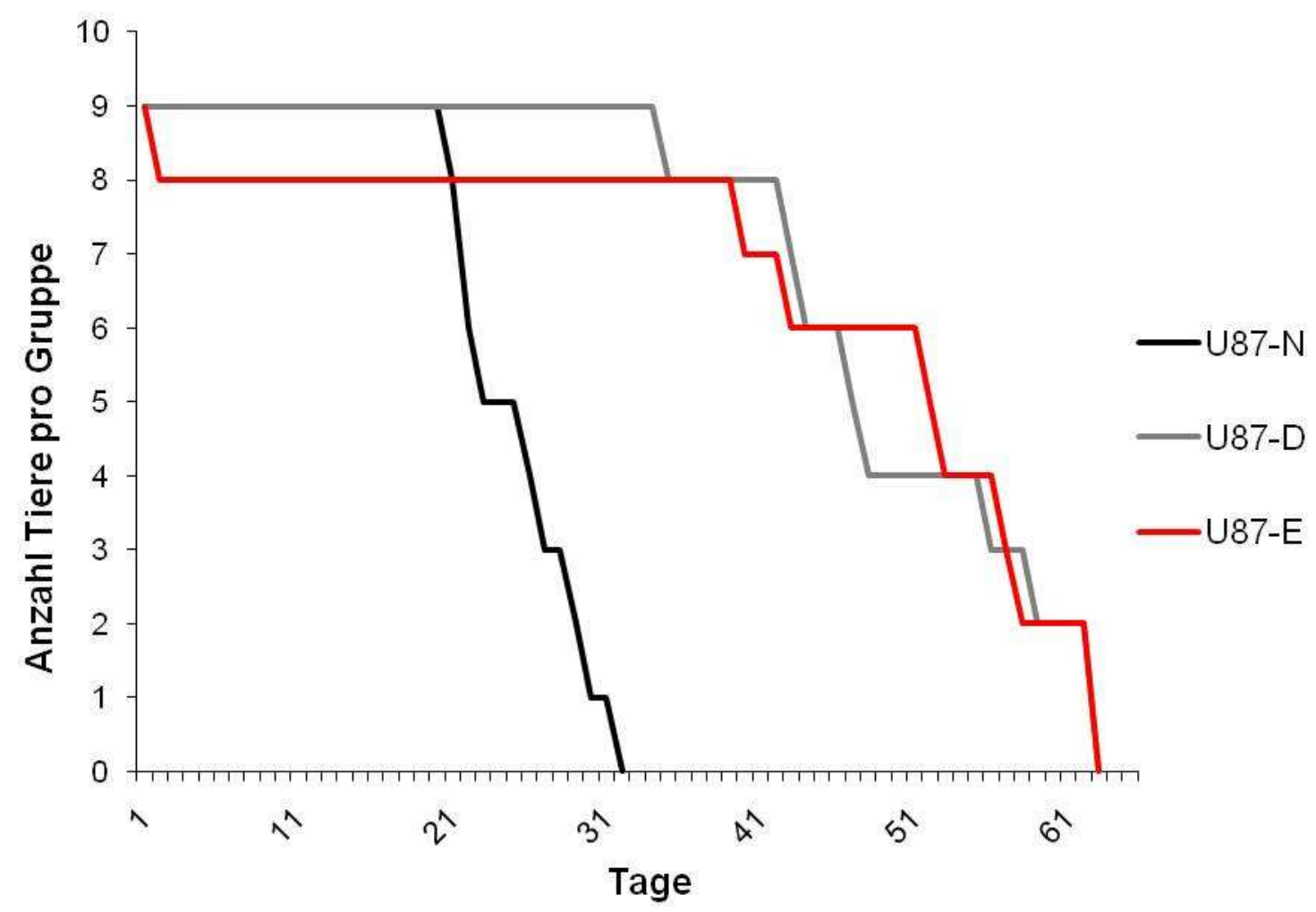

\section{Abbildung 26: Kaplan-Meier-Kurve der Mäuse nach U87M-Implantation}

U87-N-, -D- oder -E-Zellen wurden in je 9 Mäuse intrazerebral implantiert. Die schwarze Linie zeigt die Überlebenskurve der Kontrolltiere, die graue Linie das Überleben der Mäuse nach U87-D- und die rote Linie nach U87-E-Implantation. Ein Tier wurde aus dem Versuch genommen, wenn Verhaltensauffälligkeiten oder Krankheitsanzeichen auftraten. Nach 63 Tagen wurde der Versuch beendet. 

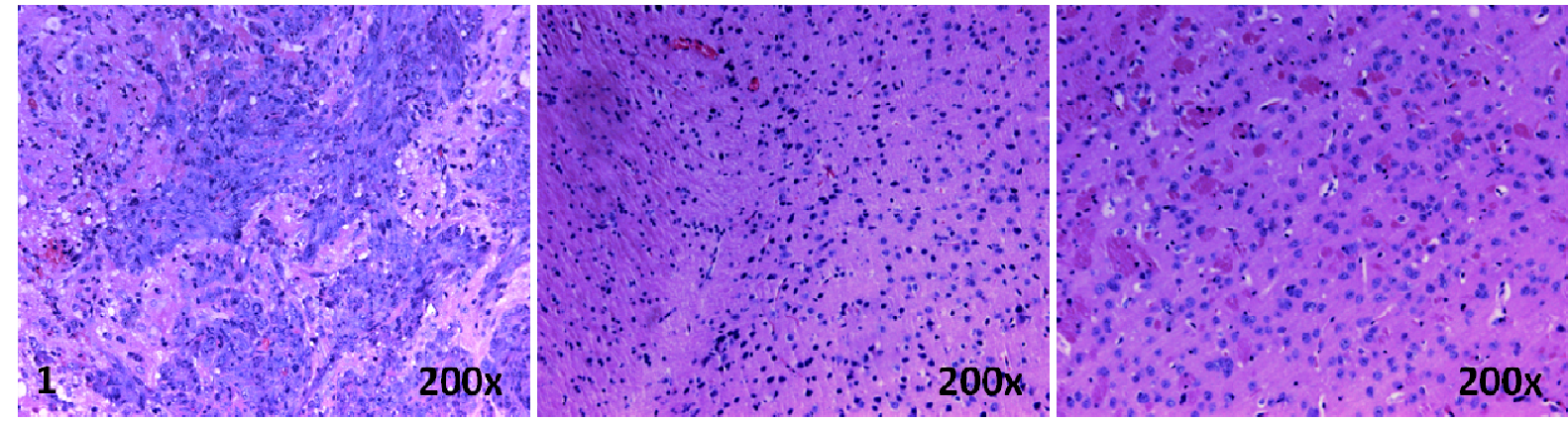

Abbildung 27: HE-Färbung nach U87-N-,-D- und -E-Implantation in das Mausgehirn

Die entnommenen Gehirne wurden in Paraffin eingebettet und in $4 \mu \mathrm{M}$ dicke Scheiben geschnitten. Nach einer anschließenden HE-Färbung wurden die Schnitte in 200facher Vergrößerung aufgenommen. Bild 1 zeigt einen Kontrolltumor (U87-N), die Bilder 2 und 3 stammen von Gehirnen, in die U87-D- bzw. U87-E-Zellen implantiert wurden.

\subsubsection{Lebenserwartung der Mäuse nach U373MG-Implantation}

Nach der Implantation von Semaphorin-überexprimierenden U87MG-Zellen in Mausgehirne zeigte sich eine Verbesserung der Lebenserwartung der Mäuse im Vergleich zu den Kontrolltieren. Um zu prüfen, ob dieser Effekt U87MG-spezifisch ist oder auch für andere Gliomzelllinien zutrifft, wurde der Einfluss der Semaphorin-Expression auf die Lebenserwartung der Mäuse nach Implantation der entsprechenden U373MG-Zellen untersucht. Wie zuvor, wurden die Mäuse alle 2-3 Tage gewogen und deren Verfassung beobachtet. Wies eine Maus Auffälligkeiten in ihrem Verhalten auf, wurde sie aus dem Versuch entfernt. Abbildung 28 zeigt, dass bis einschließlich Tag 48 nach der intrazerebralen Implantation alle Kontrollmäuse verstorben waren (schwarze Linie). Innerhalb der Tage 1 bis 61 verstarben auch jeweils 2 bzw. 3 Mäuse mit den Semaphorin-überexprimierenden Zellen (graue Linie U373-D, rote Linie U373-E).

Die Gehirne wurden nach der Perfusion der Mäuse entnommen, in Paraffin eingebettet, geschnitten und angefärbt.

Abbildung 29 zeigt pro implantierte Zelllinie ein repräsentatives Beispiel eines mittels Hämalaun und Eosin angefärbten Gehirnschnittes. Bild 1 zeigt die Tumorregion einer Kontrollmaus. Es sind diffuses Zellwachstum und Bereiche mit höherem Zellkernanteil zu sehen. Die Bilder 2 und 3 zeigen die rechten Hemisphären nach U373-D- bzw. U373-EImplantation, wobei Bereiche mit erhöhtem Zellkernanteil und somit Tumorbildung nicht zu erkennen sind. 


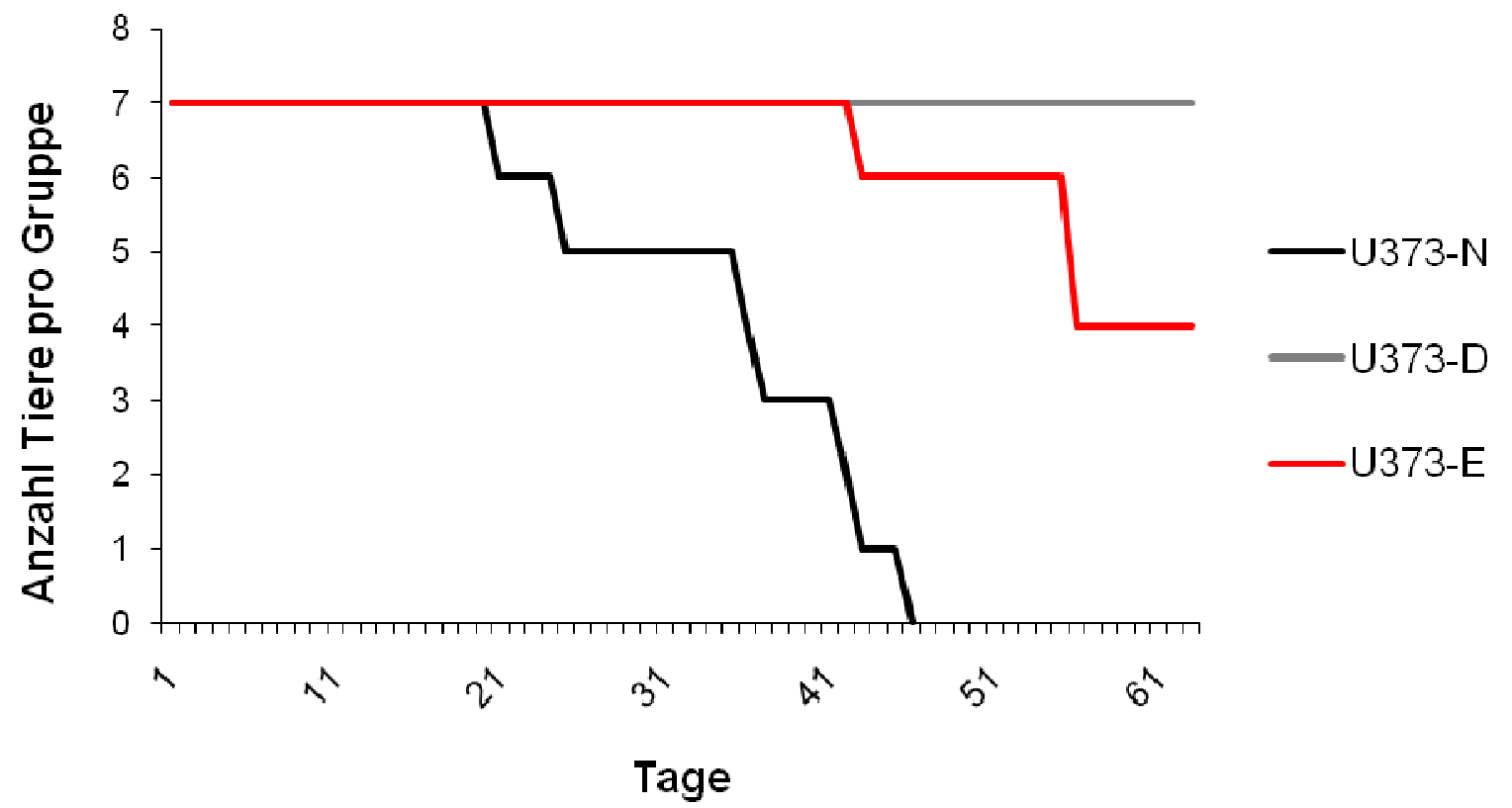

Abbildung 28: Überlebenskurve der Mäuse nach U373MG-Implantation

U373-N-, -D- und -E-Zellen wurden in je 7 Mäuse intrazerebral implantiert. Die schwarze Linie zeigt das Überleben der Kontrollmäuse, die graue und rote Linie die Überlebenskurve der Mäuse nach Implantation von U373-D- bzw. U373-E-Zellen. Ein Tier wurde aus dem Versuch genommen, sobald Verhaltensauffälligkeiten oder Krankheitsanzeichen auftraten. Die Gehirne der Mäuse wurden nach Ende des Versuches entnommen.
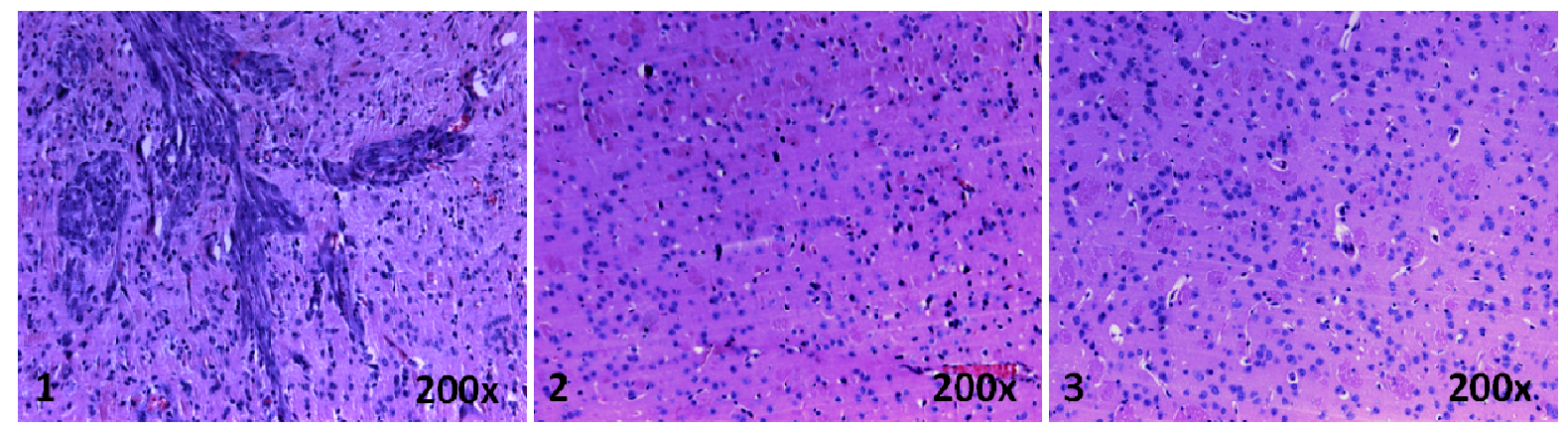

Abbildung 29: HE-Färbung nach U373-N-,-D- und-E-Implantation in das Mausgehirn

Die entnommenen Gehirne wurden in Paraffin eingebettet und in $4 \mu \mathrm{m}$ Scheiben geschnitten. Nach einer anschließenden HE-Färbung wurden die Schnitte in 200facher Vergrößerung aufgenommen. Bild 1 zeigt einen Kontrolltumor (U373-N), die Bilder 2 und 3 stammen von Gehirnen, in die U373-D- bzw. U373-E-Zellen implantiert worden waren.

\subsubsection{Chorionallantoismembran-Assay als alternatives Modell}

Eine Überexpression des Sema3A in Myelomzellen zeigte eine negative Beeinflussung der VEGF-vermittelten Angiogenese (Vacca et al. 2006). Da geprüft werden sollte, ob eine Semaphorin-Expression Einfluss auf die Angiogenese besitzt, wurde der Chorionallantoismembran (CAM)-Assay als eine zusätzliche Möglichkeit genutzt, das Wachstum von Tumorzellen und Blutgefäßen in einem Tiermodell zu beobachten. Der CAM-Assay hat den 
Vorzug, dass die Tumorzellen schnell anwachsen und dass die Entwicklung der tumorassoziierten Blutgefäße auch während des Anwachsens beobachtet werden kann.

Für diesen Versuch wurden pro Ei $10^{7}$ Zellen (U373-N und U373-D) in eine ThermanoxScheibe mit zentraler Aussparung aufgebracht. Die Zellen konnten zentral anwachsen und eine Woche später fixiert und die CAM mitsamt des Tumors aus dem Ei geschnitten werden. Abbildung 30 zeigt je ein repräsentatives Bild einer CAM eine Woche nach Aussaat der U373-N- und U373-D-Zellen. Bild 1 zeigt Kontrollzellen, die einen zentral gewachsenen runden Tumor bildeten. Deutlich zu erkennen sind die im Tumor verlaufenden, sowie die von außen strahlenförmig auf ihn zulaufenden Blutgefäße. Der Tumor hat einen Durchmesser von $1 \mathrm{~cm}$ und besitzt eine leicht gewölbte Form. Im Gegensatz zu den Kontrollzellen bildete sich kein Tumor aus den U373-D-Zellen. Bild 2 zeigt die abgestorbenen Tumorzellen auf der CAM. Deutlich $\mathrm{zu}$ sehen ist auch die wesentlich schwächere Ausprägung des Blutgefäßsystems. Diese Experimente zeigen, dass die Überexpression des Sema3D in U373MG-Gliomzellen einen deutlichen Einfluss auf das Tumorwachstum, sowie die Blutgefäßbildung hat.
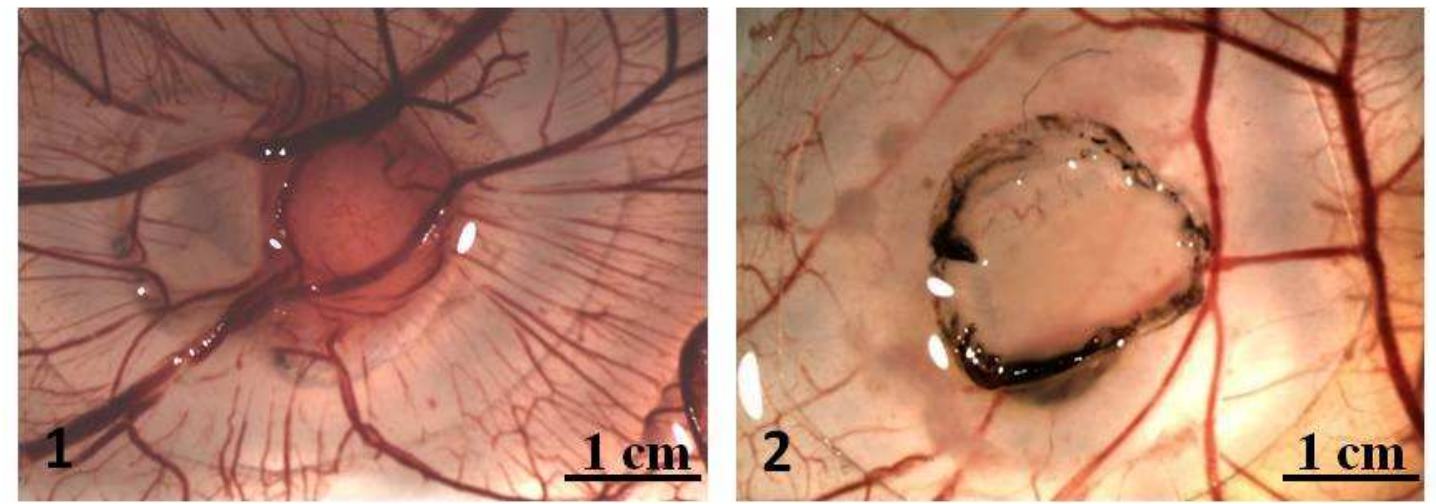

Abbildung 30: Effekte der Semaphorin-Expression auf das Wachstum der U373MG-Zellen auf einer CAM

An Tag 10 der Embryonalentwicklung des Kükens wurden U373-N- (Bild1) und U373-D-Zellen (Bild 2) auf die Chorionallantoismembran gegeben, um Tumoren anwachsen zu lassen. Nach einer Woche wurde die CAM entnommen und das Tumorwachstum begutachtet. Die Anzahl der Eier pro Zelllinie lag bei 10 ( $\mathrm{n}=10)$. Dieser Versuch wurde zweimal wiederholt. 
Die in dieser Arbeit durchgeführten in vivo-Studien zum Einfluss der Klasse-3 Semaphorine auf Gliomzellen konnten zeigen, dass

- das Tumorwachstum im Mausmodell durch Sema3A,-B,-D,-E und -F inhibiert wird.

- das Tumorwachstum auch auf der CAM gehemmt wird.

- die Angiogenese auf der CAM gehemmt wird.

\subsection{Effekte der Klasse-3 Semaphorine auf die Genexpression}

\subsubsection{Microarray-Analysen}

Um mögliche Veränderungen in der Genexpression der Semaphorin-überexprimierenden U87MG-Zellen zu ermitteln, wurden Microarray-Analysen an Triplikaten von U87-N-, U87D- und U87-G-Zellen durchgeführt, da nach intrazerebraler Implantation von U87-D-Zellen in den Mäusen keine Tumoren nachgewiesen werden konnten, während die Implantation von U87-G Zellen zu Tumorwachstum führte. Um Faktoren zu finden, welche die Unterschiede der Semaphorin-überexprimierenden Zellen in Bezug auf Tumorwachstum erklären könnten, sollte besonders auf veränderte Transkriptmengen von Tumorsuppressoren, Wachstumsfaktoren und Angiogenesefaktoren geachtet werden.

Für die Analyse wurde aus Triplikaten RNA extrahiert und diese in cDNA umgeschrieben. Nach einer Synthese zu doppelsträngiger DNA und anschließender in vitro-Transkription, wurde markierte aRNA auf den Microarray Chip (Affymetrix whole genome GeneChip® Human Exon 1.0 ST Array) gegeben und anhand der Anleitungen des „GeneChip® Expression Analysis“-Handbuchs hybridisiert und gescannt.

Die Fluoreszenz-Intensitäten wurden ausgelesen, die Microarray-Daten anhand interner auf den Chips befindlicher Kontrollhybridisierungsproben normalisiert und anschließend in der „Affymetrix-Data Suite“-Software annotiert. Abbildung 31 zeigt eine globale Ansicht der Array-Daten in einem Box-Plot aufgetragen (A). Dargestellt ist die Verteilung der Fluoreszenzen, die auf dem Chip gemessen werden konnten. Auf der y-Achse sind die Fluoreszenzintensitäten als Logarithmus zur Basis 2 und auf der $\mathrm{x}$-Achse die Triplikate dargestellt. Für weitere Analysen wurden die Fluoreszenzen normalisiert (B). Die 
Unterschiede der detektierten Fluoreszenzen zeigten keine starken Abweichungen voneinander.

Als Maß der differentiellen Genexpression wurde für jedes Gen, welches sich auf dem Array befand, der p-Wert zwischen den verglichenen Gruppen berechnet. Gene, die einen p-Wert $<0,05$ und einen zumindest doppelten Expressionsunterschied besaßen, wurden als differentiell exprimiert eingeordnet.
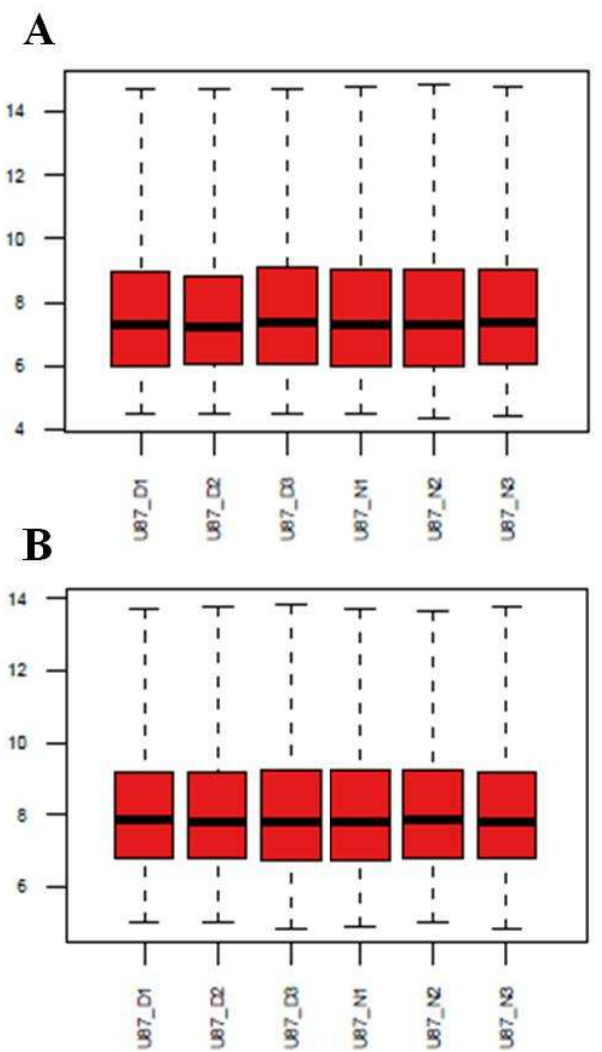

\section{Abbildung 31: Qualitätskontrolle und Normalisierung der Rohdaten}

Die Rohdaten der Microarray-Analyse werden in einem Diagramm aufgetragen, um deren Varianz untereinander zu zeigen. Dieses dient als Qualitätskontrolle der Proben (Bild A). Bild B zeigt die normalisierten Proben für die weiteren Auswertungen.

Die Analyse ergab, dass 188 Gene in den U87-D Zellen im Vergleich zu den Kontrollzellen verändert vorlagen. 119 dieser Gene waren in den U87-D Zellen hochreguliert, während 69 Gene eine geringere Anzahl an Transkripten aufwiesen. Sema3D zeigte, wie zu erwarten, den deutlichsten Zuwachs an mRNA mit einem ,fold change“ von 59 (siehe Tabelle im Anhang). Die 50 Gene, welche die deutlichsten Unterschiede in den Transkriptmessungen zeigten, wurden in der folgenden „heatmap“ (Abbildung 32) zusammengefasst. Eine sogenannte 
„heatmap“ zeigt eine Übersicht der Veränderungen in der Genexpression durch eine Farbkodierung an. In rot gekennzeichnet sind die Gene, die im Vergleich zu der Kontrollzelllinie hoch reguliert sind, während die herunter regulierten Gene in blau gezeigt werden. Dargestellt sind nur die Veränderungen zwischen den Triplikaten der U87-N- und der U87-D-Zelllinie.

In einer zweiten Microarray-Analyse wurden U87-N- mit U87-G-Zellen verglichen, die im Tierversuch zu Tumorwachstum führten. Ein Vergleich mit den Veränderungen, die in der Microarray-Analyse der U87-D-Zellen nachgewiesen wurden, sollte zur Identifikation von Genen führen, die das gegensätzliche Wachstum der U87-D- und U87-G-Zelllinien in vivo erklären könnten. Die Microarray-Analyse zeigte, dass ausschließlich das Transkript für Sema3G verändert vorlag. Wie erwartet, lag Sema3G stark reguliert in diesen Zellen vor. 


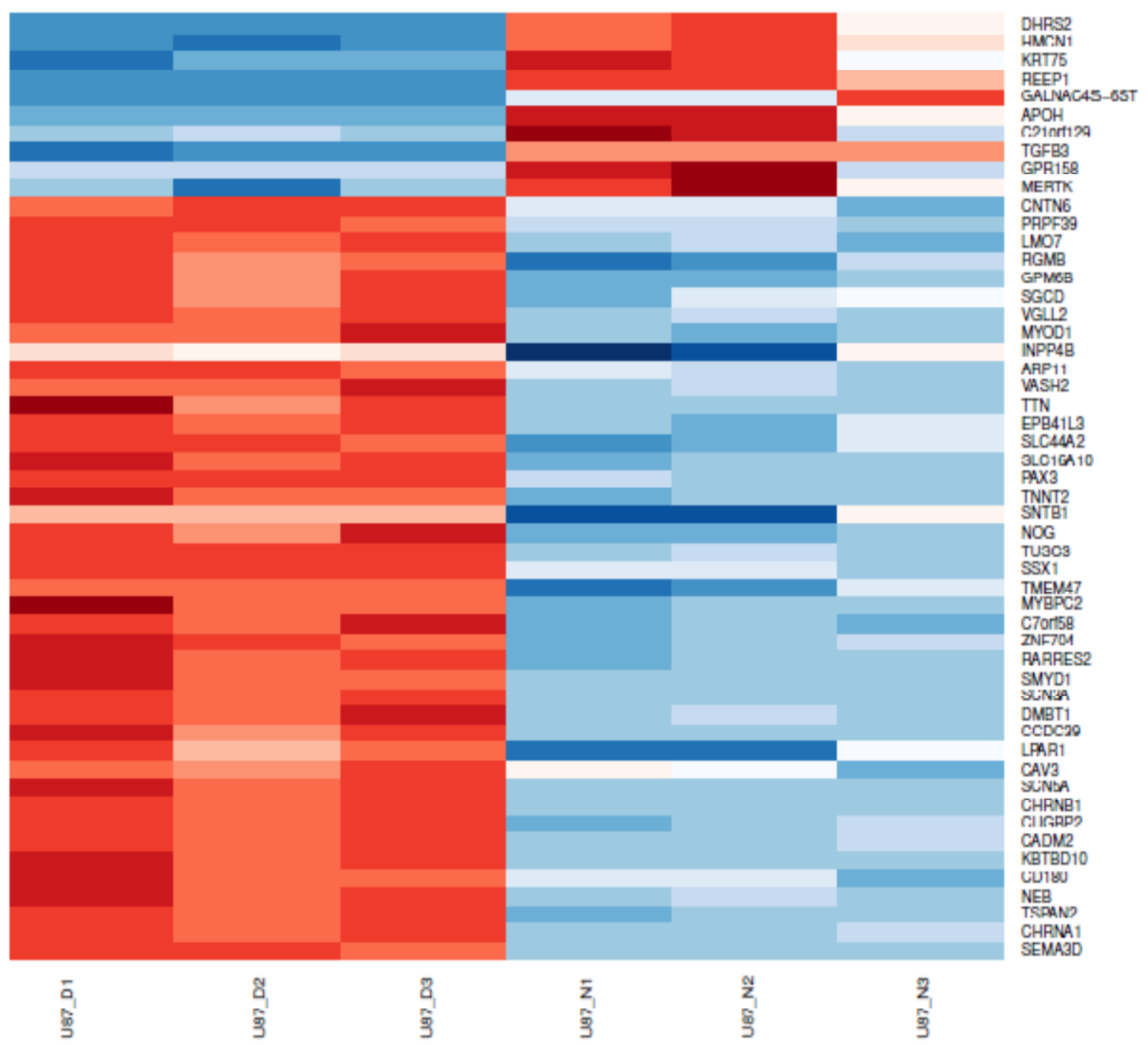

\section{Color Key}

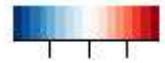

Row $^{-1}$ Z-Score

Abbildung 32: Heatmap der U87-N- und U87-D-Triplikate

In der Heatmap sind die Veränderungen in der Genexpression durch eine Farbkodierung dargestellt. In rot gekennzeichnet sind die Gene, die im Vergleich zu der Kontrolle höher exprimiert vorliegen, während die herunter regulierten Gene in blau dargestellt sind. 
Abbildung 33 zeigt die Ergebnisse der Microarray-Analyse der U87-N- und -D-Triplikate in einem „Principal Component Analysis“ (PCA)-Plot angeordnet.

In einem PCA-Plot werden große Datenmengen, wie tausende von variierenden Genen, auf kleinere Mengen reduziert und verknüpft dargestellt. In einer zweidimensionalen Ansicht werden auf der x-Achse Varianzen aufgetragen. Die Gesamtvarianz von 100\% entspricht der Menge der veränderten Gene, die auf dem Chip detektiert wurden. Die x-Achse zeigt die Varianz der zu vergleichenden Probengruppen (U87-N gegen U87-D) mit 36,35 \% und die yAchse eine Rechtfertigung dieser Auftragung mit $21 \%$ an. Auf diese Weise wird in einer 2D Ansicht der transkriptionelle Unterschied der beiden Probengruppen sichtbar gemacht, wobei eine Varianz von 36,35\% einer großen Abweichung entspricht. Die Triplikate gruppieren sich in einem zweidimensionalen Raum ein. Je näher die Triplikate zusammen liegen, desto ähnlicher sind ihre Transkripte. Die U87-N3-Probe (am obersten Rand der Darstellung) liegt etwas abseits der anderen Kontrollproben, zeigt aber immer noch einen großen Unterschied auf Basis der Transkripte im Vergleich zu den U87-D-Proben.

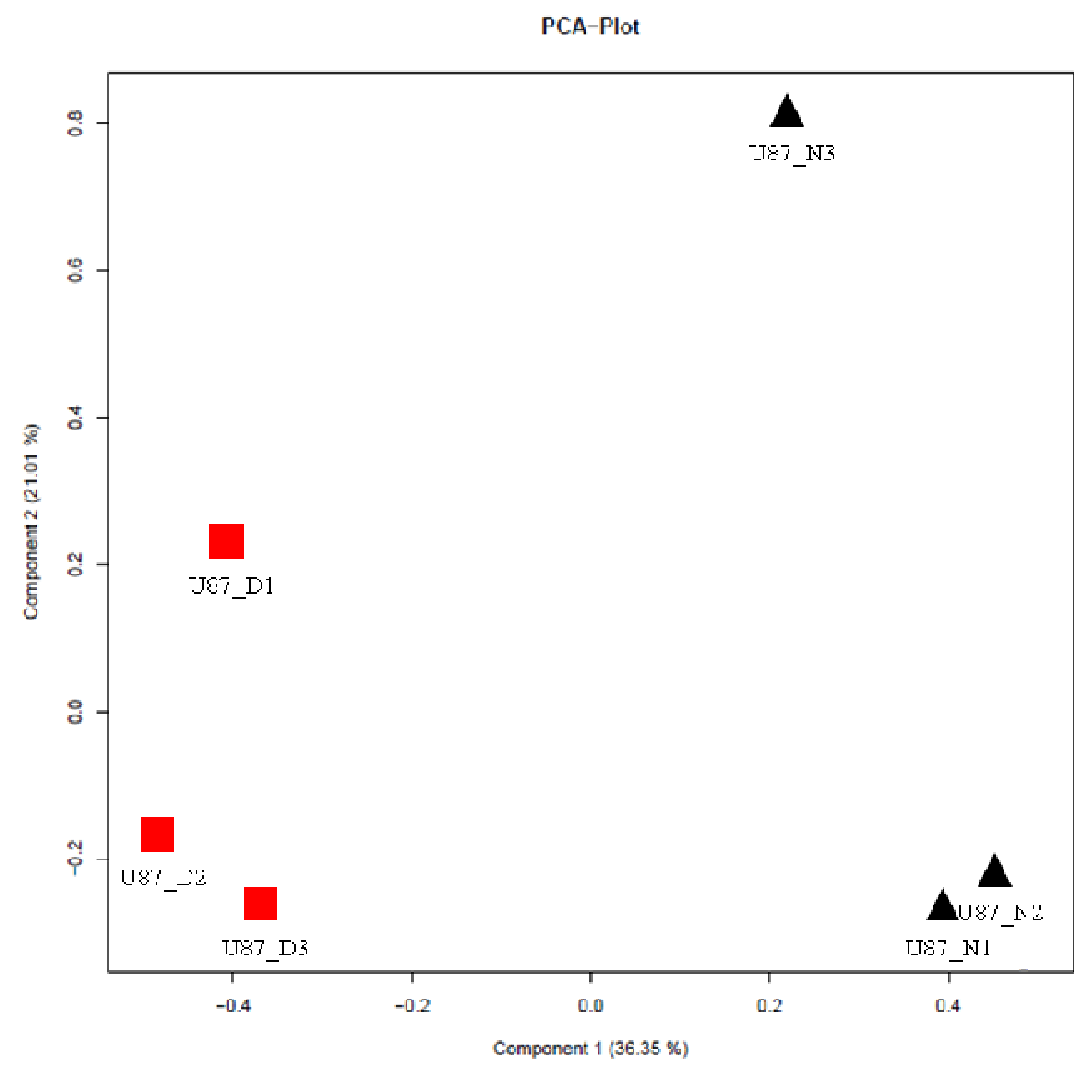

Abbildung 33: PCA-Plot der U87-N- und U87-D-Zellen

Die Triplikate der U87-N- (blau) und U87-D-Zellproben (rot) werden in einem 2D Plot aufgetragen und somit deren Expressionsunterschiede insgesamt dargestellt. 
Für weitere Analysen und um die Veränderungen in den Expressionsmustern bestimmten zellulären Prozessen zuordnen zu können, wurden die variierenden 188 Gene mithilfe des Bioinformatikprogrammes DAVID (Huang da et al. 2009) zellulären Prozessen zugeordnet. 134 der veränderten Gene konnten dabei insgesamt 6 zellulären Prozessen zugeordnet werden (siehe Tabelle 20). Die restlichen Gene waren zum Zeitpunkt der Messung noch nicht in die Datenbank des Programms integriert und konnten daher nicht eingeordnet werden. Aus der Verteilung der Gene, für die eine Einteilung möglich war, ergab sich, dass 59 Genen eine Funktion in Prozessen vielzelliger Organismen zukommt, 51 Gene spielen eine Rolle in entwicklungsbiologischen Prozessen und 30 Gene spielen eine Rolle in Lokalisierungsprozessen bzw. 27 Gene in der zellulären Organisation von ZellKomponenten. 13 Genen kommt eine Funktion in der Adhäsion und 7 Genen in Wachstumsprozessen zu. Die Namen der Gene und deren „Gene ID“ sind in Tabellen im Anhang zu finden.

Tabelle 20: Eingruppierung der veränderten Gene in zelluläre Prozesse Die veränderten Gene des Vergleiches der U87-N- mit den U87-D-Zellen wurden mithilfe des DAVIDBioinformatikprogrammes in zelluläre Prozesse eingeteilt. Die größten Gruppen sind in folgender Tabelle dargestellt.

\begin{tabular}{|c|c|}
\hline Zellulärer Prozess & Anzahl Gene \\
\hline Prozesse vielzelliger Organismen & 59 \\
\hline Entwicklungsbiologische Prozesse & 51 \\
\hline Lokalisierungsprozesse & 30 \\
\hline $\begin{array}{c}\text { Zelluläre Organisation der } \\
\text { Komponenten }\end{array}$ & 27 \\
\hline Adhäsion & 13 \\
\hline Wachstum & 7 \\
\hline
\end{tabular}




\subsubsection{Validierung veränderter Gene mittels realtime-PCR}

Aus den 188 differenziell exprimierten Transkripten, die mithilfe der Microarray-Analyse identifiziert wurden, wurden Gene zur Validierung mittels realtime-PCR ausgesucht. Diese Gene wurden unter Berücksichtigung der Funktion und des Zusammenhangs zu Adhäsion, Angiogenese oder Zellzyklus ausgewählt. Die Funktion sowie zugehörige Quellen ausgesuchter Gene werden in der Diskussion näher erläutert. Für die Validierung der ausgesuchten Kandidatengene wurden die gleichen RNA-Proben wie zuvor für die Microarray-Analyse verwendet. Abbildung 34 bis Abbildung 37 zeigen die Genexpressionsanalysen ausgewählter Gene, die in dieser Arbeit weiter analysiert wurden. Es sind jeweils die Triplikate pro Zelllinie aufgetragen, die mit 1 bis 3 gekennzeichnet sind. Die relative Expression der ersten Kontrollzelllinie (U87-N1) ist auf 1 gesetzt. Abbildung 34 zeigt die im Mittel 400fach höhere Expression des Transkriptes für das Zelladhäsions-Molekül 2.

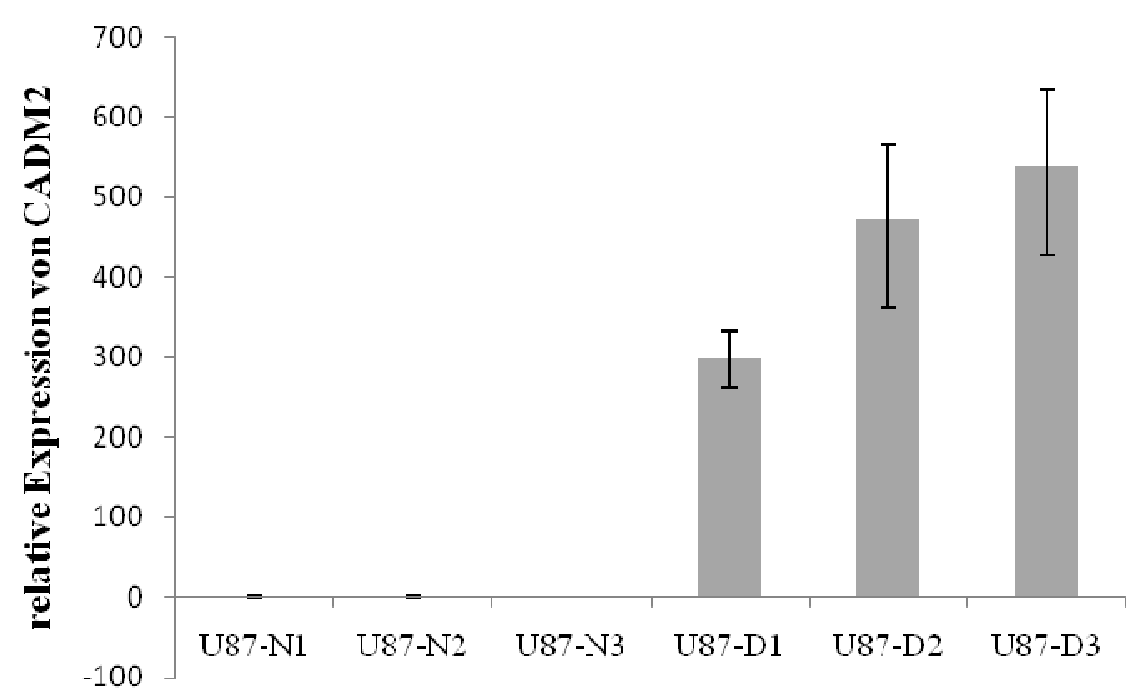

\section{Abbildung 34: realtime-PCR zum Nachweis von CADM2}

Die relative Expression des CADM2 Transkripts der Triplikate der Kontrollzellen (U87-N) und der U87-DZellen wurde bestimmt. Die Mittelwerte aus je drei Messungen in zwei unabhängigen Versuchen werden angegeben. Gezeigt werden die Mittelwerte einer Dreifachbestimmung mit Standardabweichung. 
In Abbildung 35 sind die relativen Expressionslevel des Integrin alpha 7 aufgetragen. In den Triplikaten der U87-D-Zelllinien kommt das Transkript im Mittel 3fach vor.

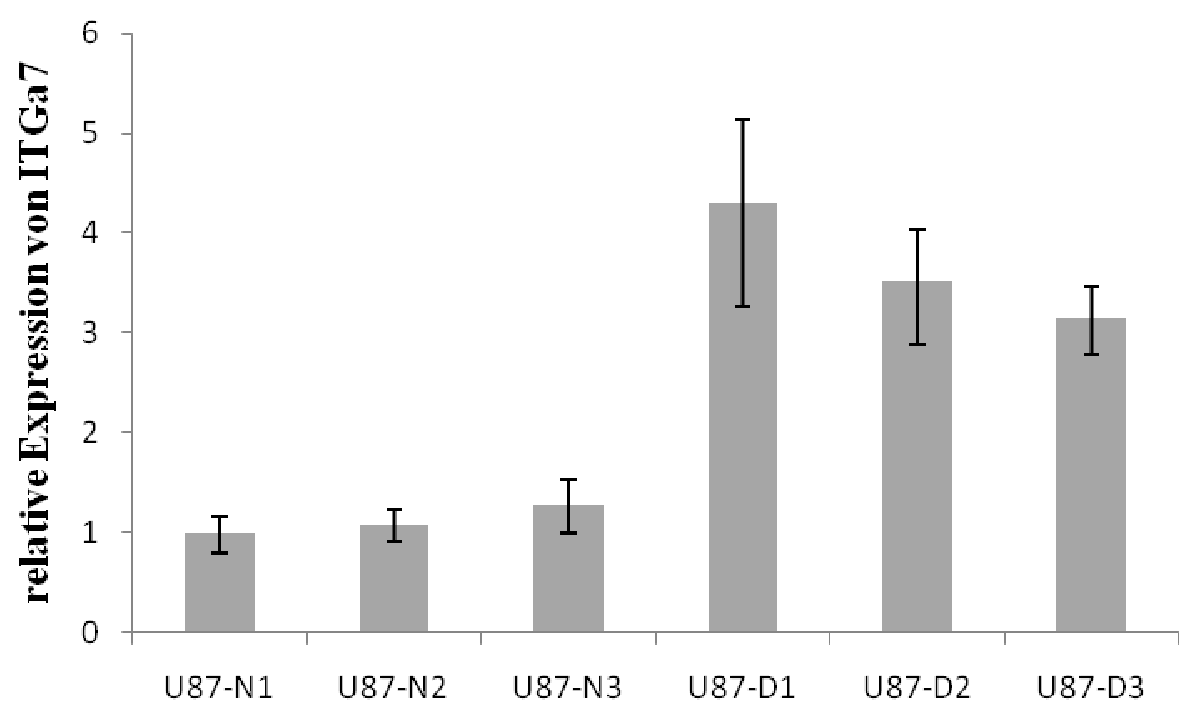

Abbildung 35: realtime-PCR zum Nachweis von Integrin alpha 7(ITGa7)

Die Abbildung zeigt die relative Expression des Integrin alpha 7 Transkripts der Triplikate der Kontrollzellen (U87-N) und der U87-D-Zellen. Die Mittelwerte aus je drei Messungen in zwei unabhängigen Versuchen werden angegeben. Gezeigt werden die Mittelwerte einer Dreifachbestimmung mit Standardabweichung.

Abbildung 36 hingegen zeigt die kaum nachweisbare Expression des Angiopoietins 2 in den U87-D-Zellen im Vergleich zu der Kontrollzelllinie. In Abbildung 37 ist im Mittel eine 4fache Expression von Vasohibin 2 in den U87-3D-Zellen im Vergleich zu den U87-NKontrollzellen zu sehen.

Für alle untersuchten Gene ließ sich der Trend der Expressionsänderung aus der Transkriptomanalyse der jeweiligen Gene verifizieren. 


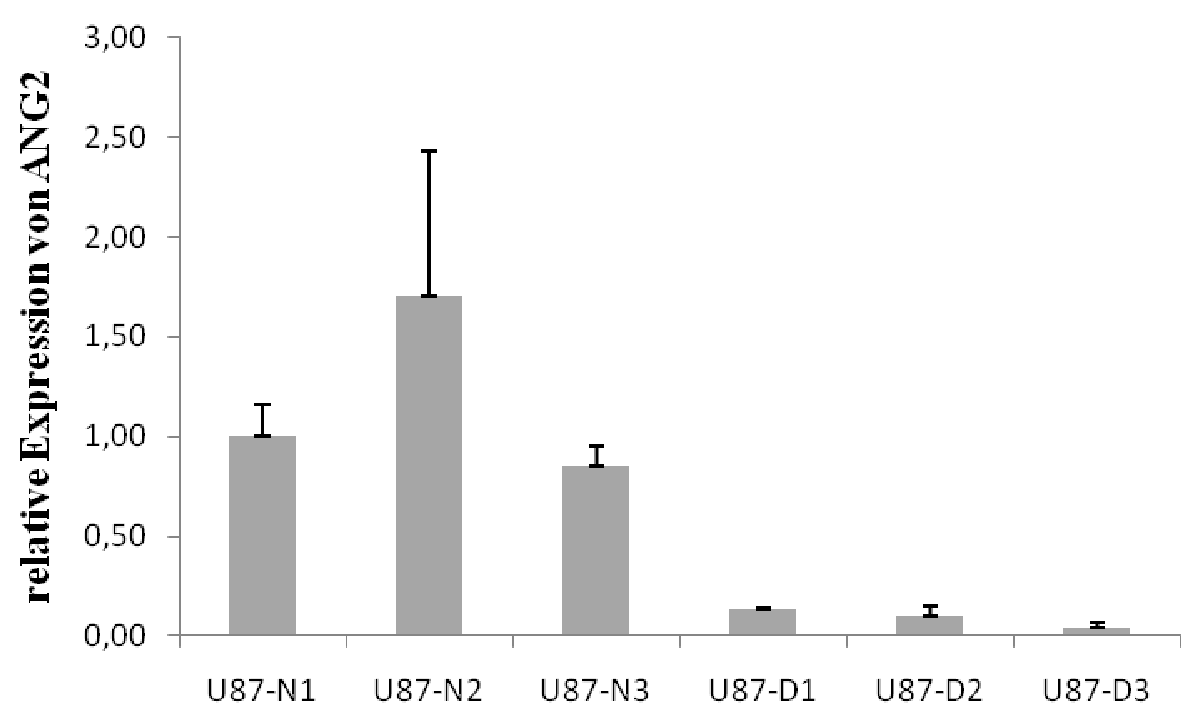

Abbildung 36: realtime-PCR zum Nachweis von Angiopoietin 2 (ANG2)

Die Abbildung zeigt die relative Expression des Angiopoietin 2 Transkripts der Triplikate der Kontrollzellen (U87-N) und der U87-D-Zellen. Die Mittelwerte aus je drei Messungen in zwei unabhängigen Versuchen werden angegeben. Gezeigt werden die Mittelwerte einer Dreifachbestimmung mit Standardabweichung.

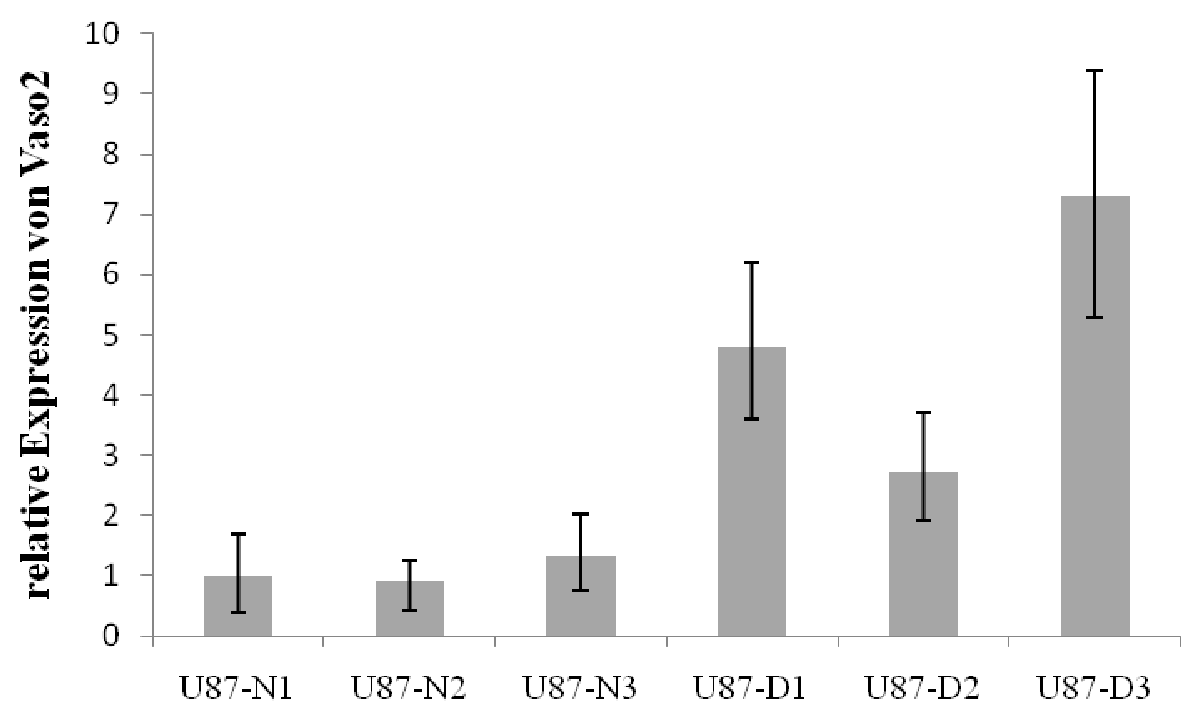

\section{Abbildung 37: realtime-PCR zum Nachweis von Vasohibin 2(Vaso2)}

Die Abbildung zeigt die relative Expression des Vasohibin 2 Transkripts der Triplikate der Kontrollzellen (U87N) und der U87-D-Zellen. Die Mittelwerte aus je drei Messungen in zwei unabhängigen Versuchen werden angegeben. Gezeigt werden die Mittelwerte einer Dreifachbestimmung mit Standardabweichung. 
Die in dieser Arbeit durchgeführten in Genexpressionsanalysen zum Einfluss der Klasse-3 Semaphorine auf Gliomzellen zeigen, dass

- die Transkripte von 188 Genen verändert werden.

- Adhäsion, Zellzyklus, Angiogenese und andere Netzwerke verändert vorliegen.

- die veränderten Transkripte mittels realtime-PCR validiert werden konnten. 


\section{Diskussion}

Neuropiline (Nrp) gehören zu den endothelialen Oberflächenrezeptoren und agieren als Rezeptoren für angiogene Faktoren aus der „Vascular endothelial growth factor" (VEGF)Familie, z.B. Semaphorine. Es konnte gezeigt werden, dass Sema3F die Tumorgefäßentwicklung hemmt und andere Klasse-3 Semaphorine, wie Sema3B, als direkte Hemmstoffe der Tumorzell-Proliferation beim kleinzelligen Bronchialkarzinom wirken (Varshavsky et al. 2008). Außerdem gibt es erste Hinweise, dass Neuropiline bei der Progression maligner Hirntumoren eine Rolle spielen (Haixia et al. 2010).

Da Hirntumoren bei Kindern besonders häufig sind und eine im Vergleich zu Leukämien schlechte Prognose aufweisen, sind neue Behandlungsmethoden notwendig, um das langfristige Überleben dieser Patienten zu verbessern. Wesentliches Ziel dieser Arbeit war es daher, die anti-angiogenen und anti-tumorösen Wirkungen von Klasse-3-Semaphorinen auf Hirntumorzelllinien in vitro und in Hirntumor-Modellen in vivo zu untersuchen. Um eine antiangiogene Wirkung nachzuweisen, wurden primäre Endothelzellen (HUVECs) mit Semaphorinen behandelt und eine Inhibierung der Proliferation nachgewiesen. Um zusätzlich einen möglichen Wirkmechanismus aufzuklären, wurde die Präsenz endothelialer Oberflächenrezeptoren nach Semaphorin-Behandlung untersucht und ein Einfluss auf den VEGFR-2 gezeigt. Da angenommen wird, dass Klasse-3 Semaphorine das Wachstum von Tumorzellen inhibieren, wurden Gliomzellen, die eben diese Proteine überexprimieren, intrazerebral in ein Mausmodell implantiert und das Wachstum über einen bestimmten Zeitraum beobachtet. Die Untersuchung zeigte eine Inhibierung des Tumorwachstums durch Klasse-3 Semaphorine und eine erhöhte Lebenserwartung der Mäuse nach Implantation der Zellen. Eine anti-tumoröse Wirkung der Semaphorine konnte zusätzlich durch eine Analyse mittels CAM-Assay bestätigt werden. In diesen Experimenten wurde außerdem eine Beeinflussung der Tumor-assoziierten Gefäßbildung nachgewiesen. Aufgrund dieser Ergebnisse wurden Microarray-Analysen durchgeführt, mit deren Hilfe ein Einfluss der Semaphorine auf die Expression von Genen, die mit Angiogenese, Entwicklung und Adhäsion assoziiert sind, bestätigt werden konnte. 
Die hier gewonnenen Erkenntnisse könnten in der Zukunft zur Entwicklung neuer Behandlungsansätze beitragen, die gezielt das Tumorwachstum im Gehirn inhibieren, im Idealfall den Tumor sogar eradizieren.

\subsection{Effekte der Klasse-3 Semaphorine auf Tumorzellen in vitro}

\subsubsection{Einfluss auf die Proliferation und den Zellzyklus}

Eine Überexpression von Sema3F in HEK293-Zellen inhibiert das Tumorwachstum in vivo, jedoch nicht die Proliferation in vitro (Kigel et al. 2008). Die Tumoren der Sema3Füberexprimierenden Zellen, die sich in dem Tiermodell formierten, wuchsen langsamer und besaßen weniger Tumor-assoziierte Blutgefäße als die Kontrolltumoren (Kessler et al. 2004). Diese Ergebnisse legen den Schluss nahe, dass der beobachtete Effekt auf einen Einfluss des Sema3F auf die Tumorangiogenese zurückzuführen seien könnte. In dieser Arbeit wurden daher die Auswirkungen von Semaphorinen auf HUVECs untersucht. Bei HUVECs handelt es sich um Endothelzellen, welche die Wände der inneren Blutgefäße der Nabelschnur auskleiden. Ein Effekt der Semaphorine auf die Proliferation der HUVECs könnte somit einen Einfluss der Semaphorine auf die Angiogenese andeuten. Die Ergebnisse der Experimente (siehe Abbildung 6) bestätigten den Effekt von Sema3F und zeigten, dass auch die Behandlung mit Sema3E einen ähnlichen Einfluss auf das Wachstum der HUVECs hat.

Dass Semaphorine einen Einfluss auf VEGF-vermittelte Signale haben, konnte ebenfalls von Catalano und Vacca demonstriert werden (Catalano et al. 2004; Vacca et al. 2006). Catalano et al. haben gezeigt, dass Sema3A eine zu VEGF antagonistische Wirkung hat, über die genauen molekularen Zusammenhänge ist allerdings nur wenig bekannt. Sema3A bindet an Nrp1/PlexinA1 und führt zu einer Phosphorylierung von spezifischen „downstream“-Zielen, wie der GTPase Rac-1 und der Glykogen-Synthase-Kinase (GSK)-3. Inwieweit diese Signale allerdings für die anti-angiogene Reaktion notwendig sind, bleibt unklar. Eine ebenfalls antiangiogene Wirkung des Sema3A im Vergleich zu VEGF wurde von Vacca et al. in Myelomzellen nachgewiesen und zeigte eine vergleichbare Wirkung wie ein anti-VEGFR-2Antikörper.

Um einen möglichen Effekt der Semaphorin-Behandlung auf molekularer Ebene zu untersuchen, wurden HUVECs mit Sema3F behandelt und die Oberflächenpräsentation von unterschiedlichen Integrinen und VEGFR-2 untersucht. Zuvor wurde postuliert, dass im Embryo die Entwicklung eines Blutgefäßnetzwerkes durch Integrin-Regulierung stattfindet. 
Zusätzlich wird die Entwicklung durch Wachstumsfaktoren und Semaphorine übermittelt (Bussolino et al. 2009).

In dieser Arbeit konnte ein Unterschied in der Präsenz des VEGFR-2 auf der Oberfläche der Zellen beobachtet werden, wobei die Semaphorin-behandelten Zellen weniger VEGFR-2 aufwiesen. Aus der Literatur ist bekannt, dass Nrp1 als Korezeptor für VEGF $_{165}$ die Affinität von VEGFR-2 erhöhen kann. VEGF-A induziert durch Aktivierung von VEGFR-2 die Proliferation und die Migration von Endothelzellen wie auch das Auswachsen und die Umstrukturierung bereits existierender Blutgefäße (Gale und Yancopoulos 1999). Somit ist VEGF von essentieller Bedeutung für die Angiogenese und Vaskulogenese. Entsprechend sterben Vegfa und Vegfr-2 Mausmutanten an 8,5 Tagen nach Implantation in utero aufgrund einer starken Reduktion der Bildung von Endothelzellen und einer fast vollständigen Inhibierung der Gefäßentwicklung (Shalaby et al. 1995). Ein Gleichgewicht von Sema3A und VEGF $_{165}$ reguliert in neuronalen Vorläuferzellen die Aktivität der Migration und Apoptose (Bagnard et al. 2001).

Da VEGFR-2 einer der Hauptrezeptoren der Angiogenese ist, könnte eine Verminderung seiner Präsenz auf der Oberfläche der HUVECs dazu führen, dass keine VEGF-Aktivierung über diesen Rezeptor gelingt und die Proliferation sowie Migration dieser Zellen stagniert.

Aufgrund, dass ein anwachsender Tumor auf die Versorgung durch Blutgefäße angewiesen ist, könnte dieser ebenfalls durch eine Verminderung des VEGFR-2 am Wachstum gehindert werden. Somit ergänzen die hier gewonnenen Daten, nämlich dass Sema3E das Wachstum von Endothelzellen inhibiert und dass eine Behandlung von Sema3F die Präsenz des VEGFR2 auf der Oberfläche der Zellen herabsetzt, das Bild einer anti-angiogenen Wirkung der Klasse-3 Semaphorine.

Die Überexpression von Sema3B und Sema3F in Lungenkrebszellen (NCI-H1299) führte zu einer Inhibierung des Zellwachstums und leitete die Apoptose in diesen Zellen ein (Tomizawa et al. 2001). Um zu prüfen, ob die Überexpression der Klasse-3 Semaphorine in Gliomzellen ebenfalls einen Effekt zeigt, wurde mithilfe eines Proliferations-Assays (WST-1) deren Wachstum verfolgt. Die Überexpression der Klasse-3 Semaphorine in U87MG-Gliomzellen zeigte nur minimale Veränderungen in deren Proliferation im Vergleich zu der Kontrollzelllinie. Zu einer der am schwächsten proliferierenden Zelllinien zählten U87-B und U87-F. Eine Inhibierung der Proliferation von 30-90 \%, wie es für die Lungenkrebszellen der Fall war (Tomizawa et al. 2001), konnte nicht beobachtet werden. Erstaunlicherweise zeigte 
die U87-D-Zelllinie, die in den in vivo-Versuchen am stärksten proliferierte, eine starke Inhibierung des Tumorwachstums im Tierversuch. Auch die Überexpression von Sema3D und Sema3E in U373MG-Zellen hatte keinen Effekt auf deren Proliferation. Die Beobachtungen von Castro-Rivera et al., dass die Überexpression von Klasse-3 Semaphorinen $\mathrm{zu}$ einer Inhibierung der Proliferation führt, ist somit nicht allgemein gültig, sondern kann je nach Zelltyp variieren (Castro-Rivera et al. 2004; Castro-Rivera et al. 2008). Der molekulare Mechanismus der Semaphorin-Wirkung auf die Proliferation der Tumorzellen muss jedoch noch charakterisiert werden, da hierzu keine Daten verfügbar sind.

In vitro konnte kein Einfluss auf die Proliferation der Gliomzellen durch Semaphorine festgestellt werden. Um zu prüfen, ob dieser Effekt Zellphasen bedingt ist, wurde der Einfluss der Semaphorin-Expression auf den Zellzyklus untersucht. Ein Arrest der Semaphorinexprimierenden Zellen in der G0/1-Phase, der Ruhephase, könnte eine Inhibierung des Tumorwachstums erklären, da die implantierten Zellen sich im Gehirn nicht weiter teilen würden und somit das Anwachsen eines Tumors verhindert werden würde. Die U87-D-Zellen befanden sich vorwiegend in der S- und G2-Phase, während nur ein geringerer Anteil in der G0/1-Phase zu finden war (siehe Abbildung 12). In der S-Phase befindliche Zellen zeichnen sich durch eine verstärkte Replikation der DNA und eine stärkere Proliferation aus, während sich die Zellen in der sich anschließenden G2-Phase auf die darauf folgende Mitose durch Abrundung und Vergrößerung vorbereiten. Die U87-D-Zellen, die sich vornehmlich in der SPhase befanden, proliferierten auch in vitro stärker als die U87-G-Zellen, von denen weniger in der S-Phase vertreten war. Somit stützt die Zellzyklusanalyse die Ergebnisse der Proliferationsmessungen in vitro. Nach intrazerebraler Implantation der Semaphorinüberexprimierenden Gliomzellen, zeigte sich jedoch eine Inhibierung des Tumorwachstums in vivo. Ein ähnlicher Effekt wurde in humanen malignen Mesothelzellen (MM-Zellen) gezeigt, hier führte eine dominant-negative Mutation in PlexinA1, dem Rezeptor des Sema3A, zu gesteigertem Zellwachstum (Catalano et al. 2004). Hier zeigte eine Überexpression des Sema3A in Gliomzellen eine minimale Inhibierung der Proliferation (siehe Abbildung 10) und bestätigt den beobachteten Effekt des Sema3A-Signaling auf das Zellwachstum von Mesothelzellen. Folglich konnte nicht nur der Effekt des Sema3A bestätigt werden, es konnte zusätzlich auch ein Einfluss auf eine andere humane Tumorzelllinie nachgewiesen werden. Im Jahr 2006 untersuchten Berndt und Kollegen den Effekt des Sema3D-knockdown in Bezug auf die Anzahl von neuroepithelialen Zellen in der S- oder G2/M-Phase durch 
„Immunolabeling“ in Zebrafischen (Danio rerio). Die Daten der Versuche ergaben, dass der „knockdown“ zu einem Arrest in der G1/G0-Phase führte (Berndt und Halloran 2006), was ebenfalls für eine zellzyklus-regulierende Funktion der Semaphorine und ihrer Signalwegspartner sprechen würde.

\subsubsection{Einfluss auf die Adhäsion und die Migration}

Während der Angiogense wird die Migration von Endothelzellen durch die Aktivität von Integrinen, z.B. durch VEGF reguliert (Martin-Bermudo et al. 1998; Kiosses et al. 2002), und es wurde beobachtet, dass Sema3A und Nrp1 mit $\alpha v \beta 3$-Integrinen co-lokalisieren (Serini et al. 2003). Exprimieren Endothelzellen dominant-negatives Nrp1 oder PlexinA1, zeigen diese Zellen eine erhöhte Migrationsbereitschaft. Sema3A kann als autokrines Signal die Migration von Endothelzellen durch die Aktivität von Integrinen regulieren. Bisher gibt es jedoch keine Beweise, dass Integrine mit dem Sema3A/Nrp-Komplex einen stabilen Verbund bilden. Die Regulation der Integrin-vermittelten Adhäsion spielt auch beim Sema3A-vermittelten Kollaps des Wachstumskegels eine wichtige Rolle (Mikule et al. 2002) und könnte damit neben den Effekten auf Aktinfilamente eine generelle Reaktion auf Semaphorine darstellen.

Die Untersuchungen des Migrationsverhaltens der U87-N-, U87-D- und U87-G-Zellen zeigte, dass die Kontrollzellen deutlich stärker migrierten, als die Semaphorin-überexprimierenden Zellen. Das Migrationsverhalten der U87-G-Zellen war um 50\%, das der U87D-Zellen um 75\% reduziert. Es ist somit ein deutlicher Einfluss von Sema3G und Sema3D auf die Migrationsbereitschaft der Zellen zu erkennen. Für Sema3F und Sema4D konnte bereits gezeigt werden, dass sie die Zellmigration beeinflussen. Eine Sema3F-Überexpression in MCF7-Brustkrebszellen führte zu einer verminderten Zellanheftung sowie Ausbreitung der Zellen durch Verlust der Fähigkeit der Lamellipodienerweiterung (Nasarre et al. 2003). MausFibroblasten (NIH-3T3), die mit Sema4D transfiziert worden waren, zeigten eine Auflösung der durch Integrine vermittelten fokalen Adhäsion wenige Minuten nach Plexin-Aktivierung, gefolgt von einer Aktin-Depolymerisation und einem zellulären Kollaps. Zusätzlich konnte eine Anheftung der Zellen an adhäsive Substrate durch eine Plexin-Aktivierung verhindert werden (Oinuma et al. 2004).

Ergänzend zum Migrationsverhalten der Gliomzellen wurde daher auch deren Fähigkeit untersucht, an adhäsive Substrate zu binden. Im Falle der U87-D-Zellen, die zuvor eine 
verminderte Migration im Vergleich $\mathrm{zu}$ der Kontrollzellline aufwiesen, zeigte sich ein verstärktes Adhäsionsverhalten. So hefteten sich die U87-D-Zellen im Mittel 20-40\% stärker an die ECM-Proteine als die Kontrolle und die U87-G-Zellen. Die Matrixproteine Fibronectin, Collagen I und IV und Laminin I spielen eine Rolle bei der Anheftung der Zellen an andere Zellverbände, sollen aber auch zusätzlich bei der Anheftung von Metastasen beteiligt sein. So zeigte eine gesteigerte Fibronectin-Expression in Lungenkrebszellen (SPCA-1 Zellen) eine stärkere Bereitschaft der Zellen, Metastasen zu bilden (Jia et al. 2010).

In den Migrationsversuchen konnte ein deutlicher Unterschied zwischen den U87-N- und -GZellen einerseits, sowie den U87-D-Zellen andererseits gesehen werden. Die Adhäsion der Zellen war ebenfalls verändert und ergänzt die Daten der Migrationsuntersuchungen. Daraus kann gefolgert werden, dass die U87-D-Zellen, welche das stärkste Adhäsionsverhalten aufweisen, auch die geringste Migrationsbereitschaft zeigen. Die Invasivität dieser Zellen wäre weniger stark ausgeprägt, was das reduzierte Tumorwachstum erklären könnte. Die Ergebnisse des Migrations-Assays spiegeln die Ergebnisse von Pan et al. wieder, die zeigten, dass Brustkrebszellen, die mit Sema3A inkubiert wurden, erhöhte Mengen an a2- und b1Integrinen aufwiesen und das Anheftungsvermögen der Tumorzellen an Collagen I erhöht war (Pan et al. 2009). Generell wurden für Gliomzellen erhöhte Integrin-Mengen im Vergleich zu normalen Astrozyten gemessen (Friedlander et al. 1996).

$\mathrm{Zu}$ den besonderen Funktionen der Gliomzellen zählt die Eigenschaft, sich ihre Umgebung nach ihren Bedürfnissen zu gestalten. So können sie ihre eigenen ECM-Komponenten, wie Laminine, synthetisieren und diese ihrer Motilität anpassen (Giese et al. 1994). Viele der Aktionen zwischen Gliomzellen und ECM- Komponenten werden durch Adhäsionsmoleküle vermittelt. Prominente Vertreter dieser Moleküle sind die Integrine (Pierschbacher und Ruoslahti 1984). Zusätzlich spielen Integrine auch eine Rolle in der Angiogenese und bei apoptotischen Prozessen (Mattern et al. 2005).

\subsubsection{Einfluss auf die Apoptose}

Castro-Rivera et al. zeigten, dass eine Überexpression von Sema3B in Lungen- und Brustkrebszellen Apoptose einleiten kann. Dieser Effekt kann auch beobachtet werden, wenn das Semaphorin als löslicher Ligand dem Medium zugesetzt wird. Im Gegensatz dazu wird durch Zugabe von VEGF $_{165}$ die Induktion der Apoptose signifikant vermindert (Castro-Rivera et al. 2004). Auch für Sema3F konnte gezeigt werden, dass es die Apoptose in 
Ovarialkrebszellen (HEY-Zellen) induzieren kann (Xiang et al. 2002). Da die Mitglieder der Semaphorin-Proteinfamilie bei vielen physiologischen Vorgängen gegensätzliche Effekte vermitteln können, ist es nicht überraschend, dass Semaphorine auch unterschiedliche Rollen bei der Apoptose-Induktion übernehmen können. Schon 1999 konnte für Sema3A, welches Collapsin genannt wurde, beobachtet werden, dass es in neuronalen Zellen durch Induktion der Apoptose einen Kollaps der Wachstumskegel bewirkt. Die Ergebnisse zeigten, dass eine Korrelation zwischen Apoptose-Induktion und dem Pulsieren der Wachstumszentren der Neuronen durch die Expression von Collapsin-1 besteht (Shirvan et al. 1999). Bestätigt werden konnte auch ein Einfluss von Sema3E auf Axone der Netzhaut (Steinbach et al. 2002). In dieser Arbeit wurde nachgewiesen, dass weder die Behandlung der Gliomzellen mit rekombinanten Semaphorinen, noch die Überexpression dieses Proteines in den Zellen zur Apoptose führt. Die in anderen Arbeiten viel untersuchten Sema3B und Sema3F zeigten überexprimiert in den untersuchten Gliomzellen keinen Unterschied in ihrer Fähigkeit, Apoptose $\mathrm{zu}$ induzieren, im Vergleich $\mathrm{zu}$ den anderen Semaphorin-überexprimierenden Zellen. Mithilfe einer Western Blot-Analyse konnte in den Proben der transfizierten U373MG- und U87MG-Zellen keine Proteolyse der Pro-Caspase-3, der Effektorcaspase, in ihre Spaltprodukte dokumentiert werden. Auch mithilfe des quantitativen „Cell Death Detection ELISA“ konnten keinerlei Veränderungen der Zellen nachgewiesen werden. Die transfizierten Gliomzelllinien wiesen untereinander keine Unterschiede auf, sondern zeigten nur die natürlich vorkommende Basisapoptose der Zellen. Zur Kontrolle wurde eine mikroskopische Bestimmung mittels Hoechst-Färbung gewählt, um eine Apoptose auszuschließen. Dabei zeigten sich abermals keine apoptotischen Veränderungen der Zellen (Daten nicht gezeigt). Somit konnte durch verschiedene Methoden, die in der Lage sind, Indikatoren für eine Apoptose auf unterschiedlichen Ebenen nachzuweisen, deutlich gezeigt werden, dass die Transfektion der Gliomzellen mit Klasse-3 Semaphorinen, im Vergleich zu den Lungen-, Brust- und Ovarialkrebszellen, nicht zur Induktion der Apoptose führt.

\subsection{Effekte der Klasse-3 Semaphorine auf Tumorzellen in vivo}

\subsubsection{Einfluss auf intrazerebrale Tumoren}

Die Expression von Semaphorinen führte zu Änderungen im Adhäsions- sowie Migrationsverhalten von Gliomzellen und zeigte zudem Effekte auf deren Zellzyklus. Da in 
Brustkrebszellen bereits eine Inhibierung des Tumorwachstums durch Semaphorine nachgewiesen werden konnte (Kigel et al. 2008), wurden die Semaphorin-exprimierenden Gliomzellen intrazerebral in ein Mausmodell gebracht, um das Wachstum der Zellen in vivo untersuchen zu können. Vorversuche, in denen die Gliomzellen subkutan in ein Mausmodell implantiert wurden, zeigten Wachstumsunterschiede der Semaphorin-überexprimierenden Zellen (Daten nicht gezeigt). Die Implantation der humanen Gliomzellen in das Mausgehirn sollte einen direkten Einfluss der Semaphorine auf das Gehirntumorwachstum zeigen, deshalb wurde dafür ein Mausmodell ohne T-Zell-Immunantwort verwendet. Dieser Tierversuch sollte auch Aufschluss darüber geben, ob die Semaphorin-Expression in vivo andere Effekte zeigt, als zuvor in vitro beobachtet.

Die Biolumineszenzmessung ist eine schnelle, überzeugende und sichere Methode, um das Wachstum von Tumoren zu verfolgen (Zabala et al. 2009). In den Versuchen zeigte sich ein deutlicher Wachstumsunterschied der Semaphorin-exprimierenden Zellen im Vergleich zu den Kontrollen im Mausgehirn. Die Kontrollzellen (U87-N und U373-N) führten intrazerebral zu starken Biolumineszenzsignalen. Die Zellen, die Semaphorine überexprimierten, zeigten dagegen sehr geringe bis keine Signale. Als Ausnahme stellten sich die U87-G- Zellen heraus, deren Signale jedoch weniger stark als die Signale der Kontrollzellen waren. Durch eine Färbung des Gehirngewebes mit Hämalaun und Eosin nach Beendigung des Versuchs zeigte sich, dass die anhand der Biolumineszenzsignale antizipierte Tumorausdehnung mit der tatsächlichen Tumorgröße übereinstimmt. Je stärker das gemessene Biolumineszenzsignal in der Maus, desto größer war auch der angefärbte Tumorbereich in den Schnitten. Konnten zuvor in den Biolumineszenzmessungen keine Signale detektiert werden, konnten auch keine entarteten Zellen in den Schnitten nachgewiesen werden. Diese Ergebnisse stimmen mit anderen Beobachtungen überein, da im Allgemeinen Korrelationen sowohl zwischen der implantierten Zellzahl und der Biolumineszenz-Signalstärke (Van Gool et al. 2009), als auch zwischen der Biolumineszenz-Signalstärke und einer MRT-Messung (Ragel et al. 2008) beobachtet werden können. Die Signalstärke eines Tumors steigt an, je größer der Tumor in seinen Ausmaßen ist (Vooijs et al. 2002).

Die Versuche der Biolumineszenzmessungen wurden spätestens einen Monat nach Implantation der Zellen beendet. Um die Auswirkungen der überexprimierten Semaphorine auf das Gehirntumorwachstum über einen längeren Zeitraum zu beobachten, wurden U87-N-, -D- und -E-Zellen sowie U373-N-, -D- und -E-Zellen implantiert und Überlebenszeitanalysen 
durchgeführt. Die Sema-D- und -E-exprimierenden Zellen wurden ausgewählt, da mit diesen Zellen die stärkste Inhibierung des Tumorwachstums erzielt werden konnte. Es zeigte sich deutlich, dass die Kontrollmäuse im Vergleich zu den anderen Mäusen eher verstarben. Zusätzlich wiesen die Kontrollen große Hirntumoren auf. Die Semaphorin-exprimierenden Zellen führten erneut zu einer Verminderung des Tumorwachstums. Die Größe des resultierenden Gehirntumors korreliert somit auch mit der Sterblichkeit der Mäuse. Die Semaphorine besitzen also einen positiven Einfluss auf das Überleben der Hirntumortragenden Mäuse.

Es zeigte sich auch, dass die Mäuse, denen U373-N-Zellen implantiert worden waren, länger lebten als nach einer U87-N-Implantation. Die U87-N-Zellen scheinen sich schneller und invasiver in einem kürzeren Zeitraum in dem Gehirn auszubreiten. Die Unterschiede in dem Tumorwachstum der Kontrollzellen können durch ihre Herkunft bedingt sein. So stammt die ursprüngliche U87MG-Zelllinie aus einem Grad IV Astrozytom einer 44jährigen Frau, während U373MG-Zellen aus einem Grad III Tumor eines 61jährigen Mannes stammen (Ponten und Macintyre 1968). Das Wachstum eines höher gradigen Tumors ist in der Regel schneller (Bocking et al. 1982). Die Zellen, die aus diesen Tumoren isoliert worden waren, zeigten auch in Proliferationsuntersuchungen dieselbe Tendenz (siehe Abbildung 26 und Abbildung 28).

Die in dieser Arbeit ermittelten Daten unterstützen die Vermutung, dass zwischen Semaphorinen und Tumorwachstum eine Verbindung besteht (Coma et al. 2010). Einen weiteren Hinweis für diese Vermutung liefert die Tatsache, dass Sema3F in der humanen Chromosom-Region 3p21.3 eingeordnet ist, die im Allgemeinen in Lungentumoren abwesend ist und somit höchstwahrscheinlich eine Rolle bei der Tumorproliferation spielt (Roche et al. 1996; Sekido et al. 1996) .

Eine Inhibierung des Tumorwachstums durch eine Semaphorin-Expression konnte auch von Tse et. al in BALB/c nu/nu Mäusen nach der Implantation von Sema3B exprimierenden „Human ovarian carcinoma“ (HEY)-Zellen beobachtet werden (Tse et al. 2002). Die resultierenden Tumoren waren deutlich kleiner als die Kontrolltumoren, allerdings lag auch die Proliferation der Sema3B exprimierenden HEY-Zellen in vitro inhibiert vor. Auch die Ergebnisse von Xiang et al. konnten deutlich eine anti-tumoröse Wirkung der Semaphorine zeigen. Die Expression von Sema3F in der murinen Fibrosarkoma Zelllinie A9 resultierte nach der Injektion der Zellen in Schultern von BALB/c nu/nu Mäusen in einer fast 
vollständigen Inhibierung des Tumorwachstums. Ähnliche Ergebnisse konnten auch mit der humanen HEY-Zelllinie erzielt werden. Im Kontrast dazu blieb die kleinzellige Lungenkrebszellinie GLC45 von der Sema3F-Expression unberührt (Xiang et al. 2002).

Sakurai et al. konnten zeigen, dass Sema3E anti-angiogene Eigenschaften besitzt und diese über die Regulation von Arf6 und R-Ras vermittelt werden (Sakurai et al. 2010). Aus diesem Grund wurden in den Schnitten der untersuchten Gehirne zusätzlich Blutgefäße mittels van Willebrand-Färbung (spezifisch für Endothelzellen) markiert. Die untersuchten Schnitte zeigten eine hohe Anzahl Blutgefäße in den Schnitten der Kontrolltumoren und nur sehr wenige in den Gehirnschnitten der U87-D- und U87-E-Implantationsgruppen. Somit zeigten die Schnitte, in denen große Tumoren nachgewiesen werden konnten, auch eine hohe Anzahl an Blutgefäßen. Die Gehirne, in denen kein Tumorwachstum nachgewiesen werden konnte, besaßen die normal vorkommende Anzahl an Gefäßen. Es könnte also ein Zusammenhang zwischen dem Tumorwachstum und der Blutgefäßversorgung in vivo bestehen. Allerdings könnten sich eine geringe Blutgefäßanzahl und ein kleiner Tumor gegenseitig herbeiführen, weshalb nicht mit Bestimmtheit gesagt werden kann, dass das geringe Wachstum Folge der anti-angiogenen Wirkung des Semaphorins ist. Für genauere Untersuchungen könnten Semaphorin-exprimierende Zellen erneut in ein Mausmodell implantiert und im täglichen Rhythmus Gehirne für weitere Untersuchungen entnommen werden. Mit speziellen Antikörpern könnte so die Wirkung auf die Angiogenese noch besser untersucht werden.

Das Wachstum der transfizierten U87MG-Zelllinien in vivo unterscheidet sich deutlich von der Proliferation in vitro. In vivo war ein deutlicher Effekt zu sehen, da nur die Kontrollzellen und U87-G-Zellen anwuchsen, während in vitro keine Wachstumsunterschiede zwischen U87-N- und U87-D-Zellen zu beobachten waren.

Die U87MG-Zellen, die Sema3A, -B, -E, und -F exprimierten, wuchsen in vitro weniger stark an, waren aber nicht apoptotisch. Die U87-G-Zellen allerdings wuchsen in vitro und in vivo weniger stark an als die Kontrollzellen. Die Semaphorin-überexprimierenden U373MGZellen zeigten in vitro keine Wachstumsunterschiede, allerdings wuchsen erneut nur die Kontrollzellen in vivo zu einem Tumor heran. Dieses Phänomen, dass in vitro und in vivo Unterschiede im Zellwachstum vorkommen können, wurde auch schon von Camphausen et al. beobachtet. Es zeigte sich, dass es Wachstumsunterschiede sowohl zwischen Zellkulturversuchen und subkutanen Implantationen, als auch zwischen subkutanen und intrazerebralen Versuchen gab (Camphausen et al. 2005). Somit wird auch hier die Bedeutung 
von in vivo-Experimenten, die das Umfeld und Zusammenspiel der Tumorumgebung berücksichtigen, deutlich.

Diese Ergebnisse zusammen vermitteln das Bild, dass die Semaphorine Einflüsse auf die Angiogenese, die Adhäsion und die Migration der Tumorzellen besitzen und somit das Tumorwachstum inhibieren. Denkbar wäre, dass die Semaphorin-exprimierenden Zellen in vivo durch verstärkte Adhäsion der Zellen in einem engen Zellverbund bleiben, wodurch ein Migrieren der Zellen in das umliegende Gewebe verhindert werden könnte. Untermauert wird dies durch die Experimente mit U87-D-Zellen, die ein erhöhtes Adhäsionsverhalten zeigten, und zudem im Vergleich zu den Kontrollzellen auch weniger stark migrierten. Zusätzlich könnte die Aktivität der Semaphorine dazu führen, dass die Proliferation der Endothelzellen inhibiert und dadurch der anwachsende Tumor nicht ausreichend mit Nährstoffen versorgt wird. Somit zeigen die Ergebnisse deutlich, dass die Aktivität der Semaphorine durch einen Einfluss auf die Adhäsion, Migration und Angiogenese das Tumorwachstum hemmt.

\subsubsection{Einfluss auf das Tumorwachstum auf einer CAM}

Analysen der Semaphorin-Rezeptoren zeigten, dass diese Proteine nicht nur eine Rolle bei der Ausbildung des Nervensystems, sondern auch bei der Entwicklung von Blutgefäßen spielen (Behar et al. 1996). Die Rezeptoren Nrp1 und Nrp2 dienen, zusätzlich zu ihrer Aufgabe als Semaphorin-Rezeptoren, auch als Rezeptoren für VEGF $_{165}$ und können mit den VEGFRezeptoren interagieren (Fantin et al. 2009). Eine Nrp1-Überexpression in transgenen Tieren führte z.B. zu einer verstärkten Blutgefäßbildung im Nervensystem (Kitsukawa et al. 1997). Nrp-1 defiziente Mäuse hingegen zeigten eine verminderte Anzahl an Blutgefäßen im ZNS und starke Defekte bei der Angiogenese (Kawasaki et al. 1999). Mäuse, denen beide funktionellen Neuropiline fehlten, bildeten keine Blutgefäße aus und ihr Phänotyp glich dem einer Maus ohne VEGFR-2. Diese Ergebnisse belegen die Bedeutung der Neuropiline während der Entwicklung des Blutgefäßsystems (Shalaby et al. 1995; Takashima et al. 2002). In dieser Arbeit konnte gezeigt werden, dass durch eine Semaphorinbehandlung das Wachstum von HUVECs inhibiert und die Anzahl des VEGFR-2 auf der Oberfläche der Zellen reduziert wird (siehe Abbildung 7). Daher stellte sich nun die Frage, ob es durch die Semaphorinexpression in den Gliomzellen nach Implantation in Tiermodelle ebenfalls zu einer Veränderung der Angiogenese in Geweben um die Tumoren kommen würde. Ein weiterer Gesichtspunkt, der untersucht und bestätigt werden sollte, war der Einfluss der 
Semaphorine auf das Tumorwachstum in einem weiteren in vivo-Modell. Durch Folkman et al. wurde bereits 1975 die CAM als Tumormodell in der Angiogeneseforschung für humane Tumorzellen genutzt (Ausprunk et al. 1975). Dieses Modell bietet viele Vorteile. Zum einen ist ein Effekt oder Anwachsen der Tumorzellen bereits nach einigen Tagen sichtbar, zum anderen besitzt das Hühnerküken noch kein voll ausgebildetes Immunsystem, wodurch die CAM im Grundsatz immuninkompetenten Mäusen entspricht. Allerdings stellt die kurze Zeitspanne, in der ein Versuch durchgeführt werden kann, auch ein Problem dar, da manche langsam proliferierenden Zellen oder Behandlungsstrategien nicht getestet werden können.

Die ersten Ergebnisse dieser Versuche zeigten, dass U373MG-Zellen deutlich besser auf der CAM anwuchsen als U87MG-Zellen, weshalb diese Ziellinie für die Versuchsdurchführung ausgewählt wurde. Wie bereits im Mausmodell, konnte auch in diesen Versuchen ein deutlicher Einfluss von Semaphorinen auf das Zellwachstum beobachtet werden. Die U373$\mathrm{N}$-Zellen bildeten innerhalb einer Woche Tumoren auf der CAM, die mit einer großen Anzahl an Blutgefäßen versorgt wurden. Im Gegensatz dazu wuchsen die U373-D-Zellen nicht zu Tumoren heran. Nach einer Woche zeigten sich nur abgestorbene Zellreste auf der CAM, die nicht mit assoziierten Blutgefäßen verbunden waren. Im CAM-Assay konnte somit ein inhibierender Effekt der Semaphorine auf die Tumorbildung bestätigt werden. Da das beschränkte Tumorwachstum mit einer deutlichen Verminderung der versorgenden Blutgefäße einherging, stützt dieses Experiment prinzipiell die Vermutung einer antiangiogenen Wirkung der Semaphorine. Es bleibt jedoch festzustellen, ob es sich bei der geringeren Bildung von Blutgefäßen um einen direkten Effekt der Semaphorin-Wirkung handelt, oder ob eine verminderte Blutgefäßbildung vorliegt, da die Tumoren selbst schlecht proliferieren.

\subsection{Effekte der Klasse-3 Semaphorine auf die Genexpression}

Bis zu diesem Zeitpunkt lag keine Analyse zur transkriptionellen Veränderung von Genen in Tumorzellen vor, die Semaphorine überexprimieren. Besonderes Augenmerk wurde auf Faktoren gelegt, welche die Unterschiede der Semaphorin-überexprimierenden Zellen in Bezug auf das Tumorwachstum erklären könnten. Es wurden Veränderungen in der Expression von Genen erwartet, die z.B. in Zusammenhang mit der Angiogenese stehen. Die U87-N-Zellen, und in geringerem Ausmaß die U87-G-Zellen, zeigten in vivo eine deutliche Proliferation, während die Expression des Sema3D zu einer Inhibierung des Tumorwachstums 
führte. Es wurde daher nach Expressionsunterschieden gesucht, die sowohl im Vergleich der Kontrolle zu U87-D-, als auch zu U87-G-Zellen auftraten, um mögliche Kandidaten für die Wachstumsinhibierung einzugrenzen. Die Analyse der Microarray-Proben ergab keine signifikanten Unterschiede in der Genexpression zwischen der U87-N- und U87-G-Zelllinie, mit Ausnahme des überexprimierten Sema3G. In der U87-D-Zelllinie jedoch wurden 188 Veränderungen im Genmuster gefunden. Von diesen veränderten Transkripten lagen 119 hoch- und 69 herunter-reguliert vor. Für weitere Analysen und um einen Überblick über die Funktion dieser veränderten Gene zu bekommen, wurden diese mithilfe des Bioinformatikprogrammes DAVID (siehe Tabelle 14) in molekulare Netzwerke eingeteilt. 134 der 188 veränderten Gene konnten sechs unterschiedlichen zellulären Prozessen zugeordnet werden, die restlichen Gene waren zum Zeitpunkt der Messung noch nicht in die Datenbank des Programms integriert und konnten daher nicht eingeordnet werden. Die Netzwerke der Gene reichten von Vorgängen der Adhäsion bis hin zu Entwicklungsprozessen der Zelle (siehe Tabelle 20). Es wurden zudem Änderungen von Transkripten festgestellt, die mit Effekten auf die Angiogenese in Zusammenhang gebracht werden können. Anhand dieser Daten wurde eine Auswahl an veränderten Transkripten getroffen, die einen direkten oder indirekten Einfluss auf das Tumorwachstum besitzen können, um deren Änderungen mittels realtime-PCR zu validieren. Da zuvor Effekte auf die Adhäsion, Migration und Angiogenese in Klasse-3 überexprimierenden Gliomzellen gezeigt werden konnten, wurden für die Validierung Transkripte aus diesen Bereichen gewählt. Verifiziert wurden die Änderungen der Expression des Zelladhäsionsmoleküls 2 (CADM2), Integrin alpha 7 (ITGa7), Angiopoietin 2 und Vasohibin 2.

Das Zelladhäsionsmolekül 2 gehört zu einer großen Immunglobulin-Superfamilie und eine der Hauptaufgaben dieses Faktors liegt in der Vermittlung der Adhäsion von Synapsen im ZNS. Desweiteren konnte für diesen Faktor eine Funktion als Tumorsuppressor nachgewiesen werden (Kuramochi et al. 2001; Pletcher et al. 2001; Biederer 2006). Es bleibt zu klären, ob CADM2 auch in Gliomzellen die Funktion eines Tumorsuppressors zukommt, oder ob es sich sogar um einen universellen Tumorsuppressor handelt.

So konnte beispielsweise in der OV-90 Eierstockkrebs-Zelllinie ein 12 Gene umfassender „tumor suppressor gene locus“ identifiziert werden, dem auch das Gen für CADM2 angehört. Einige der Gene dieses Locus führten, überexprimiert in OV-90 Zellen und in ein immuninkompetentes Mausmodell implantiert, $\mathrm{zu}$ einer kompletten oder teilweisen 
Unterdrückung des Tumorwachstums (Cody et al. 2007; Cody et al. 2009). In den Proben der U87-D-Zellen lag das Transkript für CADM2, ermittelt durch realtime-PCR-Analyse, im Vergleich zu der Kontrolle in 13fach höherer Menge vor. Dieses Ergebnis befindet sich im Einklang mit den zuvor beobachteten Änderungen des Migrations- und Adhäsionsverhalten der U87-D-Zellen und gibt erste Anhaltspunkte für eine Erklärung des Effekts auf molekularer Ebene. Um den direkten Einfluss von Sema3D auf CADM2, das AktinZytoskelett und die Migration in Gliomzellen nachzuweisen und den beobachteten Effekt zu bestätigen, bedarf es jedoch weiterer Untersuchungen. So wäre es äußert informativ, den Effekt einer CADM2-Überexpression auf das Tumorwachstum, sowie auf die Migration und Adhäsion der Gliomzellen mit den beobachteten Effekten für Sema3D zu vergleichen. Ein Zusammenspiel von Semaphorinen und Zelladhäsionsmolekülen wurde bislang im ZNS von Säugetieren gesehen. Dort gehören Zelladhäsionsmoleküle zu den wachstumsfördernden und Semaphorine zu den inhibierenden Faktoren des Gewebes (Giger et al. 2010). Ein direkter Einfluss auf das Tumorwachstum konnte allerdings bisher nicht gezeigt werden.

Ein weiteres Transkript, das mittels realtime-PCR verifiziert wurde, war Integrin alpha 7 (ITGa7), da bekannt ist, dass Integrine Einfluss auf die Adhäsion, Invasion sowie Motilität von Zellen nehmen (Lefranc et al. 2005). Auch konnte gezeigt werden, dass die Integrine $\alpha 3 \beta 1, \alpha v \beta 1, \alpha v \beta 3$, und $\alpha v \beta 5$ eine zentrale Rolle in der Migration von Astrozyten spielen und dass die Integrin-Untereinheiten $\beta 4$ und $\beta 5$ direkten Einfluss auf das Migrationsverhalten von Gliomzellen ausüben (Belot et al. 2001). In Studien von Fukushima et al. wurde demonstriert, dass ein monoklonaler Antikörper gegen das Integrin $\alpha 3 \beta 1$ die Migration der Astrozyten auf Laminin reduziert (Fukushima et al. 1998).

In den U87-D-Zellen, die ein reduziertes Migrations- und Adhäsionsverhalten zeigten, wurde das Integrin ITGa7 stärker exprimiert, was darauf schließen lässt, dass das veränderte Migrationsverhalten in Anwesenheit hoher Semaphorinkonzentrationen eventuell Integrinvermittelt ist. $\mathrm{Ob}$ es sich bei den gemachten Beobachtungen jedoch um direkte Effekte des Semaphorins auf ITGa7 bzw. des ITGa7 auf die Migration handelt, muss geprüft werden.

Zu diesem Zweck könnte ITGa7 in Gliomzellen überexprimiert und der Einfluss auf die Migration beobachtet werden.

Weitere Transkripte, die in den Microarray-Analysen verändert vorlagen und mit Hilfe der realtime-PCR bestimmt wurden, waren Vasohibin 2 und Angiopoietin 2, die ebenfalls beide an der Angiogenese beteiligt sind. Die Angiopoietine 1 und 2 spielen wichtige Rollen in der 
Angiogenese und der Gefäßbildung und können über den Tie2-Rezeptor agieren. Die Angiopoietine haben untereinander einen gegensätzlichen Effekt auf die Stabilität der Gefäße und deren Aufrechterhaltung (Holash et al. 1999). Eine Inhibierung des Angiopoietins 2 mit Hilfe eines direkten Inhibitors (L1-7[N]) in humanen Darmkrebszellen (Colo205-Zellen) führte zu einer Reduktion der Gefäßversorgung des Tumors (Falcon et al. 2009). Auch eine aktuelle Studie von Hashizume et al. zeigt, dass Angiopoietin 2 und VEGF antagonistische Effekte in der Angiogenese zeigen (Hashizume et al. 2010). Diese Ergebnisse und die Erniedrigung der relativen Expression des Angiopoietins 2 in den U87-D Zellen lassen die Vermutung $\mathrm{zu}$, dass die Inhibierung des Tumorwachstums zumindest teilweise mit der Destabilisierung der Blutgefäße zusammenhängt (Yancopoulos et al. 2000). In wieweit dies jedoch zutrifft, muss noch geprüft werden.

Die Rezeptoren der Angiopoietine, Tie-1 und -2, gehören zu den Rezeptor-Tyrosin-Kinasen, besitzen beide eine große extrazelluläre Domäne und werden ausschließlich in Endothelzellen exprimiert. Die Aktivität von Angiopoietin 2 kann durch ein VEGF-Angebot reguliert werden (Maisonpierre et al. 1997). Es bleibt zu klären, wie die Signalkaskase, ausgehend vom Semaphorin, über Neuropiline und Tie-Rezeptor verläuft und welcher Mechanismus letztendlich dazu führt, dass das Tumorwachstum beeinflusst wird.

Einen weiteren Gegenspieler des VEGF, neben Angiopoietin, stellt Vasohibin 2 dar, welches in Endothelzellen exprimiert wird und in Kombination mit Vasohibin 1 wirkt (Shibuya et al. 2006). In den U87-D-Zellen lag die relative Expression dieses Gens im Mittel 4fach höher vor als in den Kontrollzellen. Passend dazu zeigen Daten von Kimura et al., dass eine exogene Vasohibin 2-Gabe die Angiogenese stört (Kimura et al. 2009). Eine fehlerhafte Blutgefäßversorgung der Tumorzellen kann zu einer Unterversorgung der Tumorzellen und somit Inhibierung des Tumorwachstums führen, was in dem Mausmodell und dem CAMAssay zu beobachten war.

Nicht durch realtime-PCR validiert werden konnte z.B. der nachgewiesene Expressionsunterschied der Matrix-Metalloproteinase 16 (MMP16; fold change von -2,04). MMPs sind in den Abbau von Matrix-Proteinen involviert, welche für die Invasion der Zellen benötigt werden und eine Rolle in der Zellmigration spielen. Strongin et al. konnten zeigen, dass MMP2 in Gliomzellen (U251) die Zellinvasion durch Matrigel und die Expression von Adhäsionsrezeptoren auf der Zelloberfläche beeinflusst (Deryugina et al. 1997; Deryugina et 
al. 1997). Eine veränderte Konzentration an MMPs kann also die Invasion von Gliomzellen beeinflussen.

\subsection{Modell zur Inhibierung des Tumorwachstums durch Semaphorine}

Die Ergebnisse der durchgeführten Experimente zeigen eine Vielzahl an Einflüssen der Semaphorine auf die Gliomzellen. In dieser Arbeit konnte eine Inhibierung der EndothelzellProliferation durch Sema3E und 3F gezeigt werden. Eine Auswahl an Integrinen zeigte keine Beeinflussung durch Semaphorine, es konnte jedoch eine Änderung der VEGFR-2 Präsenz auf der Oberfläche der Endothelzellen nachgewiesen werden. Aufgrund der Inhibierung der Gliomzell-Proliferation durch die Semaphorin-Überexpression in vivo, sowie der Effekte auf die Endothelzellen in vitro, kann folgendes Modell für eine Inhibierung des Tumorwachstums aufgestellt werden.

Eine mögliche Theorie veranschaulicht Abbildung 38 (adaptiert nach (Norden et al. 2008)). Dargestellt sind die Zellmembranen einer Tumor- sowie einer Endothelzelle. Die Rezeptoren VEGFR-2, Nrp1 und Tie2 liegen eingebettet in der Lipiddoppelschicht der Endothelzelle vor. Während der Angiogenese geht ein Stimulus, z.B. VEGF-A, von der Tumorzelle aus, um die Endothelzellproliferation zu aktivieren und neue Gefäße zu bilden. VEGFR-2 ist dabei der Hauptrezeptor der Angiogenese in diesen Zellen. Durch die Überexpression der Klasse-3 Semaphorine wird die Angiogenese beeinflusst.

In vivo würden die implantierten Gliomzellen das Semaphorin in das umgebende Gewebe sekretieren. Als ein Antagonist von VEGF könnte das Semaphorin mit Nrp1 interagieren, welches wiederum an VEGFR-2 binden könnte. Dadurch wäre der VEGFR-2 nicht in der Lage, die durch VEGF übermittelte Signalkaskade zu induzieren. Durch die Komplexbildung des VEGFR-2 mit Nrp1 würden downstream Signale in den Endothelzellen bewirken, dass z.B. die Proliferation der Endothelzellen beeinflusst würde.

Eine veränderte Proliferation der Endothelzellen könnte $\mathrm{zu}$ einer abgeänderten Gefäßversorgung der Tumorzellen führen, die dadurch nicht ausreichend mit Nährstoffen für ihr eigenes Wachstum versorgt werden würden. In das Mausgehirn implantierte Tumorzellen würden somit eingeschränkt proliferieren und könnten nicht zu einem ausgedehnten Tumor heranwachsen. Die Blutgefäße wären durch eine anti-angiogene Wirkung der Semaphorine beeinflusst. Diese Theorie wird von Ergebnissen dieser Arbeit gestützt, die eine Beeinflussung der Angiogenese durch die Semaphorin-Expression der Gliomzellen zeigen. 
Auch zeigte die Analyse von Mausgehirnen, die wenige Tage nach der Implantation der Zellen entnommen wurden, entartete Zellen, was ebenfalls die Theorie untermauert, dass die Zellen zunächst anwachsen, dann aber aufgrund einer Nährstoff-Unterversorgung am weiteren Wachstum gehindert werden.

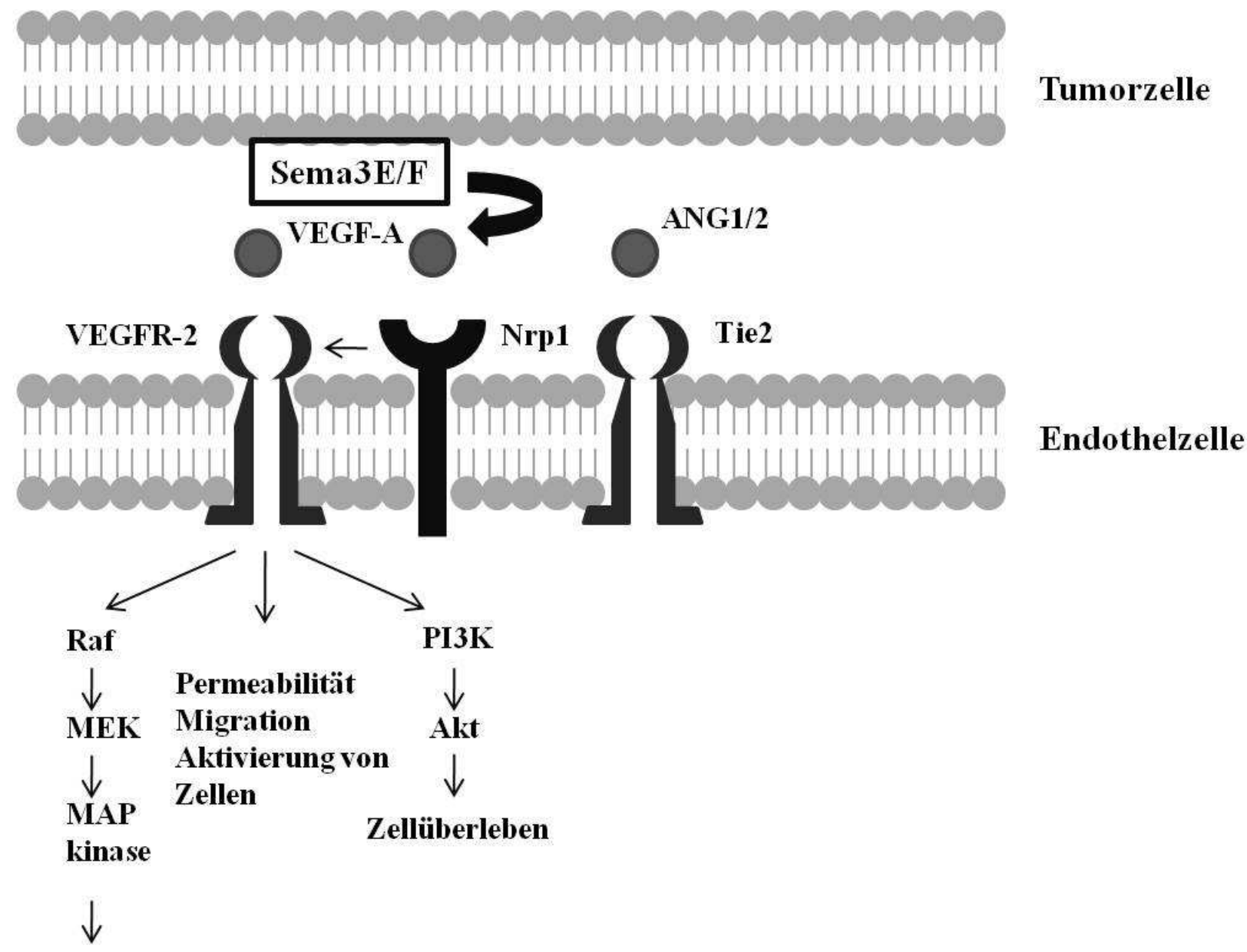

\section{Zellteilung}

Abbildung 38: VEGFR-2 als hauptverantwortlicher Rezeptor der Angiogenese in Endothelzellen (modifiziert nach (Norden et al. 2008)).

Das sezernierte Sema3E/F der Tumorzelle bindet an Nrp1, welches einen Komplex mit VEGFR-2 auf der Oberfläche der Endothelzellen bildet und steht somit in Konkurrenz mit VEGF (Einzelheiten im Text).

\subsection{Ausblick}

Die Entwicklung neuer Therapien, die gezielt auf die Hemmung des Tumorwachstums von Glioblastomen gerichtet ist, soll das Überleben von Patienten, deren Tumoren nicht auf die konventionelle Chemo- und Strahlentherapie ansprechen, verlängern. Eine 
Behandlungsmöglichkeit wäre, die in dieser Arbeit analysierten Effekte der Semaphorine zu nutzen. Zuvor müssen allerdings weitere Untersuchungen zur Angiogenese, Adhäsion und Migration Klasse-3 Semaphorin-überexprimierender Gliomzellen erfolgen, um den genauen Mechanismus der Semaphorin Wirkung zu klären. Für diesen Zweck sollen Faktoren, wie CADM2 und ITGa7, die einen veränderten Expressionsgrad in den Microarray-Analysen zeigten und mittels realtime-PCR validiert wurden, in den hier eingesetzten Gliomzellen überexprimiert und der Einfluss der Überexpression auf das Migrations-und Adhäsionsverhalten der Zellen untersucht werden. Treten Veränderungen auf, könnten die Zellen in ein Mausgehirn implantiert und die Effekte auf das Tumorwachstum in vivo beobachtet, sowie mit dem der Semaphorin-überexprimierenden Gliomzellen verglichen werden.

Die weitere Nutzung des CAM-Modells könnte helfen, die Blutgefäßversorgung, vor allem die Quantität der Blutgefäße und deren Aufbau, besser zu charakterisieren. Ein weiterer Ansatzpunkt um den Einfluss der Semaphorine auf die Migration und Adhäsion der Zellen besser zu verstehen, wäre eine nähere Untersuchung von Veränderungen des Zytoskeletts in der Anwesenheit von Semaphorinen. Ferner können heranwachsende Kontrolltumoren mit rekombinant hergestelltem Semaphorin behandelt werden, um eine deutliche Beeinflussung durch diese Moleküle nachzuweisen.

Zusätzlich sollen weitere Faktoren, die mittels Microarray-Analyse bestimmten Netzwerken zugeordnet werden konnten und die zur Aufklärung des Wirkmechanismus beitragen könnten, mittels realtime-PCR validiert werden. Die $\mathrm{zu}$ entwickelnden mathematischen Modelle werden können dafür genutzt werden, zu entschlüsseln, welche Veränderungen in intrazellulären Signaltransduktions-Netzwerken die Hemmung des Tumorwachstums fördern, um so Vorhersagen für mögliche Eingriffsmöglichkeiten machen zu können. 


\section{$6 \quad$ Zusammenfassung}

Maligne Gliome gehören sowohl bei Kindern als auch bei Erwachsenen zu den Tumorerkrankungen mit den schlechtesten Heilungschancen. Trotz intensiver Bemühungen ist es der Forschung bisher nicht gelungen, effektive Behandlungsmöglichkeiten zu entwickeln. Für eine Steigerung der Überlebensrate von Patienten müssen daher neue Therapieansätze etabliert werden. In der vorliegenden Arbeit wurden Klasse-3 Semaphorine als mögliche Zielstruktur(en) für die Beeinflussung des Hirntumorwachstums an verschiedenen Modellsystemen untersucht.

Am in vitro-Modell humaner Hirntumorzelllinien (U87MG, U373MG) konnte gezeigt werden, dass eine endogene Semaphorin-Überexpression oder eine Behandlung mit exogenem, rekombinantem Semaphorin weder einen Einfluss auf die Proliferation dieser Zellen noch auf den Gehalt an VEGFR-2, einem der Hauptrezeptoren der Angiogenese, hat. An primären Endothelzellen (HUVECs) dagegen konnte sowohl ein Effekt auf die Proliferation als auch auf die VEGFR-2-Präsenz auf der Oberfläche dieser Zellen nachgewiesen werden. Allerdings hatte die Überexpression der Semaphorine in Hirntumorzellen Auswirkungen auf deren Migration, Adhäsionsverhalten, Zellzyklus und Apoptose und zwar in einer Weise, die mit einer Inhibierung des Tumorwachstums in Einklang gebracht werden kann.

In einem zweiten Schritt wurde versucht, die in vitro gefundenen Hinweise auf eine antitumoröse Wirkung der Semaphorine im Nacktmausmodell in vivo zu untermauern. Dazu wurden Gliomzellen, die diese Proteine überexprimieren, intrazerebral implantiert und das Wachstum der Tumoren über einen bestimmten Zeitraum mithilfe von Biolumineszenzmessungen verfolgt. Diese Untersuchungen bestätigten eine Inhibierung des Tumorwachstums durch Klasse-3 Semaphorine und zeigten darüber hinaus eine erhöhte Lebenserwartung der Mäuse nach Implantation dieser modifizierten Tumorzellen.

Auch mit einem alternativen Modell, der Chorionallantoismembran (CAM) des Hühnchens, konnte eine Inhibierung des Tumorwachstums durch die Überexpression der Semaphorine in Gliomzellen bestätigt werden. Zusätzlich gelang es nachzuweisen, dass das eingeschränkte Tumorwachstum mit einer deutlichen Verminderung der versorgenden Blutgefäße einherging. Die Ursache für diese Beeinflussung der Angiogenese wurde hier nicht weiter untersucht. 
Im letzten Teil dieser Arbeit wurden durch Microarray-AnalysenVeränderungen in der Genexpressionen Semaphorin-überexprimierender Gliomzellen festgestellt, die anschließend mittels realtime-PCR validiert werden konnten. Dabei lag der Fokus auf den Transkripten des CADM2-, Angiopoietin 2-, Vasohibin 2- und Integrin alpha 7-Gens, da diesen eine Rolle bei der Zelladhäsion, Migration und Angiogenese zukommt. Die erhaltenen Ergebnisse befinden sich im Einklang mit den in vitro beobachteten Veränderungen des Migrations- und Adhäsionsverhalten der Gliomzellen und geben somit erste Anhaltspunkte für eine Erklärung des Semaphorin-Wirkmechanismus auf molekularer Ebene. 


\section{$8 \quad$ Literaturverzeichnis}

Abdollahi, A. and J. Folkman (2010). "Evading tumor evasion: current concepts and perspectives of anti-angiogenic cancer therapy." Drug Resist Updat 13(1-2): 16-28.

Acevedo, L. M., et al. (2008). "Semaphorin 3A suppresses VEGF-mediated angiogenesis yet acts as a vascular permeability factor." Blood 111(5): 2674-80.

Adams, R. H., et al. (1996). "A novel class of murine semaphorins with homology to thrombospondin is differentially expressed during early embryogenesis." Mech Dev 57(1): $33-45$.

Ausprunk, D. H., et al. (1975). "Vascularization of normal and neoplastic tissues grafted to the chick chorioallantois. Role of host and preexisting graft blood vessels." Am J Pathol 79(3): 597-618.

Bachelder, R. E., et al. (2003). "Competing autocrine pathways involving alternative neuropilin-1 ligands regulate chemotaxis of carcinoma cells." Cancer Res 63(17): 5230-3.

Badie, B. and J. Schartner (2001). "Role of microglia in glioma biology." Microsc Res Tech 54(2): 106-13.

Bagci, T., et al. (2009). "Autocrine semaphorin 3A signaling promotes glioblastoma dispersal." Oncogene 28(40): 3537-50.

Bagnard, D., et al. (2001). "Semaphorin 3A-vascular endothelial growth factor-165 balance mediates migration and apoptosis of neural progenitor cells by the recruitment of shared receptor." J Neurosci 21(10): 3332-41.

Banu, N., et al. (2006). "Semaphorin 3C regulates endothelial cell function by increasing integrin activity." FASEB J 20(12): 2150-2.

Behar, O., et al. (1996). "Semaphorin III is needed for normal patterning and growth of nerves, bones and heart." Nature 383(6600): 525-8.

Belot, N., et al. (2001). "Molecular characterization of cell substratum attachments in human glial tumors relates to prognostic features." Glia 36(3): 375-90.

Ben-Zvi, A., et al. (2008). "The Semaphorin receptor PlexinA3 mediates neuronal apoptosis during dorsal root ganglia development." J Neurosci 28(47): 12427-32. 
Berndt, J. D. and M. C. Halloran (2006). "Semaphorin 3d promotes cell proliferation and neural crest cell development downstream of TCF in the zebrafish hindbrain." Development 133(20): 3983-92.

Bidros, D. S. and M. A. Vogelbaum (2009). "Novel drug delivery strategies in neurooncology." Neurotherapeutics 6(3): 539-46.

Biederer, T. (2006). "Bioinformatic characterization of the SynCAM family of immunoglobulin-like domain-containing adhesion molecules." Genomics 87(1): 139-50.

Bielenberg, D. R., et al. (2004). "Semaphorin 3F, a chemorepulsant for endothelial cells, induces a poorly vascularized, encapsulated, nonmetastatic tumor phenotype." J Clin Invest 114(9): 1260-71.

Bocking, A., et al. (1982). "Combined histologic grading of prostatic carcinoma." Cancer 50(2): 288-94.

Bredel, M. (2001). "Anticancer drug resistance in primary human brain tumors." Brain Res Brain Res Rev 35(2): 161-204.

Bussolino, F., et al. (2009). "Angiogenesis: a balancing act between integrin activation and inhibition?" Eur Cytokine Netw 20(4): 191-6.

Camphausen, K., et al. (2005). "Influence of in vivo growth on human glioma cell line gene expression: convergent profiles under orthotopic conditions." Proc Natl Acad Sci U S A 102(23): 8287-92.

Capparuccia, L. and L. Tamagnone (2009). "Semaphorin signaling in cancer cells and in cells of the tumor microenvironment--two sides of a coin." J Cell Sci 122(Pt 11): 1723-36.

Carmeliet, P. and R. K. Jain (2000). "Angiogenesis in cancer and other diseases." Nature 407(6801): 249-57.

Castro-Rivera, E., et al. (2008). "Semaphorin 3B inhibits the phosphatidylinositol 3kinase/Akt pathway through neuropilin-1 in lung and breast cancer cells." Cancer Res 68(20): 8295-303.

Castro-Rivera, E., et al. (2004). "Semaphorin 3B (SEMA3B) induces apoptosis in lung and breast cancer, whereas VEGF165 antagonizes this effect." Proc Natl Acad Sci U S A 101(31): 11432-7. 
Catalano, A., et al. (2004). "Cross-talk between vascular endothelial growth factor and semaphorin-3A pathway in the regulation of normal and malignant mesothelial cell proliferation." FASEB J 18(2): 358-60.

Caunt, M., et al. (2008). "Blocking neuropilin-2 function inhibits tumor cell metastasis." Cancer Cell 13(4): 331-42.

Chen, H., et al. (2000). "Neuropilin-2 regulates the development of selective cranial and sensory nerves and hippocampal mossy fiber projections." Neuron 25(1): 43-56.

Chen, H., et al. (1997). "Neuropilin-2, a novel member of the neuropilin family, is a high affinity receptor for the semaphorins Sema E and Sema IV but not Sema III." Neuron 19(3): 547-59.

Cody, N. A., et al. (2007). "Transfer of chromosome 3 fragments suppresses tumorigenicity of an ovarian cancer cell line monoallelic for chromosome 3p." Oncogene 26(4): 618-32.

Cody, N. A., et al. (2009). "Characterization of the 3p12.3-pcen region associated with tumor suppression in a novel ovarian cancer cell line model genetically modified by chromosome 3 fragment transfer." Mol Carcinog 48(12): 1077-92.

Coma, S., et al. (2010). "Id2 promotes tumor cell migration and invasion through transcriptional repression of semaphorin 3F." Cancer Res 70(9): 3823-32.

Commitee, S. N. (1999). Unified nomenclature for the semaphorins/collapsins. Semaphorin Nomenclature Committee. Cell. 97: 551-2.

Conrad, C. (2004). A phase I/II trial of single- agent PTK 787/ ZK 222584 (PTK/ ZK), a novel, oral angiogenesis inhibitor, in patients with recurrent glioblastoma multiforme (abstract 1512). ASCO Meeting Abstracts 22, 1512

Deryugina, E. I., et al. (1997). "Matrix metalloproteinase-2 activation modulates glioma cell migration." J Cell Sci 110 ( Pt 19): 2473-82.

Deryugina, E. I., et al. (1997). "Tumor cell invasion through matrigel is regulated by activated matrix metalloproteinase-2." Anticancer Res 17(5A): 3201-10.

Earnshaw, W. C., et al. (1999). "Mammalian caspases: structure, activation, substrates, and functions during apoptosis." Annu Rev Biochem 68: 383-424.

Erdlenbruch, B., et al. (2003). "Alkylglycerol opening of the blood-brain barrier to small and large fluorescence markers in normal and C6 glioma-bearing rats and isolated rat brain capillaries." Br J Pharmacol 140(7): 1201-10. 
Falcon, B. L., et al. (2009). "Contrasting actions of selective inhibitors of angiopoietin-1 and angiopoietin-2 on the normalization of tumor blood vessels." Am J Pathol 175(5): 2159-70.

Fantin, A., et al. (2009). "Neuropilin ligands in vascular and neuronal patterning." Biochem Soc Trans 37(Pt 6): 1228-32.

Ferrara, N. (1999). "Vascular endothelial growth factor: molecular and biological aspects." Curr Top Microbiol Immunol 237: 1-30.

Ferrara, N., et al. (2003). "The biology of VEGF and its receptors." Nat Med 9(6): 669-76.

Folkman, J. (1990). "What is the evidence that tumors are angiogenesis dependent?" J Natl Cancer Inst 82(1): 4-6.

Folkman, J. (1992). "The role of angiogenesis in tumor growth." Semin Cancer Biol 3(2): 6571.

Forsyth, P. A. and J. B. Posner (1993). "Headaches in patients with brain tumors: a study of 111 patients." Neurology 43(9): 1678-83.

Friedlander, D. R., et al. (1996). "Migration of brain tumor cells on extracellular matrix proteins in vitro correlates with tumor type and grade and involves alphaV and beta1 integrins." Cancer Res 56(8): 1939-47.

Friese, M. A., et al. (2004). "The innate immune response in the central nervous system and its role in glioma immune surveillance." Onkologie 27(5): 487-91.

Fujisawa, H., et al. (1995). "Growth-associated expression of a membrane protein, neuropilin, in Xenopus optic nerve fibers." Dev Neurosci 17(5-6): 343-9.

Fukushima, Y., et al. (1998). "Integrin alpha3beta1-mediated interaction with laminin-5 stimulates adhesion, migration and invasion of malignant glioma cells." Int J Cancer 76(1): 63-72.

Furnari, F. B., et al. (2007). "Malignant astrocytic glioma: genetics, biology, and paths to treatment." Genes Dev 21(21): 2683-710.

Gale, N. W. and G. D. Yancopoulos (1999). "Growth factors acting via endothelial cellspecific receptor tyrosine kinases: VEGFs, angiopoietins, and ephrins in vascular development." Genes Dev 13(9): 1055-66. 
Gaur, P., et al. (2009). "Role of class 3 semaphorins and their receptors in tumor growth and angiogenesis." Clin Cancer Res 15(22): 6763-70.

Gerstner, E. R., et al. (2009). "VEGF inhibitors in the treatment of cerebral edema in patients with brain cancer." Nat Rev Clin Oncol 6(4): 229-36.

Gherardi, E., et al. (2004). "The sema domain." Curr Opin Struct Biol 14(6): 669-78.

Giese, A., et al. (1994). "Determinants of human astrocytoma migration." Cancer Res 54(14): 3897-904.

Giger, R. J., et al. (2010). "Guidance molecules in axon regeneration." Cold Spring Harb Perspect Biol 2(7): a001867.

Giger, R. J., et al. (1998). "Neuropilin-2 is a receptor for semaphorin IV: insight into the structural basis of receptor function and specificity." Neuron 21(5): 1079-92.

Guttmann-Raviv, N., et al. (2007). "Semaphorin-3A and semaphorin-3F work together to repel endothelial cells and to inhibit their survival by induction of apoptosis." $\mathrm{J}$ Biol Chem 282(36): 26294-305.

Hagemann, T., et al. (2004). "Enhanced invasiveness of breast cancer cell lines upon cocultivation with macrophages is due to TNF-alpha dependent up-regulation of matrix metalloproteases." Carcinogenesis 25(8): 1543-9.

Haixia, D., et al. (2010). "Gene Expression of Neuropilin-1 and Its Receptors, VEGF/Semaphorin 3a, in Normal and Cancer Cells." Cell Biochem Biophys.

Hanahan, D. and R. A. Weinberg (2000). "The hallmarks of cancer." Cell 100(1): 57-70.

Hashizume, H., et al. (2010). "Complementary actions of inhibitors of angiopoietin-2 and VEGF on tumor angiogenesis and growth." Cancer Res 70(6): 2213-23.

Hawkins, B. T. and T. P. Davis (2005). "The blood-brain barrier/neurovascular unit in health and disease." Pharmacol Rev 57(2): 173-85.

Hegi, M. E., et al. (2005). "MGMT gene silencing and benefit from temozolomide in glioblastoma." N Engl J Med 352(10): 997-1003.

Herman, J. G. and G. G. Meadows (2007). "Increased class 3 semaphorin expression modulates the invasive and adhesive properties of prostate cancer cells." Int J Oncol 30(5): 1231-8. 
Herman, J. G. and G. G. Meadows (2007). "Transferrin reverses the anti-invasive activity of human prostate cancer cells that overexpress sema3E." Int J Oncol 31(5): 1267-72.

Hicklin, D. J. and L. M. Ellis (2005). "Role of the vascular endothelial growth factor pathway in tumor growth and angiogenesis." J Clin Oncol 23(5): 1011-27.

Hobson, B. and J. Denekamp (1984). "Endothelial proliferation in tumours and normal tissues: continuous labelling studies." Br J Cancer 49(4): 405-13.

Holash, J., et al. (1999). "Vessel cooption, regression, and growth in tumors mediated by angiopoietins and VEGF." Science 284(5422): 1994-8.

Huang da, W., et al. (2009). "Systematic and integrative analysis of large gene lists using DAVID bioinformatics resources." Nat Protoc 4(1): 44-57.

Husmann, G. (2010). "Krebs in Deutschland." 7.

Jain, R. K. (2001). "Normalizing tumor vasculature with anti-angiogenic therapy: a new paradigm for combination therapy." Nat Med 7(9): 987-9.

Jia, D., et al. (2010). "Development of a highly metastatic model that reveals a crucial role of fibronectin in lung cancer cell migration and invasion." BMC Cancer 10(1): 364.

Jost, L. M., et al. (2006). "Metabolism and disposition of vatalanib (PTK787/ZK-222584) in cancer patients." Drug Metab Dispos 34(11): 1817-28.

Kaatsch, P., et al. (2001). "Population-based epidemiologic data on brain tumors in German children." Cancer 92(12): 3155-64.

Kanu, O. O., et al. (2009). "Glioblastoma Multiforme Oncogenomics and Signaling Pathways." Clin Med Oncol 3: 39-52.

Karayan-Tapon, L., et al. (2008). "Semaphorin, neuropilin and VEGF expression in glial tumours: SEMA3G, a prognostic marker?" Br J Cancer 99(7): 1153-60.

Kawasaki, T., et al. (1999). "A requirement for neuropilin-1 in embryonic vessel formation." Development 126(21): 4895-902.

Kemper, E. M., et al. (2004). "Modulation of the blood-brain barrier in oncology: therapeutic opportunities for the treatment of brain tumours?" Cancer Treat Rev 30(5): 415-23. 
Kessler, O., et al. (2004). "Semaphorin-3F is an inhibitor of tumor angiogenesis." Cancer Res 64(3): 1008-15.

Kigel, B., et al. (2008). "Successful inhibition of tumor development by specific class-3 semaphorins is associated with expression of appropriate semaphorin receptors by tumor cells." PLoS One 3(9): e3287.

Kimura, H., et al. (2009). "Distinctive localization and opposed roles of vasohibin-1 and vasohibin-2 in the regulation of angiogenesis." Blood 113(19): 4810-8.

Kiosses, W. B., et al. (2002). "A dominant-negative p65 PAK peptide inhibits angiogenesis." Circ Res 90(6): 697-702.

Kitsukawa, T., et al. (1997). "Neuropilin-semaphorin III/D-mediated chemorepulsive signals play a crucial role in peripheral nerve projection in mice." Neuron 19(5): 995-1005.

Kleihues, P., et al. (2002). "The WHO classification of tumors of the nervous system." $\underline{\mathbf{J}}$ Neuropathol Exp Neurol 61(3): 215-25; discussion 226-9.

Kleihues, P. and L. H. Sobin (2000). "World Health Organization classification of tumors." Cancer 88(12): 2887.

Kolodkin, A. L., et al. (1997). "Neuropilin is a semaphorin III receptor." Cell 90(4): 753-62.

Kondo, M., et al. (2001). "Overexpression of candidate tumor suppressor gene FUS1 isolated from the 3p21.3 homozygous deletion region leads to G1 arrest and growth inhibition of lung cancer cells." Oncogene 20(43): 6258-62.

Korhonen, J., et al. (1992). "Enhanced expression of the tie receptor tyrosine kinase in endothelial cells during neovascularization." Blood 80(10): 2548-55.

Kugler, W., et al. (2002). "Erucylphosphocholine-induced apoptosis in glioma cells: involvement of death receptor signalling and caspase activation." J Neurochem 82(5): 116070.

Kumanogoh, A., et al. (2002). "Class IV semaphorin Sema4A enhances T-cell activation and interacts with Tim-2." Nature 419(6907): 629-33.

Kuramochi, M., et al. (2001). "TSLC1 is a tumor-suppressor gene in human non-small-cell lung cancer." Nat Genet 27(4): 427-30. 
Lefranc, F., et al. (2005). "Possible future issues in the treatment of glioblastomas: special emphasis on cell migration and the resistance of migrating glioblastoma cells to apoptosis." $\mathbf{J}$ Clin Oncol 23(10): 2411-22.

Louis, D. N., et al. (2007). "The 2007 WHO classification of tumours of the central nervous system." Acta Neuropathol 114(2): 97-109.

Luo, Y., et al. (1993). "Collapsin: a protein in brain that induces the collapse and paralysis of neuronal growth cones." Cell 75(2): 217-27.

Maher, E. A., et al. (2001). "Malignant glioma: genetics and biology of a grave matter." Genes Dev 15(11): 1311-33.

Maione, F., et al. (2009). "Semaphorin 3A is an endogenous angiogenesis inhibitor that blocks tumor growth and normalizes tumor vasculature in transgenic mouse models." $\mathrm{J}$ Clin Invest 119(11): 3356-72.

Maisonpierre, P. C., et al. (1997). "Angiopoietin-2, a natural antagonist for Tie2 that disrupts in vivo angiogenesis." Science 277(5322): 55-60.

Malkin, D., et al. (1990). "Germ line p53 mutations in a familial syndrome of breast cancer, sarcomas, and other neoplasms." Science 250(4985): 1233-8.

Martin-Bermudo, M. D., et al. (1998). "Modulation of integrin activity is vital for morphogenesis." J Cell Biol 141(4): 1073-81.

Mattern, R. H., et al. (2005). "Glioma cell integrin expression and their interactions with integrin antagonists: Research Article." Cancer Ther 3A: 325-340.

Meadows, A. T., et al. (1985). "Second malignant neoplasms in children: an update from the Late Effects Study Group." J Clin Oncol 3(4): 532-8.

Miao, H. Q., et al. (2000). "Neuropilin-1 expression by tumor cells promotes tumor angiogenesis and progression." Faseb J 14(15): 2532-9.

Miao, H. Q., et al. (1999). "Neuropilin-1 mediates collapsin-1/semaphorin III inhibition of endothelial cell motility: functional competition of collapsin-1 and vascular endothelial growth factor-165." J Cell Biol 146(1): 233-42.

Mikule, K., et al. (2002). "Growth cone collapse induced by semaphorin 3A requires 12/15lipoxygenase." J Neurosci 22(12): 4932-41. 
Nasarre, P., et al. (2003). "Semaphorin SEMA3F and VEGF have opposing effects on cell attachment and spreading." Neoplasia 5(1): 83-92.

Naumov, G. N., et al. (2006). "Role of angiogenesis in human tumor dormancy: animal models of the angiogenic switch." Cell Cycle 5(16): 1779-87.

Neglia, J. P., et al. (2006). "New primary neoplasms of the central nervous system in survivors of childhood cancer: a report from the Childhood Cancer Survivor Study." J Natl Cancer Inst 98(21): 1528-37.

Neufeld, G., et al. (1996). "Similarities and differences between the vascular endothelial growth factor (VEGF) splice variants." Cancer Metastasis Rev 15(2): 153-8.

Neufeld, G. and O. Kessler (2008). "The semaphorins: versatile regulators of tumour progression and tumour angiogenesis." Nat Rev Cancer.

Nicoletti, I., et al. (1991). "A rapid and simple method for measuring thymocyte apoptosis by propidium iodide staining and flow cytometry." J Immunol Methods 139(2): 271-9.

Norden, A. D., et al. (2008). "Antiangiogenic therapy in malignant gliomas." Curr Opin Oncol 20(6): 652-61.

Ohgaki, H., et al. (2004). "Genetic pathways to glioblastoma: a population-based study." Cancer Res 64(19): 6892-9.

Ohgaki, H. and P. Kleihues (2005). "Epidemiology and etiology of gliomas." Acta Neuropathol 109(1): 93-108.

Ohgaki, H. and P. Kleihues (2007). "Genetic pathways to primary and secondary glioblastoma." Am J Pathol 170(5): 1445-53.

Oinuma, I., et al. (2004). "The Semaphorin 4D receptor Plexin-B1 is a GTPase activating protein for R-Ras." Science 305(5685): 862-5.

Okada, H., et al. (2009). "Immunotherapeutic approaches for glioma." $\underline{\text { Crit Rev Immunol }}$ 29(1): 1-42.

Olsson, A. K., et al. (2006). "VEGF receptor signalling - in control of vascular function." Nat Rev Mol Cell Biol 7(5): 359-71.

Pan, H., et al. (2009). "Autocrine semaphorin3A stimulates alpha2 beta1 integrin expression/function in breast tumor cells." Breast Cancer Res Treat 118(1): 197-205. 
Pellet-Many, C., et al. (2008). "Neuropilins: structure, function and role in disease." Biochem J 411(2): 211-26.

Pfaffl, M. W. (2001). "A new mathematical model for relative quantification in real-time RTPCR." Nucleic Acids Res 29(9): e45.

Pierschbacher, M. D. and E. Ruoslahti (1984). "Cell attachment activity of fibronectin can be duplicated by small synthetic fragments of the molecule." Nature 309(5963): 30-3.

Pletcher, M. T., et al. (2001). "Identification of tumor suppressor candidate genes by physical and sequence mapping of the TSLC1 region of human chromosome 11q23." Gene 273(2): $181-9$.

Ponten, J. and E. H. Macintyre (1968). "Long term culture of normal and neoplastic human glia." Acta Pathol Microbiol Scand 74(4): 465-86.

Pop, C. and G. S. Salvesen (2009). "Human caspases: activation, specificity, and regulation." J Biol Chem 284(33): 21777-81.

Ragel, B. T., et al. (2008). "A novel model of intracranial meningioma in mice using luciferase-expressing meningioma cells. Laboratory investigation." J Neurosurg 108(2): 30410.

Rice, D. S., et al. (2004). "Severe retinal degeneration associated with disruption of semaphorin 4A." Invest Ophthalmol Vis Sci 45(8): 2767-77.

Risau, W. (1997). "Mechanisms of angiogenesis." Nature 386(6626): 671-4.

Robert-Koch-Institut (2004). "Ergebnisse zur Prävalenz: Krebs insgesamt." 156-164.

Roche, J., et al. (1996). "Distinct 3p21.3 deletions in lung cancer and identification of a new human semaphorin." Oncogene 12(6): 1289-97.

Sakurai, A., et al. (2010). "Semaphorin 3E initiates antiangiogenic signaling through plexin D1 by regulating Arf6 and R-Ras." Mol Cell Biol 30(12): 3086-98.

Sampson, J. H., et al. (2008). "Intracerebral infusion of an EGFR-targeted toxin in recurrent malignant brain tumors." Neuro Oncol 10(3): 320-9.

Schlegel, U. a. W. M. (1998). Neuroonkologie. Stuttgart, Thieme 
Schuz, J., et al. (2001). "Risk factors for pediatric tumors of the central nervous system: results from a German population-based case-control study." Med Pediatr Oncol 36(2): 27482.

Sekido, Y., et al. (1996). "Human semaphorins A(V) and IV reside in the 3p21.3 small cell lung cancer deletion region and demonstrate distinct expression patterns." Proc Natl Acad Sci U S A 93(9): 4120-5.

Serini, G., et al. (2003). "Class 3 semaphorins control vascular morphogenesis by inhibiting integrin function." Nature 424(6947): 391-7.

Shalaby, F., et al. (1995). "Failure of blood-island formation and vasculogenesis in Flk-1deficient mice." Nature 376(6535): 62-6.

Shapiro, W. R. and J. R. Shapiro (1998). "Biology and treatment of malignant glioma." Oncology (Williston Park) 12(2): 233-40; discussion 240, 246.

Shibuya, T., et al. (2006). "Isolation and characterization of vasohibin-2 as a homologue of VEGF-inducible endothelium-derived angiogenesis inhibitor vasohibin." Arterioscler Thromb Vasc Biol 26(5): 1051-7.

Shirvan, A., et al. (1999). "Semaphorins as mediators of neuronal apoptosis." J Neurochem 73(3): 961-71.

Soker, S., et al. (1998). "Neuropilin-1 is expressed by endothelial and tumor cells as an isoform-specific receptor for vascular endothelial growth factor." Cell 92(6): 735-45.

Steinbach, K., et al. (2002). "Semaphorin 3E/collapsin-5 inhibits growing retinal axons." Exp Cell Res 279(1): 52-61.

Stern, J. I. and J. J. Raizer (2006). "Chemotherapy in the treatment of malignant gliomas." Expert Rev Anticancer Ther 6(5): 755-67.

Stewart, L. A. (2002). "Chemotherapy in adult high-grade glioma: a systematic review and meta-analysis of individual patient data from 12 randomised trials." Lancet 359(9311): 10118 .

Stummer, W., et al. (2006). "Fluorescence-guided surgery with 5-aminolevulinic acid for resection of malignant glioma: a randomised controlled multicentre phase III trial." Lancet Oncol 7(5): 392-401. 
Sulpice, E., et al. (2008). "Neuropilin-1 and neuropilin-2 act as coreceptors, potentiating proangiogenic activity." Blood 111(4): 2036-45.

Takano, S., et al. (1996). "Concentration of vascular endothelial growth factor in the serum and tumor tissue of brain tumor patients." Cancer Res 56(9): 2185-90.

Takashima, S., et al. (2002). "Targeting of both mouse neuropilin-1 and neuropilin-2 genes severely impairs developmental yolk sac and embryonic angiogenesis." Proc Natl Acad Sci U S A 99(6): 3657-62.

Tamagnone, L., et al. (1999). "Plexins are a large family of receptors for transmembrane, secreted, and GPI-anchored semaphorins in vertebrates." Cell 99(1): 71-80.

Tomizawa, Y., et al. (2001). "Inhibition of lung cancer cell growth and induction of apoptosis after reexpression of 3p21.3 candidate tumor suppressor gene SEMA3B." Proc Natl Acad Sci U S A 98(24): 13954-9.

Tse, C., et al. (2002). "Human Semaphorin 3B (SEMA3B) located at chromosome 3p21.3 suppresses tumor formation in an adenocarcinoma cell line." Cancer Res 62(2): 542-6.

Urbach, H. and L. Solymosi (2003). Neuroonkologie. Stuttgart, Thieme.

Vacca, A., et al. (2006). "Loss of inhibitory semaphorin 3A (SEMA3A) autocrine loops in bone marrow endothelial cells of patients with multiple myeloma." Blood 108(5): 1661-7.

van Breemen, M. S., et al. (2007). "Epilepsy in patients with brain tumours: epidemiology, mechanisms, and management." Lancet Neurol 6(5): 421-30.

Van Gool, S., et al. (2009). "Dendritic cell therapy of high-grade gliomas." Brain Pathol 19(4): 694-712.

Varshavsky, A., et al. (2008). "Semaphorin-3B Is an Angiogenesis Inhibitor That Is Inactivated by Furin-Like Pro-Protein Convertases." Cancer Res 68(17): 6922-6931.

Vooijs, M., et al. (2002). "Noninvasive imaging of spontaneous retinoblastoma pathwaydependent tumors in mice." Cancer Res 62(6): 1862-7.

Walker, P. R., et al. (2003). "T-cell immune responses in the brain and their relevance for cerebral malignancies." Brain Res Brain Res Rev 42(2): 97-122.

Warren, K., et al. (2006). "Phase II trial of intravenous lobradimil and carboplatin in childhood brain tumors: a report from the Children's Oncology Group." Cancer Chemother Pharmacol 58(3): 343-7. 
Weidner, N., et al. (1993). "Tumor angiogenesis correlates with metastasis in invasive prostate carcinoma." Am J Pathol 143(2): 401-9.

Weller, M. and A. Fontana (1995). "The failure of current immunotherapy for malignant glioma. Tumor-derived TGF-beta, T-cell apoptosis, and the immune privilege of the brain." Brain Res Brain Res Rev 21(2): 128-51.

Wiestler, O. D. and M. C. Schmidt (1998). Onkologe, Springer Verlag.

Xiang, R., et al. (2002). "Semaphorin 3F gene from human 3p21.3 suppresses tumor formation in nude mice." Cancer Res 62(9): 2637-43.

Yancopoulos, G. D., et al. (2000). "Vascular-specific growth factors and blood vessel formation." Nature 407(6801): 242-8.

Yazdani, U. and J. R. Terman (2006). "The semaphorins." Genome Biol 7(3): 211.

Zabala, M., et al. (2009). "Evaluation of bioluminescent imaging for noninvasive monitoring of colorectal cancer progression in the liver and its response to immunogene therapy." $\underline{\mathrm{Mol}}$ Cancer 8: 2 .

Zhou, Y., et al. (2008). "Semaphorin signaling: progress made and promises ahead." Trends Biochem Sci 33(4): 161-70. 


\section{$9 \quad$ Anhang}

Tabelle 21:Veränderte Transkripte der U87-D-Proben im Vergleich zu U87-N-Proben

\begin{tabular}{|c|c|c|}
\hline Gene-assignment & p-value & $\begin{array}{c}\text { Fold- } \\
\text { Change }\end{array}$ \\
\hline $\begin{array}{l}\text { NM_152754 // SEMA3D // sema domain, immunoglobulin domain (Ig), short } \\
\text { basic doma }\end{array}$ & 4,45E-012 & 58,89 \\
\hline $\begin{array}{l}\text { NM_006063 // KBTBD10 // kelch repeat and BTB (POZ) domain containing } 10 \\
\text { // 2q31. }\end{array}$ & $5,05 \mathrm{E}-010$ & 25,46 \\
\hline $\begin{array}{l}\text { NM_005725 // TSPAN2 // tetraspanin 2 // 1p13.2 // } 10100 / / / \\
\text { ENST00000369516 // T }\end{array}$ & $1,74 \mathrm{E}-010$ & 22,11 \\
\hline $\begin{array}{l}\text { NM_001039523 // CHRNA1 // cholinergic receptor, nicotinic, alpha } 1 \text { (muscle) } \\
\text { // } 2\end{array}$ & 7,19E-012 & 18,30 \\
\hline $\begin{array}{l}\text { NM_181426 // CCDC39 // coiled-coil domain containing 39 // 3q26.33 // } 339829 \\
\text { /// }\end{array}$ & $4,05 \mathrm{E}-009$ & 16,78 \\
\hline $\begin{array}{l}\text { NM_004543 // NEB // nebulin // 2q22 // } 4703 \text { /// ENST00000409198 // NEB // } \\
\text { nebuli }\end{array}$ & $3,83 \mathrm{E}-010$ & 14,73 \\
\hline $\begin{array}{l}\text { NM_153184 // CADM2 // cell adhesion molecule 2 // 3p12.1// } 253559 \text { /// } \\
\text { ENST00000 }\end{array}$ & $3,55 \mathrm{E}-008$ & 13,45 \\
\hline $\begin{array}{l}\text { NM_005582 // CD180 // CD180 molecule // 5q12 // } 4064 \text { /// ENST00000256447 } \\
\text { // CD18 }\end{array}$ & $1,98 \mathrm{E}-005$ & 11,59 \\
\hline $\begin{array}{l}\text { NM_006922 // SCN3A // sodium channel, voltage-gated, type III, alpha subunit } \\
\text { // }\end{array}$ & 3,46E-008 & 11,48 \\
\hline $\begin{array}{l}\text { NM_057159 // LPAR1 // lysophosphatidic acid receptor 1// 9q31.3 // } 1902 \text { /// } \\
\text { NM_ }\end{array}$ & 0,00010219 & 9,61 \\
\hline $\begin{array}{l}\text { NM_198274 // SMYD1 // SET and MYND domain containing 1// 2p11.2 // } \\
150572 / / / \mathrm{E}\end{array}$ & $2,08 \mathrm{E}-009$ & 9,60 \\
\hline $\begin{array}{l}\text { NM_001099404 // SCN5A // sodium channel, voltage-gated, type V, alpha } \\
\text { subunit // }\end{array}$ & $7,25 \mathrm{E}-009$ & 9,33 \\
\hline $\begin{array}{l}\text { NM_001025077 // CUGBP2 // CUG triplet repeat, RNA binding protein } 2 \text { // } \\
\text { 10p13 // }\end{array}$ & $1,43 \mathrm{E}-007$ & 9,17 \\
\hline $\begin{array}{l}\text { NM_007329 // DMBT1 // deleted in malignant brain tumors 1 // 10q26.13 // } \\
1755 / /\end{array}$ & $5,31 \mathrm{E}-010$ & 7,72 \\
\hline $\begin{array}{l}\text { NM_033337 // CAV3 // caveolin 3 // 3p25 // } 859 \text { /// NM_001234 // CAV3 // } \\
\text { caveolin }\end{array}$ & $7,15 \mathrm{E}-005$ & 7,31 \\
\hline $\begin{array}{l}\text { NM_031442 // TMEM47 // transmembrane protein } 47 \text { // Xp11.4 // } 83604 \text { /// } \\
\text { ENST00000 }\end{array}$ & 0,0001344 & 6,73 \\
\hline $\begin{array}{l}\text { NM_000747 // CHRNB1 // cholinergic receptor, nicotinic, beta } 1 \text { (muscle) // } \\
\text { 17p13 }\end{array}$ & $3,12 \mathrm{E}-009$ & 6,73 \\
\hline $\begin{array}{l}\text { NM_004533 // MYBPC2 // myosin binding protein C, fast type // 19q13.33 // } \\
4606 /\end{array}$ & $9,36 \mathrm{E}-008$ & 6,68 \\
\hline $\begin{array}{l}\text { NM_012307 // EPB41L3 // erythrocyte membrane protein band 4.1-like 3 // } \\
\text { 18p11.32 }\end{array}$ & $1,43 \mathrm{E}-007$ & 6,49 \\
\hline $\begin{array}{l}\text { NM_001033723 // ZNF704 // zinc finger protein } 704 \text { // 8q21.13 // } 619279 \text { /// } \\
\text { ENST0 }\end{array}$ & $1,01 \mathrm{E}-007$ & 6,40 \\
\hline NM_133378 // TTN // titin // 2q31 // 7273 /// NM_133437 // TTN // titin // 2q31 & $1,44 \mathrm{E}-007$ & 6,37 \\
\hline $\begin{array}{l}\text { NM_005450 // NOG // noggin // 17q21-q22 // } 9241 / / / \text { ENST00000332822 // } \\
\text { NOG // no }\end{array}$ & $4,75 \mathrm{E}-008$ & 6,24 \\
\hline $\begin{array}{l}\text { NM_006765 // TUSC3 // tumor suppressor candidate 3 // 8p22 // } 7991 / / / \\
\text { NM_178234 }\end{array}$ & $4,38 \mathrm{E}-012$ & 5,84 \\
\hline $\begin{array}{l}\text { NM_018593 // SLC16A10 // solute carrier family 16, member } 10 \text { (aromatic } \\
\text { amino aci }\end{array}$ & $2,35 \mathrm{E}-009$ & 5,62 \\
\hline $\begin{array}{l}\text { NM_005635 // SSX1 // synovial sarcoma, X breakpoint } 1 \text { // Xp11.23-p11.22 } \\
6756\end{array}$ & 4,71E-006 & 5,41 \\
\hline
\end{tabular}




\begin{tabular}{|c|c|c|}
\hline $\begin{array}{l}\text { NM_182645 // VGLL2 // vestigial like } 2 \text { (Drosophila) // 6q22.1 // } 245806 / / / \\
\text { NM_1 }\end{array}$ & $5,17 \mathrm{E}-009$ & 5,34 \\
\hline $\begin{array}{l}\text { NM_014461 // CNTN6 // contactin 6 // 3p26-p25 // } 27255 \text { /// } \\
\text { ENST00000350110 // CN }\end{array}$ & $6,88 \mathrm{E}-006$ & 5,28 \\
\hline $\begin{array}{l}\text { NM_002478 // MYOD1 // myogenic differentiation } 1 / / 11 \mathrm{p} 15.4 \text { // } 4654 \text { /// } \\
\text { ENST0000 }\end{array}$ & $2,77 \mathrm{E}-010$ & 5,19 \\
\hline $\begin{array}{l}\text { NM_002889 // RARRES2 // retinoic acid receptor responder (tazarotene } \\
\text { induced) } 2\end{array}$ & $8,59 \mathrm{E}-009$ & 5,12 \\
\hline $\begin{array}{l}\text { NM_024913 // C7orf58 // chromosome } 7 \text { open reading frame } 58 \text { // 7q31.31 // } \\
79974 /\end{array}$ & $6,16 \mathrm{E}-009$ & 4,96 \\
\hline NM_079420 // MYL1 // myosin, light chain 1, alkali; skeletal, fast // 2q33-q34 / & $1,48 \mathrm{E}-007$ & 4,58 \\
\hline $\begin{array}{l}\text { AB039791 // ARP11 // actin-related Arp11 // 7q36.1// } 653857 / / / \\
\text { ENST00000252071 }\end{array}$ & $7,70 \mathrm{E}-005$ & 4,22 \\
\hline $\begin{array}{l}\text { NM_181458 // PAX3 // paired box } 3 \text { // 2q35-q37|2q35 // } 5077 / / / \\
\text { NM_001127366 // P }\end{array}$ & $1,19 \mathrm{E}-007$ & 4,14 \\
\hline $\begin{array}{l}\text { NM_000186 // CFH // complement factor H // 1q32 // } 3075 \text { /// NM_001014975 // } \\
\text { CFH }\end{array}$ & $1,05 \mathrm{E}-005$ & 4,14 \\
\hline $\begin{array}{l}\text { NM_000364 // TNNT2 // troponin T type } 2 \text { (cardiac) // 1q32 // } 7139 \text { /// } \\
\text { NM_0010014 }\end{array}$ & $1,30 \mathrm{E}-007$ & 4,10 \\
\hline $\begin{array}{l}\text { NM_020428 // SLC44A2 // solute carrier family 44, member } 2 \text { // 19p13.1 // } \\
57153 /\end{array}$ & 2,39E-006 & 3,86 \\
\hline $\begin{array}{l}\text { NM_005328 // HAS2 // hyaluronan synthase } 2 \text { // 8q24.12 // } 3037 \text { /// } \\
\text { ENST0000030392 }\end{array}$ & 0,00029935 & 3,71 \\
\hline $\begin{array}{l}\text { NM_000337 // SGCD // sarcoglycan, delta (35kDa dystrophin-associated } \\
\text { glycoprotei }\end{array}$ & $4,02 \mathrm{E}-005$ & 3,61 \\
\hline $\begin{array}{l}\text { NM_001037132 // NRCAM // neuronal cell adhesion molecule // 7q31.1-q31.2 // } \\
4897\end{array}$ & $9,98 \mathrm{E}-007$ & 3,55 \\
\hline $\begin{array}{l}\text { NM_006257 // PRKCQ // protein kinase C, theta // 10p15 // } 5588 \text { /// } \\
\text { ENST000002631 }\end{array}$ & $2,35 \mathrm{E}-007$ & 3,45 \\
\hline $\begin{array}{l}\text { BC101698 // CXorf59 // chromosome X open reading frame } 59 \text { // Xp21.1 // } \\
286464 / /\end{array}$ & 3,77E-005 & 3,44 \\
\hline $\begin{array}{l}\text { NM_017922 // PRPF39 // PRP39 pre-mRNA processing factor } 39 \text { homolog (S. } \\
\text { cerevisia }\end{array}$ & $2,02 \mathrm{E}-010$ & 3,44 \\
\hline $\begin{array}{l}\text { NM_006438 // COLEC10 // collectin sub-family member } 10 \text { (C-type lectin) // } \\
8 \mathrm{q} 23-\mathrm{q}\end{array}$ & $6,29 \mathrm{E}-007$ & 3,40 \\
\hline $\begin{array}{l}\text { NM_005416 // SPRR3 // small proline-rich protein 3 // 1q21-q22 // } 6707 \text { /// } \\
\text { NM_00 }\end{array}$ & $1,57 \mathrm{E}-005$ & 3,39 \\
\hline $\begin{array}{l}\text { NM_001001995 // GPM6B // glycoprotein M6B // Xp22.2 // } 2824 \text { /// } \\
\text { NM_001001996 // }\end{array}$ & $5,98 \mathrm{E}-005$ & 3,38 \\
\hline $\begin{array}{l}\text { NM_014476 // PDLIM3 // PDZ and LIM domain 3 // 4q35 // } 27295 \text { /// } \\
\text { NM_001114107 // }\end{array}$ & $9,27 \mathrm{E}-007$ & 3,35 \\
\hline $\begin{array}{l}\text { NM_000069 // CACNA1S // calcium channel, voltage-dependent, L type, alpha } \\
\text { 1S sub }\end{array}$ & $1,61 \mathrm{E}-006$ & 3,22 \\
\hline $\begin{array}{l}\text { NM_001012761 // RGMB // RGM domain family, member B // 5q15 // } 285704 \\
\text { /// ENST00 }\end{array}$ & $6,70 \mathrm{E}-006$ & 3,15 \\
\hline $\begin{array}{l}\text { NM_005358 // LMO7 // LIM domain } 7 \text { // 13q22.2 // } 4008 \text { /// NM_015842 // } \\
\text { LMO7 // LI }\end{array}$ & $5,16 \mathrm{E}-008$ & 3,11 \\
\hline $\begin{array}{l}\text { NM_001098815 // KIAA0748 // KIAA0748 // 12q13.2 // } 9840 \text { /// AB018291 // } \\
\text { KIAA0748 }\end{array}$ & 4,01E-008 & 3,10 \\
\hline $\begin{array}{l}\text { NM_201596 // CACNB2 // calcium channel, voltage-dependent, beta } 2 \text { subunit // } \\
\text { 10p }\end{array}$ & $3,30 \mathrm{E}-007$ & 3,03 \\
\hline $\begin{array}{l}\text { NM_138569 // C6orf142 // chromosome } 6 \text { open reading frame } 142 \text { // 6p12.1 // } \\
90523\end{array}$ & $3,76 \mathrm{E}-005$ & 2,94 \\
\hline $\begin{array}{l}\text { NM_173357 // SSX6 // synovial sarcoma, X breakpoint } 6 \text { (pseudogene) // } \\
\text { Xp11.2 // }\end{array}$ & $1,05 \mathrm{E}-005$ & 2,92 \\
\hline $\begin{array}{l}\text { NM_018723 // A2BP1 // ataxin 2-binding protein 1// 16p13.3 // } 54715 \text { /// } \\
\text { NM_1458 }\end{array}$ & $1,45 \mathrm{E}-006$ & 2,89 \\
\hline
\end{tabular}




\begin{tabular}{|c|c|c|}
\hline $\begin{array}{l}\text { NM_004411 // DYNC1I1 // dynein, cytoplasmic 1, intermediate chain 1// } \\
\text { 7q21.3-q2 }\end{array}$ & 4,89E-008 & 2,89 \\
\hline $\begin{array}{l}\text { NM_024749 // VASH2 // vasohibin } 2 \text { // 1q32.3 // } 79805 \text { /// NM_001136474 // } \\
\text { VASH2 / }\end{array}$ & $3,45 \mathrm{E}-008$ & 2,89 \\
\hline $\begin{array}{l}\text { NM_152632 // CXorf22 // chromosome X open reading frame } 22 \text { // Xp21.1 // } \\
170063 \text { / }\end{array}$ & 0,00142942 & 2,81 \\
\hline $\begin{array}{l}\text { NM_005199 // CHRNG // cholinergic receptor, nicotinic, gamma // 2q33-q34 // } \\
1146\end{array}$ & 3,47E-006 & 2,80 \\
\hline $\begin{array}{l}\text { NM_003247 // THBS2 // thrombospondin } 2 \text { // 6q27 // } 7058 \text { /// } \\
\text { ENST00000366787 // TH }\end{array}$ & $6,22 \mathrm{E}-005$ & 2,75 \\
\hline $\begin{array}{l}\text { AK131472 // ZNF730 // zinc finger protein } 730 \text { // 19p12 // } 100129543 \text { /// } \\
\text { ENST0000 }\end{array}$ & 0,00013135 & 2,74 \\
\hline $\begin{array}{l}\text { NM_016235 // GPRC5B // G protein-coupled receptor, family C, group 5, } \\
\text { member B / }\end{array}$ & 0,00035776 & 2,64 \\
\hline $\begin{array}{l}\text { NM_005159 // ACTC1 // actin, alpha, cardiac muscle 1// 15q11-q14 // } 70 \text { /// } \\
\text { ENST }\end{array}$ & $1,42 \mathrm{E}-005$ & 2,64 \\
\hline $\begin{array}{l}\text { NM_002402 // MEST // mesoderm specific transcript homolog (mouse) // 7q32 } \\
\text { // } 423\end{array}$ & 3,70E-006 & 2,62 \\
\hline $\begin{array}{l}\text { NM_001144996 // ITGA7 // integrin, alpha } 7 \text { // 12q13 // } 3679 \text { /// NM_002206 // } \\
\text { ITG }\end{array}$ & $2,05 \mathrm{E}-007$ & 2,62 \\
\hline $\begin{array}{l}\text { NM_014729 // TOX // thymocyte selection-associated high mobility group box // } \\
8 \mathrm{q}\end{array}$ & $5,60 \mathrm{E}-006$ & 2,61 \\
\hline $\begin{array}{l}\text { NM_033058 // TRIM55 // tripartite motif-containing 55 // 8q13.1 // } 84675 \text { /// } \\
\text { NM_ }\end{array}$ & $8,16 \mathrm{E}-010$ & 2,61 \\
\hline $\begin{array}{l}\text { NM_002546 // TNFRSF11B // tumor necrosis factor receptor superfamily, } \\
\text { member } 11 \mathrm{~b}\end{array}$ & $2,20 \mathrm{E}-005$ & 2,59 \\
\hline $\begin{array}{l}\text { NM_005164 // ABCD2 // ATP-binding cassette, sub-family D (ALD), member } 2 \\
\text { // 12q1 }\end{array}$ & $1,40 \mathrm{E}-005$ & 2,54 \\
\hline $\begin{array}{l}\text { NM_002614 // PDZK1 // PDZ domain containing 1 // 1q21 // } 5174 \text { /// } \\
\text { NR_003377 // P }\end{array}$ & $1,54 \mathrm{E}-005$ & 2,53 \\
\hline $\begin{array}{l}\text { NM_032446 // MEGF10 // multiple EGF-like-domains } 10 \text { // 5q33 // } 84466 \text { /// } \\
\text { ENST000 }\end{array}$ & $3,76 \mathrm{E}-006$ & 2,48 \\
\hline $\begin{array}{l}\text { NM_004447 // EPS8 // epidermal growth factor receptor pathway substrate } 8 \text { // } \\
12 q\end{array}$ & 0,00028854 & 2,48 \\
\hline $\begin{array}{l}\text { NM_013231 // FLRT2 // fibronectin leucine rich transmembrane protein } 2 \text { // } \\
\text { 14q24- }\end{array}$ & $2,28 \mathrm{E}-005$ & 2,47 \\
\hline $\begin{array}{l}\text { NM_001394 // DUSP4 // dual specificity phosphatase } 4 \text { // 8p12-p11 // } 1846 \text { /// } \\
\text { NM__ }\end{array}$ & 2,79E-005 & 2,46 \\
\hline $\begin{array}{l}\text { NM_173648 // CCDC141 // coiled-coil domain containing 141 // 2q31.2 // } \\
285025 / /\end{array}$ & $1,30 \mathrm{E}-005$ & 2,45 \\
\hline $\begin{array}{l}\text { NM_182507 // KRT80 // keratin } 80 \text { // 12q13.13 // } 144501 / / / \text { NM_001081492 // } \\
\text { KRT80 }\end{array}$ & 0,00017818 & 2,45 \\
\hline $\begin{array}{l}\text { NM_003476 // CSRP3 // cysteine and glycine-rich protein } 3 \text { (cardiac LIM } \\
\text { protein) }\end{array}$ & 2,09E-007 & 2,43 \\
\hline $\begin{array}{l}\text { NM_000692 // ALDH1B1 // aldehyde dehydrogenase } 1 \text { family, member B1 // } \\
\text { 9p11.1// }\end{array}$ & 0,00021026 & 2,41 \\
\hline $\begin{array}{l}\text { NM_000351 // STS // steroid sulfatase (microsomal), isozyme S // Xp22.32 // } \\
412\end{array}$ & $6,37 \mathrm{E}-007$ & 2,41 \\
\hline $\begin{array}{l}\text { NM_145307 // RTKN2 // rhotekin } 2 \text { // 10q21.2 // } 219790 \text { /// ENST00000373789 } \\
\text { // RTK }\end{array}$ & 6,86E-006 & 2,40 \\
\hline $\begin{array}{l}\text { NM_000441 // SLC26A4 // solute carrier family 26, member } 4 \text { // 7q31 // } 5172 \text { /// } \\
\text { E }\end{array}$ & $1,07 \mathrm{E}-005$ & 2,40 \\
\hline $\begin{array}{l}\text { NM_021219 // JAM2 // junctional adhesion molecule } 2 \text { // 21q21.2 // } 58494 \text { /// } \\
\text { ENST }\end{array}$ & 0,00086286 & 2,37 \\
\hline $\begin{array}{l}\text { NM_002472 // MYH8 // myosin, heavy chain 8, skeletal muscle, perinatal // } \\
\text { 17p13. }\end{array}$ & 6,49E-006 & 2,36 \\
\hline NM_170710 // WDR17 // WD repeat domain 17 // 4q34 // 116966 /// & $4,16 \mathrm{E}-006$ & 2,35 \\
\hline
\end{tabular}




\begin{tabular}{|c|c|c|}
\hline \multicolumn{3}{|l|}{ NM_181265 // WDR } \\
\hline $\begin{array}{l}\text { NM_000751 // CHRND // cholinergic receptor, nicotinic, delta // 2q33-q34 // } \\
1144\end{array}$ & $1,56 \mathrm{E}-005$ & 2,35 \\
\hline $\begin{array}{l}\text { NM_153026 // PRICKLE1 // prickle homolog } 1 \text { (Drosophila) // 12q12 // } 144165 \\
\text { /// N }\end{array}$ & 0,00010049 & 2,35 \\
\hline $\begin{array}{l}\text { NM_000689 // ALDH1A1 // aldehyde dehydrogenase } 1 \text { family, member A1 // } \\
\text { 9q21.13 // }\end{array}$ & $5,24 \mathrm{E}-006$ & 2,34 \\
\hline $\begin{array}{l}\text { AK054626 // FLJ30064 // hypothetical protein LOC644975 // 7q21.3 // } 644975 \\
\text { /// E }\end{array}$ & $8,81 \mathrm{E}-006$ & 2,33 \\
\hline $\begin{array}{l}\text { NM_004067 // CHN2 // chimerin (chimaerin) 2 // 7p15.3 // } 1124 \text { /// } \\
\text { NM_001039936/ }\end{array}$ & $3,01 \mathrm{E}-007$ & 2,31 \\
\hline $\begin{array}{l}\text { NM_012272 // PRPF40B // PRP40 pre-mRNA processing factor } 40 \text { homolog B } \\
\text { (S. cerevi }\end{array}$ & $1,53 \mathrm{E}-009$ & 2,31 \\
\hline $\begin{array}{l}\text { NM_015393 // DKFZP564O0823 // prostatic androgen-repressed message-1 // } \\
\text { 4q13.3-q }\end{array}$ & 0,00014291 & 2,31 \\
\hline $\begin{array}{l}\text { NM_001128205 // SULF1 // sulfatase 1 // 8q13.2-q13.3 // } 23213 \text { /// NM_015170 } \\
\text { // S }\end{array}$ & $5,65 \mathrm{E}-007$ & 2,26 \\
\hline $\begin{array}{l}\text { NM_197941 // ADAMTS6 // ADAM metallopeptidase with thrombospondin } \\
\text { type } 1 \text { motif, }\end{array}$ & 0,00060328 & 2,24 \\
\hline $\begin{array}{l}\text { NM_001134707 // SARDH // sarcosine dehydrogenase // 9q33-q34 // } 1757 \text { /// } \\
\text { NM_0071 }\end{array}$ & 7,72E-006 & 2,20 \\
\hline $\begin{array}{l}\text { NM_001130978 // DYSF // dysferlin, limb girdle muscular dystrophy 2B } \\
\text { (autosomal }\end{array}$ & $3,68 \mathrm{E}-006$ & 2,19 \\
\hline $\begin{array}{l}\text { NM_020647 // JPH1 // junctophilin 1// 8q21 // } 56704 \text { /// ENST00000342232 // } \\
\text { JPH1 }\end{array}$ & 0,00019289 & 2,19 \\
\hline $\begin{array}{l}\text { NM_019029 // CPVL // carboxypeptidase, vitellogenic-like // 7p15-p14 // } 54504 \\
\text { // }\end{array}$ & 0,00012049 & 2,19 \\
\hline $\begin{array}{l}\text { NM_012098 // ANGPTL2 // angiopoietin-like 2 // 9q34 // } 23452 \text { /// } \\
\text { ENST00000373425 }\end{array}$ & 0,00092094 & 2,19 \\
\hline $\begin{array}{l}\text { NM_032456 // PCDH7 // protocadherin } 7 \text { // 4p15 // } 5099 \text { /// NM_002589 // } \\
\text { PCDH7 // }\end{array}$ & $4,06 \mathrm{E}-008$ & 2,17 \\
\hline $\begin{array}{l}\text { NM_001048201 // UHRF1 // ubiquitin-like with PHD and ring finger domains } 1 \\
\text { // } 19\end{array}$ & 7,64E-005 & 2,14 \\
\hline $\begin{array}{l}\text { NM_000334 // SCN4A // sodium channel, voltage-gated, type IV, alpha subunit } \\
\text { // } 1\end{array}$ & $7,25 \mathrm{E}-006$ & 2,14 \\
\hline $\begin{array}{l}\text { NM_002479 // MYOG // myogenin (myogenic factor 4) // 1q31-q41 // } 4656 / / / \\
\text { ENST00 }\end{array}$ & 2,69E-006 & 2,13 \\
\hline $\begin{array}{l}\text { AF086709 // LOH3CR2A // loss of heterozygosity, 3, chromosomal region 2, } \\
\text { gene A }\end{array}$ & 0,00046067 & 2,13 \\
\hline $\begin{array}{l}\text { NM_024680 // E2F8 // E2F transcription factor } 8 \text { // 11p15.1 // } 79733 \text { /// } \\
\text { ENST0000 }\end{array}$ & 0,00044749 & 2,13 \\
\hline $\begin{array}{l}\text { NM_032023 // RASSF4 // Ras association (RalGDS/AF-6) domain family } \\
\text { member } 4 \text { // } 1\end{array}$ & $3,72 \mathrm{E}-006$ & 2,12 \\
\hline NM_003281 // TNNI1 // troponin I type 1 (skeletal, slow) // 1q31.3 // 7135 /// E & $8,76 \mathrm{E}-007$ & 2,10 \\
\hline $\begin{array}{l}\text { NM_000540 // RYR1 // ryanodine receptor } 1 \text { (skeletal) // 19q13.1 // } 6261 \text { /// } \\
\text { NM_0 }\end{array}$ & $5,66 \mathrm{E}-007$ & 2,09 \\
\hline $\begin{array}{l}\text { NM_012137 // DDAH1 // dimethylarginine dimethylaminohydrolase 1// 1p22 // } \\
23576\end{array}$ & 0,00023795 & 2,09 \\
\hline $\begin{array}{l}\text { NM_006308 // HSPB3 // heat shock 27kDa protein } 3 \text { // 5q11.2 // } 8988 \text { /// } \\
\text { ENST00000 }\end{array}$ & 0,00017067 & 2,08 \\
\hline $\begin{array}{l}\text { NM_032854 // CORO6 // coronin 6 // 17q11.2 // } 84940 / / / \text { ENST00000388767 // } \\
\text { CORO6 }\end{array}$ & $2,76 \mathrm{E}-006$ & 2,08 \\
\hline $\begin{array}{l}\text { NM_004751 // GCNT3 // glucosaminyl (N-acetyl) transferase 3, mucin type // } \\
15 q 21\end{array}$ & $4,27 \mathrm{E}-005$ & 2,08 \\
\hline $\begin{array}{l}\text { NM_007283 // MGLL // monoglyceride lipase // 3q21.3 // } 11343 \text { /// } \\
\text { NM_001003794 // }\end{array}$ & 3,57E-006 & 2,07 \\
\hline
\end{tabular}




\begin{tabular}{|c|c|c|}
\hline $\begin{array}{l}\text { NM_024554 // PGBD5 // piggyBac transposable element derived } 5 \text { // 1q42.13 // } \\
7960\end{array}$ & $2,08 \mathrm{E}-005$ & 2,06 \\
\hline $\begin{array}{l}\text { NM_001001924 // MTUS1 // mitochondrial tumor suppressor 1 // 8p22 // } 57509 \\
\text { /// N }\end{array}$ & 0,00019526 & 2,06 \\
\hline $\begin{array}{l}\text { AL136588 // MMP16 // matrix metallopeptidase } 16 \text { (membrane-inserted) // } \\
8 \mathrm{q} 21.3 / /\end{array}$ & 0,00049583 & 2,04 \\
\hline $\begin{array}{l}\text { NM_016315 // GULP1 // GULP, engulfment adaptor PTB domain containing } 1 \text { // } \\
2 q 32.3\end{array}$ & 0,00106239 & 2,04 \\
\hline $\begin{array}{l}\text { NM_001860 // SLC31A2 // solute carrier family } 31 \text { (copper transporters), } \\
\text { member } 2\end{array}$ & 4,97E-009 & 2,01 \\
\hline $\begin{array}{l}\text { NM_001040450 // FAM63B // family with sequence similarity 63, member B // } \\
\text { 15q21. }\end{array}$ & 0,00013778 & 2,00 \\
\hline $\begin{array}{l}\text { NM_005978 // S100A2 // S100 calcium binding protein A2 // 1q21 // } 6273 \text { /// } \\
\text { ENST0 }\end{array}$ & 0,00112299 & 2,00 \\
\hline $\begin{array}{l}\text { NM_001128424 // C4orf18 // chromosome } 4 \text { open reading frame } 18 / / 4 q 32.1 / / \\
51313\end{array}$ & 0,00014826 & 2,00 \\
\hline $\begin{array}{l}\text { NM_017488 // ADD2 // adducin } 2 \text { (beta) // 2p14-p13 // } 119 \text { /// NM_001617 // } \\
\text { ADD2 / }\end{array}$ & $7,40 \mathrm{E}-005$ & $-2,00$ \\
\hline $\begin{array}{l}\text { NM_001115 // ADCY8 // adenylate cyclase } 8 \text { (brain) // 8q24 // } 114 \text { /// } \\
\text { ENST0000028 }\end{array}$ & 0,00017982 & $-2,01$ \\
\hline $\begin{array}{l}\text { NM_002825 // PTN // pleiotrophin // 7q33-q34 // } 5764 \text { /// ENST00000348225 // } \\
\text { PTN }\end{array}$ & 0,00015088 & $-2,01$ \\
\hline $\begin{array}{l}\text { NM_001009565 // CDKL4 // cyclin-dependent kinase-like 4 // 2p22.1 // } 344387 \\
\text { /// }\end{array}$ & $5,04 \mathrm{E}-006$ & $-2,02$ \\
\hline $\begin{array}{l}\text { NM_001964 // EGR1 // early growth response 1// 5q31.1// } 1958 \text { /// } \\
\text { ENST000002399 }\end{array}$ & 0,00014725 & $-2,02$ \\
\hline $\begin{array}{l}\text { NM_152780 // MAP7D2 // MAP7 domain containing } 2 \text { // Xp22.12 // } 256714 \text { /// } \\
\text { ENST000 }\end{array}$ & 0,00063644 & $-2,04$ \\
\hline NM_002404 // MFAP4 // microfibrillar-associated protein 4 // 17p11.2 // 4239 /// & 0,00036662 & $-2,04$ \\
\hline $\begin{array}{l}\text { NM_001029874 // REP15 // RAB15 effector protein // 12p11.22 // } 387849 \text { /// } \\
\text { ENST00 }\end{array}$ & 0,00050326 & $-2,07$ \\
\hline NM_003064 // SLPI // secretory leukocyte peptidase inhibitor // 20q12 // 6590 // & 0,00045779 & $-2,08$ \\
\hline $\begin{array}{l}\text { NM_001946 // DUSP6 // dual specificity phosphatase 6 // 12q22-q23 // } 1848 \text { /// } \\
\text { NM }\end{array}$ & 2,87E-006 & $-2,08$ \\
\hline $\begin{array}{l}\text { NM_002581 // PAPPA // pregnancy-associated plasma protein A, pappalysin } 1 / / \\
\text { 9q3 }\end{array}$ & $8,42 \mathrm{E}-005$ & $-2,09$ \\
\hline $\begin{array}{l}\text { NM_004445 // EPHB6 // EPH receptor B6 // 7q33-q35 // } 2051 / / / \\
\text { ENST00000392957 // }\end{array}$ & 0,00039867 & $-2,10$ \\
\hline $\begin{array}{l}\text { NM_000533 // PLP1 // proteolipid protein 1// Xq22 // } 5354 \text { /// NM_001128834 } \\
\text { // P }\end{array}$ & $6,41 \mathrm{E}-007$ & $-2,11$ \\
\hline $\begin{array}{l}\text { NM_172069 // PLEKHH2 // pleckstrin homology domain containing, family H } \\
\text { (with My }\end{array}$ & 0,00014644 & $-2,12$ \\
\hline $\begin{array}{l}\text { NM_020405 // PLXDC1 // plexin domain containing 1 // 17q21.1// } 57125 \text { /// } \\
\text { ENST00 }\end{array}$ & $6,08 \mathrm{E}-005$ & $-2,12$ \\
\hline $\begin{array}{l}\text { NM_172311 // STON1-GTF2A1L // STON1-GTF2A1L readthrough transcript // } \\
2 \mathrm{p} 16.3 / /\end{array}$ & $1,77 \mathrm{E}-005$ & $-2,12$ \\
\hline $\begin{array}{l}\text { NM_001010000 // ARHGAP28 // Rho GTPase activating protein 28 // 18p11.31 } \\
\text { // } 7982\end{array}$ & $8,73 \mathrm{E}-006$ & $-2,14$ \\
\hline $\begin{array}{l}\text { NM_020398 // SPINLW1 // serine peptidase inhibitor-like, with Kunitz and } \\
\text { WAP dom }\end{array}$ & 0,00016676 & $-2,14$ \\
\hline $\begin{array}{l}\text { NM_019043 // APBB1IP // amyloid beta (A4) precursor protein-binding, family } \\
\text { B, m }\end{array}$ & $7,98 \mathrm{E}-005$ & $-2,15$ \\
\hline $\begin{array}{l}\text { NM_001113226 // NTNG1 // netrin G1 // 1p13.3 // } 22854 \text { /// NM_001113228 // } \\
\text { NTNG1 }\end{array}$ & 0,00032921 & $-2,15$ \\
\hline NM_024997 // ATF7IP2 // activating transcription factor 7 interacting protein 2 & 0,00048238 & $-2,15$ \\
\hline NM_021205 // RHOU // ras homolog gene family, member U // 1q42.11-q42 & 0,00129828 & $-2,15$ \\
\hline
\end{tabular}




\begin{tabular}{|c|c|c|}
\hline 58480 & & \\
\hline $\begin{array}{l}\text { NM_014227 // SLC5A4 // solute carrier family } 5 \text { (low affinity glucose } \\
\text { cotransport }\end{array}$ & 0,00028395 & $-2,16$ \\
\hline NM_006097 // MYL9 // myosin, light chain 9, regulatory // 20q11.23 // 10398 /// & $4,58 \mathrm{E}-006$ & $-2,17$ \\
\hline $\begin{array}{l}\text { NM_152697 // SLC44A5 // solute carrier family 44, member } 5 \text { // 1p31.1 // } \\
204962 / \text { }\end{array}$ & 0,0004206 & $-2,19$ \\
\hline $\begin{array}{l}\text { NM_018398 // CACNA2D3 // calcium channel, voltage-dependent, alpha 2/delta } \\
\text { subun }\end{array}$ & $8,62 \mathrm{E}-007$ & $-2,20$ \\
\hline $\begin{array}{l}\text { NM_000933 // PLCB4 // phospholipase C, beta 4 // 20p12 // } 5332 \text { /// } \\
\text { NM_182797 // }\end{array}$ & $3,30 \mathrm{E}-006$ & $-2,21$ \\
\hline $\begin{array}{l}\text { NM_004696 // SLC16A4 // solute carrier family 16, member } 4 \text { (monocarboxylic } \\
\text { acid }\end{array}$ & 0,00063161 & $-2,24$ \\
\hline $\begin{array}{l}\text { NM_018490 // LGR4 // leucine-rich repeat-containing G protein-coupled } \\
\text { receptor } 4\end{array}$ & $8,74 \mathrm{E}-006$ & $-2,26$ \\
\hline $\begin{array}{l}\text { NM_005221 // DLX5 // distal-less homeobox 5 // 7q22 // } 1749 \text { /// } \\
\text { ENST00000222598 }\end{array}$ & $3,55 \mathrm{E}-006$ & $-2,26$ \\
\hline $\begin{array}{l}\text { NM_207437 // DNAH10 // dynein, axonemal, heavy chain } 10 \text { // 12q24.31 // } \\
196385 / /\end{array}$ & $1,92 \mathrm{E}-005$ & $-2,26$ \\
\hline $\begin{array}{l}\text { NM_002167 // ID3 // inhibitor of DNA binding 3, dominant negative helix-loop- } \\
\text { hel }\end{array}$ & 0,00067517 & $-2,27$ \\
\hline $\begin{array}{l}\text { NM_152989 // SOX5 // SRY (sex determining region Y)-box 5 // 12p12.1 // } \\
6660 / / /\end{array}$ & $6,96 \mathrm{E}-005$ & $-2,27$ \\
\hline $\begin{array}{l}\text { NM_000062 // SERPING1 // serpin peptidase inhibitor, clade G (C1 inhibitor), } \\
\text { mem }\end{array}$ & 0,00035184 & $-2,29$ \\
\hline $\begin{array}{l}\text { NM_178033 // CYP4X1 // cytochrome P450, family 4, subfamily X, polypeptide } \\
1 / /\end{array}$ & $5,29 \mathrm{E}-005$ & $-2,30$ \\
\hline NM_001002264 // EPSTI1 // epithelial stromal interaction 1 (breast) // 13q13.3 / & 0,00012014 & $-2,32$ \\
\hline $\begin{array}{l}\text { NM_002852 // PTX3 // pentraxin-related gene, rapidly induced by IL-1 beta // } \\
\text { 3q2 }\end{array}$ & 0,00083073 & $-2,32$ \\
\hline $\begin{array}{l}\text { NM_005337 // NCKAP1L // NCK-associated protein 1-like // 12q13.1 // } 3071 \text { /// } \\
\text { ENS }\end{array}$ & 0,00047381 & $-2,34$ \\
\hline $\begin{array}{l}\text { NM_203447 // DOCK8 // dedicator of cytokinesis } 8 \text { // 9p24.3 // } 81704 \text { /// } \\
\text { ENST0000 }\end{array}$ & 0,00013659 & $-2,36$ \\
\hline $\begin{array}{l}\text { NM_015432 // PLEKHG4 // pleckstrin homology domain containing, family G } \\
\text { (with Rh }\end{array}$ & 0,00041054 & $-2,36$ \\
\hline $\begin{array}{l}\text { NM_030647 // JHDM1D // jumonji C domain containing histone demethylase } 1 \\
\text { homolog }\end{array}$ & $3,27 \mathrm{E}-005$ & $-2,38$ \\
\hline $\begin{array}{l}\text { NM_024717 // MCTP1 // multiple C2 domains, transmembrane 1// 5q15 // } \\
79772 / / /\end{array}$ & $6,93 \mathrm{E}-005$ & $-2,39$ \\
\hline $\begin{array}{l}\text { NM_175862 // CD86 // CD86 molecule // 3q21 // } 942 \text { /// NM_006889 // CD86 // } \\
\text { CD86 }\end{array}$ & 0,0003099 & $-2,40$ \\
\hline $\begin{array}{l}\text { NM_006419 // CXCL13 // chemokine (C-X-C motif) ligand 13 // 4q21 // } 10563 \\
\text { /// EN }\end{array}$ & 0,00107483 & $-2,42$ \\
\hline $\begin{array}{l}\text { NM_001002236 // SERPINA1 // serpin peptidase inhibitor, clade A (alpha-1 } \\
\text { antipro }\end{array}$ & $4,84 \mathrm{E}-005$ & $-2,44$ \\
\hline $\begin{array}{l}\text { NM_015526 // CLIP3 // CAP-GLY domain containing linker protein } 3 \text { // } \\
\text { 19q13.12 // }\end{array}$ & $3,20 \mathrm{E}-005$ & $-2,45$ \\
\hline $\begin{array}{l}\text { NM_004065 // CDR1 // cerebellar degeneration-related protein 1, 34kDa // } \\
\text { Xq27.1- }\end{array}$ & 0,00090613 & $-2,51$ \\
\hline $\begin{array}{l}\text { NM_005252 // FOS // FBJ murine osteosarcoma viral oncogene homolog // } \\
14 \mathrm{q} 24.3 / /\end{array}$ & 0,00017336 & $-2,56$ \\
\hline $\begin{array}{l}\text { NM_005461 // MAFB // v-maf musculoaponeurotic fibrosarcoma oncogene } \\
\text { homolog B (a }\end{array}$ & 0,00015183 & $-2,57$ \\
\hline $\begin{array}{l}\text { NM_015886 // PI15 // peptidase inhibitor } 15 \text { // 8q21.11 // } 51050 / / / \\
\text { ENST00000260 }\end{array}$ & 0,00062645 & $-2,70$ \\
\hline NM_001130064 // GAP43 // growth associated protein 43 // 3q13 & $2,85 \mathrm{E}-005$ & $-2,80$ \\
\hline
\end{tabular}




\begin{tabular}{|c|c|c|}
\hline $2596 / /$ & & \\
\hline $\begin{array}{l}\text { NM_000396 // CTSK // cathepsin K // 1q21 // } 1513 \text { /// ENST00000271651 // } \\
\text { CTSK // }\end{array}$ & 7,59E-005 & $-2,89$ \\
\hline $\begin{array}{l}\text { NM_016522 // NTM // neurotrimin // 11q25 // } 50863 \text { /// NM_001048209 // NTM } \\
\text { // neu }\end{array}$ & 0,00096901 & $-2,91$ \\
\hline $\begin{array}{l}\text { NM_012340 // NFATC2 // nuclear factor of activated T-cells, cytoplasmic, } \\
\text { calcine }\end{array}$ & 0,00137656 & $-2,95$ \\
\hline $\begin{array}{l}\text { NM_000424 // KRT5 // keratin 5 // 12q12-q13 // } 3852 \text { /// ENST00000252242 // } \\
\text { KRT5 }\end{array}$ & 0,00113094 & $-2,97$ \\
\hline $\begin{array}{l}\text { NM_144629 // RFTN2 // raftlin family member } 2 / / 2 q 33.1 / / 130132 \text { /// } \\
\text { ENST000002 }\end{array}$ & 4,07E-006 & $-3,00$ \\
\hline $\begin{array}{l}\text { NM_001448 // GPC4 // glypican } 4 \text { // Xq26.1 // } 2239 \text { /// ENST00000370828 // } \\
\text { GPC4 // }\end{array}$ & $5,29 \mathrm{E}-005$ & $-3,03$ \\
\hline $\begin{array}{l}\text { NM_058237 // PPP4R4 // protein phosphatase 4, regulatory subunit } 4 \text { // } \\
\text { 14q32.12-q }\end{array}$ & $1,40 \mathrm{E}-005$ & $-3,04$ \\
\hline $\begin{array}{l}\text { NM_198232 // RNASE1 // ribonuclease, RNase A family, } 1 \text { (pancreatic) // } \\
\text { 14q11.2 / }\end{array}$ & $8,02 \mathrm{E}-007$ & $-3,34$ \\
\hline $\begin{array}{l}\text { NM_003239 // TGFB3 // transforming growth factor, beta } 3 \text { // 14q24 // } 7043 \text { /// } \\
\text { EN }\end{array}$ & $2,56 \mathrm{E}-006$ & $-3,44$ \\
\hline $\begin{array}{l}\text { NM_001134407 // GRIN2A // glutamate receptor, ionotropic, N-methyl D- } \\
\text { aspartate } 2\end{array}$ & $4,06 \mathrm{E}-005$ & $-3,56$ \\
\hline $\begin{array}{l}\text { NM_006343 // MERTK // c-mer proto-oncogene tyrosine kinase // 2q14.1 // } \\
10461 / /\end{array}$ & $3,93 \mathrm{E}-005$ & $-3,68$ \\
\hline $\begin{array}{l}\text { NM_207359 // GADL1 // glutamate decarboxylase-like 1 // 3p24.1-p23 // } \\
339896 / / /\end{array}$ & 0,00090445 & $-3,80$ \\
\hline $\begin{array}{l}\text { ENST00000400767 // MGC39584 // hypothetical gene supported by BC029568 } \\
\text { // 4q35.2 }\end{array}$ & $1,39 \mathrm{E}-006$ & $-3,81$ \\
\hline $\begin{array}{l}\text { NM_022912 // REEP1 // receptor accessory protein 1// 2p11.2 // } 65055 \text { /// } \\
\text { ENST00 }\end{array}$ & $5,50 \mathrm{E}-007$ & $-4,11$ \\
\hline $\begin{array}{l}\text { NM_004693 // KRT75 // keratin } 75 \text { // 12q13 // } 9119 \text { /// ENST00000421741 // } \\
\text { KRT75 / }\end{array}$ & $9,03 \mathrm{E}-005$ & $-5,07$ \\
\hline $\begin{array}{l}\text { NM_031935 // HMCN1 // hemicentin 1// 1q25.3-q31.1// } 83872 \text { /// } \\
\text { ENST00000271588 }\end{array}$ & $1,67 \mathrm{E}-006$ & $-5,08$ \\
\hline $\begin{array}{l}\text { NM_000042 // APOH // apolipoprotein H (beta-2-glycoprotein I) // 17q23-qter // } \\
3\end{array}$ & $8,21 \mathrm{E}-005$ & $-5,72$ \\
\hline $\begin{array}{l}\text { NM_182908 // DHRS2 // dehydrogenase/reductase (SDR family) member } 2 / / \\
14 \mathrm{q} 11.2 /\end{array}$ & 4,79E-006 & $-11,21$ \\
\hline
\end{tabular}




\section{Lebenslauf}

Julia Bode

Geburtsdatum: 25. Februar 1981

Geburtsort: Northeim

Familienstand: ledig

Staatsangehörigkeit: Deutsch

\section{Schulbildung}

1987 bis $1991 \quad$ Geschwister- Scholl Grundschule, Einbeck

1991 bis $1993 \quad$ Orientierungsstufe, Einbeck

1993 bis $2000 \quad$ Gymnasium Goetheschule, Einbeck

Abitur Juni 2000

\section{Studium}

2000 bis $2005 \quad$ Studium an der Georg-August-Universität Göttingen im Diplomstudiengang Biologie

Hauptfach: Biochemie der Pflanze

1. Nebenfach: Botanik

2. Nebenfach: Mikrobiologie

Mündliche Prüfungen im November 2004

Diplomarbeit November 2004 bis Oktober 2005 zum Thema:

„Oxylipin Profil des Moses Physcomitrella patens“

in der Abt. Biochemie der Pflanze, Universität Göttingen,

Betreuer: $\quad$ Prof. Dr. Ivo Feussner

PD Dr. Gertrud Lohaus 


\section{Beruflicher Werdegang}

2005 bis 2007 Wissenschaftliche Mitarbeiterin in der Abt. Biochemie der Pflanze,

Georg-August-Universität Göttingen

2007 bis 2010 Doktorarbeit bei Prof. Dr. M. Lakomek, Pädiatrie 1 - Hämatologie und

Onkologie, Universitätsmedizin der Georg-August-Universität Göttingen

Titel der Arbeit: „Effekte der Klasse-3 Semaphorine bei der Entwicklung und Progression maligner Hirntumoren“ 


\section{Veröffentlichungen}

\subsection{Publikationen}

Stumpe M, Bode J, Göbel C, Wichard T, Schaaf A, Frank W, Frank M, Reski R, Pohnert G, Feussner I. (2006). "Biosynthesis of C9-aldehydes in the moss Physcomitrella patens." Biochim Biophys Acta 1761(3): 301-12.

Stumpe M, Göbel C, Faltin B, Beike AK, Hause B, Himmelsbach K, Bode J, Kramell R, Wasternack C, Frank W, Reski R, Feussner I. (2010). "The moss Physcomitrella patens contains cyclopentenones but no jasmonates: mutations in allene oxide cyclase lead to reduced fertility and altered sporophyte morphology." The new phytologist

Veenman L, Zeno S, Bode J, Fridkin L, Shargorodsky L, Gaitner M, Levin E, Zaroor M, Weizman A, Kietz S, Lakomek M, Gavish M. (2010). "Knockdown of the $18 \mathrm{kDa}$ translocator protein (TSPO) in glial cell lines attenuates cell death induced by glutamate, Abeta(1-42) and nitric oxide (NO). Implications for neurodegeneration." Manuskript eingereicht bei Journal of Neuroscience for peer-review

Bode J, Liebelt D, Lakomek M, Kietz S (2010). "Differential growth pattern of two human glioma cell lines in vitro. " Manuskript eingereicht bei Neuroscience Research for peer-review 
Veenman L, Bode J, Zeno S, Kietz S, Lakomek M, Gavish M (2010). "Knockdown of the $18 \mathrm{kDa}$ Translocator Protein leads to increased brain tumor size in situ in correlation with changes in tumorigenic gene expression." Manuskript in Vorbereitung

Bode J, Fink D, Sabag A, Kietz S, Lakomek M, Neufeld G (2010). "The development tumors from xenografted glioblastoma cells implanted in the brain cortex is inhibited by semaphorin-3D and semaphorin-3E." Manuskript eingereicht bei Journal of Cancer Research

\subsection{Kongressbeiträge}

Embo workshop: "Semaphorin function \& mechanisms of action", Mai 2008, Paris

$6^{\text {th }}$ International $\mathrm{PhD}$ student symposium "Horizons in Molecular Biology", September 2009, Göttingen

Posterbeitrag: "Examination of brain tumor growth of human malignant glioma cell lines"

$18^{\text {th }}$ Annual meeting, The Israel Society for Neuroscience, November 2009, Eilat, Israel

Posterbeitrag: "In vivo bioluminescence imaging of intracranially implanted glioma cells in mice" 
American Association for Cancer Research $101^{\text {st }}$ Annual Meeting 2010, April 2010, Washington, DC; USA

Posterbeitrag: "In vivo bioluminescence imaging of intracranially implanted glioma cells and opening of the blood-brain-barrier in mice" 


\section{Danksagung}

Ich möchte mich ganz herzlich bei allen bedanken, die zum Gelingen dieser Doktorarbeit beigetragen haben.

Herrn Professor Dr. Lakomek danke ich für die Möglichkeit, meine Doktorarbeit in der Pädiatrie 1 im Universitätsklinikum Göttingen durchführen zu können.

Herrn Prof. Dr. Wimmer danke ich für die Bereitschaft mein Erstbetreuer zu sein. Ich bedanke mich für die Seminare, in denen ich Vorträge halten durfte und meine Arbeit diskutiert wurde. Herrn Prof. Dr. Kessel danke ich für die Zweitbetreuung meiner Arbeit und die Möglichkeit, mit ihm Versuche und Fragestellungen zu besprechen.

Herrn Prof. Dr. Heinrich, Herrn Prof. Dr. Groß, Herrn Prof. Dr. Stumpner und Herrn Dr. Prpic-Schäper danke ich, dass sie das thesis committee für meine Verteidigung gebildet haben.

Meinem Anleiter Herrn PD Dr. Kugler gilt besonderer Dank für die Betreuung und Einarbeitung im Labor. Außerdem möchte ich mich herzlich für Gespräche, Diskussionen, lustige E-Mails, aufmunternde Worte und die Möglichkeit, Forschungsaufenthalte am Technion in Israel wahrnehmen zu können, bedanken.

Vielen Dank an Prof. Gera Neufeld und seiner Arbeitsgruppe, sowie Dr. Leo Veenman am Technion in Haifa, Israel.

Vielen Dank an die gute Seele des Labors, Regina Krügener, für die Einarbeitung in Methoden, die 11Uhr Besprechung, hilfreiche Tipps, Aufmunterung, Telefonate, Freizeitgestaltung und vieles mehr.

Dr. Julia Alten- vielen Dank für die Unterhaltung, Unterstützung, die Seelsorge und gemeinsame Forschungsaufenthalte in Israel.

Dank gilt auch Dr. Silke Kietz, die mir in den letzten Monaten sehr hilfreich zur Seite stand. Vielen Dank auch an alle anderen, die mir im Labor zur Seite standen. Besonderer Dank gilt Dr. Nina Kollmar, Dr. Petra Hülper, Sandra Seelke, Dr. Sonja Volland, Sarah Greco, Christian Dullin, meiner Bachelor-Studentin Daniela, den Mitarbeitern der AG Kube und der Pädiatrie 1. 
Dank an meine Büromädels Alexandra Schrader und Elisabeth Hand, die mir hilfreich zur Seite stehen und mit denen ich immer viel Spaß habe.

Ich möchte mich auch bei den Menschen bedanken, die mich außerhalb des Labors unterstützt haben: Meinem Vater, meiner Schwester Rebecca, Oma, Katrin und Anja.

Und Nicolas- vielen Dank für Deine Hilfe, Unterstützung und liebe Worte! 
